INTERFERÔMETROS RECUPERADORES DE BAIXA TENSÃO DE MEIA ONDA PARA SISTEMAS

INTERFEROMÉTRICOS DE LUZ BRANCA UTILIZANDO

MODULADORES ELETRO-ÓPTICOS

Tese apresentada à Escola Politécnica da Universidade de São Paulo para obtenção do título de Doutor em Ciências. 


\section{INTERFERÔMETROS RECUPERADORES DE BAIXA TENSÃO DE MEIA ONDA PARA SISTEMAS INTERFEROMÉTRICOS DE LUZ BRANCA UTILIZANDO MODULADORES ELETRO-ÓPTICOS}

Tese apresentada à Escola Politécnica da Universidade de São Paulo para obtenção do título de Doutor em Ciências.

Área de Concentração:

Sistemas de Potência.

Orientador:

Prof. Dr. Josemir Coelho Santos 
Este exemplar foi revisado e alterado em relação à versão original, sob responsabilidade única do autor e com a anuência de seu orientador.

São Paulo, 01 de agosto de 2011.

Assinatura do autor

Assinatura do orientador

FICHA CATALOGRÁFICA

Silva, Luiz Pinheiro Cordovil da

Interferômetros recuperadores de baixa tensão de meia onda para sistemas interferométricos de luz branca utilizando moduladores eletro-ópticos / L.P.C. da Silva. -- ed. rev. -- São Paulo, 2011.

$200 \mathrm{p}$.

Tese (Doutorado) - Escola Politécnica da Universidade de São Paulo. Departamento de Engenharia de Energia e Automação Elétricas.

1. Alta tensão (Medidas) 2. Interferometria 3. Fibras ópticas 4. Processamento de sinais ópticos 5 . Efeito Pockels I. Universidade de São Paulo. Escola Politécnica. Departamento de Engenharia de Energia e Automação Elétricas II. t. 
À Ana Paula, meu primeiro e definitivo amor. 


\section{AGRADECIMENTOS}

Ao orientador e amigo, Professor Dr. Josemir Coelho Santos, a minha mais profunda gratidão por ter-me recebido em seu laboratório, permitindo-me realizar este trabalho de pesquisa na área de Sensores a Fibras Ópticas. Agradeço a confiança depositada, a cuidadosa dedicação na orientação da minha atividade científica ao longo desses anos, a disponibilidade e empenho em ajudar na solução dos problemas encontrados, que se revelaram fundamentais para a realização deste trabalho. Agradeço também, pelo acompanhamento constante no programa de doutorado, pelas oportunas "deixas" que proporcionaram uma nova visão sobre muitos assuntos, problemas e aspectos deste trabalho, a compreensão, apoio e incentivo que soube transmitir nos momentos mais difíceis.

Ao grande amigo Jonas Rubini Junior, pelas longas e frutíferas conversas que tivemos, as quais, entre outras coisas, me deram uma nova perspectiva da atividade de investigação no domínio dos Sensores a Fibras Ópticas.

Ao Professor Dr. Luiz. Cláudio Ribeiro Galvão, pela confiança, ajuda e pela construção do "Espaço Astronômico".

Aos amigos e companheiros de laboratório, Domingos, Gleison e Sandra, por toda a ajuda.

Aos amigos, Rafael Bertrand, Mario Biague, Carlos Febres e Elvis Richard, companheiros de muitas horas.

Ao amigo Marcelo Vantini, por toda a ajuda prestada.

Ao amigo Geraldo Itagiba Andrade, com quem sempre pude contar.

Aos amigos Adelino, Edson e Marcos, sempre prestativos. 
À Juliana Lopes Cardoso (LSI/PSI/EPUSP), por toda a ajuda no preparo das soluções de prata.

Ao Departamento de Engenharia e Automação - PEA-USP.

Às secretárias do PEA: Beta, Solange, Valquiria, Patrícia e Diná.

À Sra. Eniria (Nega) pelos cafés e pelas ótimas conversas.

Aos funcionários da Divisão de redes do CCE-USP, Paulo Domecq Campora e Sebastião Pereira de Sonza, por toda ajuda prestada na emenda das fibras ópticas.

À Fundação Universidade de São Paulo - FUSP, por, através da bolsa de doutoramento que me foi concedida, ter possibilitado a dedicação em tempo integral ao trabalho científico.

Ao amigo Carlos Eduardo Viana, por toda ajuda prestada.

Ao casal Eduardo Maciel e Alice que me acolheram como membro da família.

À minha familia, por ter suportado com notável paciência e generosa compreensão as minhas numerosas ausências.

A todas as pessoas que direta ou indiretamente colaboraram para a realização deste trabalho. 


\section{SUMÁRIO}

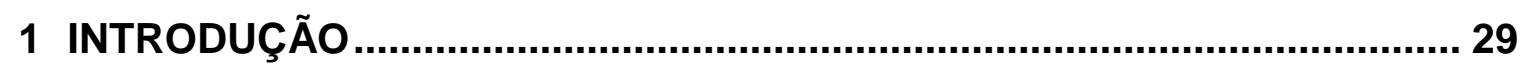

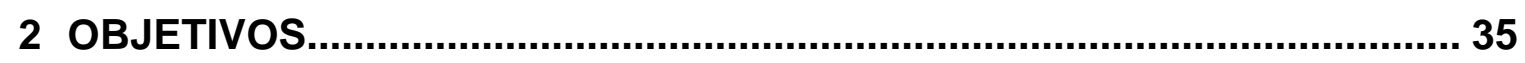

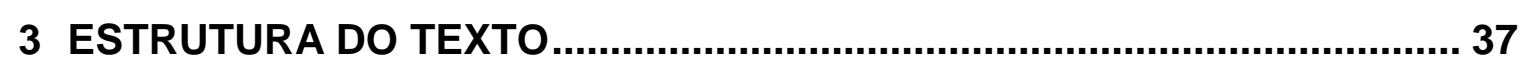

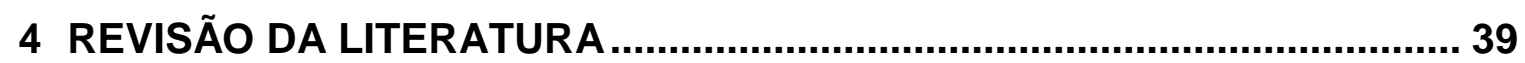

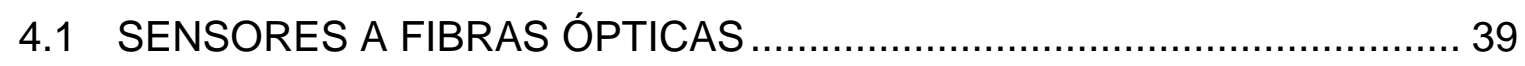

4.1.1 CLASSIFICAÇÃO DOS SENSORES A FIBRAS ÓPTICAS ..................... 40

4.2 INTERFERÔMETROS A FIBRAS ÓPTICAS ......................................... 50

4.2.1 INTERFERÔMETROS DE DUAS ONDAS …........................................ 51

4.2.2 INTERFERÔMETROS DE MÚLTIPLAS ONDAS …................................ 58

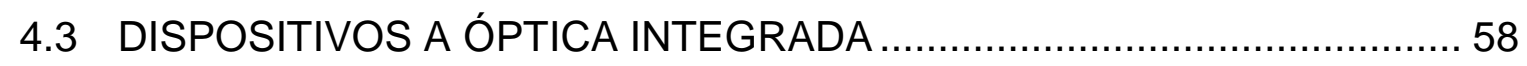

4.3.1 DISPOSITIVOS ELETRO-ÓPTICOS INTEGRADOS ............................... 60

4.4 REVISÃO DA TEORIA ELETROMAGNÉTICA APLICADA A SENSORES A

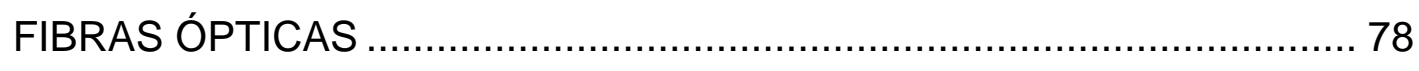

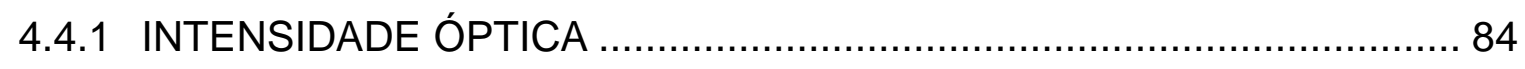

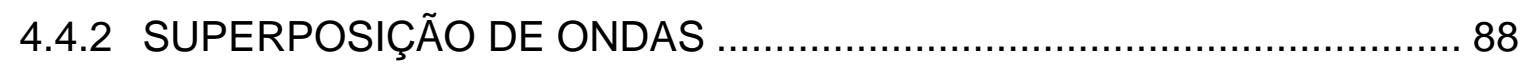

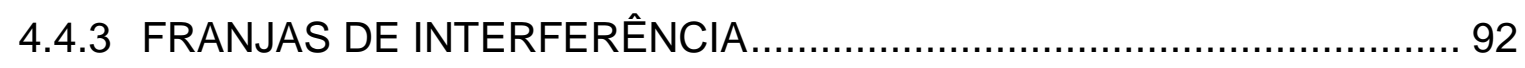

4.4.4 SUPERPOSIÇÃO DE ONDAS COM FREQUÊNCIAS IGUAIS ............... 95

4.4.5 SUPERPOSIÇÃO DE ONDAS COM DIFERENTES FREQUÊNCIAS..... 96 
4.5.1 SENSORES À FIBRA ÓPTICA COM MODULAÇÃO POR ESPECTRO. 97

4.5.2 PRINCÍPIO DE FUNCIONAMENTO DE UM INTERFERÔMETRO A WLI98

4.6 INTERAÇÃO ELETRO-ÓPTICA .

4.6.1 ÓPTICA DOS MEIOS ANISOTRÓPICOS 107

4.6.2 EFEITO ELETRO-ÓPTICO

4.6.3 EFEITO POCKELS

4.6.4 MODULADORES ELETRO-ÓPTICOS

4.6.5 MODULAÇÃO ELETRO-ÓPTICA 124

5 MATERIAIS E MÉTODOS

5.1 ESTUDO SOBRE ALTERNATIVAS DE IMPLEMENTAÇÃO DE INTERFERÔMETROS RECUPERADORES BASEADOS EM SENSORES ELETRO-ÓPTICOS DE BAIXA TENSÃO. 136

5.2 ESCOLHA DO MODULADOR ELETRO-ÓPTICO RECUPERADOR 137

5.3 METALIZAÇÃO DAS FIBRAS ÓPTICAS DO MODULADOR ELETROÓPTICO RECUPERADOR PELA TÉCNICA DE REDUÇÃO DA PRATA ATRAVÉS DA GLICOSE

5.4 MONTAGEM DO INTERFERÔMETRO RECUPERADOR COM O MODULADOR Y EM ÓPTICA INTEGRADA E SUA INTEGRAÇÃO AO SISTEMA SENSOR DO PROTÓTIPO DE TPO 148

5.4.1 O INTERFERÔMETRO SENSOR (CÉLULA DE ALTA TENSÃO) 152

5.4.2 ENLACE ÓPTICO 156

5.4.3 INTERFERÔMETRO RECUPERADOR 158 
5.4.4 PROCESSAMENTO ELETRÔNICO DO SINAL DE SAÍDA DO SISTEMA SENSOR ELETRO-ÓPTICO POR WLI ....................................................... 161

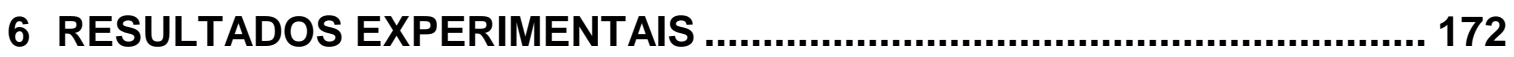

6.1 ENSAIOS FUNCIONAIS DO CONJUNTO TPO E PROCESSADOR DE

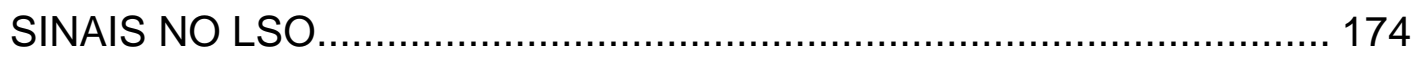

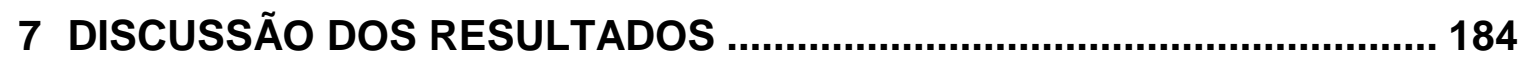

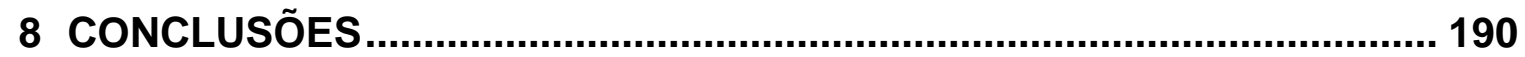

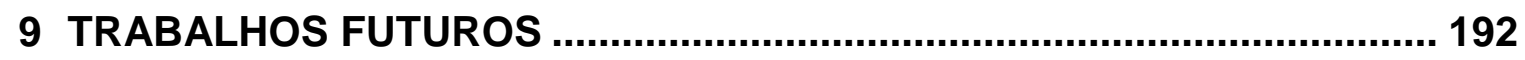

APÊNDICE A - TÉCNICAS DE FABRICAÇÃO DE DISPOSITIVOS EM ÓPTICA

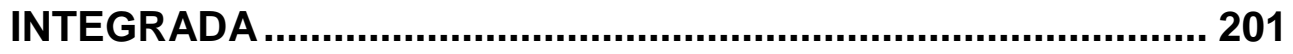

ANEXO 1 - DATASHEET DO DIODO SUPERLUMINESCENTE (SLD)

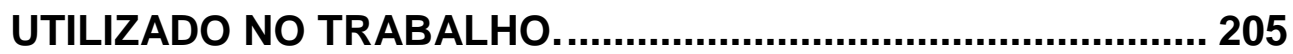

ANEXO 2 - DATASHEET DO CIRCULADOR ÓPTICO UTILIZADO NO

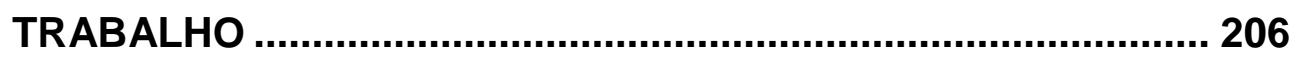

ANEXO 3 - DATASHEET DO MODULADOR EM Y UTILIZADO NO

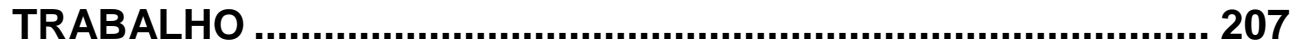

ANEXO 4 - DATASHEET DO FOTODIODO UTILIZADO NO TRABALHO .... 210

ANEXO 5 - DATASHEET DO ACOPLADOR DIRECIONAL UTILIZADO NO TRABALHO 213 


\section{LISTA DE ILUSTRAÇÔES}

Figura 1 - Diagrama de blocos de um sensor genérico [14].

Figura 2 - Diagrama de blocos com os tipos mais importantes de sensores ópticos extrínsecos [17].

Figura 3 - Diagrama de blocos com os tipos mais importantes de sensores ópticos intrínsecos [17].

Figura 4 - Diagrama de blocos mostrando os mecanismos de interação mais usados nos sensores a fibras ópticas de intensidade e interferométricos [17]. 46

Figura 5 - Tipos de grandezas que podem ser medidas utilizando sensores a fibras ópticas [17]

Figura 6 - Configurações mais comumente encontradas nos sensores ópticos interferométricos e as grandezas passíveis de serem medidas por eles [17]. 49

Figura 7 - Diagrama representativo de um acoplador direcional a fibras ópticas (3 dB). 52

Figura 8 (a) - Interferômetro de Michelson a fibras ópticas com espelho intrínseco. 54

Figura 8 (b) - Interferômetro de Michelson a fibras ópticas com espelho extrínseco 54

Figura 9 - Interferômetro de Mach-Zehnder a fibras ópticas. 55

Figura 10 - Geometrias comumente encontradas para dispositivos baseados em guias de ondas ópticos integrados. a) Dispositivo Mach-Zehnder, b) 
Acoplador direcional, c) Junção $Y$ moduladora e d) junção $Y$ fixa [15]. 60

Figura 11 - Seção transversal de um modulador de fase em configuração CPS simétrico. A posição do canal óptico é especificada pelo parâmetro "p" [24]. 61

Figura 12 - Vista geral de um modulador de fase com gerador e terminações. a) (1) e (5) são fibras ópticas, (2) é o substrato, (3) é um guia canal e (4) são eletrodos CPS. b) Vista transversal do dispositivo [24]....... 65

Figura 13 - Modulador de intensidade em configuração Mach-Zehnder. Vista geral com fonte e terminações, onde (1) é a fibra óptica de entrada e (5) é a fibra óptica de saída. (2) é o substrato, (3) é o interferômetro de Mach-Zehnder e (4) são os eletrodos CPW [24]. 71

Figura 14 - Junção em $Y$ com pigtail instalado apenas no acesso ao guia de entrada da bifurcação. 73

Figura 15 - Junção em $Y$ com pigtails instalados em todos os acessos do dispositivo. 73

Figura 16 - Interferômetro de Michelson utilizando junção em $Y$ com pigtails espelhados e com acoplador direcional na entrada. 74

Figura 17 - Representação simbólica do circulador óptico de 4 portas. 75

Figura 18 - Interferômetro de Michelson utilizando junção em $Y$ com pigtails espelhados e com circulador óptico na entrada. 76

Figura 19 - Esquema para interferência de dois feixes em um ponto $P$ do espaço. S1 e S2 são duas fontes de luz situadas à distâncias $r 1$ e r2 do ponto P. A distância entre as fontes S1 e S2 é a [25]. 88

Figura 20 - Padrão teórico de intensidade de saída de um interferômetro de luz branca [44]. 106 
Figura 21 - Elipsóide de índices para um meio uniaxial positivo.

Figura 22 - Célula Pockels de comprimento L colocada entre polarizadores... 118

Figura 23 - Modulador eletro-óptico em configuração longitudinal.

Figura 24 - Modulador eletro-óptico em configuração transversal..... 123

Figura 25 - Configuração do modulador eletro-óptico transversal, incluindo um cristal de LiNbO3 um par de polarizadores cruzados. O campo elétrico externo aplicado, paralelo ao eixo óptico do cristal, é transversal à direção de propagação da luz.

Figura 26 - Princípio do efeito eletro-óptico e do modulador eletro-óptico longitudinal. 132

Figura 27 - Modulador eletro-óptico de birrefringência volumétrico. 135

Figura 28 - Chip óptico integrado multifuncional (IOC - LiNbO3 multi-function integrated optical chip), modelo PMD1333-I [Anexo 3].

Figura 29 - Representação esquemática do modulador eletro-óptico ilustrando as fibras de saída $\mathrm{cm}$ seus comprimentos ajustados para uma diferença de caminho óptico $\underline{\Delta L}$. 140

Figura 30 - Processos principais da preparação da solução de Prata. (a) 0 reagente de Tollens. (b) Hidróxido de Sódio adicionado ao Reagente de Tollens. (c) A solução final com aspecto de "chá fraco" após adição de Amônia 144

Figura 31 - (a) Arranjo experimental para metalização de extremidades de fibras ópticas. (b) Gráfico da potência óptica refletida pela fibra óptica. . 145

Figura 32 - Materiais para polimento da fibra óptica do modulador eletro-óptico integrado. (1) Fibra óptica, (2) lixa para polimento da fibra óptica, (3) disco metálico utilizado como suporte para o conector da fibra óptica e (4) superfície plana de apoio para polimento. 
Figura 33 - Detalhes da fibra óptica metalizada. (a) Fibra óptica antes da limpeza e (b) Fibra óptica após processo de limpeza. Em (b) Cada divisão da régua abaixo da fibra óptica representa $1 \mathrm{~mm}$.

Figura 34 - a) Aspecto final do modulador $Y$ em óptica integrada. Em primeiro plano estão as fibras ópticas de saída do modulador após a metalização com Prata b) Detalhes da extremidade das fibras metalizadas. 148

Figura 35 - Esquema do protótipo de Transformador de Potencial Óptico completo.

Figura 36 - a) Esquema representativo da composição das "medalhas" com o cilindro de acrílico contendo o cristal eletro-óptico e b) Vista lateral em corte do aspecto final do modulador eletro-óptico longitudinal para medição de altas tensões [44]. 153

Figura 37 - a) Vista em corte da célula eletro-óptica de alta tensão [44] e b) Célula eletro-óptica sensora montada. 154

Figura 38 - a) Célula eletro-óptica de alta tensão e b) Célula de alta tensão e transformador de potencial. 155

Figura 39 - Esquema do sistema sensor eletro-óptico por técnica de WLI montado [44]. 159

Figura 40 - Interferômetro recuperador desenvolvido para compor o protótipo de TPO. 160

Figura $41-\operatorname{Id}(t)$, para as modulações $\phi 1(t)=0,5 \operatorname{sen}(\omega 1 t)$ e $\phi 2(t)=\pi / 2 \operatorname{sen}(\omega 2 t)$, sendo $\omega 2=16 \omega 1$ [33] 166

Figura 42 - Ampliação no domínio do tempo de um ciclo de $\mathrm{Id}(\mathrm{t})$, para as modulações $\phi 1(t)=0,5 \operatorname{sen}(\omega 1 t)$ e $\phi 2(t)=2 \pi \operatorname{sen}(\omega 2 t)$, sendo $\omega 2=$ $256 \omega 1$ [33].

Figura 43 - Configuração básica e um amplificador de transimpedância. 168 
Figura 43 - Diagrama de blocos do processador do sinal de saída do interferômetro recuperador do protótipo de TPO [33].

Figura 45 - llustrações do protótipo de TPO construído. a) Transformador elevador de tensão, b) unidade de processamento eletrônico de sinais, c) Fonte óptica (SLD), d) circulador óptico, e) célula recuperadora volumétrica, f) modulador em $\mathrm{Y}$ em óptica integrada, g) amplificador de transimpedância, h) Acoplador direcional, i) fotodetector, j) osciloscópio e k) par de fibras ópticas.

Figura 46 - Formas de onda da tensão da ordem de 0,69 kVrms, aplicadas ao interferômetro sensor (canal 1, traço inferior) e da tensão correspondente na saída do processador de sinais (canal 2, traço superior) do TPO. 176

Figura 47 - Espectro de frequências do sinal alternado de 0,69 kVrms aplicado ao interferômetro sensor do TPO. 176

Figura 48 - Espectro de frequências do sinal na saída do processador de sinais para uma tensão alternada de $0,69 \mathrm{kVrms}$ aplicada ao interferômetro sensor do TPO. 177

Figura 49 - Formas de onda da tensão da ordem de $1 \mathrm{kVrms}$, aplicada ao interferômetro sensor (canal 1, traço inferior) e da tensão correspondente na saída do processador de sinais (canal 2, traço superior) do TPO.

Figura 50 - Espectro de frequências do sinal alternado de $1 \mathrm{kVrms}$, aplicado ao interferômetro sensor do TPO. 178

Figura 51 - Formas de onda da tensão da ordem de $2 \mathrm{kVrms}$, aplicadas ao interferômetro sensor (canal 1, traço inferior) e da tensão correspondente na saída do processador de sinais (canal 2, traço superior) do TPO 178 
Figura 52 - Formas de onda da tensão da ordem de $2 \mathrm{kVrms}$, aplicadas ao interferômetro Sensor (canal 1, traço inferior) e da tensão correspondente na saída do processador de sinais (canal 2) do TPO

Figura 53 - Espectro de frequências do sinal alternado de $2 \mathrm{kVrms}$, aplicado ao interferômetro sensor do TPO. 179

Figura 54 - Espectro de frequências do sinal na saída do processador de sinais para uma tensão alternada de $2 \mathrm{kVrms}$ aplicada ao interferômetro sensor do TPO. 180

Figura 55 - Formas de onda da tensão da ordem de $4 \mathrm{kVrms}$, aplicada ao interferômetro sensor (canal 1, traço inferior) e da tensão correspondente na saída do processador d sinais (canal 2, traço superior) do TPO. 180

Figura 56 - Espectro de frequências do sinal alternado de $4 \mathrm{kVrms}$, aplicado ao interferômetro sensor do TPO.

Figura 57 - Espectro de frequências do sinal na saída do processador de sinais para uma tensão alternada de $4 \mathrm{kVrms}$ aplicada ao interferômetro sensor do TPO.

Figura 58 - Formas de onda da tensão da ordem de $8 \mathrm{kVrms}$, aplicada ao interferômetro sensor (canal 1, traço inferior) e da tensão correspondente na saída do processador de sinais (canal 2, traço superior) do TPO. 182

Figura 59 - Espectro de frequências do sinal alternado de $8 \mathrm{kVrms}$, aplicado ao interferômetro sensor do TPO.

Figura 60 - Espectro de frequências do sinal na saída do processador de sinais para uma tensão alternada de $8 \mathrm{kV}$ rms aplicada ao interferômetro sensor do TPO. 183 
Figura 61 - a) Formas de onda da tensão da ordem de 0,55 kVrms, aplicada ao interferômetro sensor (canal 1, traço superior) e da tensão correspondente na saída do processador de sinais (canal 2) do TP Óptico [33]. b) Formas de onda da tensão da ordem de 0,69 kVrms, aplicadas ao interferômetro sensor (canal 1, traço inferior) e da tensão correspondente na saída do processador de sinais (canal 2, traço superior) do TPO 185

Figura 62 - Espectro de frequências do sinal alternado de 0,55 kVrms aplicado ao interferômetro sensor do protótipo de TPO [33] b) Espectro de frequências do sinal alternado de $0,69 \mathrm{kV} r m s$ aplicado ao interferômetro sensor do protótipo de TPO. (SPAN $=1 \mathrm{kHz}$, ganho vertical $=10 \mathrm{~dB} / \mathrm{div}$, ganho horizontal $=100 \mathrm{~Hz} / \mathrm{div})$. 186

Figura 63 - a) Espectro de frequências do sinal na saída do processador de sinais para uma tensão alternada de 0,55 kVrms aplicada ao interferômetro sensor do TPO [33]. b) Espectro de frequências do sinal na saída do processador de sinais para uma tensão alternada de 0,69 kVrms aplicada ao interferômetro sensor do TPO. (SPAN =1 $\mathrm{kHz}$, ganho vertical $=10 \mathrm{~dB} /$ div, ganho horizontal $=100 \mathrm{~Hz} /$ div). .187

Figura 64 - a) Formas de onda da tensão da ordem de 8 kVrms, aplicada ao interferômetro sensor (canal 1) e da tensão correspondente na saída do processador de sinais (canal 2) do TPO [33]. b) Formas de onda da tensão da ordem de $8 \mathrm{kVrms}$, aplicada ao interferômetro sensor (canal 1, traço inferior) e da tensão correspondente na saída do processador de sinais (canal 2, traço superior) do TPO. 188

Figura 65 - Espectro de frequências do sinal alternado de $8 \mathrm{kVrms}$ aplicado ao interferômetro sensor do protótipo de TPO [33]. b) Espectro de frequências do sinal alternado de $8 \mathrm{kVrms}$, aplicado ao interferômetro sensor do protótipo de TPO. (SPAN $=1 \mathrm{kHz}$, ganho vertical $=10 \mathrm{~dB} / \mathrm{div}$, ganho horizontal $=100 \mathrm{~Hz} /$ div). 189 
Figura 66 - a) Espectro de frequências do sinal na saída do processador de sinais para uma tensão alternada de $8 \mathrm{kVrms}$ aplicada ao interferômetro sensor do TPO [33]. b) Espectro de frequências do sinal na saída do processador de sinais para uma tensão alternada de $8 \mathrm{kVrms}$ aplicada ao interferômetro sensor do TPO. (SPAN $=1$ $\mathrm{kHz}$, ganho vertical $=10 \mathrm{~dB} / \mathrm{div}$, ganho horizontal $=100 \mathrm{~Hz} / \mathrm{div}) . .189$

Figura 67 - Lâminas de Niobato de Lítio: a) Corte-X. b) Corte-Y. c) Corte-Z [24].202

Figura 68 - Fita de titânio com largura $2 \mathrm{w}$ e espessura $\underline{\tau}$ depositada sobre 0 substrato de LiNbO3 a ser difundida termicamente para o seu interior. Dx e Dy referem-se às constantes de difusão na direção $x e$ y, respectivamente. O canal óptico será estabelecido após a difusão [24]. 203 


\section{LISTA DE TABELAS}

Tabela 1 - Configurações de interferômetros e suas expressões funcionais correspondentes à diferença de fase. 57

Tabela 2 - Algumas propriedades e constantes físicas importantes do Niobato de Lítio $\left(\mathrm{LiNbO}_{3}\right)$. 63 


\section{LISTA DE ABREVIATURAS}

\begin{tabular}{|c|c|}
\hline $\mathrm{BGO}$ & Germanato de Bismuto $\left(\mathrm{Bi}_{4} \mathrm{Ge}_{3} \mathrm{O}_{12}\right)$ \\
\hline CA & Corrente Alternada \\
\hline CPS & Symmetric Coplanar Strips \\
\hline EMI & Electromagnetic Interference \\
\hline EMP & Electromagnetic Pulse \\
\hline $\mathrm{E} / \mathrm{O}$ & Conversão Elétrica/Óptica \\
\hline EPUSP & Escola Politécnica da Universidade de São Paulo \\
\hline FOI & Fiber Optic Interferometer \\
\hline FOLCl & Fiber Optic Low Coherence Interferometry \\
\hline GRIN & Gradual Index \\
\hline IEE & Instituto de Engenharia e Eletrotécnica \\
\hline LASER & Light Amplification by Stimulated Emission of Radiation \\
\hline LED & Light Emitting Diode \\
\hline $\mathrm{LiNbO}_{3}$ & Niobato de Lítio \\
\hline $\mathrm{LiTaO}_{3}$ & Tantalato de Lítio \\
\hline LSO & Laboratório de Sensores Ópticos \\
\hline $\mathrm{O} / \mathrm{E}$ & Conversão Óptica/Elétrica \\
\hline Ol & Óptica Integrada \\
\hline
\end{tabular}


OPD Optical Path Diference

PEA Departamento de Engenharia de energia e Automação Elétricas

PM Polarization-Maintaining

SEP Sistemas Elétrico de Potência

SLD Superluminescent Diode

TPC Transformador Eletromagnético de Acoplamento Capacitivo

TPI Transformador Eletromagnético de Acoplamento Indutivo

TPO Transformador de Potencial Óptico

UPS Unidade de Processamento de Sinal

WLI White Light Interferometry 


\section{LISTA DE SÍMBOLOS}

a

Distância entre fendas

$A_{e} \quad$ Constante de proporcionalidade que relaciona a potência óptica recebida com a intensidade óptica do feixe incidente sobre 0 Fotodetector

c Velocidade da luz no vácuo

$\mathrm{dB} \quad$ Decibel

$E_{3 s}$ e $E_{4 s}$ Componentes das ondas ópticas nas saídas 3 e 4 do Acoplador Direcional, respectivamente

$E_{1 e}$ e $E_{2 e} \quad$ Componentes das ondas ópticas nas entradas 3 e 4 do Acoplador Direcional, respectivamente

$E_{\text {in }} \quad$ Amplitude do campo elétrico na entrada do Interferômetro

$E_{m} \quad$ Intensidade do campo elétrico de modulação

$E_{\text {out }} \quad$ Amplitude do campo elétrico na saída do Interferômetro

$\vec{E}_{\text {out }} \quad$ Campo elétrico da onda óptica emergente

$\bar{E} \quad$ Amplitude complexa do Campo Elétrico $\vec{E}$

$\vec{E}(\vec{r}, t) \quad$ Vetor campo elétrico

h $\quad$ Constante de Planck

$\mathrm{Hz} \quad$ Hertz 

$\vec{H}(\vec{r}, t) \quad$ Vetor campo magnético
Quantidade imaginária $(i=\sqrt{-1})$
$I_{b f}(t) \quad$ Componente de baixa frequência da fotocorrente $I_{d}(t)$
$I_{d}(t) \quad$ Fotocorrente na saída do Interferômetro Sensor
$I_{r} \quad$ Intensidade óptica na saída do Interferômetro Recuperador
$l_{1}$ e $I_{2} \quad$ Intensidades ópticas dos feixes interferentes
$I_{\text {Det1 }} \quad$ Intensidade luminosa no Fotodetector 1
$I_{\text {Det2 }} \quad$ Intensidade luminosa no Fotodetector 2
$I(\vec{r}, t) \quad$ Intensidade óptica
$I_{o}(\sigma) \quad$ Distribuição de intensidade espectral da fonte óptica
$I_{v 1}$ e $I_{v 2} \quad$ Valor da Fotocorrente no vale 1 e 2 , respectivamente
$J_{n} \quad$ Função de Bessel de ordem $n$
kV Quilovolt
$\vec{k} \quad$ Vetor de onda
Kor Visibilidade da franja central do Interferômetro Recuperador
Kos Visibilidade da franja central do Interferômetro Sensor
$L \quad$ Comprimento do cristal
L $\quad$ Comprimento de interação 


\begin{tabular}{|c|c|}
\hline$L_{c}$ & Comprimento de coerência \\
\hline$\eta_{d}$ & Eficiência quântica do Fotodiodo \\
\hline$\eta_{f d}$ & Responsividade do Fotodiodo \\
\hline$n_{0}$ & Índice de refração ordinário do cristal \\
\hline$n_{e}$ & Índice de refração extraordinário do cristal \\
\hline$P$ & Potência óptica \\
\hline$q$ & Carga do Elétron \\
\hline$\vec{r}$ & Vetor posição \\
\hline$r_{i j}$ & Coeficiente eletro-óptico do Cristal de $\mathrm{LiNbO}_{3}$ \\
\hline rms & Root Mean Square (valor eficaz) \\
\hline$R_{f}$ & Resistência de realimentação do Amplificador de Transimpedância \\
\hline$\vec{S}(\vec{r}, t)$ & Vetor de Poynting \\
\hline$t$ & Tempo \\
\hline$T$ & Período da onda óptica \\
\hline$T$ & Transmitância \\
\hline$T_{1}$ & Fator de transmissão do enlace óptico no caminho de ida \\
\hline$T_{2}$ & Fator de transmissão do Interferômetro Recuperador \\
\hline$T_{c}$ & Fator de transmissão do Acoplador Direcional \\
\hline$T_{M}$ & Função de transferência do Interferômetro de Michelson \\
\hline
\end{tabular}




\begin{tabular}{|c|c|}
\hline$T_{M Z}$ & Função de transferência do Interferômetro Mach-Zehnder \\
\hline$T_{r}$ & Fator de transmissão do Interferômetro Recuperador \\
\hline$T_{s}$ & Fator de transmissão do interferômetro Sensor \\
\hline$\vec{u}_{x}, \vec{u}_{y}, \vec{u}_{z}$ & Vetores unitários nas direções $x, y$ e $z$ \\
\hline$v_{f}$ & Velocidade de fase da onda óptica \\
\hline V & Visibilidade das franjas de interferência \\
\hline V & Volt \\
\hline$V_{o}$ & Visibilidade da franja central \\
\hline$V_{a f}(t)$ & Componente de alta frequência da tensão de saída \\
\hline$V_{b f}(t)$ & Componente de baixa frequência da tensão de saída \\
\hline$V_{c c}$ & Tensão contínua de polarização \\
\hline$V_{d}(t)$ & Tensão na saída o Amplificador de Transimpedância \\
\hline$V_{r}$ & Visibilidade do Interferômetro Recuperador \\
\hline$V_{s}$ & Visibilidade do Interferômetro Sensor \\
\hline$V_{v 1}$ e $V_{v 2}$ & Valor da tensão no vale 1 e 2 , respectivamente \\
\hline$V_{p}$ & Valor de pico da tensão de saída do sistema \\
\hline$V_{\pi}$ & Tensão de meia onda \\
\hline$V_{\pi r}$ & Tensão de meia onda da Célula Recuperadora \\
\hline
\end{tabular}


$V_{\pi s} \quad$ Tensão de meia onda da Célula Sensora

$\varepsilon_{1}$ e $\varepsilon_{2} \quad$ Fases relativas

$\varphi_{0} \quad$ Fase inicial (ou na origem)

$\phi_{1}$ e $\phi_{2} \quad$ Atrasos de fases ópticos induzidos eletricamente pelos Interferômetros Sensor e Recuperador, respectivamente

$\Delta n_{c} \quad$ Birrefringência da lâmina retardadora

$\Delta \varphi \quad$ Diferença de fase óptica

$\Delta \varphi_{m} \quad$ Variação de fase óptica induzida pela ação do campo elétrico de modulação

$\varphi(t) \quad$ Fase óptica induzida dependente do tempo

$\Delta \phi_{C e l \_}$Alta $\quad$ Atraso de fase introduzido pela Célula de Alta Tensão

$\Delta L_{r} \quad$ Diferença de caminho óptico introduzida pelo Interferômetro Recuperador

$\Delta L_{s} \quad$ Diferença de caminho óptico introduzida pelo Interferômetro Sensor

$\Delta \varphi_{m}(t) \quad$ Variação de fase óptica induzida dependente do tempo

$\Gamma_{12}(\tau) \quad$ Função de correlação cruzada

$\left|\Gamma_{12}(\tau)\right| \quad$ Grau de coerência

$\Gamma \quad$ Atraso de fase induzido pelo campo elétrico

$\Gamma_{0} \quad$ Atraso de fase passivo 
$\omega$

$\omega_{m}$

$\bar{\omega}$

$\omega_{s} \quad$ Frequência de modulação

$\delta \quad$ Índice de modulação

$\lambda \quad$ Comprimento de onda

$\lambda_{S L D} \quad$ Comprimento de onda central do SLD

I Intensidade óptica na saída do Fotodetector

$I_{\text {in }} \quad$ Intensidade óptica na entrada do Fotodetector

$\sigma \quad$ Número de onda de uma componente espectral

$\sigma_{o} \quad$ Número de onda central da fonte óptica

$\delta \sigma \quad$ Largura de banda espectral

$I_{0} \quad$ Intensidade óptica em $\sigma_{0}$ 


\section{RESUMO}

O trabalho tem por objetivo o estudo e o desenvolvimento de interferômetros recuperadores com baixa tensão de meia onda utilizando moduladores eletro-ópticos para serem aplicados em sistemas Interferométricos de luz branca. Ele dá continuidade às pesquisas do autor em seu mestrado, em que foi desenvolvido e testado um sistema de sensoriamento eletro-óptico capaz de medir diretamente tensões de até 69,4 $\mathrm{kV}_{\mathrm{RMS}}$. Desta forma aperfeiçoa-se o sistema de processamento de sinais ópticos desenvolvendo um novo interferômetro recuperador, baseado em óptica integrada.

Para o desenvolvimento do tema proposto, inicialmente foi feito uma revisão da literatura/bibliografia, baseada em livros, artigos e teses, visando identificar o "estado da arte" relacionado aos moduladores eletro-ópticos para definir o tipo de modulador mais adequado à aplicação em vista. O estudo resultou na escolha de um componente em óptica integrada que foi aplicado numa configuração inédita em um protótipo de transformador de potencial óptico para medição de elevados níveis de tensão elétrica. As características de desempenho deste protótipo foram comparadas com as do protótipo previamente construído.

Como resultado deste trabalho, amplia-se o conhecimento e fixa-se em âmbito nacional o domínio sobre as técnicas de construção de interferômetros recuperadores baseados em óptica integrada aplicáveis à recuperação de sinais ópticos em sistemas interferométricos para medição de altas tensões.

Palavras-chave: Sensores a fibras ópticas. Sensores eletro-ópticos. Moduladores eletro-ópticos. Efeito Pockels. Medida de altas tensões. Óptica integrada. Interferometria de luz branca. Processamento óptico de sinais. Processamento eletrônico de sinais. 


\begin{abstract}
This work has as objective the study and development of low half-wave voltage recovery interferometers using electro-optical modulators to be applied to white light interferometric systems. This work is a continuation in the research carried out by the author to obtain his master degree, in which it was developed and tested an electrooptic sensing system capable to measure direct voltage to $69.4 \mathrm{kV}_{\mathrm{rms}}$. In the present work the optical signals processing system is improved by developing a new recovery interferometer based on integrated optics.
\end{abstract}

To develop the proposed subject, initially a review of the literature, based on books, articles and thesis, has been done aiming to identify the "State of the Art" related to electro-optic modulators and helping to define the most suitable type of modulator for the desired application. The study resulted in the selection of an integrated optical device arranged in an unpublished configuration that was applied to a prototype of optical voltage transformer, intended to measure high voltage levels.

The performance of this prototype was compared with a previous version. The results of this work increase the knowledge of the construction techniques of recovery interferometers based on integrated optic devices applicable to the recovering of optical signals in interferometric systems for high voltage measurement.

Keywords - Optical fiber sensors. Electrooptic sensors. Electrooptic Modulators. Pockels effect. High-voltage measurements. Integrated optics. White light interferometry. Optical Signal Processing. Electronic Signal Processing. 


\section{INTRODUÇÃO}

Os sensores a fibras ópticas apresentam muitas vantagens em relação aos similares convencionais. Dentre elas, pode-se destacar que, em geral, são dispositivos passivos (não requerem fonte de alimentação elétrica no local da medição) e apresentam imunidade a interferências eletromagnéticas (Electromagnetic Interference $-E M I$ ) e a pulso eletromagnético (Electromagnetic Pulse-EMP). Além disso, exibem características interessantes, tais como: pequenas dimensões, baixo peso, grande sensibilidade e ampla faixa de resposta em frequência. Contudo, em alguns campos de aplicação, os sensores a fibras ópticas enfrentam a forte concorrência de outras tecnologias mais tradicionais de ampla aceitação, como, por exemplo, aquelas que utilizam componentes eletrônicos como sensores nas medidas.

Para atrair os usuários já acostumados com tecnologias tradicionais, a superioridade dos sensores a fibras ópticas sobre os outros tipos de sensores precisa ser claramente demonstrada. Os usuários típicos de tecnologias tradicionais não estão diretamente interessados nas técnicas específicas utilizadas nas medições das grandezas em foco, mas sim em obter sistemas sensores que possuam bom desempenho e a melhor relação possível entre custo e benefício. Por conseguinte, os sistemas sensores a fibras ópticas devem estar disponíveis a preços competitivos com os sensores tradicionais e de forma completa, ou seja, o sistema sensor deve incluir o enlace de comunicação a fibras ópticas, a transdução optoeletrônica e o processamento eletrônico do sinal.

O advento das fibras ópticas tornou possível um avanço sem igual nos sistemas de telecomunicações como um todo. Este avanço permitiu um gigantesco ganho de escala na produção e comercialização de produtos voltados para o mercado de comunicações ópticas, permitindo uma redução significativa nos custos de produção tanto de fibras ópticas quanto na tecnologia de microfabricação de circuitos em óptica integrada.

Observa-se que as áreas da instrumentação e da medição, no que diz respeito ao desenvolvimento de sensores, estão entre as que mais rapidamente tem se 
expandido. Em especial, atualmente, tem-se evidenciado a necessidade de integração de sensores de elevada qualidade nos mais sofisticados sistemas de medição e controle. Em paralelo com o desenvolvimento acelerado de sensores baseados em tecnologia microeletrônica, outros sensores baseados em técnicas ópticas têm também progredido significativamente durante os últimos anos, em particular desde o aparecimento das fibras ópticas.

Em meados da década de 70 , houve um interesse crescente na possibilidade de usar as fibras ópticas em sistemas de comunicação, tirando partido da sua elevada largura de banda, comparativamente aos sistemas de comunicação tradicionais (baseados nas tecnologias que utilizam fios condutores ou ondas de rádio). Como resultado de investigações intensivas levada a cabo nos países tecnologicamente mais avançados, foram conseguidos grandes progressos na produção de fibras ópticas de melhor qualidade (principalmente com baixas perdas), o mesmo acontecendo relativamente às fontes e detectores ópticos. A investigação em torno de vários aspectos das comunicações ópticas continua hoje extremamente ativa, especialmente devido à necessidade de se obter sistemas mais eficientes e rápidos que suportem quantidades cada vez maiores de informação.

No caso dos sensores ópticos a situação foi bastante diferente, pois os métodos ópticos de monitoração e controle já estavam bem estabelecidos muito antes dos anos 70 [1-4]. Estes sensores exploravam uma vasta gama de mecanismos, desde simples interruptores ópticos baseados na interrupção de um feixe de luz, até sofisticadas técnicas de interferometria óptica. Uma característica comum à maior parte destes instrumentos ópticos baseados em propagação não guiada é o fato deles serem bastante delicados, no sentido de que o desempenho do dispositivo se degrada quando o alinhamento óptico é perturbado. Como consequência, apesar de possuírem elevado desempenho, poucas propostas de sensores deste tipo passavam da fase de desenvolvimento [3, 4].

A fibra óptica permitiu flexibilidade nas ligações entre os diversos elementos ópticos, eliminando praticamente os problemas de desalinhamentos e viabilizando, ao mesmo tempo, a monitoração e o controle remoto de vários dispositivos. Por outro lado, de forma gradual, foram adicionados em muitos destes dispositivos, os mais variados componentes desenvolvidos pela indústria optoeletrônica, dando lugar ao 
aparecimento de uma nova classe de sensores ópticos: os sensores a fibras ópticas. Sua versatilidade é muito grande, quando comparada com a de seus concorrentes convencionais, dado que a luz é caracterizada por um conjunto de parâmetros independentes, como a intensidade, o espectro, a fase e a polarização, todos potencialmente sensíveis às mais variadas grandezas de interesse.

A gama de grandezas que podem ser medidas com sensores a fibra óptica tem crescido rapidamente, bem como o número de mecanismos transdutores que estão sendo explorados.

Algumas vantagens dos sensores a fibras ópticas que os tornam uma alternativa técnica atraente relativamente aos sensores convencionais são: a sua imunidade a interferências eletromagnéticas, conduzidas pelo enlace de fibras ópticas; possibilidade de serem totalmente passivos eletricamente, o que os torna intrinsecamente seguros; baixo consumo de potência elétrica; a sua resistência a altas temperaturas; dimensões e peso reduzidos; grande largura de banda e a possibilidade de multiplexação óptica e elétrica, etc. [2, 5].

O avanço desta área deve muito ao desenvolvimento das fibras ópticas e dos dispositivos optoeletrônicos, particularmente fontes e detectores ópticos, sendo que grande parte dos sensores a fibra óptica aproveita os custos atualmente mais baixos desses componentes advindos da sua fabricação em larga escala para atender a indústria das telecomunicações. Com a expansão mundial das redes de comunicações por fibras ópticas, existe agora uma grande disponibilidade de componentes ópticos e eletrônicos de alta qualidade a preços competitivos. Associado a isto, a expansão do mercado optoeletrônico para produtos de consumo doméstico, tais como os leitores de discos ópticos e os diversos dispositivos de controle remoto, que utilizam fontes e detectores de radiação infravermelha em variados sistemas, têm também conduzido a um avanço da tecnologia disponível e passível de ser utilizada no desenvolvimento de novos sensores de fibra óptica [5, $6]$.

Sensores a fibras ópticas são especialmente indicados para ambientes que apresentem altos níveis de campos elétricos e magnéticos, típicos de instalações de alta tensão que compõem os Sistemas Elétricos de Potência (SEP). Sua indicação 
para estes casos se deve principalmente a suas características particulares, como sua potencial natureza dielétrica, imunidade a interferências e conduzidas pelo enlace a fibras ópticas, baixo peso, dimensões reduzidas, etc. [7].

Os SEPs necessitam de contínuo sensoriamento das diversas grandezas envolvidas no processo de geração, transmissão e distribuição de energia elétrica. A gama de grandezas de medição de interesse no setor é bastante ampla, indo desde grandezas químicas, como a presença de determinados contaminantes em óleos de isolamento de transformadores, até as clássicas grandezas físicas, como temperatura, força, vibração, tensão, corrente e campos eletromagnéticos em geral [2, 3]. É conhecida também a severidade do ambiente de medição a que estes sensores são submetidos, invariavelmente em presença de intensas interferências eletromagnéticas. Na maioria dos casos, a natureza dos sensores eletroeletrônicos impede ou dificulta as medições nesses ambientes com incerteza mais baixa [7].

Desta forma, a instrumentação baseada em sensores a fibras ópticas vem conquistando espaço no setor elétrico, devido à fase atual da sua tecnologia, que permite que sejam fabricados sistemas de medição (compostos por sensores, enlaces de comunicação, processadores de sinais e de indicação) praticamente imunes às interferências inerentes às medições neste setor.

Assim, têm-se pesquisado e desenvolvido sensores que se destacam pela sua miniaturização, versatilidade e, principalmente, alta compatibilidade eletromagnética, características que asseguram aos sensores a fibras ópticas uma ampla gama de aplicações no setor elétrico.

Neste ínterim, o efeito eletro-óptico Pockels tem sido muito utilizado para construir moduladores eletro-ópticos, os quais encontram inúmeras aplicações em comunicações, processamento de sinais e sensoriamento. Entre essas aplicações inclui-se a instrumentação de sistemas elétricos [7].

Estes moduladores podem ser utilizados para converter grandezas elétricas, tais como o campo elétrico, a corrente e a tensão, em grandezas ópticas, como a intensidade luminosa ou o padrão de polarização da luz, além de possuírem 
características elétricas que permitem seu uso em sistemas de medição e proteção de SEP em alta tensão [7].

Um caso particular, é a medição da tensão elétrica em níveis elevados, que é feita, convencionalmente, por meio de transformadores eletromagnéticos de acoplamento indutivo (TPI), por vezes associados a divisores capacitivos de tensão (TPC). Ultimamente, grandes esforços têm sido realizados para desenvolver sensores a fibras ópticas adequados para medir diretamente tais níveis de tensão. Tais sensores são chamados de Transformadores de Potencial Ópticos (TPO). Nesta aplicação os moduladores eletro-ópticos desempenham um importante papel, proporcionando um melhor uso das vantagens dos enlaces a fibras ópticas [7].

Pesquisas nesta área vêm sendo desenvolvidas no Laboratório de Sensores Ópticos (LSO) do Departamento de Engenharia de Energia e Automação Elétricas (PEA) da EPUSP, com a finalidade de desenvolver TPOs baseados em modernas tecnologias e, ao mesmo tempo, estudar os aspectos relativos à substituição dos transformadores convencionais pelos seus similares a fibras ópticas [7].

Como fruto de quase 20 anos de pesquisas, atualmente, o LSO já possui capacitação e "know-how" para o desenvolvimento de TPOs desse tipo, sendo que protótipos de laboratório completos com suportabilidades de 13,8 kV até $69 \mathrm{kV}$ já foram construídos e testados. Os resultados dessas pesquisas têm sido apresentados em publicações (revistas e eventos) da área, sendo que o trabalho de mestrado do autor contribuiu para esses resultados [7-9].

Em grande parte da experiência acumulada pelo autor e pela equipe ligada ao LSO nos desenvolvimentos anteriores, os TPOs desenvolvidos são baseados na técnica de Interferometria de Luz Branca (White Light Interferometry - WLI), na qual dois interferômetros conectados em série são iluminados por uma fonte óptica de espectro largo. Um dos interferômetros integra o elemento sensor primário, enquanto que o outro é o chamado modulador recuperador. O interferômetro sensor, no caso, consiste em um modulador eletro-óptico acondicionado numa montagem mecânica e eletricamente adequada para permitir que o mesmo seja submetido a altas tensões. Por meio de um enlace a fibras ópticas conecta-se este sensor à fonte óptica e ao segundo interferômetro, que também pode ser constituído por um modulador eletro- 
óptico, só que nesse caso construído de tal maneira que possa ser modulado por tensões muito inferiores àquelas a que o interferômetro sensor será submetido. $O$ sinal óptico de saída do interferômetro recuperador é enviado a um diodo fotodetector que gera um sinal elétrico que é amplificado e processado para dar origem ao sinal de saída "bruto" do TPO. Este sinal é mais uma vez processado para dar origem às medidas do TPO, cujas saídas podem ser fornecidas em formato analógico ou digital [9].

Nos desenvolvimentos anteriores os moduladores eletro-óptico utilizados como interferômetros recuperadores apresentavam características inadequadas, tais como: elevados valores de tensão de meia onda $\left(V_{\pi}\right)$, sensibilidade a vibrações mecânicas, baixa imunidade eletromagnética, dificuldade de conectorização, alta sensibilidade à variação da temperatura, montagem volumétrica e delicada, necessidade de alinhamento axial e angular precisos entre os componentes ópticos, etc.

Neste contexto, o desenvolvimento de interferômetros recuperadores baseados em moduladores eletro-ópticos que minimizassem ou eliminassem os problemas citados acima, se fazia necessário, sendo esse o foco central deste trabalho. 


\section{OBJETIVOS}

Pretende-se com este trabalho dar continuidade às pesquisas do autor em seu mestrado, em que foi desenvolvido e testado um sistema de sensoriamento eletroóptico capaz de medir diretamente tensões de até $69 \mathrm{kV}_{\mathrm{RMS}}$ utilizando um interferômetro recuperador não modulado, em montagem volumétrica, em série com o interferômetro de birrefringência da célula sensora que compõe o TPO. Desta feita, pretende-se implementar um interferômetro recuperador modulado, com características otimizadas para a aplicação em vista.

Assim sendo, os objetivos do presente trabalho são:

1. Estudar o estado da arte dos moduladores eletro-ópticos, buscando alternativas que apresentem as seguintes características:

- Baixo valor de tensão de meia onda $\left(V_{\pi}\right)$;

- Insensibilidade a vibrações mecânicas;

- Elevada imunidade eletromagnética;

- Facilidade de conectorização;

- Baixa sensibilidade à variação da temperatura;

- Montagem compacta e robusta e

- Não necessidade de alinhamento axial e angular precisos;

2. Selecionar dentre as alternativas identificadas aquela que seja mais indicada para a implementação de um interferômetro recuperador adequado para substituir a versão volumétrica utilizada nos desenvolvimentos anteriores.

3. Implementar um protótipo de interferômetro recuperador baseado no modulador selecionado.

4. Testar em laboratório o protótipo construído a fim de demonstrar sua funcionalidade; 
5. Pretende-se também, aperfeiçoar o sistema de processamento de sinais ópticos, melhorando ainda mais o desempenho do novo interferômetro recuperador e comparar suas características e desempenho com as do protótipo previamente construído.

Como resultado, pretende-se ampliar o conhecimento e fixar em âmbito nacional o domínio sobre as técnicas de construção de interferômetros recuperadores baseados em moduladores eletro-ópticos aplicáveis à recuperação de sinais ópticos em sistemas interferométricos de luz branca para medição de altas tensões. 


\section{ESTRUTURA DO TEXTO}

O trabalho é organizado inicialmente, no capitulo 1, um levantamento bibliográfico a fim de se verificar o "estado da arte". É apresentada uma visão geral dos trabalhos publicados na área de sensores a fibras ópticas. Em seguida, é feito um levantamento das principais topologias de interferômetros utilizados em sistemas de sensores a fibras ópticas.

No capítulo 2 são apresentados os objetivos do trabalho.

O capitulo 3 refere-se à estrutura do trabalho.

No capítulo 4 é apresentada a revisão da literatura e a teoria relacionada com o desenvolvimento deste trabalho.

No capítulo 5 são apresentados os procedimentos, as técnicas, os materiais utilizados no arranjo experimental e as atividades realizadas no desenvolvimento deste trabalho: o estudo das alternativas de implementação de interferômetros recuperadores baseados em sensores eletro-ópticos de baixa tensão, a escolha do modulador recuperador e a técnica de metalização das fibras ópticas e do modulador eletro-óptico, o ajuste do comprimento dos braços do interferômetro recuperador, a montagem do interferômetro recuperador com o modulador $Y$ em óptica integrada $\mathrm{e}$ será descrita a técnica utilizada para a metalização das fibras ópticas para utilização no modulador eletro-óptico recuperador.

No capítulo 6 analisam-se os resultados experimentais obtidos, comparado-os com os resultados obtidos em outro trabalho.

No capítulo 7 discutem-se os resultados deste trabalho .

No capítulo 8 apresentam-se as conclusões do trabalho.

No capitulo 9 apresentam-se propostas de trabalhos futuros. 
No apêndice A apresentam-se, de forma resumida, as técnicas de fabricação de dispositivos em óptica integrada citadas no capítulo 4 e finalmente os Anexos contendo os datasheets de alguns dos dispositivos utilizados no trabalho. 


\section{REVISÃo DA LITERATURA}

\subsection{SENSORES A FIBRAS ÓPTICAS}

Na segunda metade da década de 1970 foram publicados dois artigos que podem ser considerados como marco do início desta nova área da instrumentação, ou seja, a área dos sensores a fibra óptica. O primeiro deles foi um interferômetro de Sagnac com caminhos ópticos recíprocos implementados em fibra óptica [10]. No segundo, foi possível demonstrar a medição remota de corrente elétrica através do efeito Faraday provocada em uma fibra óptica monomodo de birrefringência muito baixa [11]. Estes dois trabalhos provaram que as fibras ópticas possuíam potencial para serem exploradas de diferentes maneiras e para diferentes aplicações na área de sensores ópticos. O primeiro trabalho mostrou ainda que interferômetros ópticos, podiam ser construídos totalmente em fibras ópticas, lançando as bases para 0 surgimento do giroscópio a fibra óptica. No caso do sensor de corrente elétrica, mostrou-se que um único cabo de fibra óptica poderia simultaneamente ser usado como sensor e como canal de transmissão, permitindo assim, que as medições pudessem, também, ser realizadas em ambientes hostis. Em ambos os casos a grandeza medida interage diretamente com a fibra óptica, produzindo alterações na radiação por ela guiada.

Adicionalmente a estas experiências iniciais, a gama de grandezas que podem ser medidas com sensores de fibra tem crescido rapidamente, bem como o número de mecanismos de transdução que estão sendo explorados.

A perspectiva inicial desta tecnologia foi a de poder ser aproveitada em um amplo leque de aplicações num largo espectro de sensores industriais. No entanto, devido aos custos inicialmente elevados, essa visão foi largamente modificada de maneira a realçar as vantagens da monitoração óptica em setores especiais do mercado, tais como instrumentação médica, sistemas de segurança críticos, aeronáutica, monitoração ambiental e, mais recentemente, na construção civil [12, 13]. 
Neste contexto, não é difícil prever um aumento do número de aplicações desses sensores e uma maior presença deles no mercado, à medida que o preço dos componentes for decrescendo, propiciando uma maior receptividade nas aplicações em que seja necessário um grande número de sensores a fibra óptica operando simultaneamente. Para isto contribuirão as técnicas de multiplexação de sensores [13], as quais permitem uma considerável economia em termos de custo por unidade.

\subsubsection{CLASSIFICAÇÃO DOS SENSORES A FIBRAS ÓPTICAS}

A fim de auxiliar o leitor a se situar no vasto território dos tipos de sensores disponíveis na literatura e permitir uma identificação adequada dos sensores a serem tratados neste trabalho foi feita uma classificação dos diversos tipos de sensores a fibras ópticas. Nesta classificação se leva em consideração os tipos mais importantes de sensores, os mecanismos de interação, as grandezas medidas e os tipos de sensores interferométricos. Desta forma, através de diagramas de blocos, facilita-se o processo de identificação dos sensores a fibras ópticas, em especial os de interesse deste trabalho, bem como as suas áreas de aplicação.

O termo sensores a fibras ópticas é utilizado quando se deseja ressaltar que o emprego dessas fibras está estreitamente ligado com a concepção, a classificação e a própria possibilidade de realização destes dispositivos [14].

$\mathrm{Na}$ Figura 1, a seguir, levam-se em consideração as várias particularidades dos elementos constituintes de um sensor, o que torna possível fazer uma classificação mais ampla de um sensor óptico genérico levando-se em consideração os seus vários aspectos. 


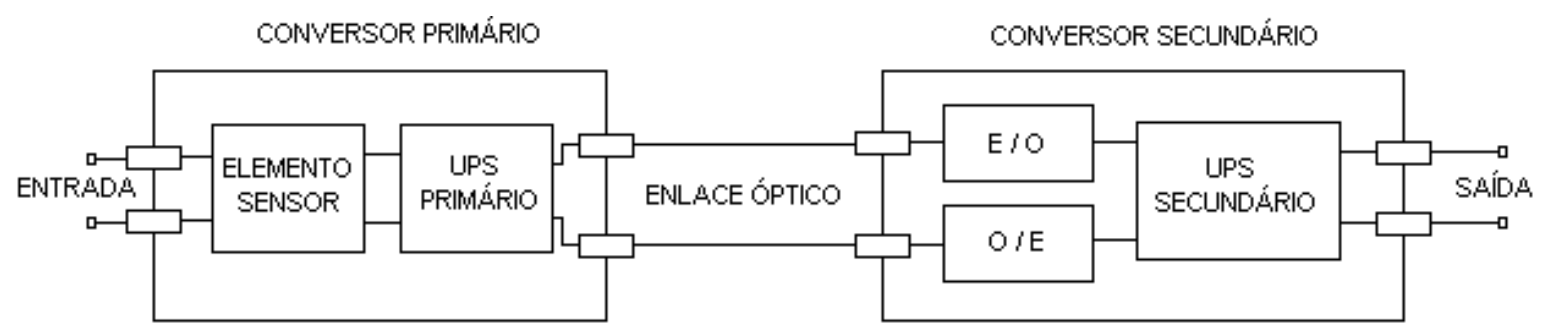

Figura 1 - Diagrama de blocos de um sensor genérico [14].

$\mathrm{Na}$ Figura 1, UPS é a unidade de processamento de sinais, E/O é a unidade conversora dos sinais elétricos em sinais ópticos e O/E é a unidade conversora de sinais ópticos em elétricos.

Os sensores a fibras ópticas podem ser agrupados em quatro classes distintas: de acordo com o tipo de grandeza medida, quanto ao tipo de distribuição espacial da grandeza medida, de acordo com a forma como eles se integram com o enlace óptico (ou quanto à transdução) e quanto ao tipo de modulação óptica utilizada.

Quanto à grandeza a ser medida, os sensores podem ser classificados como: mecânicos, térmicos, elétricos, magnéticos, de radiação, químicos e biológicos e médicos [15]. Com relação ao tipo de distribuição espacial da grandeza medida, os sensores se dividem em: puntual, integrador, distribuído e quasi distribuído [16]. Com relação a como eles se relacionam com o enlace óptico, os sensores a fibras ópticas podem ser divididos em: extrínsecos e intrínsecos. Por último, os sensores a fibras ópticas podem ser classificados de acordo com o tipo de modulação óptica empregada em: sensores de intensidade, sensores interferométricos (ou de fase), sensores polarimétricos e sensores de espectro.

Além destas classificações, outro aspecto que deve ser levado em conta nos sensores a fibras ópticas é quanto à necessidade de alimentação elétrica do sensor primário, podendo ser ativos ou passivos.

Os ativos são aqueles que possuem circuitos eletrônicos ativos indispensavelmente associados aos sensores, exigindo assim uma alimentação para o seu funcionamento. 
Quanto aos passivos, são aqueles que, por não empregarem componentes eletrônicos ativos na construção dos sensores primários, dispensam a alimentação para o seu funcionamento.

A seguir, apresentam-se alguns detalhes de duas das classificações de sensores a fibras ópticas citadas por serem consideradas as mais relevantes neste trabalho: quanto à integração ao enlace óptico e quanto ao tipo da modulação empregada.

\subsubsection{QUANTO À INTEGRAÇÃO AO ENLACE ÓPTICO}

No que diz respeito à integração com o enlace óptico, os sensores a fibras ópticas podem ser agrupados em duas classes predominantes, que são a dos sensores extrínsecos (ou híbridos) e a dos sensores intrínsecos. A seguir, descreve-se, com mais detalhes, cada uma dessas classes.

\subsection{SENSORES EXTRÍNSECOS}

Os sensores extrínsecos são caracterizados pelo fato da grandeza a ser medida atuar numa região externa à fibra óptica, ou seja, a fibra óptica é usada apenas como canal de transporte da radiação óptica até o local de medida (ou monitoração) e do ponto de medição até o bloco receptor. Nessa categoria estão todos os sensores ativos e alguns passivos

Em algumas aplicações, o elemento sensor externo pode não ser baseado em tecnologia óptica, sendo que pode ser necessário algum processamento eletrônico no local da medição, para que a luz transportada pela fibra seja modificada pela informação da grandeza a ser medida. Como este tipo de sensor extrínseco não é totalmente óptico, ele é normalmente designado por sensor híbrido.

O diagrama de blocos mostrado na Figura 2, a seguir, ilustra as configurações mais comumente encontradas nos sensores ópticos extrínsecos, e também as grandezas passíveis de serem medidas por eles [17]. 


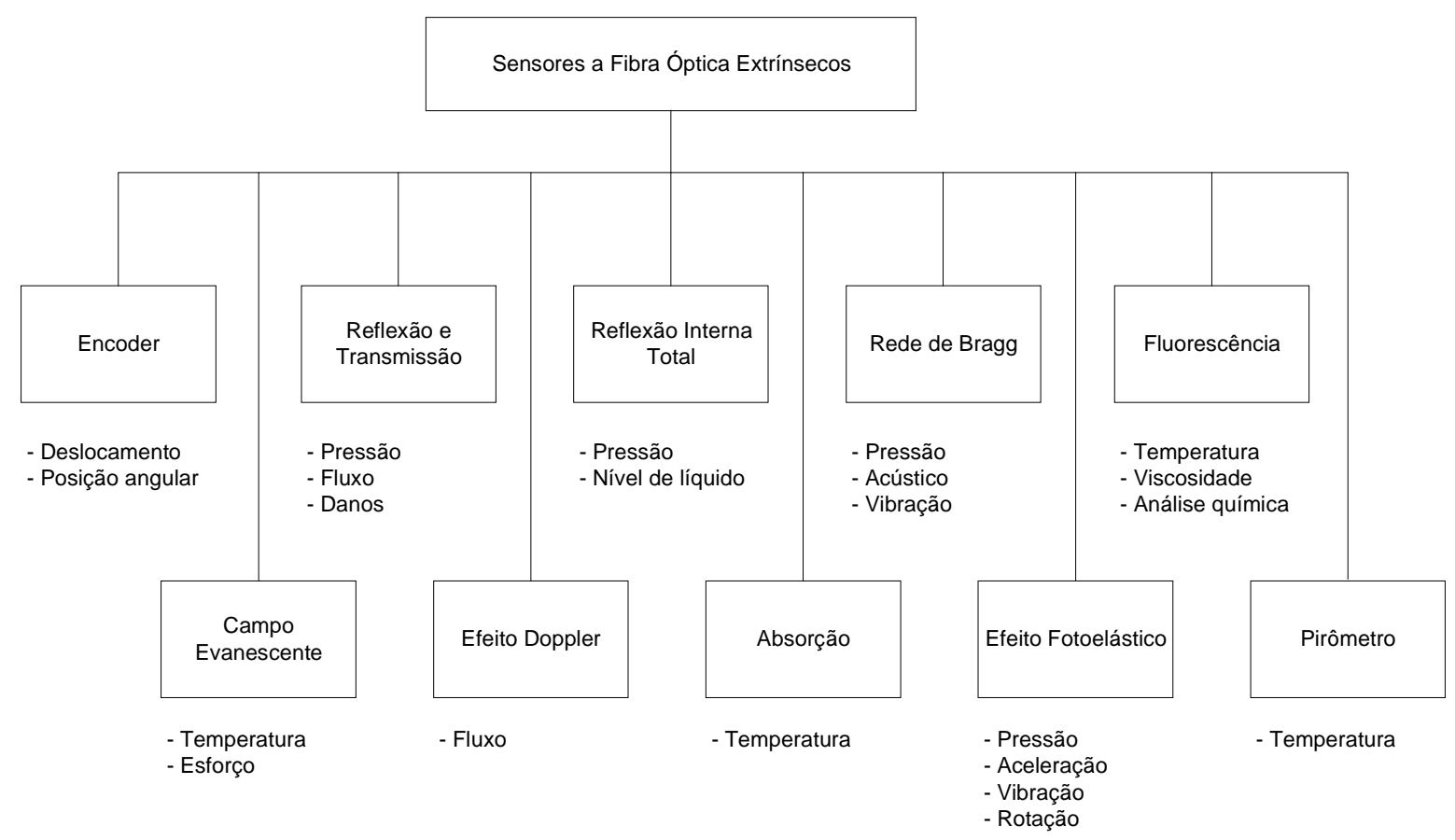

Figura 2 - Diagrama de blocos com os tipos mais importantes de sensores ópticos extrínsecos [17].

\subsection{SENSORES INTRÍNSECOS}

Nesta categoria de sensores a grandeza medida atua diretamente na fibra óptica, alterando uma ou mais propriedades ópticas da luz guiada. Assim, o elemento sensor é a própria fibra, seja apenas uma parte dela ou toda ela.

Em certas aplicações em que a sensibilidade da fibra óptica é baixa, pode-se revestir a fibra com uma camada de material sensível à presença de uma determinada grandeza a ser medida [17], ampliando assim o efeito sobre a radiação que se propaga na fibra. Esta é uma forma indireta, embora intrínseca, de medir uma grandeza de interesse.

Os sensores intrínsecos são forçosamente passivos e necessitam de um sinal óptico de referência.

O diagrama de blocos mostrado na Figura 3 , a seguir, ilustra as configurações mais comumente encontradas nos sensores ópticos intrínsecos, e também as grandezas passíveis de serem medidas por eles. 


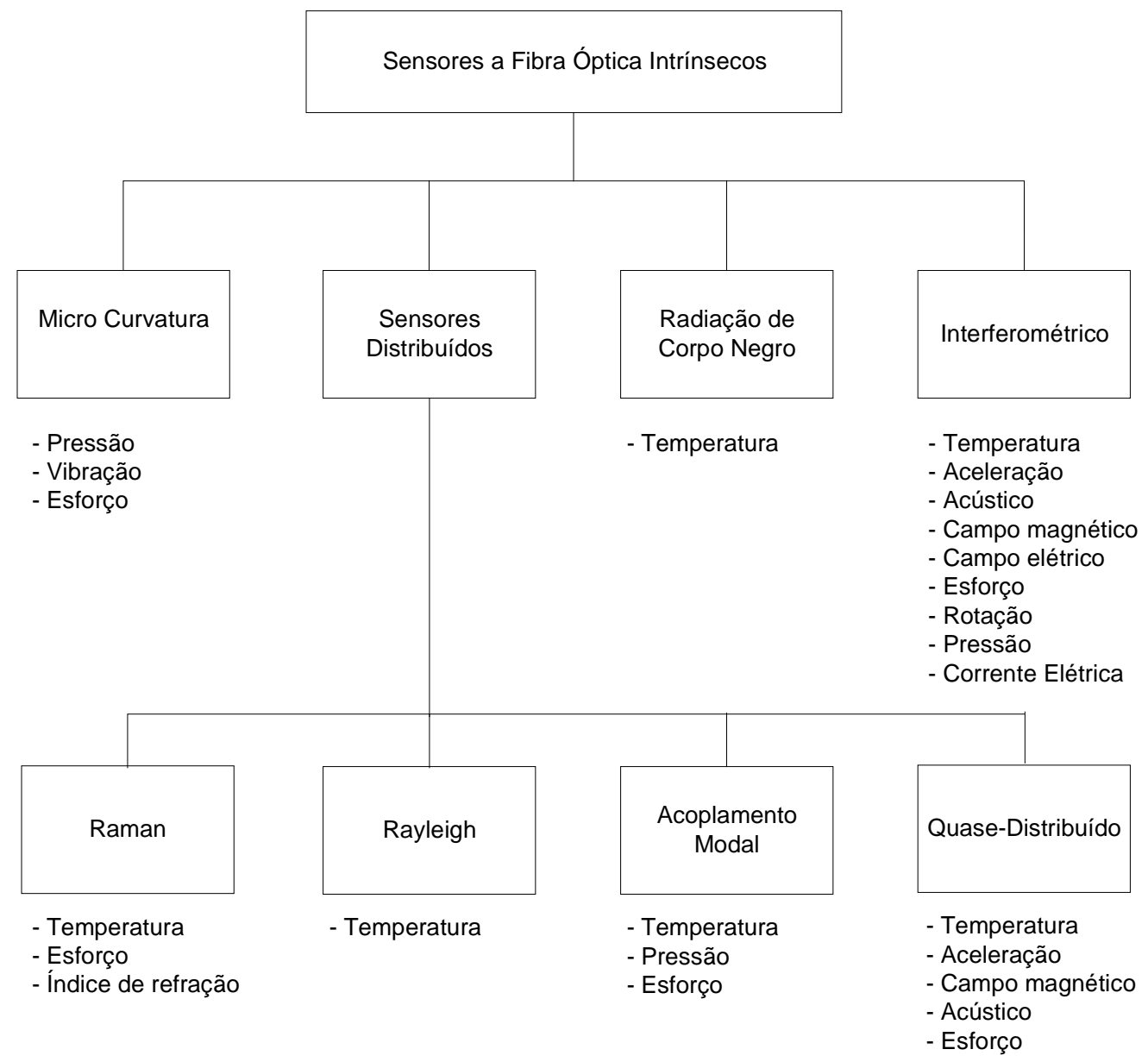

Figura 3 - Diagrama de blocos com os tipos mais importantes de sensores ópticos intrínsecos [17].

\subsubsection{QUANTO AO TIPO DA MODULAÇÃO EMPREGADA}

Os sensores a fibras ópticas, extrínsecos ou intrínsecos, operam através da modulação de uma ou mais das seguintes características da luz guiada: intensidade, polarização, fase, comprimento de onda central (ou frequência central) e conteúdo espectral, cada uma das quais potencialmente sensível a determinada grandeza de interesse [13, 15-17]. Dessa forma, os sensores a fibras ópticas podem ser subdivididos e classificados, de uma forma geral, como: sensores interferométricos e sensores não interferométricos, também conhecidos como sensores de intensidade $[15,17]$.

Os sensores não interferométricos são, em geral, construídos com fibras multimodo e são baseados na modulação em intensidade por meio de mecanismos que não 
envolvem interferometria, por exemplo, absorção, espalhamento, desalinhamento, etc.

Por outro lado, os sensores interferométricos que fazem uso dos mecanismos de interação baseados na modulação da polarização ou da fase, utilizam fibras monomodo (fibras ópticas concebidas para guiar um único modo [1]), pois nas fibras multimodo, devido aos seus efeitos de dispersão modal e cromática, estas características da radiação não se mantêm após alguns centímetros de caminho óptico.

Deve-se levar em conta, no entanto, que um sinal de saída proveniente de um sensor interferométrico que opera, por exemplo, através da modulação do estado de polarização da luz ou do comprimento de onda, continuará a ser proporcional à intensidade da luz que chega ao sistema detector.

Isso realça o fato de que fronteiras rigorosas não podem ser facilmente delineadas quando se tenta classificar os sensores a fibras ópticas pelos seus mecanismos de modulação, ocorrendo, geralmente, certa sobreposição das várias classes [17].

$\mathrm{Na}$ Figura 4, abaixo, apresenta-se um resumo dos mecanismos de interação que podem ser explorados utilizando os sensores a fibras ópticas de intensidade e interferométricos. 


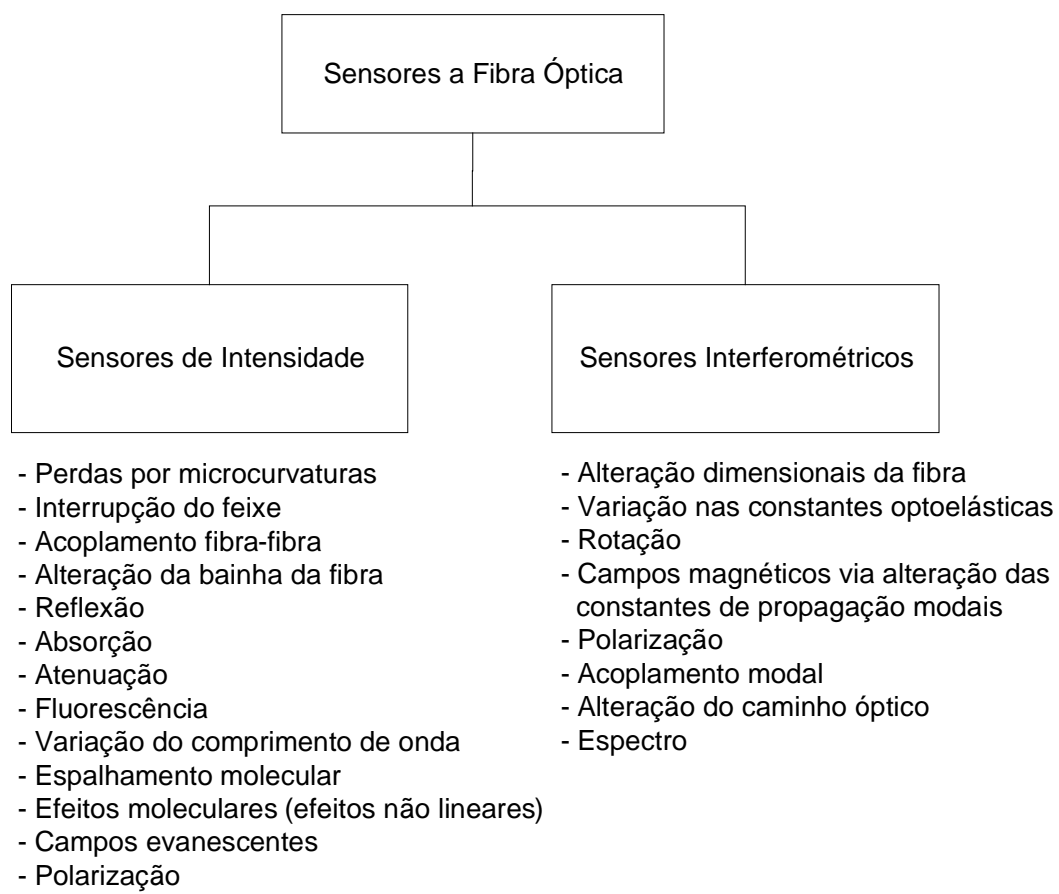

Figura 4 - Diagrama de blocos mostrando os mecanismos de interação mais usados nos sensores a fibras ópticas de intensidade e interferométricos [17].

De uma forma geral, o desempenho, em termos de resolução obtida para uma determinada grandeza medida por um sensor interferométrico, é muito maior do que aquela obtida por um sensor de intensidade. No entanto, não é difícil imaginar que em breve, os sensores que se baseiam na modulação em intensidade tornem-se mais atrativos, devido à sua simplicidade, e ao fato de poderem, até certo ponto, proporcionar sensibilidades também elevadas, em relação aos sensores não ópticos. Desta forma, o que determinará a escolha de um ou outro tipo de sensor, deverá levar em conta a resolução pretendida bem como o custo total do sistema.

Na Figura 5, abaixo, encontram-se resumidas algumas das grandezas que podem ser medidas utilizando sensores a fibras ópticas [15, 17]. 


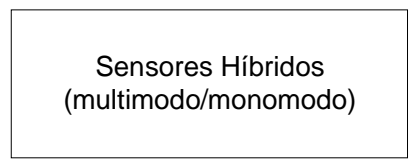

- Tamanho de partículas

- Turbulências

- $\mathrm{pH}$

- Posição (linear angular)

- Pressão

- Aceleração

- Deslocamento

- Posição

- Campo magnético

- Temperatura

- Viscosidade

- Vibração

- Nível e líquido

- Índice de refração

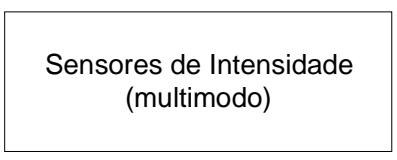

- Pressão

- Deslocamento

- Deformação

- Fluxo

- Interrupção

- Força

- Temperatura

- Vibração

- Temperatura distribuída (gradiente)
Sensores Interferométricos

- Pressão

- Deslocamento

- Deformação

- Fluxo

- Campo magnético

- Força

- Temperatura

- Vibração

- Rotação (orientação)

- Aceleração

- Campo elétrico

- Corrente e Tensão elétrica

- Comprimento de onda

- Índice de refração

Figura 5 - Tipos de grandezas que podem ser medidas utilizando sensores a fibras ópticas [17].

\subsection{SENSORES DE INTENSIDADE}

Os sensores de intensidade constituíram a primeira geração de sensores de fibras ópticas a ser implementada. Estes sensores não fazem uso de nenhuma técnica de interferometria, ou seja, como a própria designação indica, a intensidade da radiação que se propaga na fibra é o parâmetro diretamente modulado. Em geral, estes sensores são conceitualmente simples, seguros, fáceis de reproduzir e requerem apenas uma modesta quantidade de componentes. Usam normalmente fibra multimodo e diodos emissores de luz (Light Emitting Diode - LED), o que os torna atrativos em termos de custo.

Existem várias técnicas de modulação para sensores de intensidade, entre as quais cita-se a modulação por interrupção de feixe, modulação por reflexão e modulação por perdas na fibra [15-18]. Deve-se notar que em um sensor real, a intensidade da luz que se propaga ao longo da fibra não é totalmente conservada devido a vários efeitos de atenuação. Além disso, outros fatores, como flutuações da intensidade da fonte óptica e da sensibilidade do sistema detector, introduzem erros no sinal obtido na saída do sistema de sensoriamento. Sendo assim, um sensor de intensidade projetado para medições de elevada exatidão deverá incorporar um mecanismo de referência de forma a tornar o desempenho do sensor menos sensível à degradação dos componentes ópticos e às variações das condições ambientais. Deste modo, um 
sinal óptico de referência, que esteja sujeito a todos os fatores de degradação exatamente da mesma forma que o sinal do sensor, deverá ser usado para calibrar a resposta do sensor de maneira a mantê-la tão estável quanto possível.

Diversos métodos de referenciação destinados a eliminar ou, pelo menos, reduzir este problema têm sido desenvolvidos. Como exemplo pode-se citar o uso de técnicas temporais, a utilização de dois ou mais comprimentos de onda e o recurso de técnicas diferenciais $[13,16]$.

\subsection{SENSORES INTERFEROMÉTRICOS}

As fibras ópticas monomodo são utilizadas na construção de sensores quando é necessário que a luz utilizada no sistema de sensoriamento seja transmitida em um único modo de propagação. Esta característica das fibras monomodo permite construir interferômetros totalmente a fibra óptica, possibilitando a medição de pequenas variações da fase da radiação luminosa que é transmitida através do elemento sensor. Isto é conseguido comparando-se a fase do feixe de luz que atravessou a região onde atua a grandeza medida, com a fase do outro feixe da radiação luminosa proveniente da mesma fonte óptica, mas que percorreu um caminho óptico diferente (chamado de "braço" de referência) e protegido da ação da grandeza a ser medida. A diferença de fase pode, então, ser medida com uma grande sensibilidade. Como a radiação é mantida na fibra óptica, este tipo de sensor terá, em geral, baixas perdas. Os sensores que funcionam deste modo são normalmente denominados sensores interferométricos [19, 20].

Os sensores interferométricos, além de evidenciarem as vantagens inerentes a todos os sensores a fibras ópticas, apresentam também ainda outras, tais como versatilidade na geometria do elemento sensor, grande faixa dinâmica, sensibilidade elevada e possibilidade de multiplexação eficiente [13]. No entanto, foram algumas dessas características que atrasaram o seu progresso e penetração no mercado. Por exemplo, a sensibilidade da fibra óptica a diferentes influências levanta o problema da seletividade do sensor, que por sua vez torna necessário o uso de técnicas de referência de forma a calibrar e distinguir a resposta do sensor à 
grandeza de interesse. Outra dificuldade apresentada é que, embora possa existir uma relação linear entre a variação da fase óptica e o valor da grandeza a ser medido, o sinal de saída do interferômetro requer um processamento específico devido à sua função de transferência periódica. Isto pode limitar a sua faixa dinâmica, dificultar medições absolutas, degradar o desempenho e aumentar o nível de ruído do sistema. O diagrama de blocos mostrado na Figura 6, ilustra a grande diversidade de sensores ópticos interferométricos existentes e também as grandezas passíveis de serem medidas por eles.

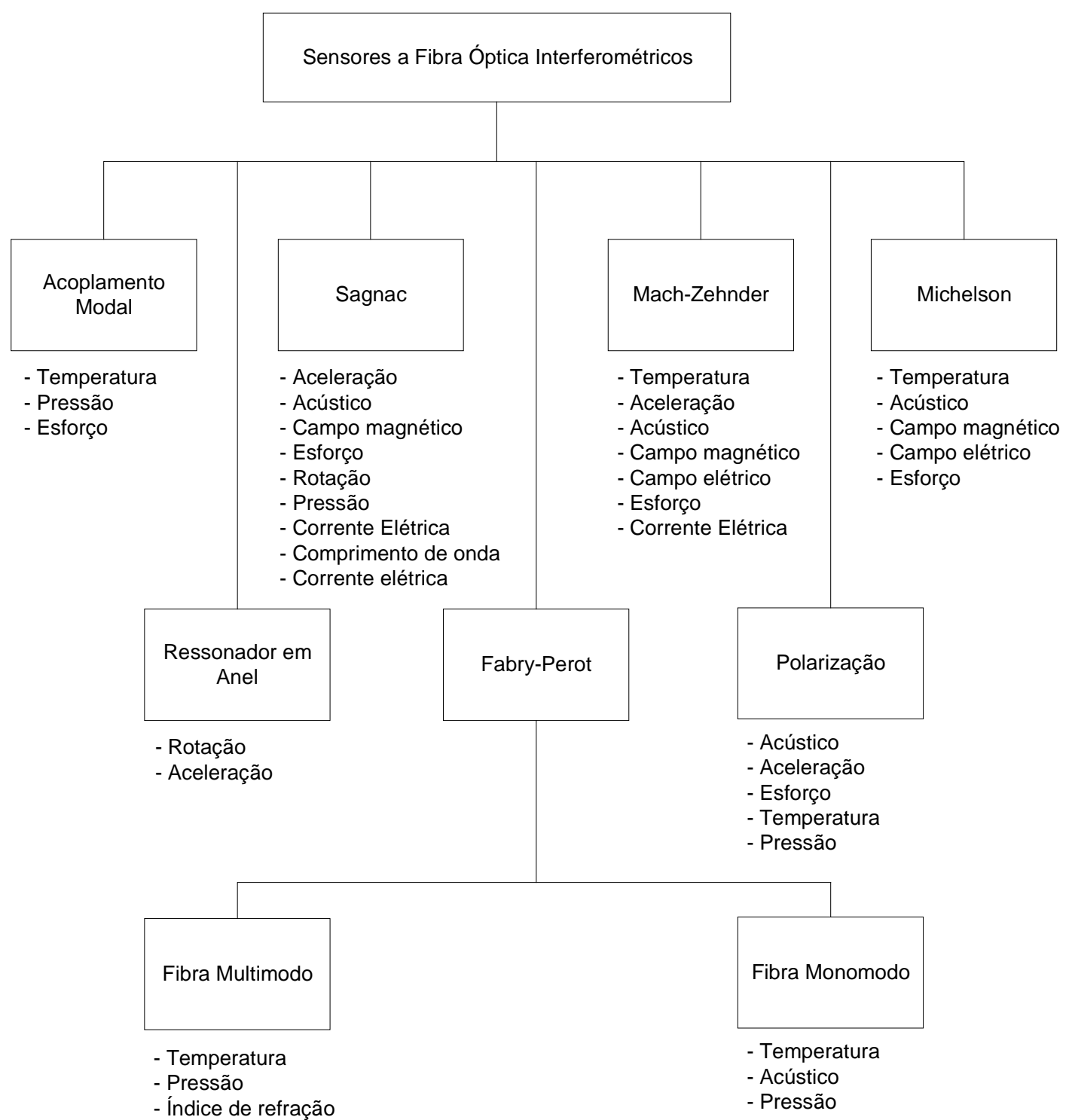

Figura 6 - Configurações mais comumente encontradas nos sensores ópticos interferométricos e as grandezas passíveis de serem medidas por eles [17]. 
O foco, neste trabalho, são os sensores interferométricos baseados em interferômetros a fibras ópticas. Na seção seguinte é apresentado um detalhamento maior dos principais interferômetros utilizados nos sensores a fibras ópticas.

\subsection{INTERFERÔMETROS A FIBRAS ÓPTICAS}

Tradicionalmente, em se tratando de óptica volumétrica, existem dois métodos para classificar interferômetros: pelo número de feixes de interferência e pelo método utilizado para separar estes feixes. No primeiro caso, os interferômetros são classificados como sendo de dois feixes ou de múltiplos feixes. Os interferômetros de dois feixes produzem franjas de interferência com variação senoidal de intensidade, enquanto que nos interferômetros de múltiplos feixes cada par de feixes contribui na produção de componentes das chamadas franjas de Fourier [21]. No segundo caso, se a frente de onda da radiação luminosa passar através de várias aberturas, diz-se que o feixe foi separado por divisão de frente de onda. Se os feixes forem produzidos pela mesma fonte e estiverem na mesma direção, mas forem separados por um elemento divisor contínuo (prisma, semi-espelho, polarizador, etc.) então diz-se que foram separados por divisão de amplitude.

De forma geral, os sensores interferométricos são baseados em configurações interferométricas clássicas. Uma discussão sobre estas configurações clássicas foi feita por Grattan [17].

Os interferômetros a fibras ópticas (Fiber Optic Interferometer - FOI) são fabricados a partir de fibras ópticas monomodo e outros componentes baseados, preferencialmente, em óptica guiada (como, por exemplo, o acoplador direcional) para realizar configurações interferométricas, clássicas ou não.

As fibras, os componentes ópticos e os sistemas formados com eles podem ser representados matematicamente por matrizes utilizando diversos formalismos, como, por exemplo, o de Jones. Dentro deste formalismo pode-se associar a cada elemento de um sistema óptico uma matriz que representa a relação entre os campos elétricos das ondas ópticas emergente e incidente. Neste contexto, o 
formalismo de Jones [17], utiliza matrizes coluna para representar os campos elétricos dos vários estados de polarização da luz e matrizes $2 \times 2$ para representar diversos elementos ópticos utilizados no sistema óptico. O cálculo utilizando formalismo de Jones é muito interessante, pois permite derivar facilmente as funções de transferência de muitos dos FOls mais amplamente utilizados.

São apresentados a seguir os tipos de interferômetros mais úteis para este trabalho, acompanhados de modelamento matemático via cálculo de Jones que permite seu tratamento em projetos de sensores interferométricos a fibras ópticas.

Como foi dito acima, no que diz respeito à quantidade de ondas adotadas nos sensores interferométricos, os interferômetros utilizados podem apresentar-se de duas formas distintas: interferômetros de duas ondas e interferômetros de múltiplas ondas.

\subsubsection{INTERFERÔMETROS DE DUAS ONDAS}

O processo mais simples de implementar um interferômetro consiste em dividir a amplitude da luz proveniente de uma fonte óptica em duas ondas que percorrem percursos diferentes antes de serem recombinadas. Existem, no entanto, diferentes maneiras de construir tais interferômetros, ou seja, diferentes configurações ou topologias. Dentre elas, as mais utilizadas são: o interferômetro de Michelson, o interferômetro de Mach-Zehnder, interferômetros diferenciais e o interferômetro de Sagnac.

Neste trabalho, dar-se-á atenção especial somente às topologias de Michelson e Mach-Zehnder, dada a sua relativa simplicidade e robustez e, também, devido ao fato de que se pode construí-los a partir de junção em $\mathrm{Y}$, encontradas com relativa facilidade no mercado de componentes a fibras ópticas. Nos dois casos citados, utilizam-se com frequência acopladores direcionais para construir os interferômetros.

O acoplador direcional é possivelmente um dos principais componentes em sistemas de comunicação e/ou de sensoriamento a fibras ópticas. Os acopladores ópticos 
podem ser considerados como dispositivos multiportas, onde o número de portas é maior do que 2, que permitem combinar ou separar sinais luminosos.

Assim, nesse contexto, as funções básicas comumente atribuídas aos acopladores são: separar ou dividir um feixe de luz e, neste caso, ele é chamado de divisor ou separador, e, combinar ou misturar feixes de luz, sendo conhecido, neste caso, como misturador.

Além da função de divisão e mistura de feixes de luz, os acopladores ópticos podem ter outras funções, como por exemplo: acoplamento direcional, acoplamento distributivo, multiplexação, demultiplicação, etc.

Um diagrama representativo de um acoplador direcional a fibras ópticas típico é mostrado na Figura 7, abaixo.

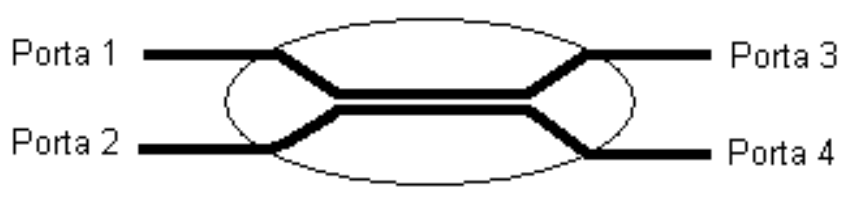

Figura 7 - Diagrama representativo de um acoplador direcional a fibras ópticas (3 dB).

Para acopladores direcionais a função de transferência pode ser expressa em termos de matrizes de Jones [17]:

$$
\left[\begin{array}{c}
E_{3 s} \\
E_{4 s}
\end{array}\right]=T_{C}\left[\begin{array}{cc}
\sqrt{1-\alpha} & i \sqrt{\alpha} \\
i \sqrt{\alpha} & \sqrt{1-\alpha}
\end{array}\right] \cdot\left[\begin{array}{c}
E_{1 e} \\
E_{2 e}
\end{array}\right]
$$

onde:

$\alpha$ é o fator de acoplamento, $T_{c}$ é a transmitância, $E_{3 s}$ e $E_{4 s}$ são as componentes das ondas ópticas nas saídas do acoplador direcional, dadas como função das componentes dos campos elétricos $E_{1 e}$ e $E_{2 e}$ nas entradas do acoplador direcional. 
Dá-se o nome de acoplador direcional de $3 \mathrm{~dB}$ para o caso particular em que $\alpha=0,5$. Neste caso, tem-se, na saída do acoplador direcional, utilizando-se a notação de Jones da eq. (4.1), a matriz de transferência, dada por:

$$
\left[\begin{array}{c}
E_{3 s} \\
E_{4 s}
\end{array}\right]=\frac{T_{C}}{\sqrt{2}}\left[\begin{array}{ll}
1 & i \\
i & 1
\end{array}\right] \cdot\left[\begin{array}{l}
E_{1 e} \\
E_{2 e}
\end{array}\right]
$$

\subsubsection{INTERFERÔMETRO DE MICHELSON}

As Figuras 8(a) e 8(b), a seguir, representam as configurações mais comuns de interferômetros de Michelson. Nelas são apresentados o esquema básico implementado totalmente a fibras ópticas.

A luz proveniente de uma fonte óptica é dividida por um acoplador direcional, originando duas ondas que percorrem dois percursos diferentes: uma delas é designada por feixe de referência e a outra o feixe de sinal, onde atua a grandeza medida. No fim de cada percurso da fibra óptica é colocado um espelho. Estes espelhos podem ser extrínsecos ou intrínsecos.

Os espelhos intrínsecos podem ser constituídos por filmes finos refletores dielétricos ou metálicos. Tais filmes podem ser depositados por várias técnicas disponíveis, por exemplo, evaporação, deposição química, etc. Os materiais metálicos mais utilizados são: prata, alumínio, titânio, dentre outros.

A radiação que se propaga no percurso de sinal fica, deste modo, duplamente sujeita à ação da grandeza medida, antes dos dois sinais ópticos serem recombinados no acoplador direcional.

Uma das ondas resultante da interferência fica disponível para detecção, enquanto que a segunda é acoplada para a fonte óptica.

Esse último aspecto pode ser indesejável, visto que luz refletida para a fonte óptica tende a perturbar o funcionamento desta, principalmente se a fonte for um laser semicondutor monomodo [17, 22]. 


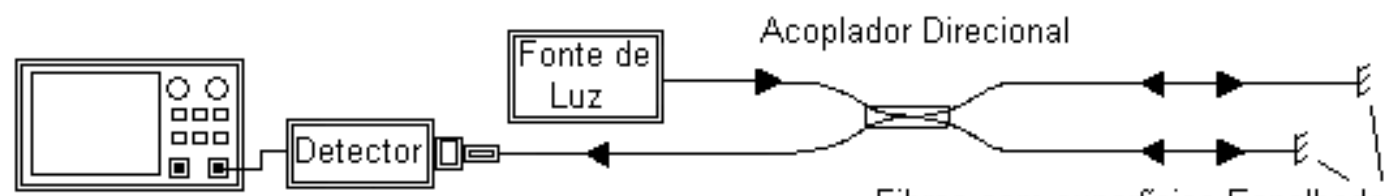

Osciloscópio

(a)

Fibras com superficies Espelhadas

Figura 8 (a) - Interferômetro de Michelson a fibras ópticas com espelho intrínseco.

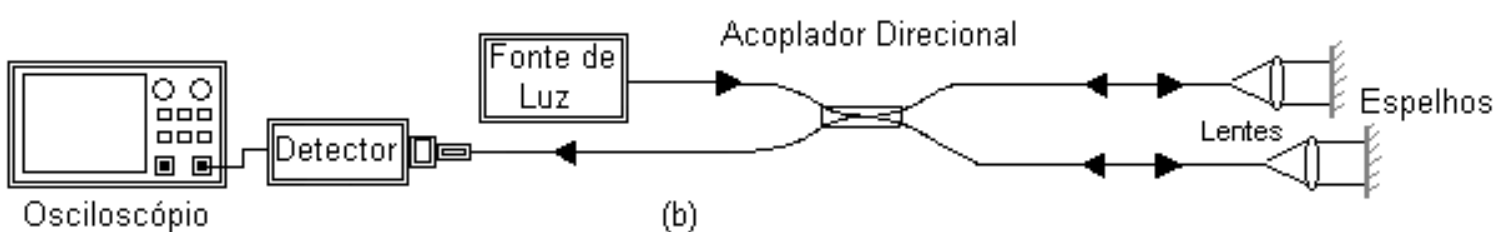

Osciloscópio

(b)

Figura 8(b) - Interferômetro de Michelson a fibras ópticas com espelho extrínseco.

A amplitude do campo na saída do interferômetro, como função da entrada, pode ser escrita utilizando-se a notação de Jones:

$$
\left[E_{\text {out }}\right]=T_{M}\left[E_{\text {in }}\right]
$$

onde:

$T_{M}=\left[\begin{array}{cc}-\left(1+e^{i(2 \Delta \varphi)}\right) & i\left(1-e^{i(2 \Delta \varphi)}\right) \\ i\left(1-e^{i(2 \Delta \varphi)}\right) & \left(1+e^{i(2 \Delta \varphi)}\right)\end{array}\right], \quad$ é a função de transferência do interferômetro de Michelson e $\Delta \varphi$ é a diferença de fase entre as ondas interferentes.

Considerando que toda a luz que entra no interferômetro é emitida pela fonte, a intensidade luminosa na saída do interferômetro será dada por [17]:

$$
I_{\text {Det } 1}=\frac{I_{\text {in }}}{2}[1+\cos (2 \Delta \varphi)]
$$


onde:

$I_{\text {Det1 }}$ é a intensidade luminosa no fotodetector 1 e $I_{\text {in }}$ é a intensidade luminosa incidente no acoplador direcional.

\subsubsection{INTERFERÔMETRO DE MACH-ZEHNDER}

Na Figura 9, a seguir, apresenta-se uma configuração do interferômetro de MachZehnder. Nela apresenta-se o esquema básico do interferômetro implementado totalmente a fibras ópticas. Neste caso são utilizados dois acopladores direcionais, sendo um para dividir o feixe óptico em dois feixes e outro para recombiná-los. Esta configuração permite a fácil obtenção de dois feixes interferidos de saída (ao contrário do interferômetro de Michelson em que uma dessas saídas retorna para a fonte de luz), o que pode ser muito conveniente em algumas técnicas de processamento de sinal. Conforme ocorre no interferômetro de Michelson, também ocorre reflexão da luz para a fonte óptica no interferômetro de Mach-Zehnder, porém, esta é muito menor [17,22], pois deve-se apenas à retro-reflexões nos componentes.

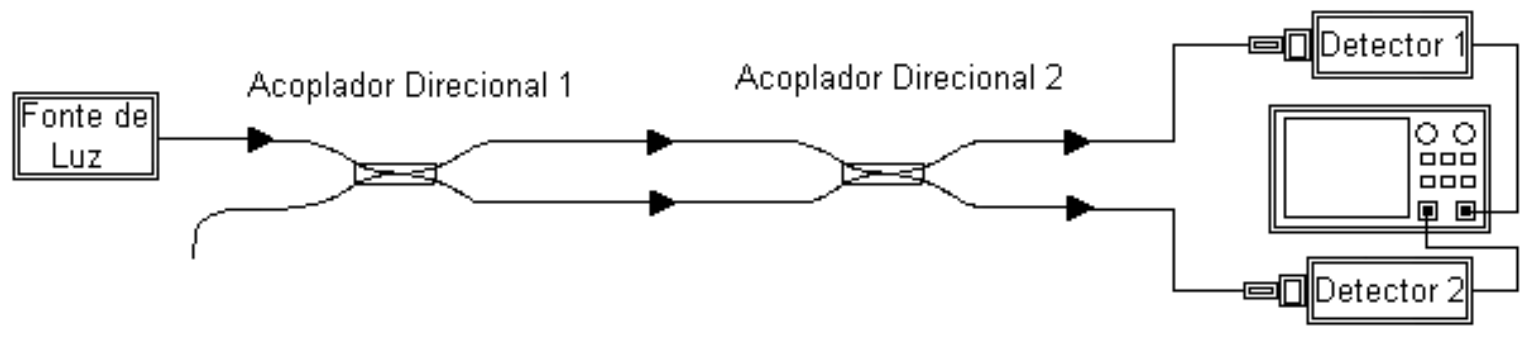

Figura 9 - Interferômetro de Mach-Zehnder a fibras ópticas.

As amplitudes dos campos nas saídas do interferômetro, como função das entradas, podem ser escritas utilizando-se a notação de Jones:

$$
\left[\begin{array}{c}
E_{3 s} \\
E_{4 s}
\end{array}\right]=T_{M Z}\left[\begin{array}{l}
E_{1 e} \\
E_{2 e}
\end{array}\right]
$$


onde:

$T_{M Z}=\frac{1}{2}\left[\begin{array}{cc}-\left(1-e^{i(\Delta \varphi)}\right) & i\left(1+e^{i(\Delta \varphi)}\right) \\ i\left(1+e^{i(\Delta \varphi)}\right) & \left(1-i e^{i(\Delta \varphi)}\right)\end{array}\right]$, é a função de transferência do interferômetro de Mach-Zehnder.

Considerando que toda a luz que entra no interferômetro é injetada na porta 1 $\left(E_{2 e}=0\right)$ e é emitida pela fonte, as intensidades luminosas nas saídas 3 e 4 do interferômetro variam em contra-fase, e são dadas pelas seguintes equações, [17].

$$
\begin{aligned}
& I_{\text {Det1 }}=\frac{I_{\text {in }}}{2}[1-\cos (\Delta \varphi)] \\
& I_{\text {Det2 }}=\frac{I_{\text {in }}}{2}[1+\cos (\Delta \varphi)]
\end{aligned}
$$

onde:

$I_{\text {Det1 }}$ é a intensidade luminosa no fotodetector $1, I_{\text {Det2 }}$ a intensidade luminosa no fotodetector $2, I_{\text {in }}$ a intensidade luminosa incidente no primeiro acoplador direcional e $\Delta \varphi$ a diferença de fase entre as ondas interferentes.

Estes dois interferômetros de dois feixes exibem uma mesma função de transferência com respeito à diferença de fase entre eles, conforme pode ser visto equação (4.8), [23]:

$$
I_{\text {out }}=\left(I_{1}+I_{2}\right) \cdot[1+V \cdot \cos (\Delta \varphi)]
$$


onde:

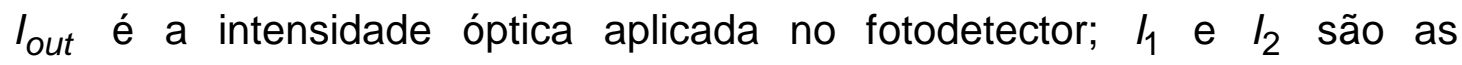
intensidades ópticas dos feixes interferentes (um de sinal e outro de referência, que dependem das constantes de acoplamento dos acopladores direcionais, das perdas e, no caso do interferômetro de Michelson, das reflectividades dos espelhos); $\Delta \varphi$ é a diferença de fase entre os dois feixes e $V$ é a visibilidade (ou contraste) das franjas de interferência.

Embora a função de transferência seja idêntica para todos os interferômetros de dois feixes, a diferença de fase óptica entre os dois feixes exprime-se de formas ligeiramente diferentes dependendo da configuração do interferômetro. Na Tabela 1 apresenta-se um resumo dos tipos de configurações de interferômetros de dois feixes e sua respectiva expressão funcional para a diferença de fase óptica.

Tabela 1 - Configurações de interferômetros e suas expressões funcionais correspondentes à diferença de fase.

\begin{tabular}{|c|c|}
\hline Tipo de interferômetro & Diferença de fase óptica \\
\hline Mach-Zehnder & $\Delta \varphi_{M Z}=\frac{2 n \pi L}{\lambda}$ \\
\hline Michelson & $\Delta \varphi_{M}=\frac{4 n \pi L}{\lambda}=2 \Delta \varphi_{M Z}$ \\
\hline
\end{tabular}

onde:

$n$ é o índice de refração efetivo do modo guiado da fibra, $L$ é a diferença dos caminhos ópticos entre as duas ondas, $\lambda$ é o comprimento de onda central da luz e $\Delta \varphi$ é a diferença de fase óptica [13,17]. 


\subsubsection{INTERFERÔMETROS DE MÚLTIPLAS ONDAS}

Neste tipo de interferômetro a onda proveniente da fonte óptica é dividida por múltiplos percursos antes de ocorrer a recombinação dos feixes. Uma maneira de se conseguir tal efeito consiste em construir uma cavidade óptica que possua um único percurso o qual é atravessado diversas vezes pela luz incidente. Se a cavidade óptica funcionar como região de medição, isto é, como sensor, então a grandeza medida atuará em cada etapa do percurso na radiação que se propaga, multiplicando assim o seu efeito sobre esta [13]. Os tipos mais importantes de interferômetros de múltiplas ondas são: o interferômetro de Fabry-Perot e o interferômetro em anel.

Outro processo de se conseguir um sensor baseado na interferência de múltiplas ondas é através da utilização do chamado filtro de interferência ou rede de difração em fibra óptica. Neste caso, cada onda é originada pela reflexão parcial de diferentes refletores parciais distribuídos em série.

Além dos componentes baseados em fibras ópticas ou em óptica volumétrica, outra forma importante de implementação de dispositivos ópticos é baseada em técnicas de fabricação em óptica integrada, que é apresentada na seção seguinte.

\subsection{DISPOSITIVOS A ÓPTICA INTEGRADA}

O termo óptica integrada é referido à aplicação de filmes finos e uso de tecnologia de micro-fabricação para definição e desenvolvimento de sistemas de guias de onda ópticos em escala reduzida [15] com vistas à construção de dispositivos. Estas bases foram lançadas há cinco décadas atrás, quando as pesquisas em óptica integrada estavam voltadas para a área de comunicações. No entanto, com o aprimoramento das técnicas de micro-fabricação e pesquisas em novos materiais, o espectro de influência da opto-eletrônica tem se estendido por várias áreas, dentre elas incluem-se: guiamento da luz, modulação, acoplamento de sinais, geração, detecção, sensoriamento, filtragem, interferometria, processamento de sinais [13, 16], etc. 
Pode-se afirmar que a área de sensores ópticos é uma das que mais tem se beneficiado com o avanço da tecnologia de óptica integrada. A utilização de sensores ópticos integrados além, de herdar as vantagens dos sensores a fibras ópticas sobre os sensores convencionais já citadas (larga faixa de temperatura de operação, imunidade eletromagnética, aquisição de medidas sem contato físico, possibilidade de utilização em ambientes hostis, etc.), oferece algumas vantagens adicionais, dentre as quais podem-se destacar: baixíssimo peso e dimensões muito reduzidas, utilização de tecnologia da indústria micro-eletrônica (que implica em reprodutibilidade e baixo custo, em função do potencial de produção em larga escala) e possibilidade de integração de dispositivos ópticos e eletrônicos num mesmo substrato [13].

Além disso, as técnicas de detecção de variações no campo da óptica estão bastante desenvolvidas, o que proporciona alta sensibilidade aos sensores ópticos. Isto tem permitido uma ampla gama de aplicações, como por exemplo: refratômetros, sensores de gás, sensores de pressão, sensores biológicos, etc. Em sua grande maioria, estas estruturas utilizam interferômetros cuja configuração é do tipo Mach-Zehnder, utilizando-se de fibras ópticas ou dispositivos de óptica integrada.

$\mathrm{Na}$ Figura 10, abaixo, ilustram-se algumas das geometrias mais comumente encontradas para dispositivos baseados em guias de ondas ópticos. Nos exemplos ilustrados, é possível observar que a maior parte das estruturas, foram consideradas apresentando eletrodos. Neste caso, considerando que o substrato exiba o efeito eletro-óptico, a variação da intensidade da onda luminosa, ou de sua fase, na saída dos interferômetros ocorre em função da variação da tensão elétrica aplicada aos eletrodos. Isto permitindo que estas estruturas sejam utilizadas como moduladores ópticos. A estrutura (b) também pode ser utilizada como acoplador óptico sintonizável. 


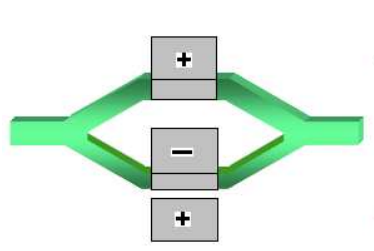

a)

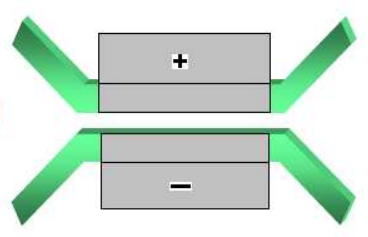

b)

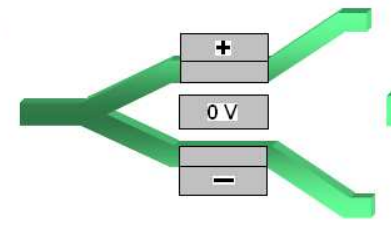

c)

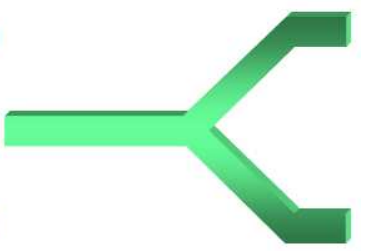

d)

Figura 10 - Geometrias comumente encontradas para dispositivos baseados em guias de ondas ópticos integrados. a) Dispositivo Mach-Zehnder, b) Acoplador direcional, c) Junção Y moduladora e d) junção $Y$ fixa [15].

No Apêndice A são apresentadas as principais técnicas de fabricação de dispositivos baseados em óptica integrada.

Os dispositivos a óptica integrada geralmente são dotados de trechos de fibras ópticas instaladas próximas aos seus acessos para prover facilidade de conexão com outros dispositivos ópticos. Estes trechos são chamados de rabichos (pigtails) que são pequenos segmentos de fibras ópticas, com 1 a $1,5 \mathrm{~m}$ de comprimento, podendo ser conectorizados em suas extremidades.

\subsubsection{DISPOSITIVOS ELETRO-ÓPTICOS INTEGRADOS}

$\mathrm{Na}$ modulação eletro-óptica uma portadora óptica propaga-se num guia tipo canal fabricado em substrato de material eletro-óptico, cujas características de índice de refração podem ser controladas através de um campo elétrico de modulação externo. Devido ao confinamento da energia do modo óptico estar próximo à superfície, obtêm-se uma maior eficiência de efeito eletro-óptico, beneficiando-se da elevada intensidade dos campos produzidos por estruturas de eletrodos depositados muito próximos entre si, no plano da superfície do modulador. Assim, uma vez que as técnicas de litografia para circuitos integrados convencionais encontram-se dominadas e podem ser aplicadas, neste caso, os processos de fabricação dos dispositivos eletro-óptico integrados podem ser facilitados, tornando a montagem robusta e compacta [24]. 
Na Figura 11, é apresentada, em forma de um esquema, a seção transversal de uma estrutura de modulação com eletrodos planos, denominada fitas simétricas coplanares (Symmetric Coplanar Strips - CPS).

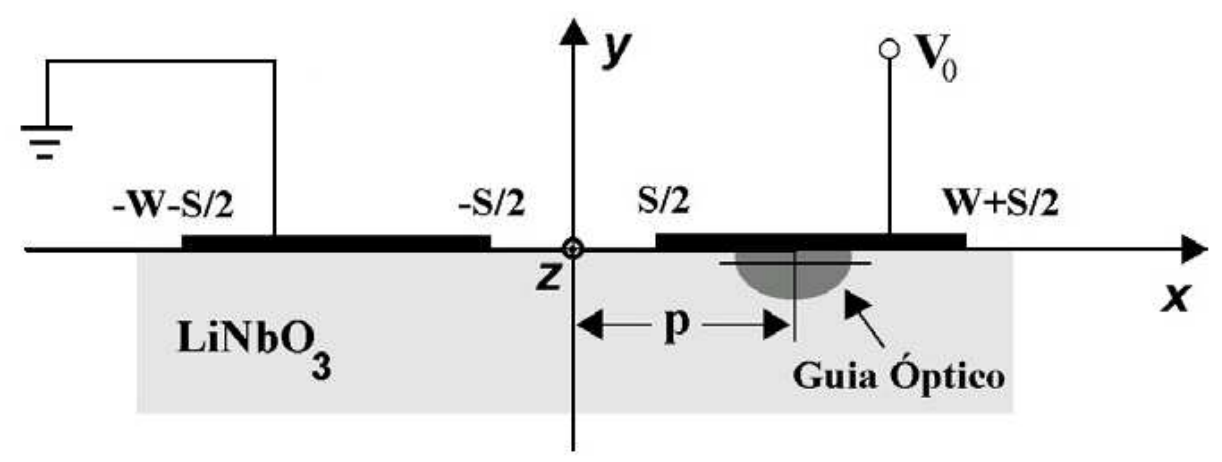

Figura 11 - Seção transversal de um modulador de fase em configuração CPS simétrico. A posição do canal óptico é especificada pelo parâmetro "p" [24].

Na Figura 11, x, y e $z$ representam os eixos de um sistema de coordenadas cartesianas, os quais correspondem a eixos geométricos, e não necessariamente coincidem com os eixos cristalinos $(X, Y, Z)$ do material. Segundo Kitano [24], a introdução deste sistema de coordenadas possibilita o desenvolvimento de uma análise generalizada do modulador, no qual a normal à superfície do cristal é representada por y e a direção de propagação do sinal óptico e do sinal de modulação é sempre $z$, independentemente da orientação dos eixos cristalinos do substrato anisotrópico $\left(\mathrm{LiNbO}_{3}\right)$.

Ainda na Figura 11, os eletrodos planos possuem larguras iguais a W, espaçamento $S$ e a tensão aplicada entre eles $V_{0}$. O guia canal encontra-se difundido no substrato e pode ter sido estabelecido, por exemplo, por difusão de titânio (Ti) ou troca de prótons. A posição do guia óptico, relativamente aos eletrodos, é caracterizada pelo parâmetro "p" [24].

Na subseção seguinte, é feita uma breve descrição do mecanismo através do qual a luz que se propaga no canal óptico sofre modulação devido ao campo elétrico 
gerado pelos eletrodos planos depositados sobre o substrato de Niobato de Lítio. Este fenômeno se deve ao efeito eletro-óptico, através do qual a aplicação do campo elétrico externo modifica a distribuição de índices de refração no canal, tendo como consequência, uma variação de fase do sinal óptico. Conforme será visto, o modulador eletro-óptico de fase constitui a célula básica a partir da qual podem ser implementados vários tipos de dispositivos como, por exemplo, moduladores de intensidade, chaves ópticas, acopladores direcionais e interferômetros ajustáveis, etc.

\subsubsection{EFEITO ELETRO-ÓPTICO EM GUIA CANAL}

Parte considerável dos dispositivos eletro-ópticos funcionais, os guias canal difundidos sobre substrato de $\mathrm{LiNbO}_{3}$ possuem características de guiagem fraca, ou seja, as amplitudes das variações de índice de refração não possuem valores acentuados em relação aos índices dos substratos. Além disso, embora seja suficiente para causar modulação eletro-óptica, a perturbação de índice causada pela ação do campo elétrico de modulação é muito reduzida. Sendo assim, a aplicação do cálculo perturbacional, para resolver o problema da interação eletroóptica, torna-se adequada e proporciona resultados satisfatórios. Neste método, uma pequena perturbação na permissividade dielétrica relativa da estrutura de guiagem (devido à presença do campo elétrico de modulação) é considerada, permitindo-se que a equação de onda resultante seja resolvida a partir da solução conhecida para o guia não-perturbado. Deste modo, utilizando-se o sistema cristalino de coordenadas para representar o campo de modulação e a matemática apropriada, pode-se calcular a variação de fase do modo óptico guiado devido ao campo elétrico externo através de grandezas do sistema não-perturbado [24].

Os substratos de $\mathrm{LiNbO}_{3}$ comparecem entre os principais materiais utilizados na fabricação de dispositivos a óptica integrada devido, particularmente, a seus elevados valores de coeficientes eletro-ópticos. $\mathrm{Na}$ tabela 2, a seguir, são apresentadas algumas propriedades e constantes físicas do $\mathrm{LiNbO}_{3}$. 
Tabela 2 - Algumas propriedades e constantes físicas importantes do Niobato de Lítio $\left(\mathrm{LiNbO}_{3}\right)$.

\begin{tabular}{|c|c|}
\hline \multicolumn{2}{|c|}{ Niobato de Lítio - $\mathrm{LiNbO}_{3}$} \\
\hline \multicolumn{2}{|c|}{ Propriedades Físicas Gerais } \\
\hline Classe de simetria & Romboédrico \\
\hline Grupo de ponto & $3 m$ \\
\hline Densidade $\left(\mathrm{g} / \mathrm{cm}^{3}\right)$ & 4,64 \\
\hline Ponto de fusão $\left({ }^{\circ} \mathrm{C}\right)$ & 1253 \\
\hline Temperatura Curie $\left({ }^{\circ} \mathrm{C}\right)$ & 1150 \\
\hline \multicolumn{2}{|c|}{ Índices de refração } \\
\hline$n_{e}\left(\lambda_{0}=1300 \mathrm{~nm}\right)$ & $2,1464^{*}$ \\
\hline$n_{0}\left(\lambda_{0}=1300 \mathrm{~nm}\right)$ & $2,2211^{*}$ \\
\hline \multicolumn{2}{|c|}{ Coeficientes eletro-ópticos (@ $632 \mathrm{~nm}) \times 10^{-12} \mathrm{~m} / \mathrm{V}$} \\
\hline$r_{13}^{T}$ & 10 \\
\hline$r_{22}^{T}$ & 6,8 \\
\hline$r_{33}^{T}$ & 32,2 \\
\hline$r_{51}^{T}$ & 32 \\
\hline$r_{13}^{S}$ & 8,6 \\
\hline$r_{22}^{S}$ & 3,4 \\
\hline$r_{33}^{S}$ & 30,8 \\
\hline$r_{51}^{S}$ & 28 \\
\hline
\end{tabular}

*valores calculados a partir da equação de Sellmeier.

onde:

os índices $T$ e $S$ referem-se, respectivamente à aplicação de baixas frequências (faixa de áudio) e a altas frequências [26].

Segundo Kitano [24], a variação de fase induzida pela ação do campo elétrico de modulação é dada por: 


$$
\Delta \varphi_{m}=\pi\left(\frac{V_{0}}{V_{\pi}}\right)
$$

onde:

$\left(V_{0}\right)$ é valor da tensão entre eletrodos que faz com que a variação de fase induzida pela ação do campo elétrico de modulação atinja $\pm \pi$ radianos e, é denominada tensão de meia-onda, $V_{\pi}$.

\subsubsection{MODULADOR DE FASE COM GUIA CANAL}

A modulação em fase constitui uma operação fundamental no controle de dispositivos eletro-ópticos. A variação do índice de refração, induzida por um campo elétrico externo, produz uma variação de fase na onda óptica que se propaga em um guia de ondas dielétrico pertencente ao dispositivo. Adicionalmente, o modulador de fase é um elemento essencial em um grande número de estruturas mais complexas, tais como os moduladores interferométricos baseados em óptica integrada, por exemplo.

Aplicando-se uma tensão de modulação entre os eletrodos adjacentes ao guia óptico, gera-se um campo elétrico intenso que se sobrepõe ao modo óptico. A variação de índice de refração induzida por esse campo modifica a velocidade de propagação da luz no guia e, por conseguinte, altera a fase óptica na saída do dispositivo. A medida da quantidade dessa variação de fase depende dos coeficientes eletro-ópticos, da tensão aplicada, do comprimento de interação $(L)$ e das orientações relativas entre os eixos cristalinos do material e as direções de aplicação do campo elétrico e da propagação da luz, assim como de sua polarização [24].

Em um modulador de fase a óptica integrada, o feixe óptico propaga-se em um guia canal cujos parâmetros estruturais devem estar associados à condição de operação monomodo. Na Figura 12, ilustra-se o diagrama de um modulador de fase básico, onde (1) é a fibra óptica que acopla luz ao modulador, (2) é o substrato, (3) é o guia 
canal, (4) corresponde aos eletrodos de modulação e (5) é a fibra óptica de saída [24].

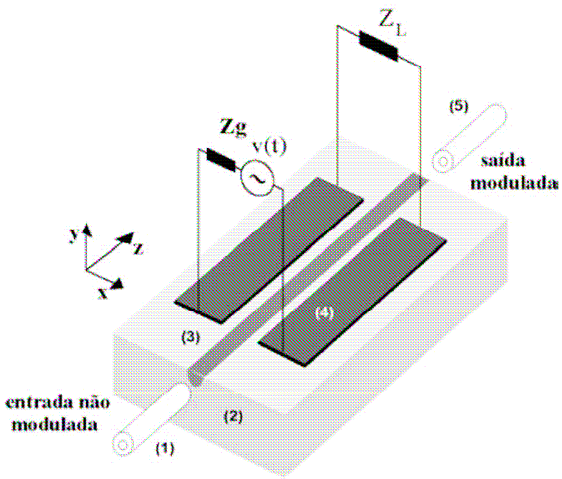

(a)

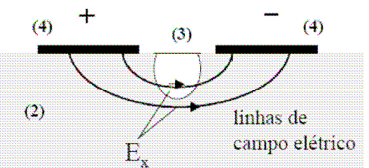

(b)

Figura 12 - Vista geral de um modulador de fase com gerador e terminações. a) (1) e (5) são fibras ópticas, (2) é o substrato, (3) é um guia canal e (4) são eletrodos CPS. b) Vista transversal do dispositivo [24].

Conforme será visto na seção 4.6.5.2, a configuração do modulador de fase é muito semelhante à configuração do modulador de amplitude, diferindo apenas no que concerne ao polarizador e ao analisador, ou seja, no modulador de fase o analisador não está presente. O polarizador de entrada está alinhado com o eixo x'. Nestas condições o campo elétrico da onda luminosa que emerge do cristal possui polarização linear segundo a direção x' [23-26].

$$
\begin{gathered}
\vec{E}_{\text {out }}=\bar{E}_{o} \vec{u}_{x^{\prime}} \\
\bar{E}_{o}=E_{i n} e^{-i k_{0} L n_{x}}
\end{gathered}
$$

$\operatorname{com} n_{x^{\prime}}=n_{0}+n_{0}^{3} r \frac{E_{m}}{2}$ e $k_{0}=\omega / c$

onde:

$\vec{E}_{\text {out }}$ é o campo elétrico da onda luminosa emergente e $\bar{E}_{O}$ é a sua amplitude complexa, $r$ é o coeficiente eletro-óptico relevante do cristal e $E_{\text {in }}$ a amplitude do campo de modulação. 
Desta forma, com relação à fase, pode-se escrever a intensidade do campo elétrico da onda luminosa emergente como uma função de duas componentes distintas, ou seja, uma componente estática (ou passiva), $\varphi_{0}$, que é uma fase estática (ou passiva), acumulada ao longo do cristal e referida ao feixe incidente, e uma componente induzida, $\Delta \varphi_{m}$, que é a diferença de fase introduzida pelo campo de modulação, ou seja, [24]:

$$
E_{\text {out }}=E_{i n} e^{-i \varphi_{0}} e^{-i \Delta \varphi_{m}}
$$

Segundo Kitano [24], o campo óptico utilizado em um modulador, pode ser quase-TE ou quase-TM indiferentemente, importando apenas que a operação seja monomodo. Por isso, a notação escalar para o campo é adequada. No entanto, se o guia suportar dois modos de polarização, poderá haver modulação de birrefringência.

No domínio do tempo, a equação (4.11), torna-se [24]:

$$
E_{\text {out }}=E_{\text {in }} \cos \left[\omega t-\varphi_{0}-\Delta \varphi_{m}\right]
$$

onde:

$\omega$ é a frequência óptica e $\varphi_{0}=k_{0} L n_{0}$.

Considerando que o campo elétrico aplicado externamente varia harmonicamente no tempo, fazendo com que a variação de fase induzida também seja dependente do tempo, $\Delta \varphi_{m}=\Delta \varphi_{m}(t)$, obtém-se [26]

$$
E_{\text {out }}(t)=E_{\text {in }} \cos [\omega t-\underbrace{k_{0} L n_{0}}_{\varphi_{0}}+\underbrace{k_{0} L n_{0}^{3} r \operatorname{sen}\left(\omega_{m} t\right) \frac{E_{m}}{2}}_{\Delta \varphi_{m}}]
$$

Obtém-se, portanto, um campo resultante cuja fase vem modulada como segue:

$$
E_{\text {out }}(t)=E_{\text {in }} \cos \left[\omega t-\delta \operatorname{sen}\left(\omega_{m} t\right)-\varphi_{0}\right]
$$


onde:

$r$ é o índice relevante do cristal, $\varphi_{0}=\omega L n_{d} / c$ é a fase na origem e $\delta$ é onde o índice de modulação.

O índice de modulação $\delta$ é proporcional ao valor máximo do campo elétrico aplicado, e é dado por [26]:

$$
\delta=\frac{\omega n_{0}^{3} r E_{m} L}{2 c}=\frac{\pi n_{0}^{3} r E_{m} L}{\lambda_{0}}
$$

onde:

c é a velocidade da luz no meio, $n_{o}$ é o índice de refração ordinário do cristal e $\lambda_{0}$ é o comprimento de onda central da fonte de luz.

\subsubsection{MODULADOR DE FASE COM JUNÇÃO Y}

A junção em $\mathrm{Y}$, também conhecida como guia de ondas bifurcado (branching waveguide) [24, 25] é um dispositivo óptico de 4 acessos, como qualquer divisor (ou acoplador) de $3 \mathrm{~dB}$. No entanto, três dos acessos são guiados, enquanto que o quarto acesso corresponde à radiação irradiada para o substrato na qual é montado o dispositivo.

Esta junção é composta de um guia de onda óptico tipo canal, monomodo, de base (base waveguide) que se divide em dois guias de onda ópticos tipo canal, bifurcados, monomodo, conforme mostrado na Figura 10(d) acima. Sua fabricação é relativamente simples, a partir de uma máscara em forma de $\mathrm{Y}$. A simples simetria geométrica implica em um divisor de radiação óptica de $3 \mathrm{~dB}$, enquanto que os acopladores a óptica integrada, que utilizam a técnica de campos evanescentes, como mostrado na Figura 10(b), requerem cuidadoso controle do processo de difusão para obtenção de adequada razão de acoplamento [24]. 
O princípio de operação ocorre da seguinte maneira: a radiação óptica que se propaga no guia óptico de base é dividida em dois guias ópticos bifurcados simétricos, que divergem com um ângulo muito pequeno (aproximadamente 0,01 radiano) para minimizar as perdas [15, 27].

Referentemente à Figura 10(c), é possível modular uma junção em $Y$ de três maneiras diferentes, ou seja, modulando-se apenas um braço do dispositivo, modulando-se os dois braços independentemente ou, com a introdução de um terceiro eletrodo, colocado entre os braços do dispositivo, pela modulação dos dois braços em contra-fase (push-pull). No primeiro caso tem-se o campo de modulação no primeiro braço do dispositivo diferente de zero $\left(E_{m_{1}} \neq 0\right)$ enquanto que no segundo braço o campo de modulação é igual a zero $\left(E_{m_{2}}=0\right)$. Neste caso, de acordo com a eq. (4.13), a diferença de fase entre os dois braços, $(\Delta \varphi)$, é dada por [26]:

$$
\Delta \varphi=\varphi_{1}-\varphi_{0}=k_{0} L n_{o}^{3} r \operatorname{sen}\left(\omega_{m} t\right)\left[\frac{E_{m_{1}}}{2}\right]
$$

onde:

$$
\varphi_{0}=k_{0} L n_{0} \text { é a fase no braço sem modulação. }
$$

No segundo caso tem-se modulação nos dois braços do dispositivo de forma tal que $E_{m_{1}} \neq E_{m_{2}} \neq 0$. Nestas condições a diferença de fase entre os dois braços, $(\Delta \varphi)$, é dada por [26]:

$$
\Delta \varphi=\varphi_{2}-\varphi_{1}=k_{0} L n_{o}^{3} r \operatorname{sen}\left(\omega_{m} t\right)\left[\frac{E_{m_{2}}-E_{m_{1}}}{2}\right]
$$

onde:

$$
\varphi_{1}=k_{0} L n_{o}+k_{0} L n_{o}^{3} r \operatorname{sen}\left(\omega_{m} t\right)\left[\frac{E_{m_{1}}}{2}\right] \mathrm{e}
$$


$\varphi_{2}=k_{0} L n_{o}+k_{0} L n_{o}^{3} r \operatorname{sen}\left(\omega_{m} t\right)\left[\frac{E_{m_{2}}}{2}\right]$

No terceiro caso, tem-se modulação nos dois braços de forma tal que $E_{m_{2}}=-E_{m_{1}}$. Nestas condições a diferença de fase entre os dois braços, $(\Delta \varphi)$, será dada por:

$$
\Delta \varphi=\varphi_{2}-\varphi_{1}
$$

onde:

se considera $\omega_{m}$ constante e

$$
\varphi_{1}=k_{0} L n_{o}+k_{0} L n_{o}^{3} r \operatorname{sen}\left(\omega_{m} t\right)\left[\frac{E_{m_{1}}}{2}\right]
$$

e

$$
\varphi_{2}=k_{0} L n_{o}-k_{0} L n_{o}^{3} r \operatorname{sen}\left(\omega_{m} t\right)\left[\frac{E_{m_{1}}}{2}\right]
$$

Substituindo $\varphi_{1}$ e $\varphi_{2}$ na eq. (4.18), obtém-se [26]:

$$
\Delta \varphi=k_{0} L n_{o}^{3} r \operatorname{sen}\left(\omega_{m} t\right)\left[E_{m_{1}}\right]
$$

Neste caso, com modulação em push-pull, a diferença de fase entre os braços do dispositivo é o dobro daquela vista no primeiro caso.

Como essa diferença de fase se manifesta em feixes que se propagam em guias diferentes, para observá-la é necessário reunir os feixes num mesmo guia. Isso 
pode ser feito, por exemplo, por meio de uma segunda junção em $Y$ o que equivale à construção de um interferômetro de Mach-Zehnder em óptica integrada.

O feixe obtido na saída deste interferômetro estará modulado em intensidade, como é apresentado na próxima seção.

\subsubsection{MODULADOR DE INTENSIDADE COM INTERFERÔMETRO DE MACH- ZEHNDER EM ÓPTICA INTEGRADA}

O interferômetro de Mach-Zehnder a óptica integrada é um dispositivo utilizado extensivamente como modulador de intensidade pelas indústrias e centros de pesquisa e desenvolvimento nas áreas de sensores e de telecomunicações. Neste tipo de dispositivo, a luz é dividida igualmente entre dois braços (através de uma junção Y), sendo que, no caso de sensores, um deles é tomado como o braço de referência e o outro como o braço sensor. No primeiro, a luz passa sem sofrer perturbações, enquanto que no outro (o braço sensor), a luz é influenciada por alguma grandeza externa. O próximo passo consiste em recombinar a luz proveniente destes dois braços, de modo a permitir que haja uma interferência entre o sinal que transita por eles. Normalmente isto é feito utilizando-se uma segunda junção Y. A perturbação introduzida no braço sensor produz uma variação na fase da luz que, quando recombinada com a luz proveniente do braço de referência, resulta em uma variação proporcional de intensidade óptica na saída do dispositivo.

Um modulador de intensidade óptica, obtido a partir de um dispositivo interferométrico de Mach-Zehnder é ilustrado na Figura 13, a seguir, na qual (1) é a fibra óptica de entrada, (2) é o substrato eletro-óptico, (3) é o interferômetro de Mach-Zehnder, (4) são os eletrodos de modulação e (5) a fibra óptica de saída [24]. 


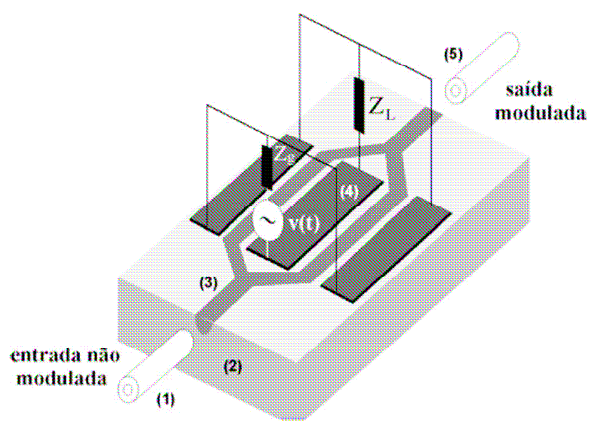

Figura 13 - Modulador de intensidade em configuração Mach-Zehnder. Vista geral com fonte e terminações, onde (1) é a fibra óptica de entrada e (5) é a fibra óptica de saída. (2) é o substrato, (3) é o interferômetro de Mach-Zehnder e (4) são os eletrodos CPW [24].

Os eletrodos podem ser aplicados a um só braço do interferômetro, correspondendo à estrutura CPS, ou aos dois braços simultaneamente (como indicado na Figura 13), [24]. Como foi dito anteriormente, este último tipo de operação é denominada pushpull e o campo elétrico modulador apresenta direções opostas sobre cada braço do interferômetro de Mach-Zehnder, gerando diferenças de fases também opostas. Desta forma, a diferença de fase relativa total entre os braços do interferômetro de Mach-Zehnder é duplicada.

Segundo Kitano, este tipo de dispositivo, em condições ideais, apresenta transmitância dada pela equação abaixo [24]:

$$
T=\frac{l_{\text {out }}}{l_{\text {in }}}=\frac{1}{2}\left[1+\cos \left(\Delta \varphi_{m}\right)\right]
$$

onde:

$\Delta \varphi_{m}$ é a diferença de fase entre os braços do interferômetro de MachZehnder e, normalmente, é constituída de duas partes sendo uma estática e outra variável no tempo, como apresentado na seção anterior. A primeira está associada a algum nível C.C. (bias) ou a uma diferença de comprimento dos braços do interferômetro, enquanto que a segunda está associada ao sinal elétrico de modulação. 
Desta forma, pode-se escrever [24]:

$$
\Delta \varphi_{m}=\varphi_{\text {Bias }}+\varphi(t)
$$

A intensidade óptica na saída de um interferômetro Mach-Zehnder a óptica integrada é equivalente à intensidade óptica de saída de um interferômetro de Mach-Zehnder construído a partir de fibras ópticas utilizando acopladores direcionas [17, 22].

\subsubsection{MODULADOR DE INTENSIDADE COM INTERFERÔMETRO DE MICHELSON EM ÓPTICA INTEGRADA}

Conforme foi visto anteriormente, a partir de uma junção $\mathrm{Y}$, como a exposta na Figura 10(d), vários tipos de dispositivos a óptica integrada podem ser construídos, dentre eles os interferômetros utilizados nos principais sistemas que utilizam sensores interferométricos. Sendo assim, é interessante mostrar algumas possíveis alternativas para se construir interferômetros de Michelson a partir de uma junção Y.

Uma primeira possibilidade seria a utilização de uma junção em $\mathrm{Y}$ com pigtail instalado apenas no acesso ao guia de entrada da bifurcação. Os acessos dos guias dos dois braços bifurcados não necessitariam de pigtails, uma vez que o objetivo é utilizar a luz refletida em suas extremidades. A reflectividade nessas extremidades pode ser originada apenas pela diferença de índices entre os guias e o meio (reflexão de Fresnel) ou pode ser modificada pela deposição de uma camada refletora (metálica ou dielétrica) na face de saída do dispositivo. Na Figura 14, abaixo, ilustra-se esta configuração. 


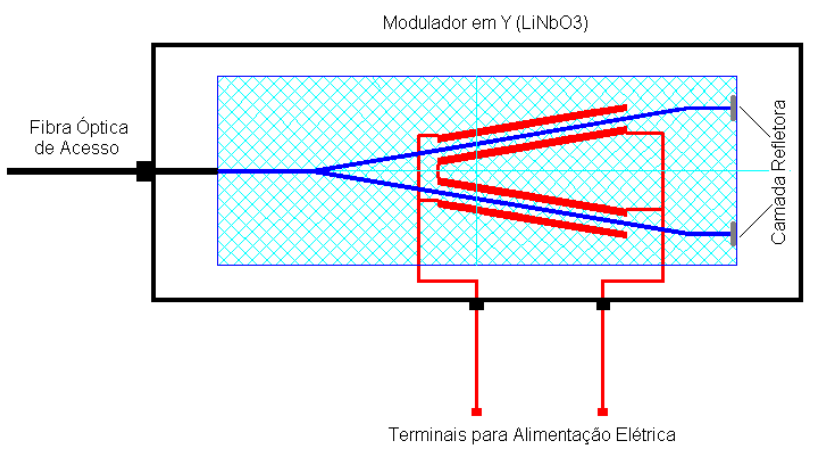

Figura 14 - Junção em Y com pigtail instalado apenas no acesso ao guia de entrada da bifurcação.

Outra possibilidade de configuração para construir o interferômetro faria uso de uma junção em $Y$ com pigtails em todos os seus acessos. Assim como no caso anterior, o objetivo é também utilizar a luz que se propaga pelos braços bifurcados, mas, desta vez, refletida nas extremidades de saída dos pigtails neles instalados. As reflectividades das terminações das fibras, neste caso, ficam sujeitas às mesmas considerações feitas no caso anterior. Na Figura 15, abaixo, ilustra-se esta configuração.

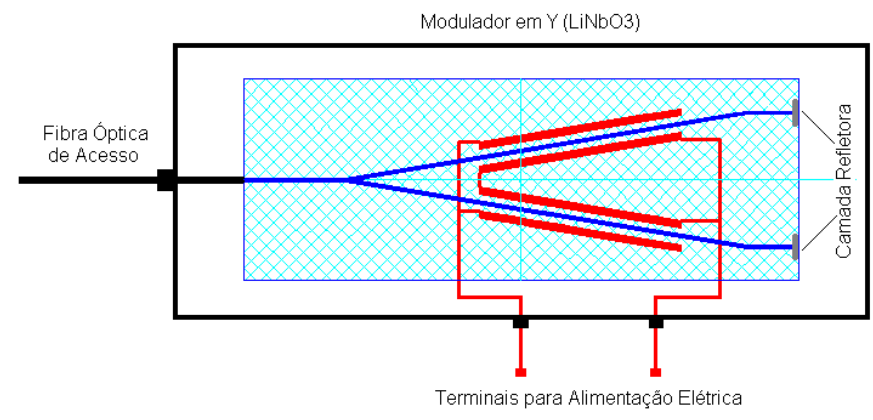

Figura 15 - Junção em Y com pigtails instalados em todos os acessos do dispositivo.

Os dois dispositivos a óptica integrada, montados a partir de uma estrutura em $Y$ modificada, mostrados nas Figuras 14 e 15, possuem comportamentos equivalentes ao interferômetro de Michelson, ou seja, o feixe de luz que entra na fibra óptica de acesso sofrerá divisão de amplitude e cada um dos dois feixes ópticos percorrerá o respectivo braço do guia óptico, refletindo-se na extremidade deste. Após estas 
reflexões os dois feixes interferirão na região da bifurcação do guia óptico, continuando a se propagar de volta pelo acesso de entrada.

Após as etapas de finalização (da face da saída da junção Y ou dos pigtails ligados aos braços bifurcados) descritas acima é necessário adicionar um acoplador direcional na entrada do dispositivo a fim de tornar possível enviar para um fotodetector a potência óptica proveniente dos feixes refletidos nos espelhos e depois interferidos na junção $Y$, que de outra forma seria enviada de volta para a fonte.

$\mathrm{Na}$ Figura 16, abaixo, ilustra-se o interferômetro de Michelson montado a partir de uma junção em $\mathrm{Y}$ com pigtails espelhados e com acoplador direcional na entrada.

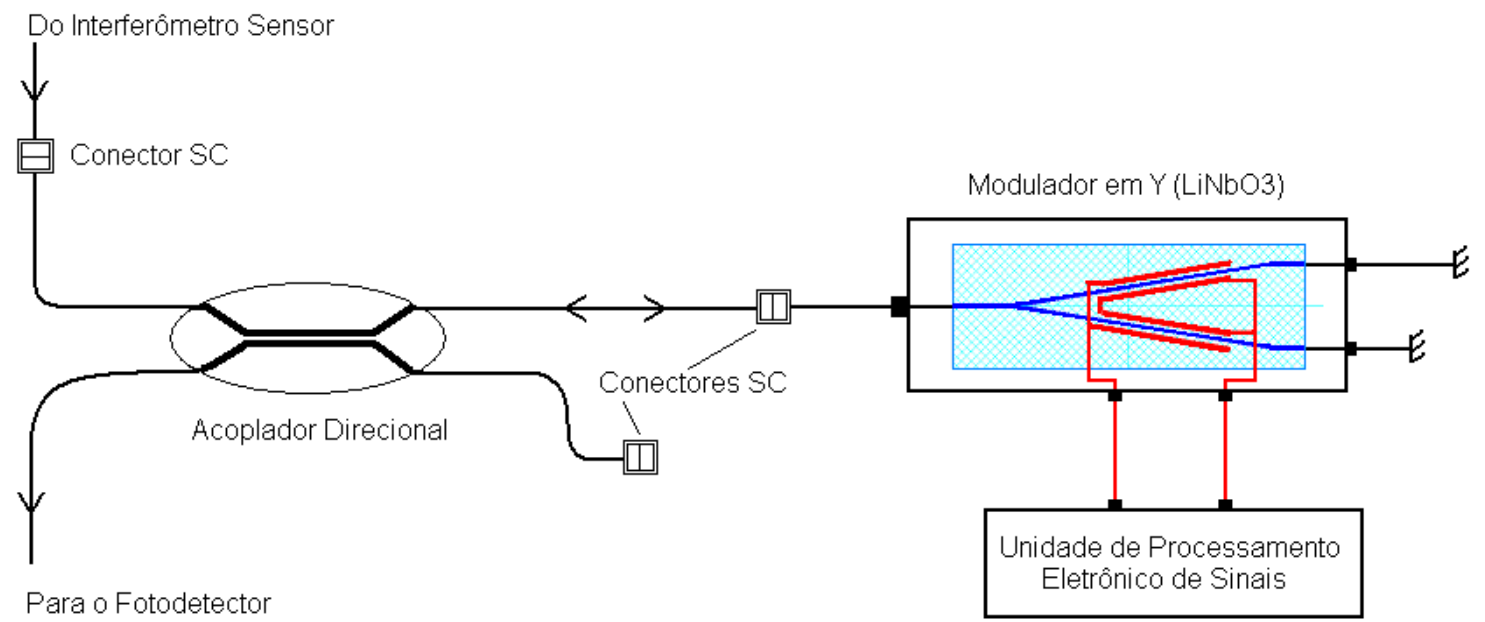

Figura 16 - Interferômetro de Michelson utilizando junção em $Y$ com pigtails espelhados e com acoplador direcional na entrada.

Desta forma, pode-se mostrar que a intensidade óptica na saída de um interferômetro de Michelson, que utiliza dispositivos a óptica integrada, montado a partir de uma das configurações mostradas nas Figuras 14 e 15, é equivalente à intensidade óptica na saída de um interferômetro de Michelson montado a partir de fibras ópticas utilizando apenas um acoplador direcional e pode ser descrita através da equação abaixo [17, 22]: 


$$
I_{\text {out }}=\frac{l_{\text {in }}}{4}[1+\cos (2 \Delta \varphi)]
$$

Pode-se notar, na equação acima, a variação da intensidade óptica de saída $\left(l_{\text {out }}\right)$ como uma função da diferença de fase óptica $(\Delta \varphi)$. A eq. (4.22) é similar à eq. (4.20), que calcula a intensidade de saída do interferômetro de Mach-Zehnder, diferindo desta apenas na diferença de fase.

Outra possibilidade é utilizar um circulador óptico no lugar do acoplador direcional. Circuladores ópticos são dispositivos muito versáteis que podem ser utilizados, por exemplo, em aplicações onde são necessárias isolação elevada entre as portas e baixo nível de perdas.

Os circuladores ópticos podem utilizar elementos ópticos discretos em escala reduzida e serem construídos com um número elevado de portas (acessos). No entanto as montagens que utilizam 3 ou 4 portas são as mais comuns.

O funcionamento básico de um circulador óptico é ilustrado na Figura 17. A luz que entra por uma determinada porta, por exemplo a porta 1, viaja ao redor do circulador e sai pela próxima porta, no caso a porta 2 , com pequena atenuação, tipicamente de -06 a $-1,2 \mathrm{~dB}$. A luz que entra na porta 2 sai pela porta 3 e assim por diante. A quantidade de luz que retorna de uma porta para anterior é muito pequena, tipicamente entre -35 e $-50 \mathrm{~dB}$.

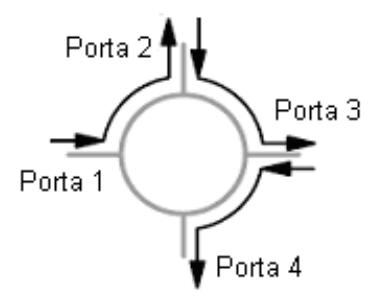

Figura 17 - Representação simbólica do circulador óptico de 4 portas.

Na Figura 18, a seguir, ilustra-se o interferômetro de Michelson montado a partir de uma junção em $Y$ com pigtails espelhados e com circulador óptico na entrada. 


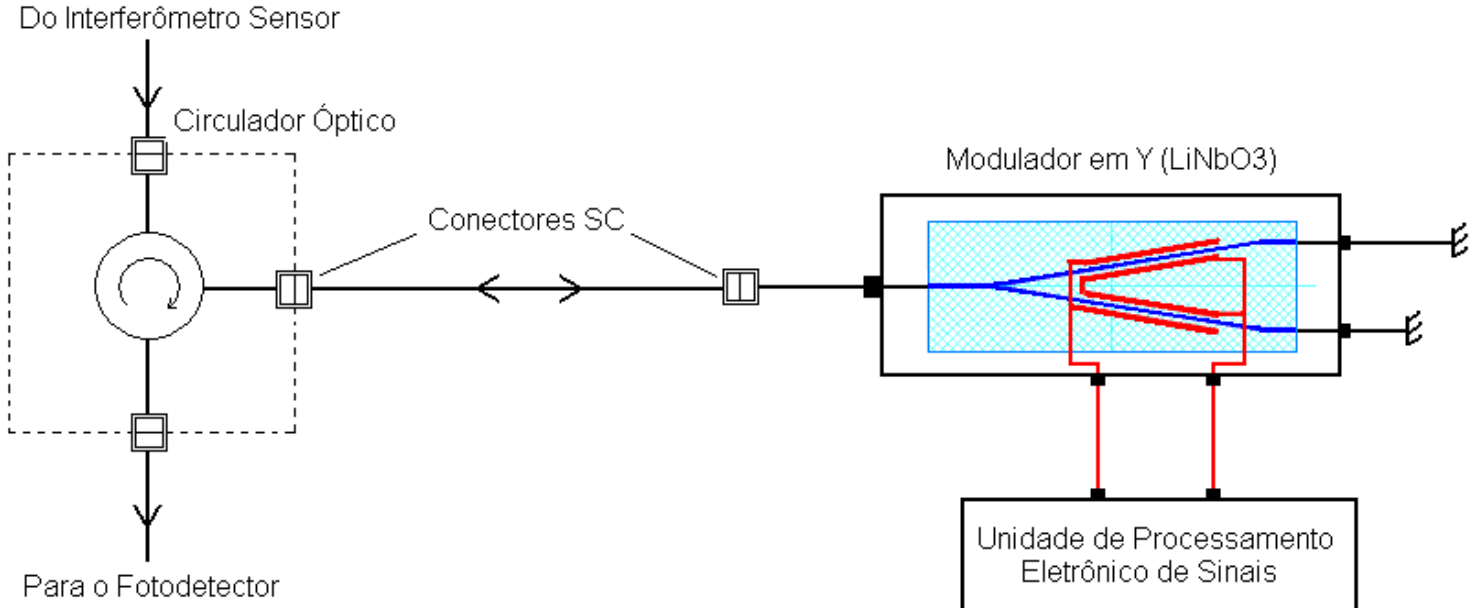

Figura 18 - Interferômetro de Michelson utilizando junção em $Y$ com pigtails espelhados e com circulador óptico na entrada.

É importante notar que o interferômetro de Michelson montado a partir de uma junção em $\mathrm{Y}$ com pigtails de saída espelhados e com circulador óptico na entrada (ou acoplador direcional) apresenta algumas diferenças significativas com relação ao interferômetro de Mach-Zehnder a óptica integrada, sendo elas:

- O comprimento do dispositivo: É razoavelmente menor em um interferômetro de Michelson do que num interferômetro de Mach-Zehnder. Esta diferença deve-se ao fato de a primeira montagem utilizar em sua construção apenas um dispositivo eletro-óptico em $\mathrm{Y}$, enquanto que na segunda há a necessidade de utilização de duas junções em $Y$ ligadas por dois guias canal retos.

- O interferômetro de Mach-Zehnder pode ser montado inteiramente sobre um substrato eletro-óptico, não necessitando nenhum ajuste externo, enquanto que para montar o interferômetro de Michelson são necessárias etapas de finalização.

- O interferômetro de Mach-Zehnder é transmissivo, enquanto que o interferômetro de Michelson a fibras ópticas é reflexivo. 
- Com respeito à sensibilidade, a variação de fase $(\Delta \varphi)$ do interferômetro de Michelson é mais sensível à tensão de modulação $\left(E_{m}\right)$ do que 0 interferômetro de Mach-Zehnder (para dispositivos construídos com as mesmas dimensões, materiais e orientações nas partes submetidas às modulações).

Essas diferenças nas topologias influem na razão entre as intensidades de saída e de entrada $\left(I_{\text {out }} / I_{\text {in }}\right)$, que podem variar consideravelmente da topologia de Michelson para a topologia de Mach-Zehnder.

Ao contrário da versão volumétrica, a versão integrada e a fibras ópticas do interferômetro de Michelson apresentam montagens mais simples, não necessitando de placas compensadoras. Além disso, estas versões apresentam perdas de intensidade menores do que a sua correspondente versão volumétrica, provendo melhor alinhamento entre os componentes ópticos, entre outras vantagens [12, 13, 22, 28-30].

No que diz respeito visibilidade, considerando um coeficiente de reflexão próximo de $100 \%$, a topologia de Michelson, apresenta perdas equivalentes ao interferômetro de Mach-Zehnder (transmissivo), uma vez que neste a luz atravessa duas junções em $Y$ diferentes até atingir o fotodetector. $O$ mesmo acontece no interferômetro de Michelson, por que a luz atravessa a mesma junção em $Y$ duas vezes, no caminho de ida até o espelho e após refletir-se neste.

Essa semelhança nas perdas pode ser fortemente desequilibrada pela qualidade dos espelhos na topologia de Michelson, pendendo a vantagem para a topologia de Mach-Zehnder à medida que essa qualidade se degrada [12, 13, 22, 28-30].

No que tange ao espelhamento das fibras, as duas extremidades das fibras que saem do modulador eletro-óptico em $Y$ integrado podem ser metalizadas através de técnica apropriada (espelho intrínseco), como mostrado na seção 5.3, ou pode-se adicionar um conjunto composto de lente focalizadora e espelho, (espelho extrínseco) para se atingir uma dada reflectividade desejada. Com a metalização 
direta das fibras ópticas, caso espelho intrínseco, melhora-se muito a função visibilidade, do interferômetro, quando comparado com o caso espelho extrínseco.

Com respeito ao comprimento dos braços da junção $\mathrm{Y}$, estes podem ser balanceados (caso possuam o mesmo comprimento) ou desbalanceados (caso possuam comprimentos diferentes).

\subsection{REVISÃo DA TEORIA ELETROMAGNÉtICA APLICADA A SENSORES A FIBRAS ÓPTICAS}

As origens da tecnologia óptica datam da remota antiguidade, quando os primeiros espelhos foram feitos de Cobre polido, Bronze, e mais tarde um material que era constituído de uma liga de Cobre rica em Estanho [23]. Alguns espécimes do antigo Egito sobreviveram ao tempo, um deles, um espelho em perfeitas condições foi desenterrado junto à moradia de trabalhadores nas proximidades da pirâmide de Sesostris II (1900 a.C.) no vale do Nilo. Os filósofos gregos, Pitágoras, Demócrito, Empédocles, Platão, Aristóteles e outros desenvolveram várias teorias a respeito da natureza da luz. Pitágoras desenvolveu uma teoria que fazia menção a uma "substância", denominada "aithér" muito parecida com a idéia de éter que surgiria no século XIX. A propagação retilínea da luz era conhecida, como era também conhecida a lei da reflexão enunciada por Euclides (300 a.C.) em seu livro Catóptrica. Hero de Alexandria explicou ambos os fenômenos afirmando que a luz viaja ao longo do caminho mais curto entre dois pontos. Aristófanes em sua sátira As Nuvens (424 a.C.), fazia menção ao "vidro queimador", provavelmente uma lente convergente. Em A República, Platão refere-se à curvatura aparente dos objetos parcialmente submergidos em água [23].

No entanto, a refração já havia sido estudada por Cleomedes (50 d.C.) e mais tarde por Cláudio Tolomeo (130 d.C) de Alexandria, o qual tabulou medidas muito precisas dos ângulos de incidência e refração para vários meios. Segundo os escritos do historiador Plínio (23-79 d.C.), os romanos também possuíam vidros queimadores. Várias esferas de vidro e cristal, que provavelmente foram usadas para fazer fogo, 
foram encontradas em ruínas romanas, inclusive uma lente plano-convexa em Pompéia. O filósofo romano Séneca (3 a.C.- 65 d.C.) notou que um globo de vidro cheio de água podia ser usado para fins de aumento. Depois da queda do Império Romano Ocidental (475 d.C.), que marca aproximadamente o começo da Idade Média, durante muito tempo não se produziu quase nenhum progresso científico na Europa [23].

Ainda que adormecida, a óptica, em vez de permanecer estática, se desenvolveu graças a Alhazen (1000 d.C.) o qual trabalhou na lei de reflexão, colocando os ângulos de incidência e reflexão no mesmo plano normal à interface; estudou os espelhos esféricos e parabólicos e deu uma descrição detalhada do olho humano.

No final do século XIII, a Europa começava a levantar-se graças ao seu grande impulso intelectual. Os trabalhos de Alhazen foram traduzidos para o Latim e tiveram uma grande influência nos trabalhos de Robert Grosseteste, o bispo de Lincoln, e no matemático Vitello, que contribuíram para o reinicio do estudo da óptica. Seus trabalhos foram conhecidos por Roger Bacon o qual é considerado por muitos autores, no sentido moderno do termo, como o primeiro cientista. Alguns textos sugerem que Bacon, que também possuía algum conhecimento da forma pela qual os raios atravessam uma lente, deu início à idéia de usar lentes para corrigir a vista e sugeriu a possibilidade de combiná-las para formar um telescópio. No entanto, após a sua morte a óptica definhou novamente [23].

Contudo, em meados do século XIII, as pinturas européias mostravam monges com óculos. Os alquimistas haviam obtido uma substância, amálgama líquido de estanho e mercúrio, que era aplicado na parte posterior de vidros para fazer espelhos. Leonardo da Vinci, por sua vez, desenhou e descreveu o princípio de funcionamento da câmara escura, que mais tarde foi popularizada por Giovanni Battista della Porta. Porta examinou, em 1589, em sua obra Magia Naturalis, os espelhos múltiplos e vários arranjos de lentes positivas e negativas.

Esta sucessão de acontecimentos, em sua maior parte, constitui o que se poderia chamar de primeiro período da óptica. Foi um começo aparentemente difícil, porém em seu conjunto foi um tempo dedicado ao aprendizado dos princípios básicos da 
óptica. O apogeu e a excitação nesse campo da ciência viriam mais tarde, no século XVII [23].

Em 1621, Willebrord Snell, redescobriu empiricamente a lei da refração, que por muito tempo ficou escondida. Este feito constituiu um dos maiores momentos da óptica. Ao dar a conhecer, precisamente, a forma como os raios da luz são encaminhados ao atravessar uma interface entre dois meios, Snell, de uma só vez, abriu as portas para a óptica moderna. René Descartes foi o primeiro a publicar a formulação agora familiar da refração em termos de senos. Em sua obra La Dioptrique (1637), Descartes deduziu a mesma lei usando um modelo no qual a luz era visualizada como uma pressão transmitida por um meio elástico. Pierre Fermat, sem levar em conta as suposições de Descartes, deduziu de novo a lei da reflexão a partir de seu próprio princípio de tempo mínimo (1657). Afastando-se do postulado de Hero, ou seja do caminho mais curto, Fermat manteve que a luz se propaga de um ponto a outro ao longo de uma reta que lhe toma o menor tempo, todavia ela tem que se desviar da trajetória mais curta para fazê-lo [23].

O fenômeno da difração foi verificado primeiramente por Francisco Maria Grimaldi quando observou as faixas de luz dentro da sombra de uma vareta iluminada por uma pequena fonte. Robert Hooke, também observou os efeitos da difração e foi o primeiro a estudar os padrões de interferência coloridos gerados por películas delgadas (Micrographia, 1665) e concluiu corretamente que estes se deviam a uma interação entre a luz refletida nas superfícies frontal e posterior do filme. Ele também propôs que a luz era um movimento vibratório rápido do meio propagando-se com grande velocidade, além disso, escreveu: "cada pulso ou vibração do corpo luminoso gera uma esfera". Era o início de uma nova era da óptica: a da teoria ondulatória.

Grande impulso científico foi dado por Isaac Newton quando ele publicou Filosofia Experimental. No entanto, apesar de Newton possuir uma certa apreciação pela teoria corpuscular da luz, permaneceu ambivalente por algum tempo sobre a sua verdadeira natureza - corpuscular ou ondulatória [23,29].

Pode-se considerar que o estudo inicial da interferometria óptica aconteceu na última metade do século XVII com a descrição, por Boyle, e independentemente, por Hooke, daquilo que mais tarde passou a ser conhecido como Anéis de Newton, 
(franjas coloridas vistas através de um filme fino de ar envolvido por duas placas de vidro em contato) [23]. Tais franjas eram produzidas pela interferência de ondas de luz refletidas pelas duas superfícies do filme. Hooke interpretava a luz como onda, para explicar as franjas, assim como Huygens, que em 1690 apresentou uma primeira formulação a esta teoria. Contudo, tal idéia obteve muito pouco progresso devido à oposição dos físicos da época, que se inclinavam às tendências de Newton, que cada vez mais acreditava na natureza puramente corpuscular da luz [23].

Os obstáculos à aceitação da teoria ondulatória começaram a ser rompidos pelo físico inglês Thomas Young, que entre 1801 e 1803, estabeleceu o princípio de interferência, demonstrando que a soma de dois raios de luz poderia dar origem a zonas de escuridão. Com base nas medições de Newton, da espessura dos filmes de ar necessários para produzir as diversas cores, realizadas cerca de 100 anos antes, Young calculou os seus comprimentos de onda. Realizou ainda diversos experimentos com filmes e difração em bordas planas e fontes secundárias obtidas por orifícios, e chegando aos mesmos valores de comprimento de onda [23].

Porém, mesmo tal demonstração não levou à aceitação da teoria ondulatória da luz, pelo seu caráter qualitativo. Quando em 1809, Malus, descobriu que a luz poderia ser polarizada por reflexão, ocorreu um abalo nas crenças de Huygens e Young, de que a luz se propagava segundo ondas longitudinais (as únicas conhecidas na época, dos estudos da propagação do som).

A reação só iniciou 14 anos após a descoberta do princípio de interferência de Young, com as idéias do engenheiro francês $A$. J. Fresnel, que aprimorou o princípio de Huygens e o princípio de interferência de Young, acrescentando o conceito de fase da onda óptica, para explicar as figuras de difração formadas pela luz ao atravessar orifícios ou passar por objetos. Arago e Fresnel, a partir de uma idéia de Young, demonstraram que dois feixes polarizados ortogonalmente não podem interferir entre si, ocasionando a conclusão inevitável de que a luz é uma onda transversal [23].

Entretanto, desde que apenas ondas longitudinais podem propagar-se num fluido, Fresnel teve que postular a existência do chamado "eter", um meio com densidade 
menor que a do vácuo e elasticidade maior que a do aço, preenchendo toda do espaço, através do qual as ondas de luz poderiam se propagar. A idéia do éter prevaleceu até o século XIX. Porém, questões como o fenômeno de aberração, descoberto por J. Bradley em 1728, indicavam que o éter deveria ser estacionário, o que contradizia os cálculos de próprio Fresnel e os experimentos de Fizeau, realizadas em 1581. Baseados nestes cálculos, Maxwell previu, em 1880, que o movimento da Terra através do éter resultaria numa variação de velocidade da luz proporcionalmente ao quadrado da relação entre a velocidade da Terra e a velocidade da luz. Tal efeito deveria ser muito pequeno para ser detectado experimentalmente, mas Michelson acreditava que poderia ser medido, utilizando-se da interferometria, a fim de aumentar enormemente a exatidão dos resultados. Isto levou ao célebre experimento de Michelson em 1881 e a outro em 1887 juntamente com E. W. Morley sobre a deriva do éter [23], que, por obter resultado nulo em ambos os experimentos, estabeleceu um marco para a rejeição do conceito do éter e lançou base para a teoria da relatividade especial de Einstein, em 1905, [23].

Outras aplicações da interferometria seguiram-se rapidamente e em 1896 Michelson realizou experimentos em que demonstrou a possibilidade de utilizar a luz de fontes monocromáticas como padrão de comprimento, fato que aconteceu em 1960, quando o metro foi redefinido em termos do comprimento de onda da radiação laranja emitida pelo elemento químico $\mathrm{Kr}^{86}$ [23].

Aplicações em testes de componentes ópticos foram realizados por Twyman em 1916, usando um interferômetro de Michelson modificado. Em 1933, Linnik adaptou esse interferômetro para permitir o exame de superfícies refletoras.

Os estudos de Michelson revelaram também a conexão entre a visibilidade das franjas e as dimensões e pureza espectral da fonte, donde nasceu a idéia de iluminação coerente. Contudo, somente em 1907 foi feito o primeiro estudo quantitativo da coerência, formulado por Von Laue. Demorou quase três décadas até que os fundamentos da teoria de coerência fossem estabelecidos por Van Cittert, em 1934, e por Zernike, em 1938. Passaram-se mais de 20 anos até que tal teoria fosse completamente detalhada por Hopkin (1951) e Wolf (1954), dentre outros [23]. 
Até a primeira metade do século $X X$, a maioria das fontes de luz comumente empregadas em interferometria eram produzidas baseadas na luz emitida por arcos elétricos em atmosferas contendo mercúrio e passada através de um filtro que isolava a linha verde. Tal fonte produzia luz com baixa coerência espacial e temporal, além de possuir intensidade muito reduzida. Uma revolução na interferometria ocorreu com o desenvolvimento do laser (Light Amplification by Stimulated Emission of Radiation), na década de 1960, como uma fonte de luz com elevado grau de coerência espacial e temporal. O laser veio remover a maioria das limitações das fontes térmicas, relativamente à interferometria e possibilitou importantes mudanças nesta área. Ocorreram a partir de então desenvolvimentos de diversas técnicas ópticas, dentre elas pode-se destacar, a holografia, que é um método de imagem baseado em interferometria óptica, e as técnicas heterodinas, que revolucionaram a interferometria de medição de comprimentos e de frequências na região óptica [23]

Com o advento das fibras ópticas na década de 1970, surgiram também, análogos dos interferômetros de dois feixes, utilizando fibras ópticas monomodo, que possuem a vantagem de permitir comprimentos de caminhos ópticos muito longos, acomodados em pequenos espaços. Além disso, como as fibras sofrem mudanças de comprimento, com a deformação e a temperatura, por exemplo, alterando assim o comprimento do caminho óptico, tornou-se possível a implementação de sensores de alta sensibilidade e baixo ruído, utilizando-se configurações interferométricas à fibra óptica [23].

Outro progresso notável ocorreu também devido ao desenvolvimento de sofisticadas técnicas de detecção de intensidades de ondas ópticas, baseadas em dispositivos opto-eletrônicos, substituindo os antigos procedimentos de leitura de resultados baseados na observação direta, pelo olho humano, das franjas de interferência. Isto permitiu ainda explorar as regiões do espectro infravermelho e ultra-violeta, impossíveis a olho nu. Obteve-se assim enorme avanço permitindo o processamento analógico/digital de sinais opto-eletrônicos, aumentando a velocidade e precisão das medidas.

Dentre os sistemas ópticos que podem produzir interferência citam-se dois tipos fundamentais $[23,29]$ : o de divisão de frente de onda e o de divisão de amplitude. 
Nos sistemas baseados em divisão de frente de onda porções de uma frente de onda primária são usadas ou diretamente como fontes, para emitir ondas secundárias, ou em conjunto com dispositivos ópticos, para produzir fontes virtuais de ondas secundárias. Tais ondas secundárias são então trazidas a interferir entre si.

Nos sistemas baseados em divisão de amplitude, a intensidade da própria onda primária é dividida entre dois feixes que viajam por diferentes caminhos antes de se recombinarem e interferirem. Para produzir a divisão de amplitude pode-se utilizar, por exemplo, um filme parcialmente refletor, de metal ou dielétrico, comumente denominado como divisor de feixes (ou beam-splitter), ou um elemento polarizador birrefringente para produzir dois feixes polarizados ortogonalmente, ou ainda uma grade ou placa de espalhamento que produza um ou mais feixes difratados, além de um feixe principal refletido ou transmitido. Estes dispositivos são comumente utilizados em interferômetros de dois feixes, como nas configurações de Michelson e Mach-Zehnder, dentre outros [29].

\subsubsection{INTENSIDADE ÓPTICA}

A radiação eletromagnética situada na faixa espectral denominada óptica, que abrange as regiões do infra-vermelho, visível e ultra-violeta, varia muito rapidamente, numa faixa de frequências de aproximadamente $3,0 \times 10^{11} \mathrm{~Hz}$ até $3,8 \times 10^{14} \mathrm{~Hz}$ para o infra-vermelho, de aproximadamente $3,8 \times 10^{14} \mathrm{~Hz}$ a $7,6 \times 10^{14} \mathrm{~Hz}$ para a radiação correspondente à faixa visível e, de aproximadamente, $8,0 \times 10^{14} \mathrm{~Hz}$ até $3,0 \times 10^{17} \mathrm{~Hz}$ para o ultra-violeta. Contudo, apesar de não haver uma universalidade, é possível classificar a região do infravermelho em quatro outras sub-regiões, que são: $O$ infra-vermelho próximo $(780-3.000 \mathrm{~nm})$, o infra-vermelho intermediário $(3000-6.000 \mathrm{~nm}), \quad 0$ infra-

vermelho distante $(6.000-15.000 \mathrm{~nm})$ e 0 infra-vermelho extremo $(15.000 \mathrm{~nm}-1 \mathrm{~mm})$. Por serem estas radiações, variações muito rápidas, o processo de detecção do valor instantâneo do campo, no tempo, se torna 
praticamente inviável. Por outro lado, nessa mesma faixa, a intensidade óptica (ou irradiância) pode ser medida diretamente usando-se uma grande variedade de sensores (como por exemplo, fotocélulas, bolômetros, filmes fotográficos, etc.) [23].

A intensidade de luz, $I$, é definida como o valor médio no tempo da quantidade de energia que atravessa uma área unitária perpendicular à direção do fluxo de energia. Assim, a intensidade corresponde ao valor médio do vetor de Poynting, $\vec{S}(\vec{r}, t)$. Da teoria eletromagnética, tem-se que a definição da intensidade óptica é dada por [23, 25, 29]:

$$
I(\vec{r}, t)=\langle|\vec{S}(\vec{r}, t)|\rangle=\frac{1}{T} \int_{t}^{t+T}\left|\vec{E}\left(\vec{r}, t^{\prime}\right) \times \vec{H}\left(\vec{r}, t^{\prime}\right)\right| d t^{\prime}
$$

onde:

$\vec{E}(\vec{r}, t)$ é o vetor campo elétrico, $\vec{H}(\vec{r}, t)$ é o vetor campo magnético, $T$ é o período da onda óptica e $\vec{r}$ é o vetor posição.

Embora pareça haver alguma inconsistência nesta expressão (uma vez que não deveria restar a dependência da intensidade óptica com a variável $t$, do cálculo de uma integral em $d t^{\prime}$ ), como poderá ser visto mais adiante, que naquelas situações onde a luz é deslocada em frequência de um valor muito pequeno, $\Delta \omega$, comparado com a frequência óptica, $\omega$, ainda poderá restar uma dependência temporal lenta do cálculo da integral do valor médio em $t$, dado pela eq. (4.23), modulando a intensidade óptica resultante nos casos de interferência. Ainda que seja uma aproximação, a identidade dada pela eq. (4.23) será válida neste trabalho, uma vez que a relação $\omega / \Delta \omega$ é da ordem de $10^{8}[23,25,29]$.

Considere-se o caso de uma onda eletromagnética monocromática, representada na forma dada pela equação abaixo:

$$
\vec{E}(\vec{r}, t)=\Re e\left[\vec{E} e^{i \omega t}\right]=\frac{1}{2}\left[\vec{E} e^{i \omega t}+\vec{E}^{*} e^{-i \omega t}\right]
$$


onde:

$$
\begin{gathered}
\vec{E}=E_{x} \hat{i}+E_{y} \hat{j}+E_{z} \hat{k} \text { e cujas amplitudes são dadas por: } \\
E_{x}=E_{1}(r) e^{i g_{1}(r)} \\
E_{y}=E_{2}(r) e^{i g_{2}(r)} \\
E_{z}=E_{3}(r) e^{i g_{3}(r)}
\end{gathered}
$$

onde:

$E_{j}(r)$ e $g_{j}(r)$ são funções reais. No caso de ondas planas e uniformes, os termos em $E_{j}$ são constantes e $g_{j}(\vec{r})=\vec{k}_{j} \cdot \vec{r}-\varphi_{j}$, sendo $\vec{k}_{j}$ o vetor de propagação e $\varphi_{j}$ a constante de fase que especifica o estado de polarização da onda [25].

A representação acima aplica-se analogamente para o campo $\vec{H}(\vec{r}, t)$.

Calculando-se o produto vetorial dos campos elétrico e magnético, obtém-se a equação [23, 25, 29]:

$$
\vec{E}(\vec{r}, t) \times \vec{H}(\vec{r}, t)=\frac{1}{4}\left[(\vec{E} \times \vec{H}) e^{2 i \omega t}+\left(\vec{E}^{*} \times \vec{H}^{*}\right) e^{-2 i \omega t}+\left(\vec{E}^{*} \times \vec{H}\right)+\left(\vec{E} \times \vec{H}^{*}\right)\right]
$$

Substituindo o resultado de (4.28) e efetuando as operações sobre a integral do valor médio em (4.23) obtém-se a intensidade óptica, dada pela equação a seguir $[23,25]$ :

$$
I(\vec{r}, t)=\frac{1}{4}\left[\left(\vec{E}^{*} \times \vec{H}\right)+\left(\vec{E} \times \vec{H}^{*}\right)\right]
$$

ou ainda 


$$
I(\vec{r}, t)=\frac{1}{2} \Re e\left[\vec{E} \times \vec{H}^{*}\right]
$$

O resultado de (4.30) também é válido para campos modulados em fase (ou em frequência), desde que a freqüência do sinal modulador seja muito pequena em relação à frequência óptica $\omega$. Para uma onda TEM propagando-se na direção do versor $\hat{n}$, num meio linear e isotrópico de impedância intrínseca $Z_{0}$, obtém-se [23, 25]:

$$
\vec{E} \times \vec{H}^{*}=\vec{E} \times \frac{1}{Z_{0}}\left(\hat{n} \times \vec{E}^{*}\right)=\frac{1}{Z_{0}}\left(\vec{E} \cdot \vec{E}^{*}\right) \hat{n}
$$

onde:

$$
\vec{E} \cdot \vec{E}^{*}=E_{x}^{2}+E_{y}^{2}+E_{z}^{2}=|\vec{E}|^{2}
$$

Finalmente, a eq. (4.30), que define a intensidade óptica, torna-se:

$$
I(\vec{r}, t)=\frac{1}{2 Z_{0}} \Re e|\vec{E}|^{2}
$$

Em alguns casos, não existe interesse em trabalhar com 0 valor absoluto da intensidade óptica, mas apenas com valores relativos (a fim de efetuar comparações de intensidades em um mesmo meio), de forma que pode-se tomar sua medida, ignorando-se os fatores de proporcionalidade em (4.33), isto é, usando-se [23, 25]:

$$
I(\vec{r}, t) \propto \Re e\left\langle E^{2}(\vec{r}, t)\right\rangle
$$

É de grande importância neste trabalho, o qual envolve o desenvolvimento de um interferômetro, estudar como se comporta a intensidade devido à superposição de 
ondas eletromagnéticas no espaço. Destacam-se a seguir dois casos importantes: ondas de mesma frequência e ondas de frequências diferentes.

\subsubsection{SUPERPOSIÇÃO DE ONDAS}

Considere-se o caso em que duas ondas planas caracterizadas por seus campos elétricos $\vec{E}_{1}\left(\vec{r}_{1}, t\right)$ e $\vec{E}_{2}\left(\vec{r}_{2}, t\right)$, com frequências $\omega_{1}$ e $\omega_{2}$, respectivamente, sejam superpostas num determinado ponto $P$ do espaço. Os vetores $\vec{r}_{1}$ e $\vec{r}_{2}$ representam os raios vetores das fontes $S_{1}$ e $S_{2}$, com campos elétricos $\vec{E}_{1}$ e $\vec{E}_{2}$, respectivamente, referidos ao ponto $P$, conforme ilustra a Figura 19, abaixo [23, 25]:

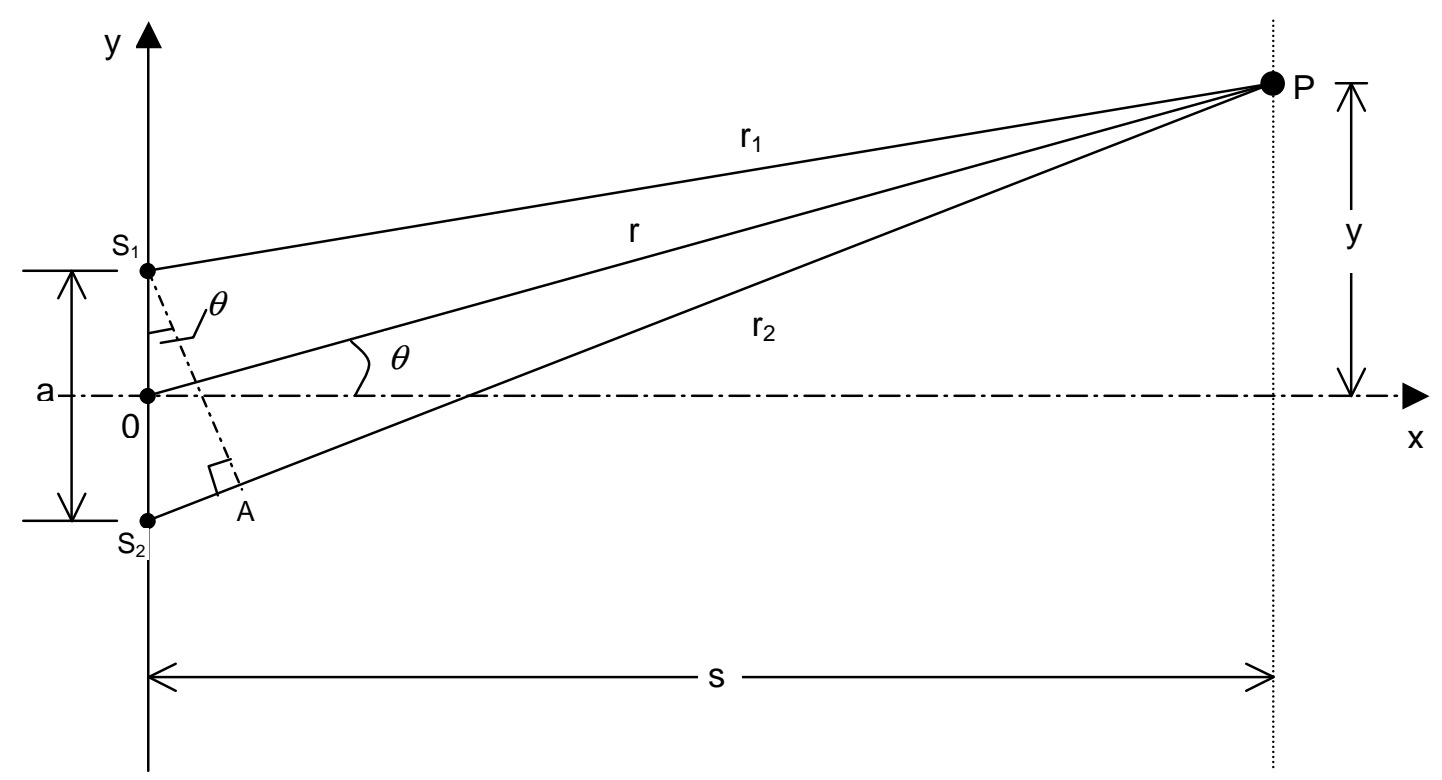

Figura 19 - Esquema para interferência de dois feixes em um ponto $P$ do espaço. $S_{1}$ e $S_{2}$ são duas fontes de luz situadas à distâncias $r_{1}$ e $r_{2}$ do ponto $P$. A distância entre as fontes $S_{1}$ e $S_{2}$ é a [25].

Tais campos são representados pelas equações a seguir [23, 25]:

$$
\vec{E}_{1}\left(\vec{r}_{1}, t\right)=\Re e\left[\vec{E}_{01} e^{i\left(\omega_{1} t+\vec{k}_{1} \cdot \vec{r}_{1}+\varepsilon_{1}\right)}\right]=\Re e\left[\vec{A} e^{i \omega_{1} t}\right]
$$




$$
\vec{E}_{2}\left(\vec{r}_{2}, t\right)=\Re e\left[\vec{E}_{02} e^{i\left(\omega_{2} t+\vec{k}_{2} \cdot \vec{r}_{2}+\varepsilon_{2}\right)}\right]=\Re e\left[\vec{B} e^{i \omega_{2} t}\right]
$$

onde:

$$
\begin{aligned}
& \vec{A}=\vec{E}_{01} e^{i\left(\vec{k}_{1} \cdot \vec{r}_{1}+\varepsilon_{1}\right)} \\
& \vec{B}=\vec{E}_{02} e^{i\left(\vec{k}_{2} \cdot \vec{r}_{2}+\varepsilon_{2}\right)}
\end{aligned}
$$

Nas equações (4.37) e (4.38), $\vec{E}_{01}$ e $\vec{E}_{02}$ são vetores reais e $\varepsilon_{1}$ e $\varepsilon_{2}$ são as fases de $S_{1}$ e $S_{2}$, respectivamente. O campo total será dado pela expressão [23,25]:

$$
\vec{E}(\vec{r}, t)=\vec{E}_{1}\left(\vec{r}_{1}, t\right)+\vec{E}_{2}\left(\vec{r}_{2}, t\right)
$$

onde:

$\vec{r}$ é o vetor posição do ponto $P$ em relação à origem do sistema de coordenadas. Calculando-se o valor de $|\vec{E}(\vec{r}, t)|^{2}$, obtém-se:

$$
|\vec{E}(\vec{r}, t)|^{2}=E_{1}^{2}\left(\vec{r}_{1}, t\right)+E_{2}^{2}\left(\vec{r}_{2}, t\right)+2 E_{1}\left(\vec{r}_{1}, t\right) \cdot E_{2}\left(\vec{r}_{2}, t\right)
$$

Assim, usando (4.34), pode-se determinar a intensidade total [23, 25]:

$$
I=I_{1}+I_{2}+I_{12}
$$

com

$$
\begin{aligned}
& I_{1}=\left\langle\vec{E}_{1}^{2}\left(\vec{r}_{1}, t\right)\right\rangle \\
& I_{2}=\left\langle\vec{E}_{2}^{2}\left(\vec{r}_{2}, t\right)\right\rangle
\end{aligned}
$$




$$
l_{12}=2\left\langle\vec{E}_{1}\left(\vec{r}_{1}, t\right) \cdot \vec{E}_{2}\left(\vec{r}_{2}, t\right)\right\rangle
$$

Efetuando-se os cálculos em (4.42), tem-se [23, 25]:

$$
I_{1}=\frac{1}{2}\left[\vec{A} \cdot \vec{A}^{*}\right]=\frac{1}{2}\left[\vec{E}_{01} \cdot \vec{E}_{02}^{*}\right]=\frac{1}{2}\left|\vec{E}_{01}\right|^{2}
$$

e procedendo da mesma maneira para $I_{2}$, em (4.43), tem-se:

$$
I_{2}=\frac{1}{2}\left|\vec{E}_{02}\right|^{2}
$$

O termo $l_{12}$ é denominado termo de interferência e será determinado notando-se que $[23,25]$ :

$$
\vec{E}_{1}\left(\vec{r}_{1}, t\right) \cdot \vec{E}_{2}\left(\vec{r}_{2}, t\right)=\frac{1}{4}\left[\vec{A} e^{i \omega_{1} t}+\vec{A}^{*} e^{-i \omega_{1} t}\right] \cdot\left[\vec{B} e^{i \omega_{2} t}+\vec{B}^{*} e^{-i \omega_{2} t}\right]
$$

ou ainda:

$$
\vec{E}_{1}\left(\vec{r}_{1}, t\right) \cdot \vec{E}_{2}\left(\vec{r}_{2}, t\right)=\frac{1}{4}\left[\vec{A} \cdot \vec{B} e^{2 i \bar{\omega} t}+\vec{A}^{*} \cdot \vec{B}^{*} e^{-2 i \bar{\omega} t}+\vec{A} \cdot \vec{B}^{*} e^{2 i \omega_{s} t}+\vec{A}^{*} \cdot B e^{-2 i \omega_{s} t}\right](4
$$

onde:

os parâmetros $\bar{\omega}$ e $\omega_{S}$, são as frequências angulares média e de modulação, respectivamente, e são definidas como [23, 25]:

$$
\begin{gathered}
\bar{\omega}=\frac{1}{2}\left(\omega_{1}+\omega_{2}\right) \\
\omega_{s}=\frac{1}{2}\left(\omega_{1}-\omega_{2}\right)
\end{gathered}
$$


Se os valores de $\omega_{1}$ e $\omega_{2}$ forem aproximadamente iguais, o cálculo da integral do valor médio em (4.44) fornece, [23, 25]:

$$
I_{12}=\frac{1}{4}\left[\vec{A} \cdot \vec{B}^{*} e^{2 i \omega_{s} t}+\vec{A}^{*} \cdot \vec{B} e^{-2 i \omega_{s} t}\right]
$$

onde considera-se que $\omega_{s}<<\bar{\omega} \cong 2 \omega$.

Substituindo os valores de $\vec{A}$ e $\vec{B}$, dados por (4.37) e (4.38), a expressão (4.51) torna-se [23, 25]:

$$
I_{12}=\frac{1}{4}\left[\left(\vec{E}_{01} \cdot \vec{E}_{02}^{*}\right) e^{i\left(2 \omega_{s} t+\delta\right)}+\left(\vec{E}_{01}^{*} \cdot \vec{E}_{02}\right) e^{-i\left(2 \omega_{s} t+\delta\right)}\right]
$$

com

$$
\delta=\vec{k}_{1} \cdot \vec{r}_{1}-\vec{k}_{2} \cdot \vec{r}_{2}+\varepsilon_{1}-\varepsilon_{2}
$$

Finalmente, levando-se em consideração que $\vec{E}_{01}$ e $\vec{E}_{02}$ são quantidades reais, a eq. (4.44) torna-se:

$$
I_{12}=\vec{E}_{01} \cdot \vec{E}_{02} \cos \left(2 \omega_{s} t+\delta\right)
$$

Nota-se que se $\vec{E}_{01}$ e $\vec{E}_{02}$ forem perpendiculares entre si, o termo de interferência será igual a zero $\left(l_{12}=0\right)$, e $/$ será dado simplesmente pela soma das intensidades dos raios. Diz-se neste caso, que não ocorre interferência entre os feixes.

Quando $\vec{E}_{01}$ for paralelo a $\vec{E}_{02}$, ou seja, as ondas possuem a mesma polarização, obtém-se: 


$$
I_{12}=\left|\vec{E}_{01}\right| \cdot\left|\vec{E}_{02}\right| \cos \left(2 \omega_{s} t+\delta\right)
$$

e pode-se reescrever a eq. (4.41) na forma [23, 25]:

$$
I=I_{1}+I_{2}+2 \sqrt{I_{1} \cdot I_{2}} \cos \left(2 \omega_{s} t+\delta\right)
$$

Para o caso de $I_{1}=I_{2}=I_{0}$ e utilizando identidade trigonométrica dada pela equação abaixo [23]:

$$
\cos ^{2}(\xi)=\frac{1}{2}[1+\cos (2 \xi)]
$$

tem-se $[23,25]$ :

$$
I=2 I_{0}\left[1+\cos \left(2 \omega_{s} t+\delta\right)\right]=4 I_{0} \cos ^{2}\left(\omega_{s} t+\frac{\delta}{2}\right)
$$

onde pode-se notar que $I_{\min }=0$ e $I_{\max }=4 I_{0}$.

\subsubsection{FRANJAS DE INTERFERÊNCIA}

Conforme foi visto anteriormente, quando duas frentes de ondas com polarizações paralelas e com amplitudes iguais se interferem, a intensidade será dada pela eq. (4.57). Portanto, I é função de $\delta$ e $t$ e pode assumir resultados diferentes de acordo com seus valores, em um determinado ponto do espaço. Nesta seção será feita a análise do comportamento de I no espaço para este caso particular. A partir daí, serão obtidos resultados importantes para a parte experimental deste trabalho.

Para tal, será considerado novamente o diagrama da Figura 19. A razão de se trabalhar com essas duas fontes, $S_{1}$ e $S_{2}$, deve ficar mais clara com as discussões no final desta seção, a respeito de localização de franjas de interferência. A distância "a" entre $S_{1}$ e $S_{2}$ é considerada muito pequena $(a<r)$. Da eq. (4.57) 
deduz-se que a intensidade será máxima para $\delta=2 \pi m-2 \omega_{s} t$, onde $m=0, \pm 1, \pm 2, \ldots$, ou seja, ocorrerá quando [23, 25-29]:

$$
r_{1}-r_{2}=\frac{\left[2 \pi m-2 \omega_{s} t-\left(\varepsilon_{1}-\varepsilon_{2}\right)\right]}{k}
$$

onde:

$r_{1}$ e $r_{2}$ são os módulos de $\vec{r}_{1}$ e $\vec{r}_{2}$, respectivamente. Esta expressão pode ser obtida a partir da eq. (4.52), fazendo-se $\vec{k}_{1}$ paralelo a $\vec{r}_{1}$ e $\vec{k}_{2}$ paralelo a $\vec{r}_{2}$ $\operatorname{com}\left|\vec{k}_{1}\right|=\left|\vec{k}_{2}\right|=k$.

A intensidade mínima $(I=0)$ acontece quando $\left(2 \omega_{s} t+\delta\right)=\pi(2 m+1)$, ou seja, ocorrerá quando $[23,25]$ :

$$
r_{1}-r_{2}=\frac{\left[\pi(2 m+1)-2 \omega_{s} t-\left(\varepsilon_{1}-\varepsilon_{2}\right)\right]}{k}
$$

Se os emissores $S_{1}$ e $S_{2}$ estiverem em fase, ou seja, se $\left(\varepsilon_{1}-\varepsilon_{2}=0\right)$, ocorrerão intensidades máxima e mínima, respectivamente, quando [23, 25]:

$$
\begin{gathered}
r_{1}-r_{2}=m \lambda-\omega_{s} t\left(\frac{\lambda}{\pi}\right) \\
r_{1}-r_{2}=\left(m+\frac{1}{2}\right) \lambda-\omega_{s} t\left(\frac{\lambda}{\pi}\right)
\end{gathered}
$$

Em primeira aproximação, para $a<<s$ na Figura 19, tem-se, [23, 25]:

$$
S_{2} A=S_{1} P-S_{2} P=r_{1}-r_{2}=a \cdot \operatorname{sen}(\theta) \cong a \theta
$$


Para valores de $\theta$ muito pequenos, na Figura 19, observa-se também que $\operatorname{tg}(\theta)=\theta=y / s$, portanto substituindo na eq. (4.62), obtém-se [23, 25]:

$$
r_{1}-r_{2}=\left(\frac{a y}{s}\right)
$$

Ocorrerá interferência construtiva quando a condição dada pela eq. (4.60) for satisfeita, e assim [23, 25]:

$$
y_{m}=\left(\frac{s}{a}\right) m \lambda-\left(\frac{s \lambda}{a \pi}\right) \omega_{s} t
$$

que fornece a relação entre a posição do m-ésimo máximo num anteparo localizado em $P$ (ortogonal ao plano formado por $S_{1}, S_{2}, P$, e o eixo $x$.

Substituindo-se a eq. (4.64) na expressão $\theta=y / s$, obtém-se o ângulo do m-ésimo máximo $[23,25]$ :

$$
\theta_{m}=\left(\frac{m \lambda}{a}\right)-\left(\frac{\lambda}{a \pi}\right) \omega_{s} t
$$

A distância entre dois máximos consecutivos vale, [23, 25]:

$$
\Delta y=y_{m+1}-y_{m}=\frac{s}{a}(m+1) \lambda-\left(\frac{s}{\lambda}\right) m \lambda
$$

ou seja,

$$
\Delta y=\left(\frac{s}{a}\right) \lambda
$$

Substituindo-se o valor de $\delta$, dado pela eq. (4.52) na eq. (4.57) e usando a eq. (4.63), obtém-se [23, 25]: 


$$
I=4 I_{0} \cos ^{2}\left[\left(\frac{a \pi}{s \lambda}\right) y+\omega_{s} t\right]
$$

Trata-se, portanto, de uma onda progressiva na direção y e com velocidade de fase $\left(v_{f}\right)$ ao longo do anteparo em $P$ dada pela expressão $[23,25]$ :

$$
v_{f}=\left(\frac{s \lambda}{a \pi}\right) \omega_{s}
$$

A partir da eq. (4.68) serão feitas, a seguir, observações a respeito de dois importantes casos, ou seja, quando $\omega_{s}=0$ e quando $\omega_{s} \neq 0$.

\subsubsection{SUPERPOSIÇÃO DE ONDAS COM FREQUÊNCIAS IGUAIS}

Neste caso a relação dada pela eq. (4.68) deixa de ser uma onda progressiva $\left(v_{f}=0\right.$ para $\left.\omega_{s}=0\right)$ e passa a ser uma onda estacionária. Sua distribuição de intensidade pode ser observada sobre uma tela, como aquela colocada em $P$, na Figura 19, como uma região de claros e escuros conhecidas como franjas de interferência. As franjas brilhantes são os lugares do espaço nos quais as amplitudes das ondas superpostas somam-se em fase, ou seja, ocorre a interferência construtiva; sua diferença de fase é um número inteiro $m$ multiplicado por $2 \pi$ e a diferença de caminho óptico é $m \lambda$. Nas franjas escuras a diferença de fase é $(m+1 / 2)(2 \pi)$, a diferença de caminho óptico é $(m+1 / 2) \lambda$ e a interferência é dita destrutiva. Neste tipo de interferência, as franjas assumem a forma de linhas retas paralelas e equidistantes sobre o anteparo. O índice $m$ na eq. (4.64) é denominado ordem das franjas de interferência [23, 25].

Um fato que deve ser destacado é que a relação dada pela eq. (4.68) foi deduzida para uma situação na qual $\left(\varepsilon_{1}-\varepsilon_{2}=0\right)$ significando que o interferômetro tem braços com comprimentos iguais. Naquelas situações em que esses braços possuam 
comprimentos de caminhos ópticos diferentes, ou quando ocorra um desequilíbrio de fases devido a um agente externo qualquer (como por exemplo, nas aplicações de interferômetros como sensores), as fontes $S_{1}$ e $S_{2}$ não estarão mais em fase e a quantidade $\left(\varepsilon_{1}-\varepsilon_{2} \neq 0\right)$. Denominando esta diferença por $\Delta \varepsilon$, pode-se demonstrar que a eq. (4.68) torna-se [23, 25-29]:

$$
I=4 I_{0} \cos ^{2}\left[\left(\frac{a \pi}{s \lambda}\right) y+\left(\frac{\Delta \varepsilon}{2}\right)\right]
$$

Desta forma, pode-se concluir que o perfil de intensidade óptica fica deslocado em relação à origem do eixo $y$, por um valor $\Delta \varepsilon / 2$.

Observa-se que quanto menor for o valor da distância a (para um mesmo valor de $s$, na Figura 19, ou seja, quanto mais alinhados estiverem os raios, maior será a separação entre as franjas, $\Delta y$. Para um alinhamento perfeito, obtém-se uma região de claro ocupando toda a tela em $P$ (franja de ordem $m=0$ ).

\subsubsection{SUPERPOSIÇÃO DE ONDAS COM DIFERENTES FREQUÊNCIAS}

Nesta situação, conforme foi dito anteriormente, as freqüências das fontes $S_{1}$ e $S_{2}$ apresentam uma pequena diferença $\left(\omega_{1}-\omega_{2}\right)$ entre si. Neste caso ainda ocorre o processo de formação de franjas de interferência sobre o plano de observação em $P$, no entanto, tal distribuição de intensidade deixa de ser uma onda estacionária e passa a ser uma onda progressiva, conforme eq. (4.68).

Deste modo, as figuras de franjas somente poderão ser observadas visualmente se a diferença $\left(\omega_{1}-\omega_{2}\right)$ for muito pequena (da ordem de poucos Hertz) [23, 25], pois nesses casos o padrão de interferência se deslocará muito lentamente.

A partir dos resultados apresentados pode-se observar que, se for de interesse a observação das figuras de interferência, as fontes devem ser coerentes. Caso 
contrário (em fontes térmicas, por exemplo, nas quais essas diferenças de fase flutuam aleatoriamente), a figura resultante não será mantida por um tempo suficiente para poder ser observada.

Nesse aspecto, no sistema sensor de que trata este trabalho e que é apresentado no capítulo 5, foram utilizados interferômetros iluminados por luz proveniente de uma única fonte óptica parcialmente coerente, de tal forma que, em algumas partes do sistema, os feixes interferidos experimentarão defasagens menores que a equivalente ao comprimento de coerência da fonte e, em outras partes, defasagens maiores do que esta. A técnica que utiliza esta estratégia é chamada de Interferometria de luz branca ou interferometria de baixa coerência, que será abordada no próximo item.

\subsection{INTERFEROMETRIA DE LUZ BRANCA}

\subsubsection{SENSORES À FIBRA ÓPTICA COM MODULAÇÃO POR ESPECTRO}

Muitos dos moduladores de espectro óptico de que se tem notícia são baseados na técnica conhecida como Interferometria de Luz Branca (White Light Interferometry WLI) ou Interferometria a Fibras Ópticas de Baixa Coerência (Fiber Optic Low Coherence Interferometry - FOLCl). Utiliza-se na construção deste tipo de modulador, um interferômetro que separa duas componentes da luz proveniente de uma fonte óptica de espectro largo (luz branca) e introduz entre elas um grande atraso de fase, maior que o equivalente ao comprimento de coerência da luz empregada. $O$ atraso de fase expresso em termos de defasagem espacial entre ondas ópticas é chamado de diferença de caminho óptico (Optical Path Diference $O P D$ ). Na saída deste modulador obtém-se um feixe óptico que se encontra modulado em conteúdo espectral. Existem várias abordagens possíveis para se recuperar a informação introduzida na luz por um modulador deste tipo. Por exemplo, pode-se aplicar sua saída a um analisador de espectro óptico, ou, a um segundo interferômetro, que introduza entre as componentes da onda óptica um OPD idêntico ao introduzido pelo primeiro interferômetro. 
Uma das principais vantagens dos sensores baseados em WLI, em relação aos sensores a fibras ópticas baseados em intensidade ou polarimétricos [30-35], é que - valor da medida em sua saída pode ser tornado praticamente insensível a flutuações de potência óptica que ocorram ao longo do enlace óptico utilizado para conectar o sensor à unidade de processamento. Além disso, ele pode oferecer características de resolução e faixa dinâmica muito maiores que os sensores convencionais, o que faz consequentemente, esta técnica, ser muito promissora para uma grande variedade de aplicações.

A interferometria de baixa coerência é um fenômeno muito bem descrito pela óptica clássica [23, 34, 36] e o uso da técnica foi primeiramente relatado por Al-Chalabi em 1983 [35], embora seu princípio de operação tenha sido proposto originalmente em 1975 e demonstrado em 1976 como um possível método de transmissão para uso em comunicações ópticas [37]. O primeiro sistema sensor desenvolvido baseado na técnica de WLI foi reportado em 1884, por Bosselmann [38], em um sensor para medição de deslocamento que utilizava como fonte de luz uma lâmpada convencional. Os vários trabalhos publicados neste período serviram para mostrar que a técnica WLI também poderia ser aplicada adequadamente na medida de outras grandezas físicas com elevada precisão [34]. Durante o período de 19851989, uma grande quantidade de sensores ópticos baseados em WLI foi apresentada à comunidade científica, sendo a sua grande maioria composta de sensores de temperatura [38-40], deformação [41, 42] e pressão [43].

\subsubsection{PRINCÍPIO DE FUNCIONAMENTO DE UM INTERFERÔMETRO A WLI}

Interferometria é a técnica derivada da interferência, que é a observação experimental do fenômeno de coerência. A teoria de coerência é uma descrição estatística da radiação expressa em termos de funções de correlação. Já que a fonte de luz não é completamente coerente, a coerência temporal de uma fonte de luz real pode ser representada por sua função de auto-correlação, como será visto mais adiante. 
Conforme descrito por Santos [44], em um interferômetro, a interferência ocorre quando a radiação segue por caminhos diferentes, da fonte de luz até o ponto de detecção. Pode-se expandir a eq. (4.55) para representar a lei geral de interferência para luz parcialmente coerente, dada por [23]:

$$
I_{p}=I_{1}+I_{2}+2 \sqrt{I_{1} \cdot I_{2}} \Re \mathrm{ee}\left[\gamma_{12}(\tau)\right]
$$

onde:

$\gamma_{12}(\tau)$ é a função de correlação cruzada e $\gamma_{12}(\tau)=\frac{\left|\gamma_{12}(\tau)\right|}{\gamma_{12}(0)}$ é uma quantidade complexa conhecida como grau de coerência (ou função de autocorrelação) dos campos luminosos nos pontos $p_{1}$ e $p_{2}$, respectivamente. A quantidade $\tau=t_{2}-t_{1}$ está relacionada à tomada de tempo nos pontos $P_{1} \mathrm{e}$ $P_{2}$.

A partir de agora, por simplicidade, as intensidades $I_{p 1}$ e $I_{p 2}$, serão reescritas, sem perda de generalidade, como $I_{1}$ e $I_{2}$, respectivamente.

O ângulo de fase de $\gamma_{12}(\tau)$ se relaciona com a função de correlação cruzada e o ângulo de fase entre os campos luminosos. Desta forma, se este ângulo de fase for $\phi_{12}(\tau)=\alpha_{12}(\tau)-\varphi$, tem-se [23]:

$$
\Re e\left[\gamma_{12}(\tau)\right]=\left|\gamma_{12}(\tau)\right| \cos \left[\alpha_{12}(\tau)-\varphi\right]
$$

A diferença no ângulo de fase $\varphi$, para a luz quase-monocromática, é concomitante com a diferença de caminho óptico e é dada por:

$$
\varphi=\frac{2 \pi}{\lambda}\left(r_{2}-r_{1}\right)
$$

e, por conseguinte, pode-se reescrever a eq. (4.72) como segue [23]: 


$$
I_{p}=I_{1}+I_{2}+2 \sqrt{I_{1} \cdot I_{2}}\left|\gamma_{12}(\tau)\right| \cos \left[\alpha_{12}(\tau)-\varphi\right]
$$

Da desigualdade de Schwarz [23], pode-se demonstrar que $0 \leq\left|\gamma_{12}(\tau)\right| \leq 1$. De fato, quando se compara a equação acima com aquela para o caso de coerência completa, fica evidente que se $\left|\gamma_{12}(\tau)\right|=1$, a intensidade I seria a mesma que aquela gerada por duas ondas coerentes fora de fase, em $S_{1}$ e $S_{2}$, por uma quantidade $\alpha_{12}(\tau)$. Por outro lado, em outro extremo se $\left|\gamma_{12}(\tau)\right|=0, I=I_{1}+I_{2}$, não haverá interferência e diz-se que as perturbações são incoerentes. Neste ínterim, quando $0<\left|\gamma_{12}(\tau)\right|<1$ ter-se-á coerência parcial, cuja medida é o mesmo $\left|\gamma_{12}(\tau)\right|$, que se conhece como grau de coerência. Em resumo, pode-se escrever [23]:

$\left|\gamma_{12}(\tau)\right|=1 \rightarrow$ limite de coerência total;

$\left|\gamma_{12}(\tau)\right|=0 \rightarrow$ limite de incoerência total;

$\left|\gamma_{12}(\tau)\right|<1 \rightarrow$ coerência parcial.

Nos sensores interferométricos WLI a fibra óptica, são usados, geralmente, dois interferômetros de divisão de amplitude. Nestes tipos de interferômetros, dois divisores de feixe são utilizados: um para dividir o feixe luminoso inicial em dois feixes e que após viajarem por diferentes braços do interferômetro, serão recombinados no segundo divisor, no final destes braços. Se os braços possuírem comprimentos diferentes $\left(L_{1}\right.$ e $\left.L_{2}\right)$, por exemplo, a diferença de fase entre os dois feixes luminosos que será introduzida é proporcional à diferença de caminho óptico, $\Delta L=L_{1}-L_{2}$. Se $I_{1}$ e $I_{2}$ forem as intensidades luminosas destes dois feixes, após a recombinação deles (se as propriedades de polarização da luz forem mantidas) a intensidade resultante dependerá da coerência temporal da fonte e será dada por $[23,44]$. 


$$
I=I_{1}+I_{2}+2 \sqrt{I_{1} \cdot I_{2}}\left|\gamma_{12}(\tau)\right| \cos \Delta \phi(t)
$$

onde:

$\tau=\frac{\left|L_{1}-L_{2}\right|}{c}=\frac{\Delta L}{c}$ é a diferença de tempo,

$c$ é a velocidade de propagação da luz no meio e

$\Delta \phi$ é a diferença de fase óptica.

A diferença de fase óptica $\Delta \phi(t)$ pode ser escrita como:

$$
\Delta \phi(t)=\frac{2 \pi}{\lambda} \Delta L \quad \text { e } \quad k=\frac{2 \pi}{\lambda}
$$

onde:

$\lambda$ é o comprimento de onda da luz no meio.

A qualidade das franjas de interferência produzidas por um interferômetro pode ser descrita quantitativamente usando o conceito da visibilidade $(V)$, a qual, tal como foi formulada por Michelson, pode ser escrita como [23, 26, 27]:

$$
V=\frac{I_{\max }-I_{\min }}{I_{\max }+I_{\min }} \quad \text { ou } \quad V=V_{o}\left|\gamma_{12}(\tau)\right|
$$

onde:

$V_{o}$ é a visibilidade da franja central, que corresponde a uma diferença de caminho óptico igual a zero $(O P D=0)$, equivalentemente a $\tau=0$. 
Um padrão de interferência aparece se o valor absoluto de $\gamma_{12}(\tau)$ diverge de zero. Em um padrão de franjas de interferência, a intensidade varia entre dois limites: a intensidade máxima e a intensidade mínima, $I_{\max }$ e $I_{\min }$, respectivamente. A visibilidade das franjas pode então ser definida como sendo a razão fornecida por, $[11,31]$.

Fazendo $V_{o}=2 \frac{\left(l_{1} \cdot l_{2}\right)^{1 / 2}}{l_{1}+l_{2}}$ e utilizando (4.77), substitui-se este resultado na eq. (4.75), obtendo-se [23, 26]:

$$
I=\left(I_{1}+I_{2}\right) \cdot[1 \pm V \cos \Delta \phi(t)]
$$

O padrão de intensidade de saída de um interferômetro de luz branca possui um perfil de visibilidade dado pela eq. (4.77), determinado pela propriedade de baixa coerência da fonte de banda larga utilizada. A distribuição do espectro de intensidade de uma fonte óptica de banda larga típica pode ser representada, aproximadamente, por uma função gaussiana, tal como [44]:

$$
I(\sigma)=\frac{I_{o}}{\sqrt{\pi}(\delta \sigma)} e^{-\left[\frac{\sigma-\sigma_{0}}{(\delta \sigma)}\right]^{2}}
$$

onde:

$\sigma=1 / \lambda$ é o número de onda de uma componente espectral,

$\sigma_{o}$ é o número de onda central da fonte luminosa,

$\delta \sigma$ é a largura da banda espectral e

$I_{o}$ é a intensidade em $\sigma_{0}$. 
Neste caso, o comprimento de coerência da fonte $L_{c}$ é dado, aproximadamente, por [44]:

$$
L_{c} \cong \frac{1}{(\delta \sigma)} \cong \frac{\lambda_{o}^{2}}{(\delta \lambda)}
$$

Visto que a saída de um interferômetro é, em teoria, a transformada de Fourier do espectro da fonte e, a transformada de Fourier de uma função gaussiana é também uma função gaussiana, deduz-se que o padrão de intensidade de saída normalizado de um interferômetro de luz branca é uma função cosseno modificado por um perfil de visibilidade gaussiano.

Uma das maneiras de se construir um sistema de sensoriamento utilizando a técnica WLI é baseada na ligação em série de dois interferômetros. De uma forma genérica, o princípio de funcionamento de um sistema de sensoriamento WLI deste tipo pode ser explicado da seguinte maneira: a luz emitida de uma fonte espectral de luz de banda larga (um SLD, por exemplo) é acoplada a uma fibra óptica que é conectada ao divisor de feixe localizado na entrada de um sensor interferométrico.

A diferença de caminho óptico introduzido pelo interferômetro sensor, $\Delta L_{s}$, é linearmente sensível à grandeza externa a ser medida. No caso da fonte de luz ser de banda larga, com um comprimento de coerência pequeno, se o OPD introduzido pelo interferômetro sensor for maior que o comprimento de coerência $L_{C}$ da fonte, não será observado nenhuma interferência na saída do interferômetro sensor. Se a luz que sai do interferômetro sensor for acoplada a outra fibra óptica e introduzida em um segundo interferômetro, chamado interferômetro recuperador, pode-se observar interferência em sua saída se, e somente se, a diferença de caminho óptico introduzida pelo interferômetro recuperador, $\Delta L_{r}$, se aproximar da que foi introduzida no interferômetro sensor, $\Delta L_{s}$. 
Uma demonstração analítica deste princípio pode ser feita utilizando a eq. (4.78) e omitindo a dependência espectral do OPD. O comportamento do interferômetro sensor pode ser descrito pela seguinte relação [7, 44]:

$$
I_{s}(\sigma)=T_{1} T_{s} I_{o}(\sigma)\left[1+V_{s} \cos \left(2 \pi \sigma \Delta L_{s}\right)\right]
$$

onde:

$T_{1}$ é o fator de transmissão do enlace óptico de ida,

$T_{s}$ é o fator de transmissão do interferômetro sensor,

$V_{s}$ é a visibilidade do interferômetro sensor, dada pela eq. (4.77),

$\Delta L_{s}$ é a OPD introduzida pelo interferômetro sensor,

$\sigma$ é o número de onda de uma componente espectral e

$I_{O}(\sigma)$ é a distribuição de intensidade espectral da fonte óptica.

Analogamente, o comportamento do interferômetro recuperador, em montagem volumétrica, pode ser descrito como [7, 44]:

$$
I_{r}(\sigma)=T_{2} T_{r} I_{s}(\sigma)\left[1+V_{r} \cos \left(2 \pi \sigma \Delta L_{r}\right)\right]
$$

onde:

$T_{2}$ é o fator de transmissão no enlace óptico de volta,

$T_{r}$ é o fator de transmissão do interferômetro recuperador,

$V_{r}$ é a visibilidade do interferômetro recuperador,

$\Delta L_{r}$ é a OPD introduzida pelo interferômetro recuperador e 
$\sigma$ é o número de onda de uma componente espectral.

A intensidade total disponível na saída do sistema interferométrico é calculada a partir da integral abaixo, sobre todos os números de onda [44]:

$$
I=\int_{\sigma} I_{r}(\sigma) d \sigma
$$

Se a fonte possuir uma distribuição espectral gaussiana, esta integral torna-se [7, 44]:

$$
I=T_{1} T_{2} T_{s} T_{r} I_{O}\left[1+\frac{1}{2} K_{o s} K_{o r} e^{-\left[\frac{\pi\left(\Delta L_{s}-\Delta L_{r}\right)}{L_{c}}\right]^{2}} \cos 2 \pi\left(\frac{\Delta L_{s}-\Delta L_{r}}{\lambda_{o}}\right)\right]
$$

onde:

$K_{o s}$ é a visibilidade da franja central do interferômetro sensor e

$K_{o r}$ é a visibilidade da franja central do interferômetro recuperador.

A intensidade I resultante aparece como uma função cosseno do OPD modificado por uma visibilidade dependente da fase, exatamente como mostrado na Figura 20. Verifica-se que o sistema apresenta a vantagem de um espectrômetro de transformada de Fourier onde o sinal é proporcional à potência total de saída, e que a máxima visibilidade ocorre no ponto de casamento dos OPD, ou seja, $\Delta L_{s}=\Delta L_{r}$. 


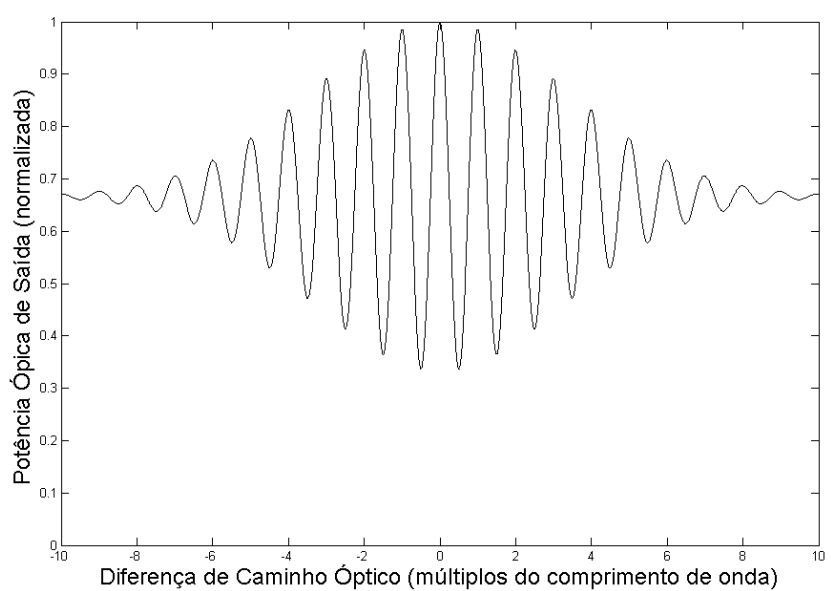

Figura 20 - Padrão teórico de intensidade de saída de um interferômetro de luz branca [44].

O OPD introduzido pelo interferômetro recuperador, $\Delta L_{r}$, pode ser ajustado para se igualar ao OPD do interferômetro sensor quando a grandeza medida é igual a zero. Nesse caso, verifica-se através da eq. (4.84) que, no ponto de casamento, a saída do interferômetro recuperador está no pico central da figura de interferência.

Se $\Delta L_{r}$ for fixo, verifica-se na eq. (4.84) que a intensidade óptica na saída do sistema depende do $\Delta L_{s}$, proporcional à grandeza a ser medida, e das transmissões dos componentes ópticos do sistema, $\left(T_{1}, T_{2}, T_{S}, T_{r}\right)$. Caso essas transmissões variem no tempo o resultado dessa variação será confundido com o sinal a ser medido, o que é indesejável. Para garantir a estabilidade da medida em relação à variação da potência óptica total transmitida pelo enlace faz-se necessário o uso de algum método para eliminar esta dependência. 


\subsection{INTERAÇÃO ELETRO-ÓPTICA}

\subsection{1 ÓPTICA DOS MEIOS ANISOTRÓPICOS}

A maioria dos meios materiais utilizados para controlar e modificar as propriedades de propagação da luz é de natureza anisotrópica (essencialmente anisotropia elétrica).

Num meio anisotrópico, sem perdas, a relação entre os vetores deslocamento elétrico e campo elétrico é estabelecida num sistema de coordenadas cartesianas $\left(x_{1}, x_{2}, x_{3}\right)$ orientado arbitrariamente, através do tensor de permeabilidade dielétrica, $\varepsilon_{i j}$, definido a partir do tensor de impermeabilidade relativa, $\varepsilon_{r}$, por $[26,27]$ :

$$
\left[\begin{array}{l}
D_{1} \\
D_{2} \\
D_{3}
\end{array}\right]=\underbrace{\left[\begin{array}{lll}
\varepsilon_{11} & \varepsilon_{12} & \varepsilon_{13} \\
\varepsilon_{21} & \varepsilon_{22} & \varepsilon_{23} \\
\varepsilon_{31} & \varepsilon_{32} & \varepsilon_{3}
\end{array}\right]}_{\left[\varepsilon_{r}\right]}\left[\begin{array}{c}
E_{1} \\
E_{2} \\
E_{3}
\end{array}\right]
$$

ou

$$
\vec{D}=\varepsilon_{0} \varepsilon_{r} \vec{E}=\varepsilon_{i j} \vec{E}
$$

A densidade volumétrica de energia elétrica é calculada, para meios lineares, através de:

$$
W_{E}=\frac{1}{2}[\vec{E} \cdot \vec{D}]
$$

Usando-se as componentes $\varepsilon_{i j}$ do tensor na eq. (4.86), obtém-se [26, 27]:

$$
W_{E}=\frac{\varepsilon_{0}}{2} \sum_{i=1}^{3} \underbrace{\left(\sum_{j=1}^{3} \varepsilon_{i j} E_{j}\right)}_{A_{i}} E_{i}
$$


Dado que a densidade de energia $W_{E}$ é uma função de estado, e que o tensor dielétrico deve ser simétrico, deverá ocorrer:

$$
\frac{\partial A_{i}}{\partial E_{j}}=\frac{\partial A_{j}}{\partial E_{i}} \rightarrow \varepsilon_{i j}=\varepsilon_{j i}
$$

Tendo-se em conta esta simetria e desenvolvendo-se a eq. (4.88), tem-se [26, 27]:

$$
\varepsilon_{11} E_{1}^{2}+\varepsilon_{22} E_{2}^{2}+\varepsilon_{33} E_{3}^{2}+2 \varepsilon_{12} E_{1} E_{2}+2 \varepsilon_{13} E_{1} E_{3}+2 \varepsilon_{23} E_{2} E_{3}=2 W_{E}
$$

Dada a positividade de $W_{E}$, o resultado da equação acima traduz uma forma quadrática definida positiva, cuja representação gráfica tridimensional consiste em um elipsóide.

A descrição mais simples desse elipsóide é obtida usando os seus eixos principais. Para tal, é necessário girar apropriadamente o sistema de coordenada inicial para uma nova posição, tal que a descrição do tensor dielétrico seja feita por uma matriz diagonal. Seja $[T]$ a matriz de transformação de coordenadas que produz essa mudança $[26,27]$ :

$$
\left(\vec{u}_{1}, \vec{u}_{2}, \vec{u}_{3}\right) \stackrel{T}{\longleftarrow}\left(\vec{u}_{x}, \vec{u}_{y}, \vec{u}_{z}\right)
$$

onde:

$x, y, z$ são as novas coordenadas (orientadas segundo os eixos principais do elipsóide). Desta forma, têm-se [26, 27]: 


$$
\left\{\begin{array}{l}
{\left[\begin{array}{l}
D_{1} \\
D_{2} \\
D_{3}
\end{array}\right]=[T]\left[\begin{array}{l}
D_{x} \\
D_{y} \\
D_{z}
\end{array}\right] \text { ou }[D]=[T]\left[D^{\prime}\right]} \\
{\left[\begin{array}{l}
E_{1} \\
E_{2} \\
E_{3}
\end{array}\right]=[T]\left[\begin{array}{l}
E_{x} \\
E_{y} \\
E_{z}
\end{array}\right] \text { ou }[E]=[T]\left[E^{\prime}\right]}
\end{array}\right.
$$

Substituindo a equação acima em (4.86), tem-se [26, 27]:

$$
[D]=\varepsilon_{0}\left[\varepsilon_{r}\right][E] \rightarrow\left[D^{\prime}\right]=\varepsilon_{0}\left([T]^{-1}\left[\varepsilon_{r}\right][T]\right)\left[E^{\prime}\right]
$$

Onde o problema descrito acima é o da diagonalização de uma matriz simétrica. A transformação de coordenadas é uma transformação de congruência [26, 27]:

$$
[T]^{-1}=[T]^{t}
$$

e os valores próprios (reais e positivos) $\varepsilon_{x}, \varepsilon_{y}, \varepsilon_{z}$ constituem as constantes dielétricas principais [26, 27]:

$$
[T]^{t}\left[\varepsilon_{r}\right][T]=\left[\begin{array}{ccc}
\varepsilon_{x} & 0 & 0 \\
0 & \varepsilon_{y} & 0 \\
0 & 0 & \varepsilon_{z}
\end{array}\right]
$$

Assim, por escolha apropriada do sistema de eixos de referência, é sempre possível relacionar $\vec{D}$ com $\vec{E}$ através de um tensor com representação diagonal, originando $[26,27]$ :

$$
D_{x}=\varepsilon_{x} E_{x}, D_{y}=\varepsilon_{y} E_{y}, D_{z}=\varepsilon_{z} E_{z}
$$


Nesta base, a densidade de energia elétrica $W_{E}$, reduz-se a uma soma de quadrados [26, 27]:

$$
W_{E}=\frac{1}{2}\left[\left(\frac{D_{x}}{\sqrt{\varepsilon_{x}}}\right)^{2}+\left(\frac{D_{y}}{\sqrt{\varepsilon_{y}}}\right)^{2}+\left(\frac{D_{z}}{\sqrt{\varepsilon_{z}}}\right)^{2}\right]
$$

Normalizando-se a expressão anterior no espaço das coordenadas, obtém-se [26, 27]:

$$
x \equiv \frac{D_{x}}{a}, \mathrm{y} \equiv \frac{D_{y}}{a}, \mathrm{z} \equiv \frac{D_{z}}{a}
$$

onde:

$$
a=\sqrt{2 \varepsilon_{0} W_{E}} .
$$

Introduzindo os chamados índices de refração principais:

$$
n_{x}=\sqrt{\frac{\varepsilon_{x}}{\varepsilon_{0}}}=\sqrt{\varepsilon_{r_{x}}}, n_{y}=\sqrt{\frac{\varepsilon_{y}}{\varepsilon_{0}}}=\sqrt{\varepsilon_{r_{y}}}, n_{z}=\sqrt{\frac{\varepsilon_{z}}{\varepsilon_{0}}}=\sqrt{\varepsilon_{r_{z}}}
$$

E, finalmente, substituindo-se as eq. (4.97) e (4.98) na expressão (4.96), obtém-se $[26,27]:$

$$
\frac{x^{2}}{n_{x}^{2}}+\frac{y^{2}}{n_{y}^{2}}+\frac{z^{2}}{n_{z}^{2}}=1
$$

que é a equação do elipsóide de índices, mas agora expresso, de uma forma mais simples, em coordenadas próprias. Se está diante de um elipsóide triaxial cujos semi-eixos principais ortogonais têm como comprimento os índices de refração 
principais do meio $n_{x}, n_{y}$ e $n_{z}$. Este elipsóide é conhecido na literatura por várias designações, dentre as quais podemos citar: indicatriz óptica, elipsóide de índices e elipsóide das normais de onda, por exemplo [27].

De acordo com as propriedades de simetria cristalográfica dos meios materiais, pode-se classificar os meios anisotrópicos em três grandes grupos: Biaxiais, uniaxiais e isotrópicos.

Os meios biaxiais são aqueles que têm um elipsóide de índices com três semi-eixos principais diferentes entre si. Nesses casos, o tensor dielétrico em coordenadas principais possui três elementos distintos na diagonal principal, ou seja [26, 27]:

$$
\left[\varepsilon_{r}\right]=\left[\begin{array}{ccc}
n_{x}^{2} & 0 & 0 \\
0 & n_{y}^{2} & 0 \\
0 & 0 & n_{z}^{2}
\end{array}\right]
$$

Tais meios caracterizam-se por terem dois eixos ópticos distintos, daí a designação de biaxiais. Pertencem a este grupo os materiais que cristalizam no sistema triclínico, monoclínico e ortorrômbico.

Os materiais uniaxiais têm como elipsóide de índices um elipsóide de revolução (com dois semi-eixos principais iguais). O tensor dielétrico é da forma [26, 27]:

$$
\left[\varepsilon_{r}\right]=\left[\begin{array}{ccc}
n_{o}^{2} & 0 & 0 \\
0 & n_{0}^{2} & 0 \\
0 & 0 & n_{e}^{2}
\end{array}\right]
$$


Nesses materiais há apenas um eixo óptico (orientado segundo a direção $z$ ). 0 índice de refração para uma onda polarizada paralelamente ao eixo $z$ é usualmente denominado como extraordinário, $n_{e}$, já os índices experimentados para ondas polarizadas paralelamente $x$ ou $y$ são iguais ao usualmente denominados como índice ordinário, $n_{0}$.

De acordo com o sinal algébrico da diferença $\left(n_{e}-n_{o}\right)$, os meios uniaxiais, podem ser classificados em positivo ou negativo. Neste contexto, o Niobato de Lítio é um cristal uniaxial negativo. A Figura 21 é uma ilustração do elipsóide de índices para um meio uniaxial positivo. Pertencem a este grupo os materiais que cristalizam no sistema tetragonal, hexagonal e trigonal. É dentro deste grupo que se encontram os materiais com maior número de aplicações em óptica e eletro-óptica.

Finalmente, os materiais isotrópicos têm como elipsóide de índices uma esfera (três semi-eixos iguais). Nesses materiais o tensor dielétrico é da forma diagonal escalar, ou seja $[26,27]$ :

$$
\left[\varepsilon_{r}\right]=n^{2}\left[\begin{array}{lll}
1 & 0 & 0 \\
0 & 1 & 0 \\
0 & 0 & 1
\end{array}\right]
$$

Para estes meios, qualquer direção de $\vec{k}$ constitui um eixo óptico. Pertencem a esta categoria os materiais que cristalizam no sistema cúbico. 


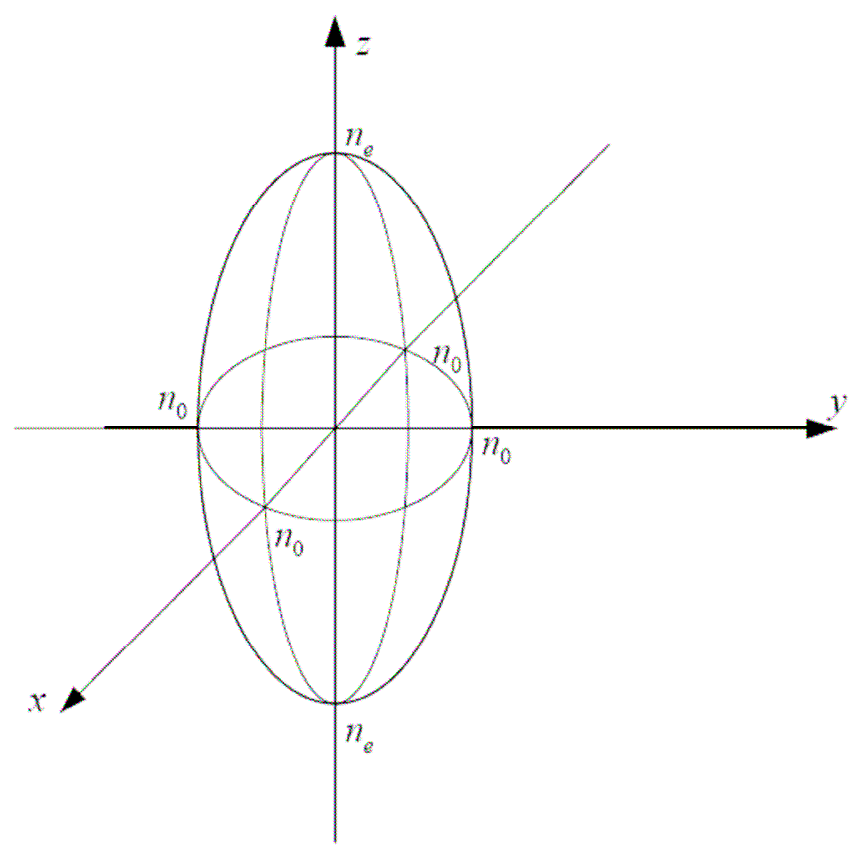

Figura 21 - Elipsóide de índices para um meio uniaxial positivo.

\subsubsection{EFEITO ELETRO-ÓPTICO}

Como os índices de refração não se transformam tensorialmente, a propagação da luz num cristal pode ser descrita em termos do tensor de impermeabilidade dielétrica, definido por $[\eta]=\left[\varepsilon_{r}\right]^{-1}$, cujos elementos são designados por $\eta_{i j}$. Num sistema de coordenadas principais, onde esse tensor tem representação diagonal, obtém-se o elipsóide de índices abaixo [26, 27]:

$$
\left(\frac{x}{n_{x}}\right)^{2}+\left(\frac{y}{n_{y}}\right)^{2}+\left(\frac{z}{n_{z}}\right)^{2}=1
$$

onde:

$x, y, z$ são as direções dos eixos principais (isto é, as direções no cristal segundo as quais $\vec{D}$ e $\vec{E}$ são paralelos), e onde $1 / n_{x}^{2}, 1 / n_{y}^{2}$ e $1 / n_{z}^{2}$ são os valores principais do tensor de impermeabilidade. 
Os elementos do tensor caracterizam-se por valores que dependem da distribuição de cargas no interior do cristal. A aplicação de um campo elétrico externo provoca uma redistribuição dessas cargas causando, concomitantemente, uma variação dos valores dos elementos do tensor de impermeabilidade. Tal fenômeno é conhecido como efeito eletro-óptico.

A dependência desses valores relativamente ao campo elétrico aplicado, $\vec{E}$, é traduzida por um conjunto de coeficientes (os chamados coeficientes eletro-ópticos) e exprime-se tradicionalmente sob a forma [26, 27]:

$$
\eta_{i j}(\vec{E})=\eta_{i j}(0)+\{\underbrace{\sum_{k}\left(r_{i j}\right)_{k} E_{k}+\sum_{k, l}\left(s_{i j}\right)_{k l} E_{k} E_{l}}_{\Delta \eta_{i j}}\}+\cdots
$$

onde:

ignoram-se as correções de ordem superior à segunda.

As constantes $r_{i j k}$ constituem os coeficientes eletro-ópticos lineares, ou de Pockels, e as constantes $s_{i j k l}$ constituem os coeficientes eletro-ópticos quadráticos, ou de Kerr.

Dada a simetria do tensor $[\eta]$ pode-se, na eq. (4.104), permutar os índices $i$ e $j$. Por outro lado, se esta expressão for o resultado de um desenvolvimento em série, os coeficientes $s_{i j k l}$ satisfarão a equação abaixo [26, 27]:

$$
s_{i j k l}=\frac{1}{2}\left(\frac{\partial^{2} \eta_{i j}}{\partial E_{k} \partial E_{l}}\right)_{E=0}
$$


Sendo irrelevante a sequência de derivação, segue-se que os índices $k$ e $/$ podem também ser permutados. Por consequência pode-se afirmar que [26, 27]:

$$
\begin{aligned}
& r_{i j k}=r_{j i k} \\
& s_{i j k l}=s_{j i k l}=s_{j i k k}=s_{i j k k}
\end{aligned}
$$

Face a essas regras de permutação é conveniente, e habitual, para abreviar a notação, introduzir os chamados índices contraídos [26, 27]:

$$
\overbrace{\left[\begin{array}{lll}
11 & 12 & 13 \\
21 & 22 & 23 \\
31 & 32 & 33
\end{array}\right]_{k}}^{i j} \leftrightarrow \overbrace{\left[\begin{array}{lll}
1 & 6 & 5 \\
6 & 2 & 4 \\
5 & 4 & 3
\end{array}\right]_{k}}^{1}
$$

Com esta abreviação os coeficientes lineares $r_{i j k}$ em número de 27 reduzem-se a 18 , e os coeficientes quadráticos $s_{i j k l}$ em número de 81 reduzem-se a 36 independentes. Na presença de um campo elétrico aplicado, o elipsóide de índices é dado pela forma quadrática [26, 27]:

$$
\sum_{i j} \eta_{i j}(\overrightarrow{\mathrm{E}}) x_{i} x_{j}=1
$$

com $\eta_{i j}$ dado pela eq. (4.104). Na ausência de campo elétrico aplicado o elipsóide reduz-se à forma simples dada pela eq. (4.103).

\subsubsection{EFEITO POCKELS}

O efeito Pockels, ou efeito eletro-óptico linear, é, como o nome sugere, o termo linear em $\vec{E}$ da perturbação do tensor de impermeabilidade, envolvendo apenas os coeficientes $r_{i j k}$, com desprezo do termo quadrático. 
Este desprezo é legítimo na grande maioria das aplicações dada a pequenez relativa do campo elétrico aplicado face ao campo elétrico inter-atômico (da ordem típica de $100 \mathrm{MV} / \mathrm{cm})$.

Ressalva-se, no entanto, uma classe especial de materiais (centro-simétricos) para os quais os coeficientes $r_{i j k}$ são nulos, onde, por conseqüência, o efeito quadrático é o que se faz sentir dominantemente.

Dos materiais eletro-ópticos lineares de uso mais frequênte, há que destacar os seguintes: Niobato de Lítio $\left(\mathrm{LiNbO}_{3}\right)$, Germanato de Bismuto $\left(\mathrm{Bi}_{4} \mathrm{Ge}_{3} \mathrm{O}_{12}\right)$, o Tantalato de Lítio $\left(\mathrm{LiTaO}_{3}\right)$, dentre outros. As propriedades ópticas destes materiais são, em geral, dependentes da temperatura e do comprimento de onda da luz.

Desta forma, para o Niobato de Lítio têm-se os seguintes coeficientes eletro-ópticos $[26,27]$ :

$$
\left[r_{i j}\right]=\left[\begin{array}{ccc}
0 & -r_{22} & r_{13} \\
0 & r_{22} & r_{13} \\
0 & 0 & r_{33} \\
0 & r_{51} & 0 \\
r_{51} & 0 & 0 \\
-r_{22} & 0 & 0
\end{array}\right],\left\{\begin{array}{l}
r_{13}=8,6 \mathrm{pm} / V \\
r_{33}=30,8 \mathrm{pm} / V \\
r_{22}=3,4 \mathrm{pm} / V \\
r_{51}=28 \mathrm{pm} / V
\end{array}\right.
$$

Esses coeficientes encontram-se expressos em notação de índices contraídos (4.107). Por exemplo, onde se representa $r_{22}$ deve-se ler $r_{222}$.

Retornando à equação do elipsóide de índices em (4.108) e substituindo as equações (4.103) e (4.104) e desprezando-se o termo quadrático, obtém-se [26, 27]:

$$
\sum_{i j} \eta_{i j}(0) x_{i} x_{j}+\sum_{i j}\left\{\sum_{k} r_{i j k} E_{k}\right\} x_{i} x_{j}=1
$$


A partir de (4.110), procedendo à identificação $x_{1}=x, x_{2}=y$ e $x_{3}=z$, e usando a notação de índices contraídos obtém-se [26, 27]:

$$
\begin{aligned}
& \frac{x^{2}}{n_{x}^{2}}+\frac{y^{2}}{n_{y}^{2}}+\frac{z^{2}}{n_{z}^{2}}+ \\
& +\sum_{k}\left\{r_{1 k} x^{2}+r_{2 k} y^{2}+r_{3 k} z^{2}+2 r_{6 k} x y+2 r_{5 k} x z+2 r_{4 k} y z\right\} E_{k}=1
\end{aligned}
$$

Os eixos principais deste novo elipsóide não coincidirão com os eixos iniciais $x, y$ e $z$ (para $\vec{E}=0)$ e dependerão claramente do campo elétrico aplicado $\vec{E}=E_{x} \vec{u}_{x}+E_{y} \vec{u}_{y}+E_{z} \vec{u}_{z}$, bem como, da natureza do material (através dos valores dos coeficientes $r_{l k}$ ).

Um novo sistema de eixos principais $\left(x^{\prime}, y^{\prime}, z^{\prime}\right)$, pode ser sempre obtido por uma rotação apropriada do sistema primitivo não-perturbado, conduzindo a redução da forma quadrática à sua expressão elementar, dada por [26, 27]:

$$
\left(\frac{x^{\prime}}{n_{x^{\prime}}}\right)^{2}+\left(\frac{y^{\prime}}{n_{y^{\prime}}}\right)^{2}+\left(\frac{z^{\prime}}{n_{z^{\prime}}}\right)^{2}=1
$$

Haverá uma rotação apropriada para cada caso específico de orientações relativas entre as direções do campo elétrico, dos eixos cristalinos do material, de propagação da luz e de sua polarização.

Considere-se, por exemplo, o caso descrito na Figura 22, a seguir, em que um cristal eletro-óptico uniaxial de comprimento $L$ se encontra colocado entre dois polarizadores cruzados, o polarizador $\mathrm{P}$ e o analisador $\mathrm{A}$. 


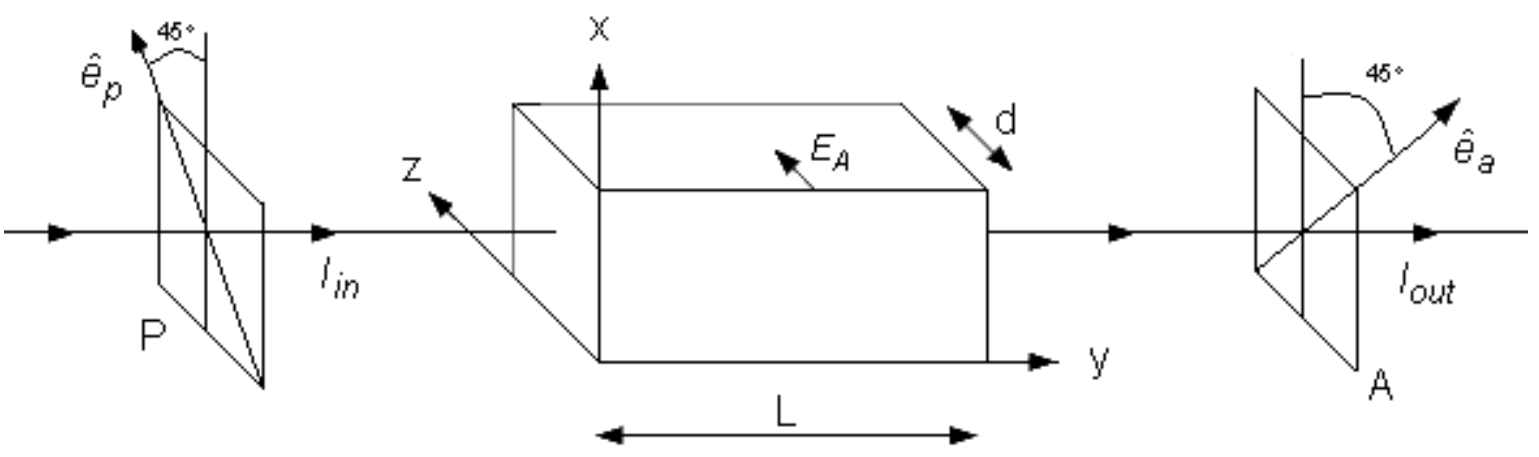

Figura 22 - Célula Pockels de comprimento $L$ colocada entre polarizadores.

$\mathrm{Na}$ Figura 22, tem-se o eixo y como a direção de propagação do feixe óptico, sendo o eixo óptico do cristal orientado segundo a direção $z$.

Considerando que as características de propagação de uma onda óptica em um cristal são completamente descritas pelo elipsóide de índices, o efeito da aplicação de um campo elétrico externo é mais convenientemente expresso em termos das variações das constantes $1 / n_{x}^{2}, 1 / n_{y}^{2}, 1 / n_{z}^{2}$ do elipsóide de índices.

$\mathrm{Na}$ presença de um campo elétrico externo aplicado, o elipsóide de índices é expresso na forma [26, 27]:

$$
\left(\frac{1}{n^{2}}\right)_{1} x^{2}+\left(\frac{1}{n^{2}}\right)_{2} y^{2}+\left(\frac{1}{n^{2}}\right)_{3} z^{2}+2\left(\frac{1}{n^{2}}\right)_{4} y z+2\left(\frac{1}{n^{2}}\right)_{5} x z+2\left(\frac{1}{n^{2}}\right)_{6} x y=1
$$

A variação linear dos coeficientes $\left(1 / n^{2}\right)_{i}, i=1,2,3, \ldots, 6$, provocada por um campo elétrico externo aplicado arbitrário, $\vec{E}=E_{x} \hat{x}+E_{y} \hat{y}+E_{z} \hat{z}$, é definida por, [26, 27]:

$$
\Delta\left(\frac{1}{n^{2}}\right)_{i}=\sum_{j=1}^{3} r_{i j} E_{j}
$$


onde: $E_{1}=E_{x}, E_{2}=E_{y}, E_{3}=E_{z}$.

Esta equação também pode ser expressa da seguinte forma:

$$
\left[\begin{array}{l}
\Delta\left(\frac{1}{n^{2}}\right)_{1} \\
\Delta\left(\frac{1}{n^{2}}\right)_{2} \\
\Delta\left(\frac{1}{n^{2}}\right)_{3} \\
\Delta\left(\frac{1}{n^{2}}\right)_{4} \\
\Delta\left(\frac{1}{n^{2}}\right)_{5} \\
\Delta\left(\frac{1}{n^{2}}\right)_{6}
\end{array}\right]=\left[\begin{array}{lll}
r_{11} & r_{12} & r_{13} \\
r_{21} & r_{22} & r_{23} \\
r_{31} & r_{32} & r_{33} \\
r_{41} & r_{42} & r_{43} \\
r_{51} & r_{52} & r_{53} \\
r_{61} & r_{62} & r_{63}
\end{array}\right] \cdot\left[\begin{array}{c}
E_{x} \\
E_{y} \\
E_{z}
\end{array}\right]
$$

onde:

A matriz $6 \times 3$ apresentada na eq. (4.115) é designada por Tensor EletroÓptico, e, para o caso do Niobato de Lítio, tem-se os valores dados por (4.109).

Sabendo-se que o eixo $z$ é o eixo óptico do cristal uniaxial de Niobato de Lítio, e que $E_{A}=E_{A} \hat{z}$, o referencial $(x, y, z)$ é, de fato, o referencial dos eixos dielétricos principais.

Fazendo-se $n_{x}=n_{y}=n_{0}$ e $n_{z}=n_{e}$, da eq. (4.103) vem que o elipsóide de índices na ausência de campo elétrico aplicado, é dado por [26, 27]:

$$
\frac{x^{2}+y^{2}}{n_{o}^{2}}+\frac{z^{2}}{n_{e}^{2}}=1
$$


Tomando o tensor eletro-óptico correspondente e fazendo uso das equações (4.113), (4.114) e (4.115), o elipsóide de índices na presença de campo elétrico externo será descrito pela seguinte expressão [26, 27]:

$$
\begin{aligned}
\left(\frac{1}{n_{x}^{2}}-r_{22} E_{y}+r_{13} E_{z}\right) x^{2} & +\left(\frac{1}{n_{y}^{2}}+r_{22} E_{y}+r_{13} E_{z}\right) y^{2}+\left(\frac{1}{n_{z}^{2}}+r_{33} E_{z}\right) z^{2}+ \\
& +2 r_{51} E_{y} y z+2 r_{51} E_{x} x z-2 r_{22} E_{x} x y=1
\end{aligned}
$$

Considerando que a polarização do campo elétrico externo aplicado está dirigida segundo o eixo $z$ do cristal e o fato do cristal ser uniaxial, a equação anterior reduzse à forma [26, 27]:

$$
\left(\frac{1}{n_{o}^{2}}+r_{13} E_{z}\right) x^{2}+\left(\frac{1}{n_{o}^{2}}+r_{13} E_{z}\right) y^{2}+\left(\frac{1}{n_{e}^{2}}+r_{33} E_{z}\right) z^{2}=1
$$

ou seja

$$
\frac{x^{2}+y^{2}}{\left(n_{o}^{\prime}\right)}+\frac{z^{2}}{\left(n_{e}^{\prime}\right)}=1
$$

onde:

$$
\begin{aligned}
& n_{o}^{\prime}=\frac{n_{o}}{\sqrt{1+n_{o}^{2} r_{13} E_{z}}} \approx n_{o}\left[1-\frac{1}{2} n_{o}^{2} r_{13} E_{z}\right] \\
& n_{e}^{\prime}=\frac{n_{e}}{\sqrt{1+n_{e}^{2} r_{33} E_{z}}} \approx n_{e}\left[1-\frac{1}{2} n_{e}^{2} r_{33} E_{z}\right]
\end{aligned}
$$

Pode-se notar que, como não existem termos compostos em $x y, x z, y z$ na equação do elipsóide de índices do Niobato de Lítio, os eixos principais do elipsóide 
permanecem paralelos aos eixos $x, y, z$, quando é aplicado um campo elétrico externo ao longo da direção $z$.

\subsubsection{MODULADORES ELETRO-ÓPTICOS}

Moduladores eletro-ópticos são dispositivos passivos que traduzem diretamente para a forma luminosa as informações de uma determinada tensão. Eles não são transdutores, no sentido estrito do termo, pois não convertem energia da grandeza medida para o sinal e, por serem passivos, não geram a potência óptica que o porta [44].

Sendo assim, eles necessitam receber uma potência óptica de referência sobre a qual atuam, modulando (daí sua denominação) algumas de suas características como, intensidade, fase, espectro, padrão de polarização ou mesmo direção de polarização.

Como os fotodetectores, que são os responsáveis pela transformação dos sinais ópticos em elétricos, são sensíveis apenas à intensidade luminosa, ou potência óptica, todas as formas de modulação têm que ser convertidas, ao final, para modulação em intensidade. Isto é feito nos moduladores de fase por interferometria e nos moduladores de polarização por polarimetria.

É possível construir moduladores ópticos que sejam sensíveis a praticamente qualquer grandeza física, como, por exemplo à temperatura, pressão, deslocamento, vibração, campos eletromagnéticos, etc.

Dentre uma quantidade relativamente grande de moduladores possíveis, o interesse deste trabalho está voltado para os eletro-ópticos. Em tais moduladores aproveitase alguma propriedade de interação da luz propagante com um campo elétrico externo proporcionada pelo meio material, pelo qual ela se propaga.

A radiação luminosa tem suas características de propagação associadas às grandezas permissividade elétrica $(\varepsilon)$ e permeabilidade magnética $(\mu)$, do meio. 
Num meio material homogêneo, linear e isotrópico essas grandezas são quantidades escalares enquanto que nos meios não-homogêneos elas são funções escalares de ponto.

Nos meios anisotrópicos elas passam a ser tensores. Por fim, nos meios eletroópticos uma ou mais componentes do tensor dielétrico, ou de permissividade do meio, são funções da intensidade do campo elétrico no ponto.

Assim sendo, pode-se construir um modulador óptico sensível à tensão, submetendo ao campo elétrico por ela gerado, um meio material que apresente uma dependência de $(\varepsilon)$ com campos externos.

As manifestações resultantes desta dependência sobre a onda óptica propagante são chamadas de efeito eletro-óptico. Os principais efeitos eletro-ópticos empregados nos sensores ópticos de tensão são os de primeira ordem, chamado de efeito Pockels, e o de segunda ordem, chamado de efeito Kerr.

Os moduladores eletro-ópticos que empregam efeito Pockels são, as vezes, também chamados de células Pockels.

Quanto à direção de aplicação do campo elétrico, há duas configurações possíveis para os moduladores eletro-ópticos: a configuração longitudinal e a configuração transversal.

$\mathrm{Na}$ configuração longitudinal o campo elétrico é aplicado paralelamente à direção de propagação da luz. Para permitir a passagem do feixe luminoso os eletrodos devem ser feitos de material transparente ou vazados.

Normalmente são utilizados como eletrodos óxidos metálicos depositados, filmes metálicos, grades ou anéis aplicados às faces opostas do elemento sensor, como, por exemplo, o ilustrado na Figura 23, a seguir: 


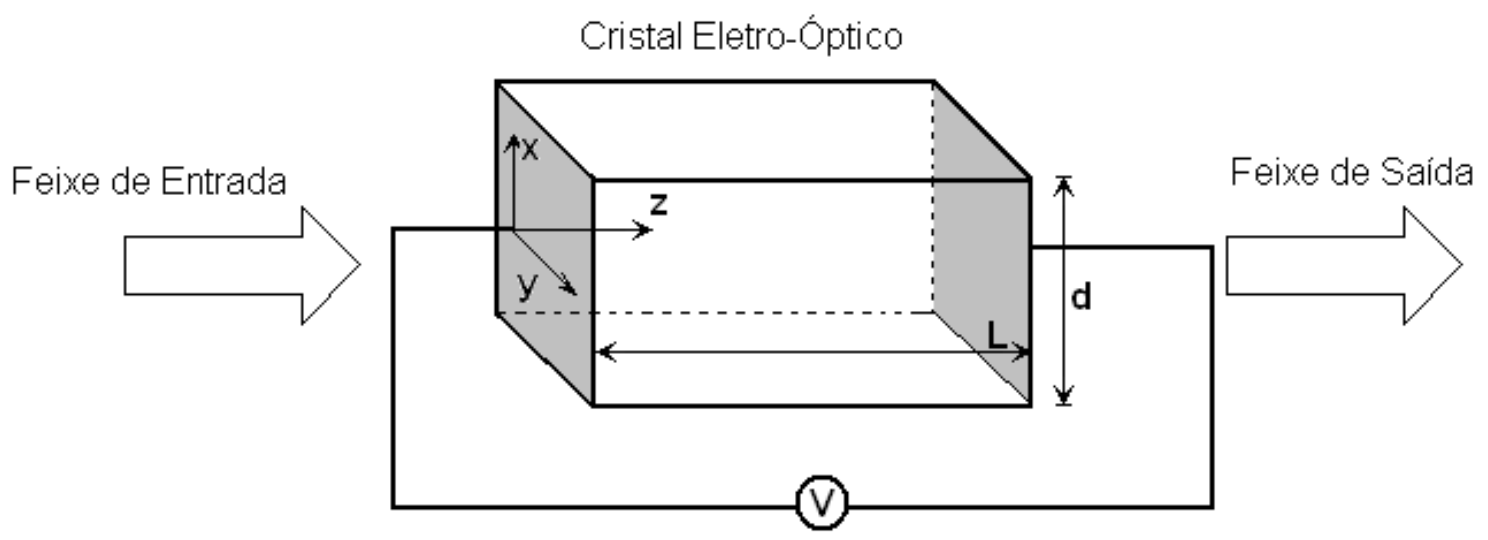

Figura 23 - Modulador eletro-óptico em configuração longitudinal.

$\mathrm{Na}$ configuração transversal o campo elétrico é aplicado numa direção perpendicular à de propagação da luz. Nessa configuração a aplicação do campo elétrico é simplificada, podendo ser feita também através de placas metálicas ou tintas condutoras aplicadas nas superfícies laterais do elemento sensor, como exemplifica a forma esquematizada na Figura 24, abaixo:

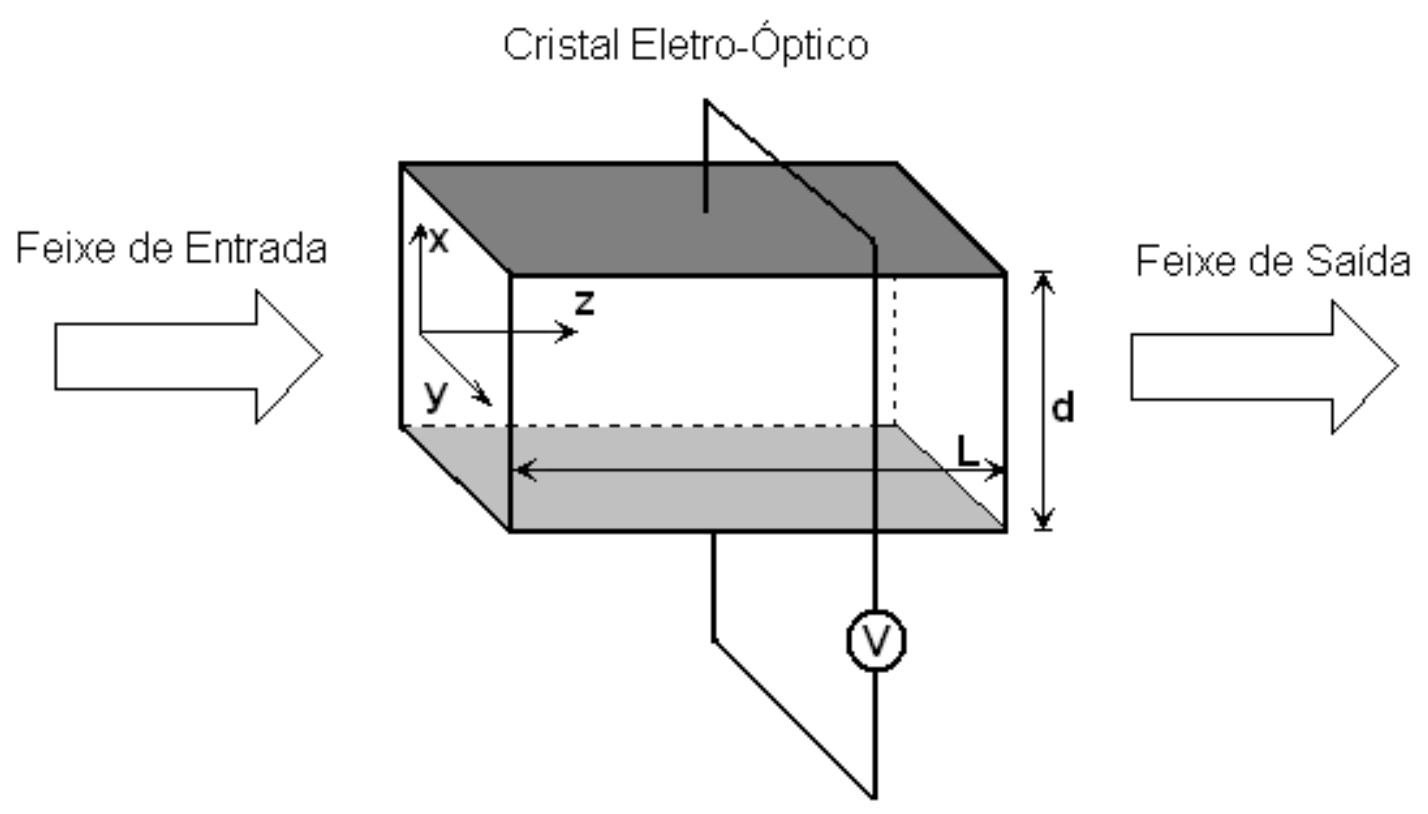

Figura 24 - Modulador eletro-óptico em configuração transversal. 


\subsubsection{MODULAÇÃO ELETRO-ÓPTICA}

Dentre os métodos de modulação existentes, destacam-se os moduladores de amplitude e os moduladores de fase, podendo ser, ambos, montados em configuração longitudinal ou transversal. Neste item, será dada ênfase somente à configuração transversal.

\subsubsection{MODULAÇÃO ELETRO-ÓPTICA DE AMPLITUDE EM CONFIGURAÇÃO TRANSVERSAL}

No caso da modulação transversal, o campo elétrico aplicado $\vec{E}_{A}$, encontra-se dirigido transversalmente à direção de propagação da luz no cristal. O esquema do modulador transversal está representado na Figura 25, onde $x, y, z$ representam os eixos dielétricos principais do elipsóide de índices com campo elétrico aplicado nulo (o eixo $z$ é o eixo óptico).

Para o cristal de Niobato de Lítio, com campo elétrico externo aplicado na direção do eixo óptico, $\vec{E}_{A}=E_{A} \vec{u}_{z}$, o elipsóide inicial transforma-se num novo, caracterizado pelas direções $x^{\prime}, y^{\prime}, z^{\prime}$ indicadas na Figura 25 e são definidos, segundo [26, 27], onde se especificam os novos índices de refração, $n_{x}^{\prime}, n_{y}^{\prime}, n_{z}^{\prime}$.

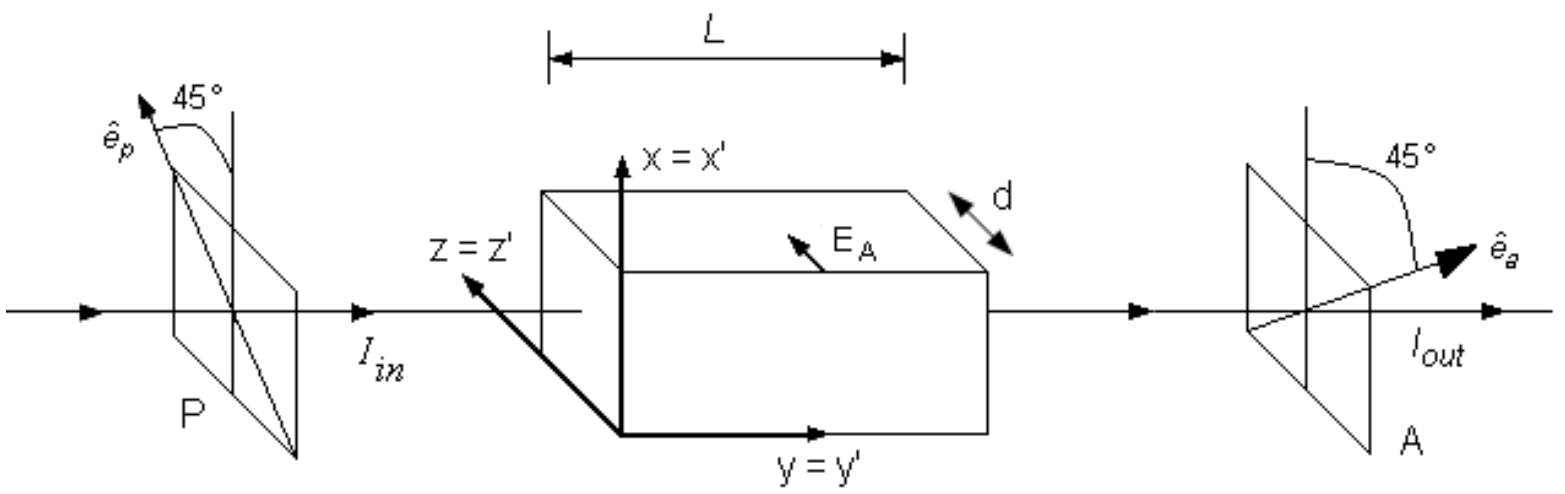

Figura 25 - Configuração do modulador eletro-óptico transversal, incluindo um cristal de $\mathrm{LiNbO}_{3}$ um par de polarizadores cruzados. O campo elétrico externo aplicado, paralelo ao eixo óptico do cristal, é transversal à direção de propagação da luz. 
Sendo $\vec{E}_{i n}$ a amplitude do campo elétrico do feixe óptico de frequência $\omega$, incidente sobre a célula Pockels, tem-se:

$$
\vec{E}_{i n}=E_{i n} e^{i \omega t} \hat{e}_{p}
$$

onde

$$
\hat{e}_{p}=\frac{1}{\sqrt{2}}[\hat{x}+\hat{z}]
$$

A intensidade luminosa correspondente a $E_{\text {in }}$ será dada por:

$$
I_{\text {in }}=\vec{E}_{i n} \cdot \vec{E}_{i n}^{*}
$$

Mesmo após se aplicar o campo elétrico externo, o eixo óptico da célula Pockels é o eixo $z$. O feixe óptico $\vec{E}_{\text {in }}$ excita uma onda polarizada segundo a direção de $\hat{x}$ que se desloca com uma constante de propagação $\beta_{0}=n_{0}^{\prime} k_{0}$ e uma onda polarizada segundo a direção de $\hat{z}$ que se desloca com uma constante de propagação $\beta_{e}=n_{e}^{\prime} k_{0}$. Logo, na saída da célula Pockels, tem-se, [23, 26, 27]:

$$
\vec{E}=\frac{E_{i n}}{\sqrt{2}}\left[e^{-i\left(n_{0}^{\prime} k_{0} L\right)} \hat{x}+e^{-i\left(n_{e}^{\prime} k_{0} L\right)} \hat{z}\right]
$$

e na saída do polarizador analisador, o campo óptico $\vec{E}_{\text {out }}$ é dado por

$$
\vec{E}_{\text {out }}=E_{\text {out }} \hat{e}_{a}=\vec{E} \cdot \hat{e}_{a}
$$

onde:

$$
\hat{e}_{a}=\frac{1}{\sqrt{2}} \hat{x}-\frac{1}{\sqrt{2}} \hat{z}
$$


e com a utilização das equações (4.126) e (4.127), obtém-se [26, 27]:

$$
E_{\text {out }}=\frac{E_{\text {in }}}{2}\left[e^{-i\left(n_{o}^{\prime} k_{0} L\right)}-e^{-i\left(n_{e}^{\prime} k_{0} L\right)}\right]
$$

Admitindo que, por definição, tem-se [23, 26, 27]:

$$
\Gamma=k_{0} L\left(n_{o}^{\prime}-n_{e}^{\prime}\right)
$$

e

$$
\varphi=\frac{1}{2} k_{0} L\left(n_{o}^{\prime}+n_{e}^{\prime}\right)
$$

resultando:

$$
e^{-i\left(n_{o}^{\prime} k_{0} L\right)}=e^{-i \varphi} \cdot e^{-i \Gamma / 2}
$$

e

$$
e^{-i\left(n_{e}^{\prime} k_{0} L\right)}=e^{-i \varphi} \cdot e^{i \Gamma / 2}
$$

Utilizando as eq. (4.131) e (4.132), a eq. (4.128) assume a forma [23, 26, 27]:

$$
E_{\text {out }}=\frac{E_{\text {in }}}{2} e^{-i \varphi}\left[e^{-i \Gamma / 2}-e^{i \Gamma / 2}\right]
$$

ou seja,

$$
E_{\text {out }}=-i E_{i n} e^{-i \varphi} \cdot \operatorname{sen}\left(\frac{\Gamma}{2}\right)
$$

Definindo, 


$$
I_{\text {out }}=\vec{E}_{\text {out }} \cdot \vec{E}_{\text {out }}^{*}=\left|E_{\text {out }}\right|^{2}
$$

para a intensidade luminosa associada a $E_{\text {out }}$, assim, pode-se escrever, [23, 26, 27]:

$$
I_{\text {out }}=I_{\text {in }} \operatorname{sen}^{2}\left(\frac{\Gamma}{2}\right)
$$

Definindo $T$ como sendo a transmissividade da célula Pockels mostrada na Figura 25 , tem-se [23, 26, 27]:

$$
T=\frac{I_{\text {out }}}{I_{\text {in }}}=\operatorname{sen}^{2}\left(\frac{\Gamma}{2}\right)
$$

Aplicando-se uma tensão modulante $V(t)=V_{m} \operatorname{sen}\left(\omega_{m} t\right)$ entre a face $z=0$ e a face $z=d$ da célula Pockels, pode-se determinar $T$, substituindo-se as eqs. (4.120) e (4.121) na eq. (4.129). Obtém-se o atraso diferencial de fase [26, 27]:

$$
\Gamma=\Gamma_{o}+\frac{1}{2} k_{0} L\left[n_{e}^{3} r_{33}-n_{o}^{3} r_{13}\right] E_{A}
$$

em que

$$
\Gamma_{0}=k_{0} L\left[n_{0}-n_{e}\right]
$$

é a componente passiva do atraso de fase.

Considerando que o campo elétrico aplicado sobre a célula Pockels, $E_{A}$, é uniforme entre $z=0$ e $z=d$, pode-se introduzir a tensão $V(t)$ tal que [26, 27]: 


$$
V(t)=E_{A}(t) d
$$

Nestas condições, a eq. (4.139), torna-se, [26]:

$$
\Gamma(t)=\Gamma_{0}+\pi \frac{V(t)}{V_{\pi}}
$$

onde $V_{\pi}$ é a tensão $V(t)$ tal que, $\Gamma(t)-\Gamma_{0}=\pi$, e é dada por [26, 27]:

$$
V_{\pi}=\frac{\lambda_{0}}{n_{e}^{3} r_{33}-n_{o}^{3} r_{13}}\left(\frac{d}{L}\right)
$$

onde:

$V_{\pi}$ é chamada de tensão de meia-onda.

É possível acrescentar um atraso de fase fixo adicional ao sistema. Para isso, duas alternativas estão disponíveis. A primeira consiste na introdução de uma placa retardadora adicional entre a célula Pockels e o analisador, acrescentando assim, um atraso de fase fixo ao atraso diferencial passivo de fase. A segunda alternativa consiste em colocar em série com a tensão modulante uma tensão contínua de polarização (bias), e desta forma, ter-se-ia [26, 27]:

$$
V(t)=V_{c c}+V_{m} \operatorname{sen}\left(\omega_{m} t\right)
$$

\subsubsection{MODULAÇÃO ELETRO-ÓPTICA DE FASE}

A modulação de fase constitui uma operação fundamental no controle dos dispositivos eletro-ópticos. A variação de índice de refração, induzida por um campo elétrico externo, produz uma variação de fase na onda luminosa que se propaga num guia de ondas dielétrico pertencente ao dispositivo. Adicionalmente, o 
modulador de fase é um elemento essencial de um grande conjunto de estruturas mais complexas, como por exemplo, os moduladores interferométricos. A configuração do modulador é a mesma que foi apresentada na Figura 25, exceto que o polarizador $P$ está agora, alinhado com o eixo $x^{\prime}$ e o analisador foi retirado. Nestas condições o campo elétrico da onda luminosa que emerge do cristal tem polarização linear segundo a direção $x$ ' é dado por [26, 27]:

$$
\vec{E}_{\text {out }}=E_{\text {out }} \vec{u}_{x}
$$

onde:

$$
E_{\text {out }}=E_{i n} e^{-i k_{0} L n_{x}^{\prime}} \text { e } n_{x}^{\prime}=n_{o}+n_{o}^{3} r E_{A} / 2
$$

Assim, se o campo da luz incidente for da forma $E_{i n}(t)=E_{i n} \cos (\omega t)$ e se o campo modulante for $E_{A}(t)=E_{A} \operatorname{sen}\left(\omega_{A} t\right)$, de acordo com a eq. (4.144), a onda luminosa na saída exibirá um campo elétrico dado por [26, 27]:

$$
E_{\text {out }}(t)=E_{\text {in }} \cos \left[\omega t-k_{0} L n_{x}^{\prime}\right]
$$

ou

$$
E_{\text {out }}(t)=E_{\text {in }} \cos \left[\omega t-k_{0} L\left(n_{o}+n_{o}^{3} r \frac{E_{A}}{2} \operatorname{sen}\left(\omega_{A} t\right)\right)\right]
$$

Obtém-se, portanto, um campo resultante cuja fase vem modulada por [26, 27]:

$$
E_{\text {out }}(t)=E_{\text {in }} \cos \left[\omega t-\delta \operatorname{sen}\left(\omega_{a} t\right)-\varphi_{0}\right]
$$

onde:

$$
\varphi_{0}=\omega L n_{0} / c \text { é a fase estática. }
$$


O índice de modulação $\delta$ é proporcional ao valor máximo do campo elétrico aplicado, podendo ser escrito como [26, 27]:

$$
\delta=\frac{\omega n_{O}^{3} r E_{A} L}{2 c}=\frac{\pi n_{o}^{3} r E_{A} L}{\lambda_{0}}
$$




\section{MATERIAIS E MÉTODOS}

As motivações que deram origem aos objetivos deste trabalho foram identificadas num estudo realizado ainda no mestrado do autor, que teve como finalidade subsidiar e apoiar as decisões a serem tomadas quanto às alternativas de implementação de um protótipo de TPO, em desenvolvimento no LSO, baseado na técnica de WLI com recuperação eletro-óptica.

No protótipo de TPO de alta tensão em configuração WLI citado, são utilizados dois interferômetros de birrefringência nos quais são introduzidos atrasos de fase fixos elevados.

Desta forma, o OPD resultante na saída do primeiro interferômetro, que é um modulador eletro-óptico Pockels próprio para ser submetido a elevadas tensões, também chamado de sensor primário, é sempre muito maior do que o comprimento de coerência da fonte óptica, o que garante que a informação esteja codificada somente no espectro da luz e não em sua intensidade.

$\mathrm{Na}$ Figura 26, a seguir, ilustra-se o esquema do modulador eletro-óptico utilizado na célula sensora de alta tensão do TPO e, em sua essência, é um interferômetro de birrefringência.

Assume-se que as duas componentes da luz incidente, que estão polarizadas paralelamente aos eixos x e y, são dois feixes separados da mesma onda luminosa e com intensidades $I_{x}$ e $I_{y}$, respectivamente.

Cada uma dessas componentes viaja ao longo de um caminho de mesmo comprimento $L$, mas com diferentes índices de refração, $n_{x}$ e $n_{y}$, respectivamente. A diferença entre esses dois índices de refração $(\Delta n)$ é a birrefringência. 


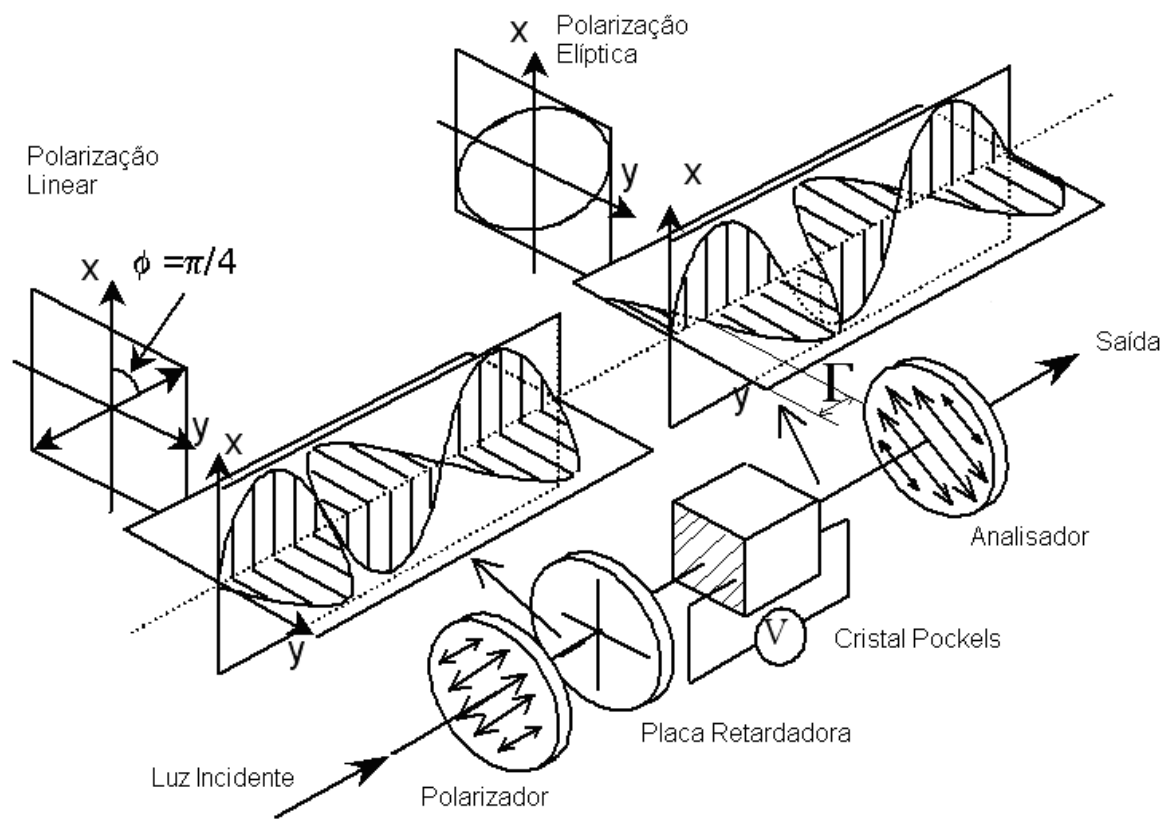

Figura 26 - Princípio do efeito eletro-óptico e do modulador eletro-óptico longitudinal.

A célula de alta tensão utilizada no transformador óptico construído utiliza um cristal de Germanato de Bismuto e este não apresenta birrefringência natural. Com a introdução de uma lâmina retardadora (lâmina de Niobato de Lítio - corte-X), que apresenta uma birrefringência própria, $\Delta n_{c}$, a birrefringência total será dada pela soma das birrefringências, natural (da lâmina retardadora) e eletricamente induzida, por [7]:

$$
\Delta n=\underbrace{\Delta n_{C}}_{\text {fixa }}+\underbrace{n_{o}^{3} r_{41} \frac{V}{L}}_{\text {induzida }}
$$

onde:

$\Delta n_{c}$ é a birrefringência da lâmina retardadora,

$n_{o}$ é o índice de refração ordinário do cristal,

$V / L$ é a intensidade do campo elétrico aplicado e

$r_{41}$ é o coeficiente eletro-óptico relevante do cristal. 
Portanto, uma diferença de fase óptica $\Gamma(=\Delta \phi)$ é introduzida entre as duas componentes da luz na saída do cristal e é dada por [7]:

$$
\Gamma=\Delta \phi(t)=\Delta \phi_{C}+\frac{2 \pi}{\lambda} n_{o}^{3} r_{41} V
$$

onde:

$\Delta \phi_{C}=\frac{2 \pi}{\lambda} \Delta n_{C} L$ é o atraso de fase óptico fixo introduzido pela lâmina retardadora.

A diferença de caminho óptico $\Delta L$ correspondente a este atraso de fase óptico é dado por [7]:

$$
\Delta L=\frac{\lambda}{2 \pi} \Delta \phi(t)
$$

A partir das equações (5.2) e (5.3), obtém-se [7]:

$$
\Delta L=\frac{\lambda}{2 \pi} \Delta \phi_{C}+n_{o}^{3} r_{41} V
$$

logo:

$$
\Delta L=\Delta L_{c}+n_{o}^{3} r_{41} V
$$

onde:

$$
\Delta L_{C}=\frac{\lambda}{2 \pi} \Delta \phi_{C} \quad \text { está associado a OPD introduzida pela lâmina }
$$
retardadora. 
Para recuperar o sinal interferométrico, um interferômetro recuperador deve ser colocado em série com a fibra óptica, no caminho de volta do sistema sensor. O atraso de fase dado neste interferômetro deve ser igual ao atraso de fase imposto no interferômetro sensor, ou seja, a célula primária (célula de alta tensão). A diferença de fase $\Delta \phi$ da luz introduzida na célula de alta pela lâmina retardadora de $\mathrm{LiNbO}_{3}$ é dada por [7]:

$$
\Delta \phi=\frac{2 \pi}{\lambda_{S L D}}\left|n_{e}-n_{O}\right| L
$$

onde:

$\lambda_{S L D}=1550 \mathrm{~nm}$, é o comprimento de onda central da fonte luminosa,

$n_{e}-n_{o}$ é a birrefringência (diferença entre os índices de refração extraordinário e ordinário do Niobato de Lítio) e

L é a espessura da lâmina de Niobato de Lítio, que, no caso, é de $1 \mathrm{~mm}$.

Assim, a partir da eq. (5.6), obtém-se:

$$
\Delta \phi_{C e I_{-} \text {Alta }}=\frac{2 \pi}{1560 \times 10^{-9}}|2,286-2,200| \times 0,001=110,25 \pi \mathrm{rad}
$$

No protótipo de TPO construído o interferômetro recuperador anterior foi baseado num modulador eletro-óptico volumétrico de birrefringência, conforme ilustrado na Figura 27, a seguir: 


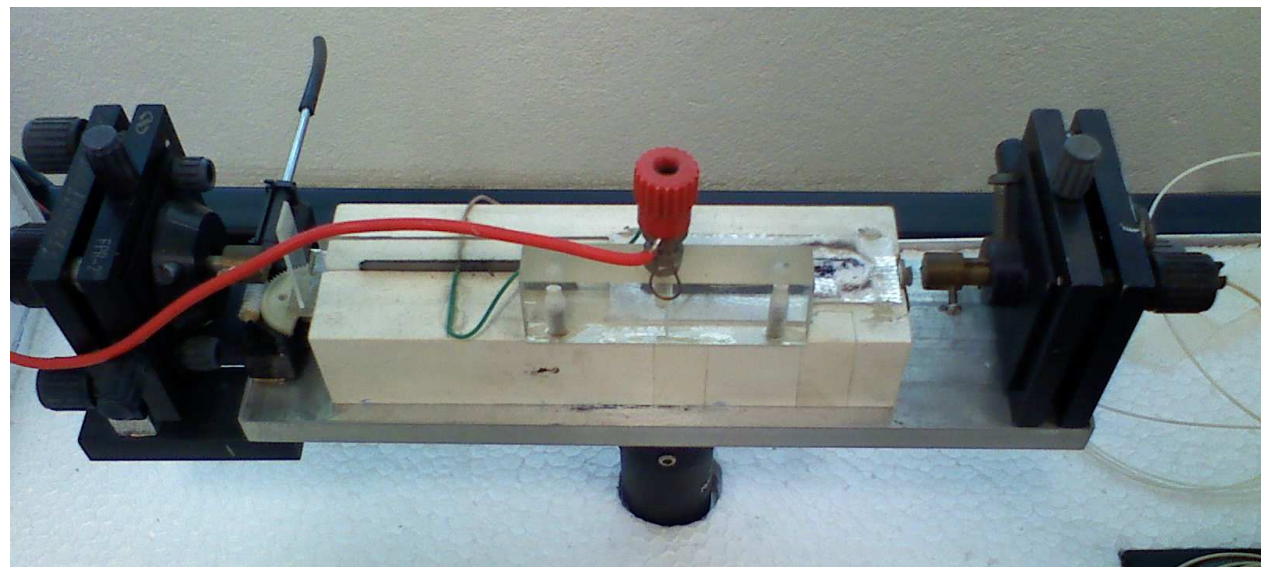

Figura 27 - Modulador eletro-óptico de birrefringência volumétrico.

O interferômetro recuperador em montagem volumétrica apresentado, que é descrito em detalhes no item 5.4.3, é composto por uma lâmina retardadora seguido de duas lâminas de Niobato de Lítio (cruzadas) inseridas entre dois polarizadores alinhados e conectados em série através de fibras ópticas no caminho de volta do sistema interferométrico sensor. Por se tratar de uma montagem volumétrica, este interferômetro recuperador birrefringente apresentou algumas desvantagens, como por exemplo: elevada tensão de meia onda $\left(V_{\pi} \approx 57,7 \mathrm{~V}\right)$, sensibilidade a vibrações mecânicas, baixa imunidade eletromagnética, dificuldades de conectorização, sensibilidade à variação da temperatura, montagem volumétrica e delicada, necessidade de um preciso alinhamento axial e angular entre os componentes ópticos, etc.

As desvantagens citadas indicaram claramente a necessidade do desenvolvimento de uma solução alternativa para implementar o interferômetro recuperador que as eliminasse ou, pelo menos, as minimizasse. No estudo realizado, considerou-se que a principal desvantagem a ser reduzida é o elevado valor de $V_{\pi}$ do modulador, uma vez que este parâmetro dificulta a implementação da unidade de processamento eletrônico de sinais, que trabalha conectada ao interferômetro recuperador. Para atingir tal objetivo, no estudo e desenvolvimento do interferômetro recuperador eletro-óptico implementado neste trabalho foram realizadas as etapas descritas a seguir. 


\subsection{ESTUDO SOBRE ALTERNATIVAS DE IMPLEMENTAÇÃO DE INTERFERÔMETROS RECUPERADORES BASEADOS EM SENSORES ELETRO-ÓPTICOS DE BAIXA TENSÃO}

Para a implementação do interferômetro recuperador de baixa tensão de meia onda algumas alternativas foram encontradas, dentre elas podem-se destacar: interferômetros birrefringentes (como o utilizado no trabalho de mestrado), interferômetros construídos a partir de fibras eletro-ópticas (com técnicas de poling térmico e poling por ultravioleta) [45], interferômetros com bobina de fibra óptica enrolada sobre transdutores piezoelétricos cilíndricos [45] e interferômetros baseados em óptica integrada [24, 25, 28].

Entre as possíveis topologias empregadas para a construção de moduladores eletroópticos baseados em óptica integrada encontram-se: 0 modulador canal birrefringente, o interferômetro de Mach-Zehnder e o modulador eletro-óptico em Y $[24,25]$.

Dentre as topologias acima citadas, a última mostrou-se mais atrativa, pois dispositivos como os descritos nas outras não foram encontrados disponíveis comercialmente. Desta forma, optou-se por construir um interferômetro de Michelson a partir de um dispositivo modulador eletro-óptico em óptica integrada composto por uma junção em $Y$ com pigtails nos três acessos. Para tanto são necessárias várias etapas de fabricação, tais como: cortar os pigtails dos acessos de saída do $\mathrm{Y}$, no menor comprimento possível, para compor os braços do interferômetro, igualar os comprimentos dos pigtails (para reproduzir a configuração de interferômetro com braços desbalanceados) e, caso seja necessário, alterar a refletividade das terminações dos pigtails de saída por meio da deposição de camadas refletoras em suas faces. Os estudos e desenvolvimentos realizados para efetuar as etapas citadas são descritos a seguir. 


\subsection{ESCOLHA DO MODULADOR ELETRO-ÓPTICO RECUPERADOR}

O dispositivo modulador eletro-óptico comercial escolhido para implementar o novo interferômetro recuperador para o protótipo de TPO foi o chip óptico integrado multifuncional (IOC - $\mathrm{LiNbO}_{3}$ multi-function integrated optical chip), modelo PMD1333-I, fabricado pela empresa Beijing SWT Optical Communication Technology Co. Ltd., mostrado na Figura 28, (o datasheet deste dispositivo está disponível no Anexo 3). Este dispositivo é um modulador de fase eletro-óptico construído com guias de onda em Niobato de Lítio e eletrodos metálicos depositados na superfície do substrato, nas laterais dos guias de onda conectados eletricamente em configuração push-pull. As características principais deste dispositivo são: resposta rápida, baixas perdas por inserção, pequenas dimensões, baixo peso, montagem mecanicamente estável, facilidade de conectorização, excelente imunidade eletromagnética e excelente estabilidade térmica. Tais características são bem atrativas para o desenvolvimento deste trabalho.

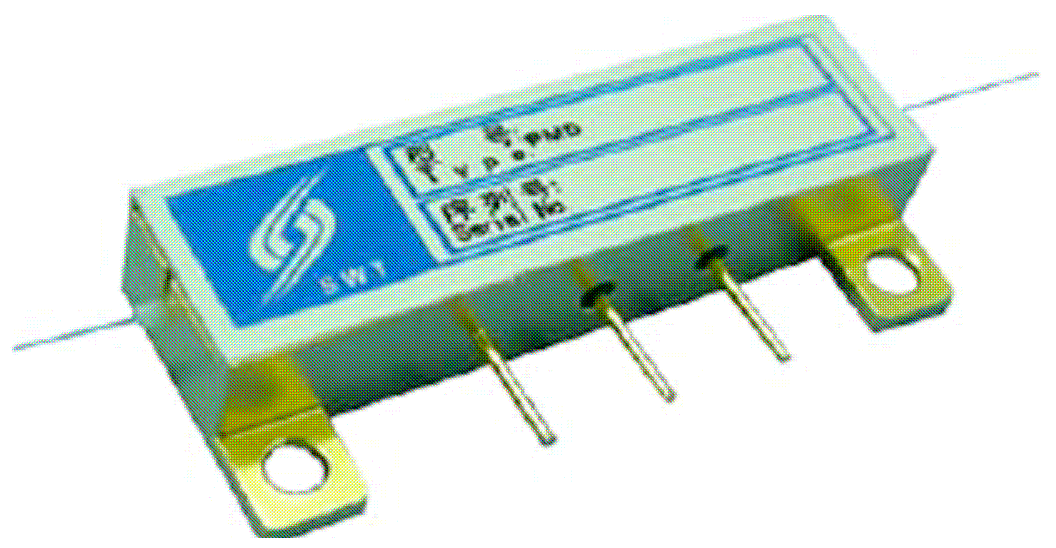

Figura 28 - Chip óptico integrado multifuncional (IOC - $\mathrm{LiNbO}_{3}$ multi-function integrated optical chip), modelo PMD1333-I [Anexo 3].

A opção por este dispositivo, que é um produto disponível no mercado, se deu por várias razões, entre elas pode-se destacar: custo relativamente baixo, pequenas dimensões, baixo valor de tensão de meia onda ( $\left.V_{\pi} \cong 4,5 V @ 1550 \mathrm{~nm}\right)$, facilidade de integração com o sistema óptico e facilidade de conectorização. 
Com este dispositivo, iniciou-se a montagem de um interferômetro de Michelson desbalanceado. Nesta etapa foram ajustados os comprimentos dos braços do modulador (comprimento físico das fibras ópticas de saída) de forma que a diferença de caminho óptico introduza uma diferença de fase $\Delta \phi$ desejada.

Para que o interferômetro recuperador introduza o mesmo atraso de fase da célula de alta-tensão $\Delta \phi_{C e l-A l t a}$, dado na equação (5.7), ele deve introduzir uma diferença de caminho óptico $\Delta L^{\prime}$, dada por:

$$
\Delta L^{\prime}=\frac{\lambda}{2 \pi}\left(\frac{\Delta \phi_{C e l} \text { Alta }}{n_{O}}\right)=\frac{1560 \times 10^{-9}}{2 \pi}\left(\frac{110,25 \pi}{1,44520}\right)=59,5 \mu \mathrm{m}
$$

A luz que transita pelos braços do modulador, mostrado na Figura 34, devido à reflexão nas extremidades das fibras ópticas, experimenta uma diferença de caminho óptico de $2 \Delta L$. Portanto, para que o valor da diferença de caminho óptico seja o mesmo introduzido pela célula primária, o valor de $\Delta L$ ' deve ser a metade deste valor.

De posse dessas informações, pode-se iniciar a etapa de polimento das fibras para que a diferença de caminho óptico no interferômetro recuperador seja alcançada. Esta etapa foi realizada seguindo os procedimentos abaixo:

1) Posicionar e fixar o modulador em $Y$ a óptica integrada (OI) em um suporte apropriado para o polimento;

2) Medir o comprimento das fibras de saída do modulador OI (sensoras) e cortá-las de 2 a $4 \mathrm{~cm}$ maiores que o tamanho do suporte a qual está fixado 0 modulador;

3) Decapar as fibras ópticas de saída do modulador Ol, mecanicamente (utilizando um decapador apropriado) ou quimicamente (por exemplo 
utilizando um banho de diclorometano $\left(\mathrm{CH}_{2} \mathrm{Cl}_{2}\right)$ por 1,5 minuto e limpando, posteriormente, com acetona);

4) Clivar as duas fibras de saída do modulador Ol simultaneamente (utilizando um clivador apropriado ou uma "machadinha);

5) Conectar o acesso de entrada do interferômetro sensor com a fonte de luz (SLD);

6) Verificar a potência óptica obtida na saída do interferômetro sensor;

7) Decapar e clivar os terminais de acesso de um acoplador direcional;

8) Emendar a fibra de saída do interferômetro sensor ao acesso de entrada do acoplador direcional (otimizar a emenda monitorando a potência de saída num dos acessos sem uso do lado contrário do acoplador);

9) Emendar a fibra de entrada do modulador Ol com uma das fibras de acesso do acoplador direcional do lado contrário à fibra conectada ao interferômetro sensor (otimizar a emenda monitorando a potência de saída num dos terminais de saída do modulador);

10) Conectar o medidor de potência óptica ao terminal de acesso de saída do acoplador direcional (do mesmo lado da fibra ligada ao interferômetro sensor) e verificar a presença de potência óptica refletida residual;

11) Aplicar ao modulador tensão senoidal com $V_{P P} \cong 3,5 \mathrm{~V}$ somada a uma componente contínua entre -15 e +15 Volts, observando a saída no medidor de potência óptica num osciloscópio. Verificar se é possível observar a modulação do sinal óptico e se é possível localizar o pico central da curva interferométrica. Se for possível operar desta forma, seguir diretamente para o passo 15;

12) Fixar o modulador à base para polimento de fibras;

13) Polir levemente a ponta de uma das fibras sensoras do modulador; 
14) Voltar ao passo 11;

15) Retirar o modulador da base de polimento, proteger mecanicamente as pontas das fibras sensoras e espelhar as pontas das fibras;

16) Remover a proteção mecânica e limpar as pontas das fibras;

17) Verificar o funcionamento do conjunto repetindo o passo 11 ;

18) Proteger com verniz as pontas de fibra óptica espelhadas do modulador Ol;

19) Fixar o modulador à base definitiva do interferômetro recuperador;

20) Testar o conjunto.

Conforme descrito, após acertar os comprimentos das fibras ópticas de saída do modulador eletro-óptico integrado foi feita a metalização das extremidades de suas fibras de saída do Y. A Figura 29, a seguir, ilustra o esquema do modulador eletroóptico indicando uma diferença entre os comprimentos de seus braços de $\Delta L$.

Em seguida, essas fibras ópticas foram metalizadas utilizando solução de prata, com o objetivo de melhorar o desempenho do modulador eletro-óptico Ol como um interferômetro de Michelson desbalanceado. Esta metalização deu-se através de uma técnica muito conhecida entre os astrônomos amadores e que será descrita na seção 5.3 , a seguir.

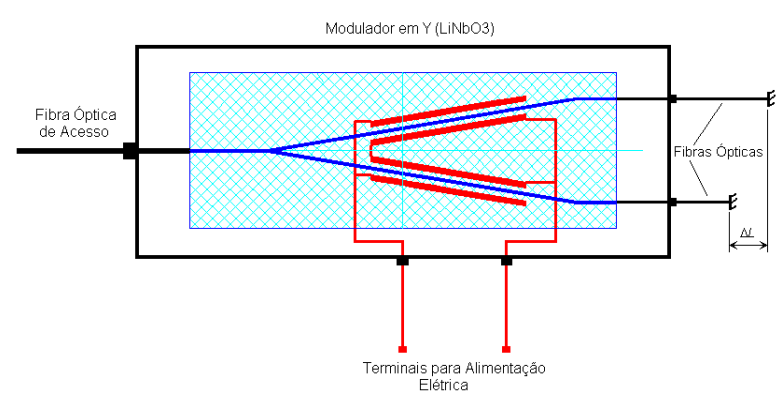

Figura 29 - Representação esquemática do modulador eletro-óptico ilustrando as fibras de saída cm seus comprimentos ajustados para uma diferença de caminho óptico $\Delta L$. 


\subsection{METALIZAÇÃO DAS FIBRAS ÓPTICAS DO MODULADOR ELETRO- ÓPTICO RECUPERADOR PELA TÉCNICA DE REDUÇÃO DA PRATA ATRAVÉS DA GLICOSE ${ }^{1}$}

$\mathrm{Na}$ metalização da extremidade das fibras ópticas de saída do modulador $\mathrm{Y}$ em óptica integrada, foi utilizada a técnica de metalização por solução de Prata. Esta técnica faz uso do Reagente de Tollens e é descrita a seguir.

O Reagente de Tollens é uma solução amoniacal de Nitrato de Prata muito utilizada para diferenciar aldeídos de cetonas. Sua composição química é dada pela fórmula abaixo:

$$
\left[A g\left(\mathrm{NH}_{3}\right)_{2}\right] \mathrm{OH}
$$

Esta solução, devido ao seu alto poder de redução, reage apenas com os aldeídos e não com as cetonas. Nessa reação, os aldeídos reduzem o cátion da prata $\left(\mathrm{Ag}^{+}\right)$que compõe o reagente. Isso ocasiona a formação de prata metálica que é depositada nas paredes do recipiente. Pode ser preparada a partir da mistura do Nitrato de Prata $\left(\mathrm{AgNO}_{3}\right)$ com Hidróxido de $\mathrm{Sódio}^{2}(\mathrm{NaOH})$ em solução aquosa com Amônia $\left(\mathrm{NH}_{3}\right)$. Esta solução é amplamente utilizada na fabricação de espelhos e na identificação de compostos orgânicos. Explora-se nesta atividade a redução do íon de Prata $\left(A g^{+}\right)$à Prata sólida pela glicose, com a finalidade de produzir uma superfície espelhada com prata na extremidade das fibras ópticas do modulador eletro-óptico da célula recuperadora de baixa tensão. Para tal, inicia-se o processo com a preparação do Reagente de Tollens [46, 47].

\footnotetext{
${ }^{1}$ Também conhecida como glucose e dextrose.

${ }^{2}$ Nome comercial: Soda Cáustica.
} 
Como foi dito anteriormente, o Reagente de Tollens consiste basicamente em uma solução amoniacal de Nitrato de Prata obtida a partir de uma reação entre as soluções de Nitrato de Prata e Hidróxido de Sódio (pode-se também utilizar o Hidróxido de Potássio) com a formação de óxido de Prata que, por sua vez, reage com o amoníaco originando o íon complexo diaminoprata $\left[\mathrm{Ag}\left(\mathrm{NH}_{3}\right)_{2}\right]^{+}$. As reações que ocorrem na preparação do Reagente de Tollens podem ser traduzidas pelas seguintes equações químicas [46, 47]:

$$
\begin{gathered}
2 \mathrm{AgNO}_{3}(\mathrm{aq})+2 \mathrm{NaOH}(\mathrm{aq}) \rightarrow \mathrm{Ag}_{2} \mathrm{O}(\mathrm{s})+\mathrm{H}_{2} \mathrm{O}(I)+2 \mathrm{NaNO}_{3}(\mathrm{aq}) \\
\mathrm{Ag}_{2} \mathrm{O}(\mathrm{s})+4 \mathrm{NH}_{3}(\mathrm{aq})+\mathrm{H}_{2} \mathrm{O}(I) \rightarrow 2 \mathrm{Ag}\left(\mathrm{NH}_{3}\right)_{2} \mathrm{OH}(\mathrm{aq})
\end{gathered}
$$

onde:

$\mathrm{Ag}\left(\mathrm{NH}_{3}\right)_{2} \mathrm{OH}(\mathrm{aq})$ é o reagente de Tollens.

Após a preparação do Reagente de Tollens basta adicionar à mesma uma pequena quantidade de glicose. Esta substância, quando em contato com o Reagente de Tollens, oxida-se em um ácido carboxílico, reduzindo, por sua vez, o íon de prata do complexo $\left[\mathrm{Ag}\left(\mathrm{NH}_{3}\right)_{2}\right]^{+}$. Esta reação química pode ser traduzida pela seguinte equação [46, 47]:

$$
\begin{aligned}
& R-\mathrm{CHO}+2\left[\mathrm{Ag}\left(\mathrm{NH}_{3}\right)_{2}\right]^{+}(\mathrm{aq})+2 \mathrm{OH}^{-}(\mathrm{aq}) \rightarrow \\
& \rightarrow R-\mathrm{COOH}(\mathrm{aq})+2 \mathrm{Ag}(\mathrm{s})+4 \mathrm{NH}_{3}(\mathrm{aq})+\mathrm{H}_{2} \mathrm{O}(\mathrm{I})
\end{aligned}
$$

onde $\mathrm{R}=\mathrm{CH}_{3}$.

Esta reação é a essência do processo de fabricação de espelhos de Prata. A razão pela qual se adiciona uma solução de amoníaco à solução de Nitrato de Prata é para diminuir, da seguinte forma, o potencial de redução de eletrodo padrão do íon $\mathrm{Ag}^{+}$ $[46,47]$ : 


$$
\begin{array}{lc}
\mathrm{Ag}^{+}(\mathrm{aq})+\mathrm{e}^{-} \rightarrow \mathrm{Ag}(\mathrm{s}), & E_{0}=+0,799 \mathrm{~V} \\
\mathrm{Ag}\left(\mathrm{NH}_{3}\right)_{2}^{+}(\mathrm{aq})+\mathrm{e}^{-} \rightarrow \mathrm{Ag}(\mathrm{s})+2 \mathrm{NH}_{3}(\mathrm{aq}), & E_{0}=+0,373 \mathrm{~V}
\end{array}
$$

Nas equações apresentadas em (5.13) indicam-se que o amoníaco forma um complexo com o íon de $\mathrm{Ag}^{+}$, que é mais difícil de reduzir do que ele próprio. Com esta diminuição do potencial de redução de eletrodo padrão do íon de $\mathrm{Ag}^{+}$, formase um espelho de Prata de melhor qualidade [47].

Caso não se adicionasse a solução aquosa de amoníaco, o íon de $\mathrm{Ag}^{+}$seria reduzido tão rapidamente pela glicose que surgiria uma solução coloidal deste metal. Isto é, a solução se transformaria num líquido nublado e negro [47].

A adição da solução aquosa de Hidróxido de Sódio, além de servir para formar um intermediário que, ao reagir com a solução de amoníaco origina o complexo pretendido, serve também para tornar a mistura ainda mais básica, dado que a glicose oxida-se mais facilmente em meio básico. Este procedimento é dado pela equação abaixo [46]:

$$
\begin{aligned}
& \mathrm{CH}_{3}-\mathrm{CHO}(I)+2\left[\mathrm{Ag}\left(\mathrm{NH}_{3}\right)_{2}\right]^{+}(\mathrm{aq})+\mathrm{H}_{2} \mathrm{O}(I) \rightarrow \\
& \rightarrow 2 \mathrm{Ag}(\mathrm{s})+\mathrm{CH}_{3} \mathrm{COOH}(I)+4 \mathrm{NH}_{3}(\mathrm{aq})+2 \mathrm{H}^{+}(\mathrm{aq})
\end{aligned}
$$

onde:

(I), (s) e (aq) representam os estados líquido, sólido e aquoso, respectivamente.

Na preparação desta solução, deve-se evitar a possibilidade de criação do Fulminato de Prata $(A g O N C)$ que é um composto iônico de prata explosivo e sem nenhum valor prático no processo de metalização, porém, extremamente sensível. Assim, pequenas quantidades deste material podem causar extensos danos, seja pelos resíduos aquecidos da solução ou por estilhaços do recipiente que a contém, normalmente de vidro. 
A seguir, na Figura 30, apresenta-se uma sequência de figuras ilustrando os três processos principais da preparação da solução de Prata para metalização das fibras ópticas [47].

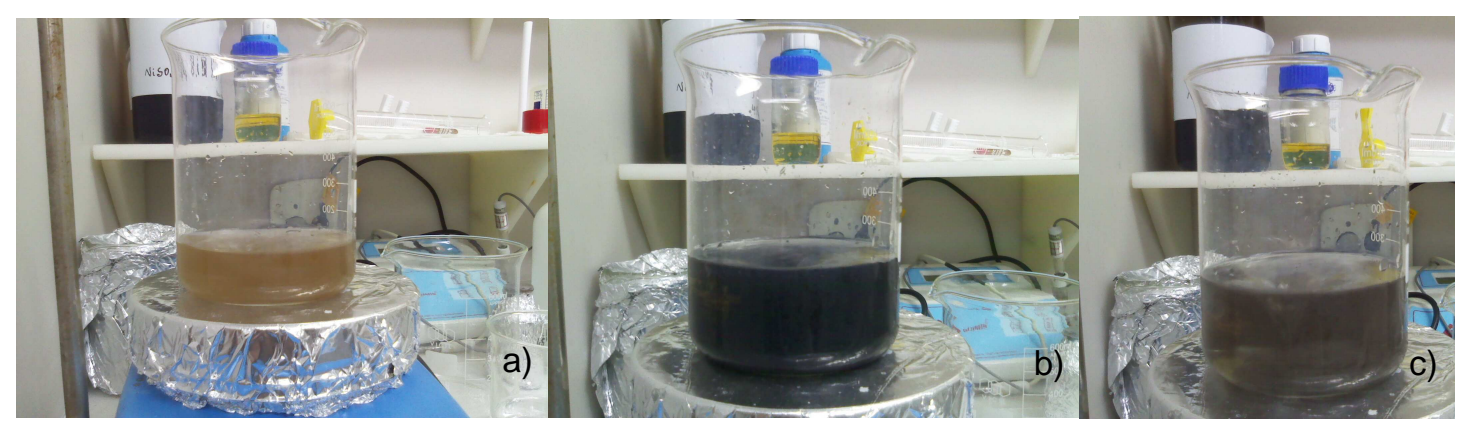

Figura 30 - Processos principais da preparação da solução de Prata. (a) O reagente de Tollens. (b) Hidróxido de Sódio adicionado ao Reagente de Tollens. (c) A solução final com aspecto de "chá fraco" após adição de Amônia.

O processo de fabricação da solução de Prata, como foi dito anteriormente, envolve a formação de gases perigosos e de subprodutos explosivos, por este motivo, esta etapa foi realizada no Laboratório de Sistemas Integráveis (LSI-USP), sob orientação de um técnico de laboratório.

Para a fabricação da solução de prata, foram necessários os seguintes materiais:

- Nitrato de Prata;

- Hidróxido de Potássio (ou Sódio);

- Dextrose;

- Cloreto de Estanho e

- Água deionizada.

s testes iniciais de metalização utilizando a solução de Prata foram realizados em lâminas de vidro (lâminas de microscópio) que, após alguns experimentos, em que se variou a concentração de dextrose, chegou-se a um resultado satisfatório, ou seja, a deposição de um espelho de boa qualidade.

A etapa seguinte consistiu em transferir este conhecimento para a metalização de fibras ópticas. Com a finalidade de conseguir experiência suficiente para a metalização final do modulador $Y$ em óptica integrada, ainda nesta etapa, foram 
feitos alguns testes adicionais em pedaços de fibras ópticas soltos, limpos e devidamente polidos. A metalização se deu através de um arranjo que permite acompanhar a taxa de Prata depositada na extremidade da fibra óptica medindo-se a quantidade de luz que retorna do sistema. A Figura 31, a seguir, ilustra este arranjo.

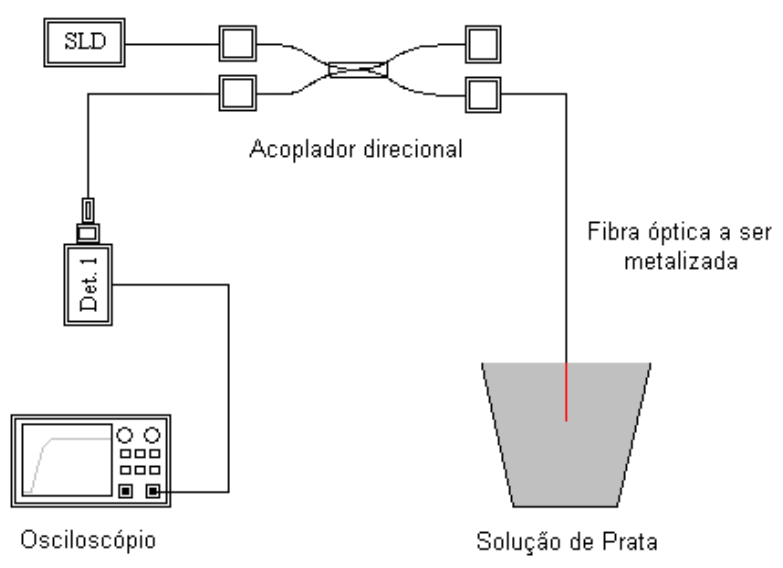

(a)

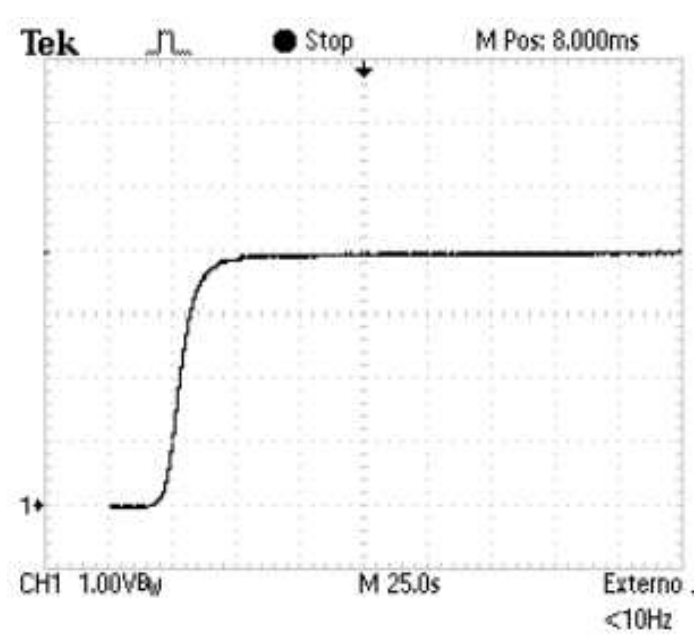

(b)

Figura 31 - (a) Arranjo experimental para metalização de extremidades de fibras ópticas. (b) Gráfico da potência óptica refletida pela fibra óptica.

Assim, com maior domínio da técnica de metalização, iniciou-se o processo de espelhamento da extremidade do modulador $Y$ em óptica integrada - o interferômetro recuperador. Para a metalização da fibra óptica foi necessária a preparação de sua superfície, ou seja, o polimento óptico da mesma. Este polimento foi feito através de um disco metálico apropriado, em que a fibra óptica a ser polida foi encaixada em um conector para fibra óptica nua (tipo SC) deslizando-o, em seguida, segundo a figura geométrica do número oito sobre uma superfície abrasiva, constituída de uma lixa apropriada com granulação muito fina. As lixas utilizadas para este fim possuem granulações da ordem de 3, 1, 0,5 e 0,05 micrômetro, sendo esta última utilizada para o polimento final da fibra óptica. Este arranjo é mostrado na Figura 32, a seguir. 


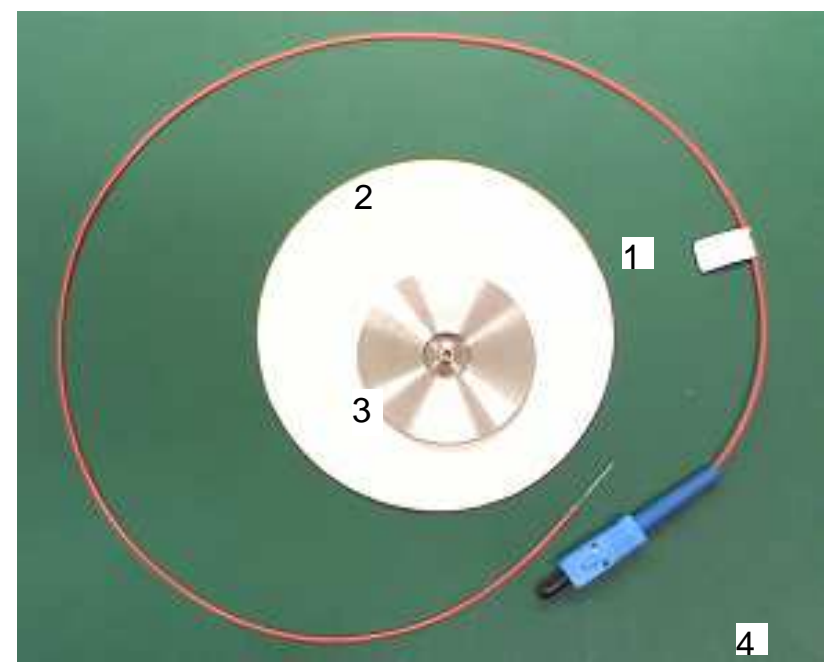

Figura 32 - Materiais para polimento da fibra óptica do modulador eletro-óptico integrado. (1) Fibra óptica, (2) lixa para polimento da fibra óptica, (3) disco metálico utilizado como suporte para o conector da fibra óptica e (4) superfície plana de apoio para polimento.

Uma vez polida a fibra óptica, o passo seguinte foi a sua metalização. No processo de metalização, algumas fibras ópticas foram utilizadas como teste (controle da metalização). Esta metalização se deu de forma tal que fosse possível injetar luz em um dos braços de um acoplador direcional e acompanhar o percentual de reflexão na extremidade da fibra óptica, a ser metalizada, conectada no outro braço, onde inicialmente só havia a reflexão de Fresnel, que foi utilizada como referência inicial. Neste arranjo, mostrado na Figura 31(a), injetou-se luz em um dos braços de um acoplador óptico e analisou-se, através de um fotodiodo ligado a um osciloscópio, o percentual de luz refletida pelo outro braço do acoplador, conforme mostra o gráfico da Figura 31(b). O melhor resultado obtido nesses testes foi de $77 \%$ de reflectividade e foram utilizadas as seguintes quantidades de material:

- $10 \mathrm{ml}$ de solução de prata (Reagente de Tollens) e

- $5 \mathrm{ml}$ de dextrose líquida. 
O processo de metalização, utilizando a solução de prata indicada anteriormente, mostrou-se extremamente rápido, durando o processo, aproximadamente 25 segundos, conforme mostra o gráfico da Figura 31(b).

Após a metalização, foi verificado que as fibras ópticas (tanto as fibras de teste como a fibras do modulador em Y) apresentavam, na região metalizada, pequenas granulações. Estas granulações são sobras do processo e foram facilmente removidas após lavagem com água destilada. As Figuras 33(a) e 33(b) mostram detalhes das fibras ópticas de teste antes e depois da lavagem.

As manchas que aparecem na fibra de teste da Figura 33(b) são oxidações devido à manipulação e devem ser evitadas.

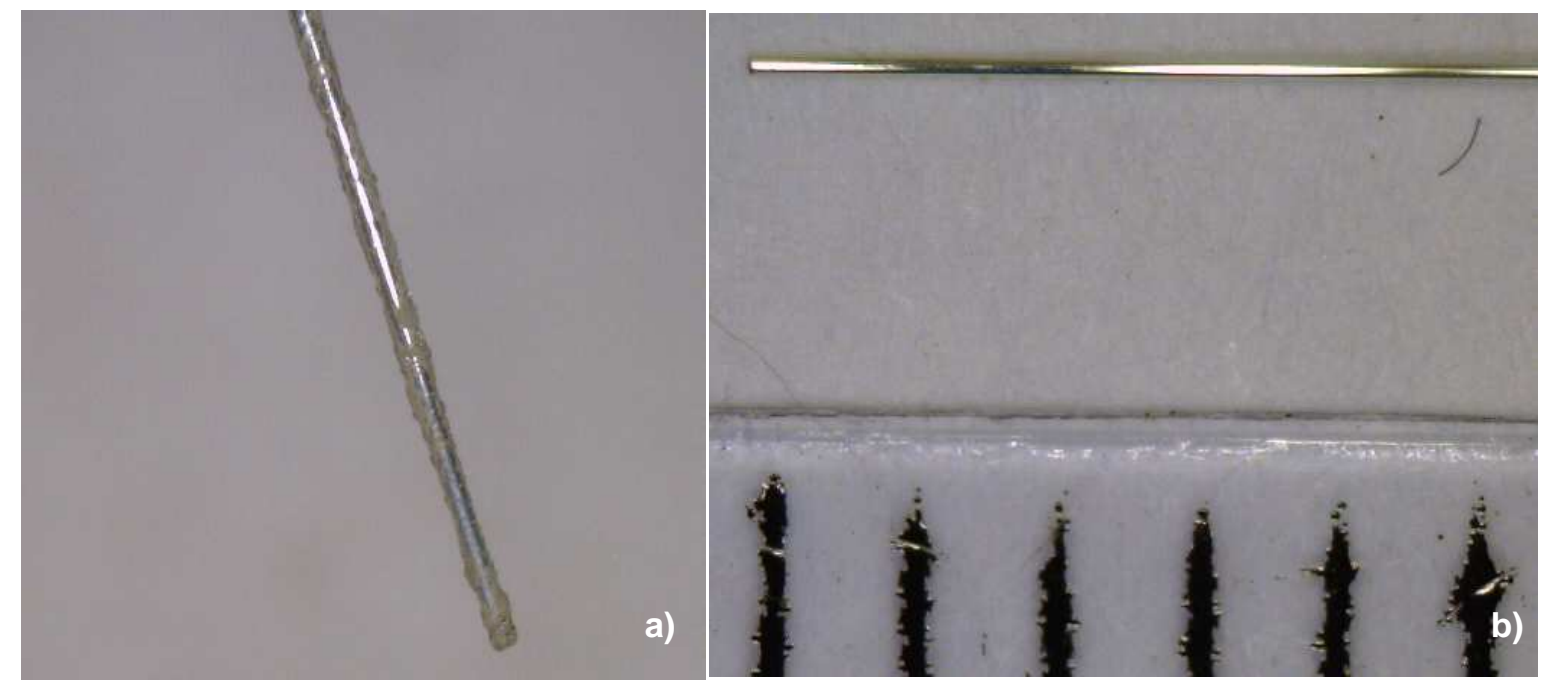

Figura 33 - Detalhes da fibra óptica metalizada. (a) Fibra óptica antes da limpeza e (b) Fibra óptica após processo de limpeza. Em (b) Cada divisão da régua abaixo da fibra óptica representa $1 \mathrm{~mm}$.

Após a metalização da extremidade de algumas fibras ópticas de teste, adquiriu-se experiência suficiente para a metalização do modulador $Y$ em óptica integrada que será utilizado como o interferômetro recuperador.

A seguir, iniciou-se o ajuste dos comprimentos dos braços do modulador e o seu polimento de forma a se conseguir a metade da OPD indicada pela eq. (5.8). 
$\mathrm{Na}$ etapa seguinte foi feita a metalização das extremidades das fibras ópticas do modulador $\mathrm{Y}$ em óptica integrada.

A Figura 34(a), a seguir, as fibras ópticas se saída do modulador $Y$ em óptica integrada após a metalização com Prata, segundo o método exposto anteriormente. $\mathrm{Na}$ Figura 34(b) é possível observar as duas fibras de saída do modulador e a metalização lateral delas.

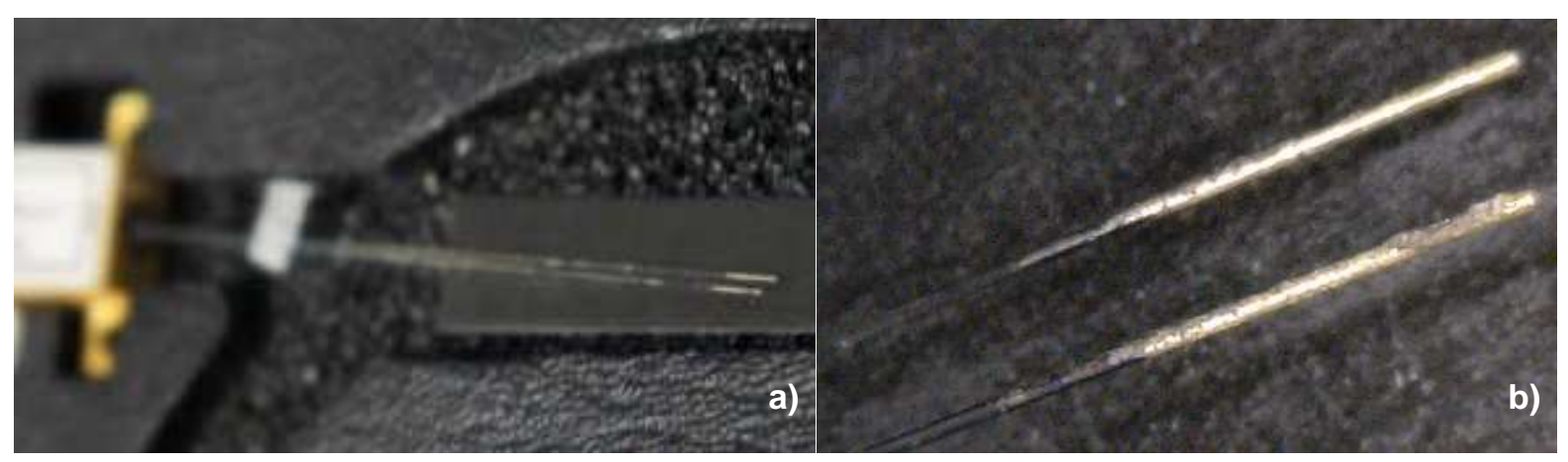

Figura 34 - a) Aspecto final do modulador $Y$ em óptica integrada. Em primeiro plano estão as fibras ópticas de saída do modulador após a metalização com Prata b) Detalhes da extremidade das fibras metalizadas.

\subsection{MONTAGEM DO INTERFERÔMETRO RECUPERADOR COM O MODULADOR Y EM ÓPTICA INTEGRADA E SUA INTEGRAÇÃO AO SISTEMA SENSOR DO PROTÓTIPO DE TPO}

Para a montagem do interferômetro recuperador, utilizando o modulador $Y$ em óptica integrada, duas topologias foram testadas. Conforme descrito na seção 4.3.1.5, numa delas utiliza-se um acoplador direcional para integrar o modulador Y em óptica integrada com o sistema sensor, enquanto que na outra faz-se uso de um circulador óptico para realizar a mesma função. Estas duas topologias são mostradas nas Figuras 16 e 18 da seção referida.

Quanto ao dispositivo de integração das células primária e secundária, para a escolha da topologia a ser utilizada na montagem do TPO, foram levados em 
consideração vários fatores, tais como preço, disponibilidade, perdas introduzidas, faixa espectral de operação, etc.

Dentre eles, a perda de potência óptica introduzida por cada dispositivo foi considerado o mais relevante. Com o intuito de facilitar a escolha, torna-se útil explicitar as perdas introduzidas por cada elemento de ligação entre os interferômetros.

A seguir, são apresentadas algumas das características do circulador óptico utilizado neste trabalho, conforme consta em seu datasheet no Anexo 2:

- Máxima perda por inserção: Porta 1 para porta 2 (0,50 dB);

- Máxima perda por inserção: Porta 2 para porta $3(0,39 \mathrm{~dB})$;

- Isolação mínima entre portas: Porta 2 para porta 1 (60 dB);

- Isolação mínima entre portas: Porta 3 para porta 3 (58 dB);

- Faixa de operação: 1520 -1565 nm (permitindo operar com o SLD utilizado).

Desta forma, o feixe de luz proveniente do interferômetro sensor ao passar pelo circulador óptico, sofrerá uma atenuação (devida a este dispositivo) em seu caminho de ida e volta ao interferômetro recuperador, de $0,89 \mathrm{~dB}$.

As características do acoplador direcional utilizado neste trabalho, constam no Anexo 5 e nele observa-se que a perda por inserção típica do acoplador direcional é de $50 \%$ (3 dB). Desta forma, o feixe de luz, ao passar pelo acoplador no caminho de ida para o modulador em $Y$ sofrerá uma perda de $3 \mathrm{~dB}$ em sua potência óptica. Analogamente, sofrerá os outros $3 \mathrm{~dB}$ ao retornar deste. Desta forma a perda total introduzida unicamente por este dispositivo será de $6 \mathrm{~dB}$.

Sendo assim, a opção pelo circulador óptico, cuja topologia do TPO incluindo este dispositivo é mostrada na Figura 35, se justifica por este introduzir perdas de potência óptica significativamente menores (aproximadamente $-5,11 \mathrm{~dB}$ de diferença) do que aquelas introduzidas pelo acoplador direcional. 
Quanto à montagem do interferômetro recuperador, apesar do modulador em Y ser um dispositivo comercial, disposto em um encapsulamento compacto, metálico e robusto, com imunidade a algumas grandezas físicas, ainda assim houve problemas de sensibilidade do interferômetro à temperatura e vibração.

Pelo fato do modulador possuir dois pigtails de saída relativamente longos $(\sim 1,5 \mathrm{~m})$, estes pigtails experimentam diferentes variações de temperatura ao longo do seu comprimento em cada uma das fibras. Adicionalmente, estas fibras estão também sujeitas a diferentes vibrações mecânicas. Para efeito de minimização destas contribuições (térmicas e mecânicas), as fibras de saída foram cortadas em comprimentos mínimos, aproximadamente $5 \mathrm{~cm}$, de forma que ainda fosse possível montá-la no suporte para fazer o seu polimento. Embora tenha havido uma melhora substancial o dispositivo ainda mostrou alguma sensibilidade à temperatura e vibração. Desta forma, para equalizar o efeito térmico nos dois braços de fibra óptica, estes foram mantidos o mais próximo possível um do outro, reduzindo ainda mais esta dependência.

Por outro lado, dada a fragilidade do dispositivo, no que concerne aos seus acessos por fibras ópticas, resolveu-se acondicioná-lo em ambiente amortecido (caixa forrada de borracha de polipropileno), o que diminuiu bastante a sua sensibilidade à vibração mecânica.

A Figura 35, a seguir, mostra o esquema do TPO montado utilizando o interferômetro recuperador desenvolvido. 


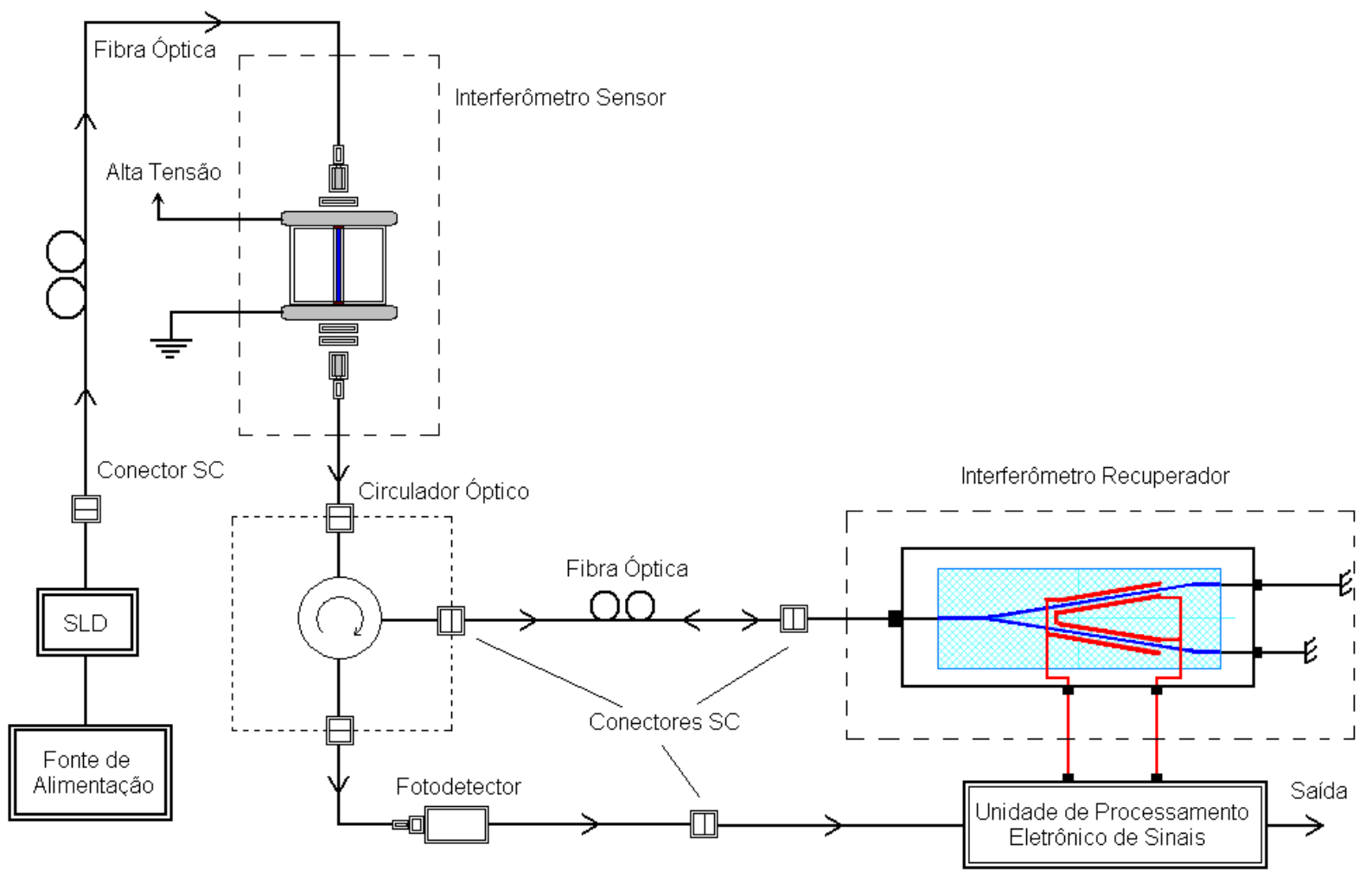

Figura 35 - Esquema do protótipo de Transformador de Potencial Óptico completo.

O transformador para medida de altas tensões aqui apresentado, é composto de quatro elementos básicos, que são:

- Interferômetro sensor (célula de alta tensão);

- Enlace óptico;

- Interferômetro recuperador (célula de baixa tensão);

- Unidade de Processamento de sinal.

A seguir, descreve-se cada um dos quatro elementos que constituem o TPO construído. 


\subsubsection{O INTERFERÔMETRO SENSOR (CÉLULA DE ALTA TENSÃO)}

O interferômetro sensor construído, também chamado de célula Pockels de alta tensão, foi especialmente projetado para resistir aos elevados valores de campo elétrico sem sofrer ruptura dielétrica e possuir sensibilidade adequada para reproduzir a tensão medida na forma de um sinal óptico que exiba linearidade, estabilidade e precisão na faixa dinâmica pretendida.

A célula sensora é constituída pelo conjunto das montagens mecânicas, ópticas e elétricas que formam o dispositivo no qual é aplicada a tensão a ser medida e que entrega em sua saída, por meio de uma fibra óptica, um sinal óptico com alguma de suas características modulada de forma proporcional àquela tensão. A célula sensora, no caso, contém um modulador eletro-óptico construído com materiais e geometria adequados para atender as exigências do projeto.

O modulador eletro-óptico utilizado nesta célula de alta tensão, montado na configuração longitudinal, consiste no conjunto formado por um cilindro de acrílico (contendo um cristal de BGO) e duas "medalhas" (contendo os polarizadores corretamente orientados e a lâmina retardadora). Este tipo de modulador não contém, em si, dispositivos de colimação e alinhamento do feixe óptico, o qual deve provir de uma fibra óptica de entrada, atravessá-lo e ser acoplado a uma fibra óptica de saída, conforme será visto na seção 5.4.2. Tais dispositivos estão incorporados na célula sensora de alta tensão. Para ensaiar o modulador é necessário, então, montá-lo na célula sensora.

Nesse tipo de sensor a tensão a ser medida é aplicada totalmente ao cristal eletroóptico. Nestas condições, a modulação da luz é proporcional à integral de linha do campo elétrico entre as extremidades do cristal, ou seja, é proporcional à própria tensão aplicada. O comprimento da célula sensora relaciona-se diretamente com a distância entre os eletrodos que aplicam a alta tensão ao cristal do modulador eletroóptico. A rigidez dielétrica e a tensão de ruptura da célula são afetadas por esta distância. 
A Figura 36(a), a seguir, ilustra a composição das "medalhas" com o cilindro, e, a Figura 36(b) mostra a vista lateral em corte do aspecto final do modulador eletroóptico longitudinal para medição de altas tensões, obtido como descrito acima.
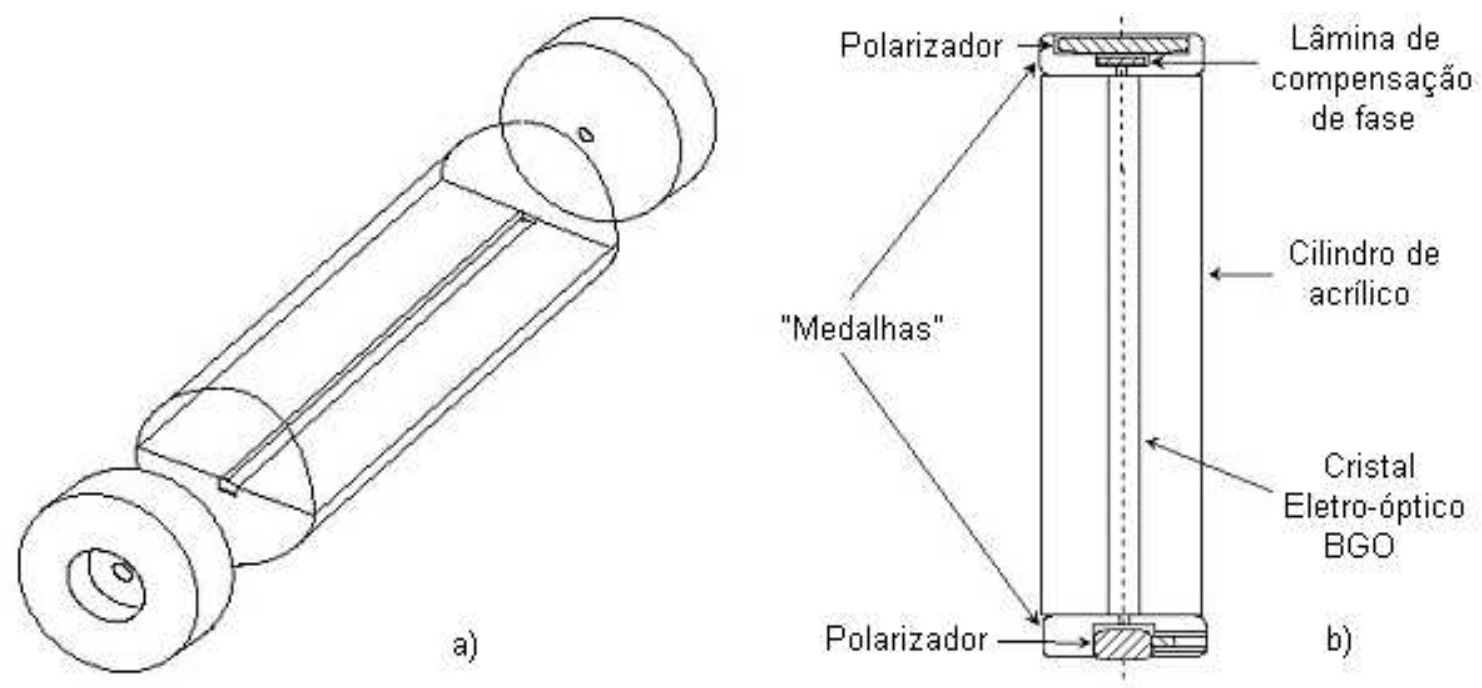

Figura 36 - a) Esquema representativo da composição das "medalhas" com o cilindro de acrílico contendo o cristal eletro-óptico e b) Vista lateral em corte do aspecto final do modulador eletro-óptico longitudinal para medição de altas tensões [44].

A configuração da célula sensora eletro-óptica, ou célula Pockels, que constitui o sensor de alta tensão (como é chamado o conjunto do modulador com os acopladores ópticos e elétricos necessários para a medição de altas tensões), foi definida a partir da experiência anterior dos pesquisadores do LSO [7, 44] e após estudos de viabilidade técnica que levaram em conta os parâmetros, a disponibilidade e a facilidade de processamento mecânico dos materiais condutores e isolantes necessários ao projeto. Este processo de escolha conduziu à configuração mostrada nas Figuras 37(a) e 37(b), a seguir. 

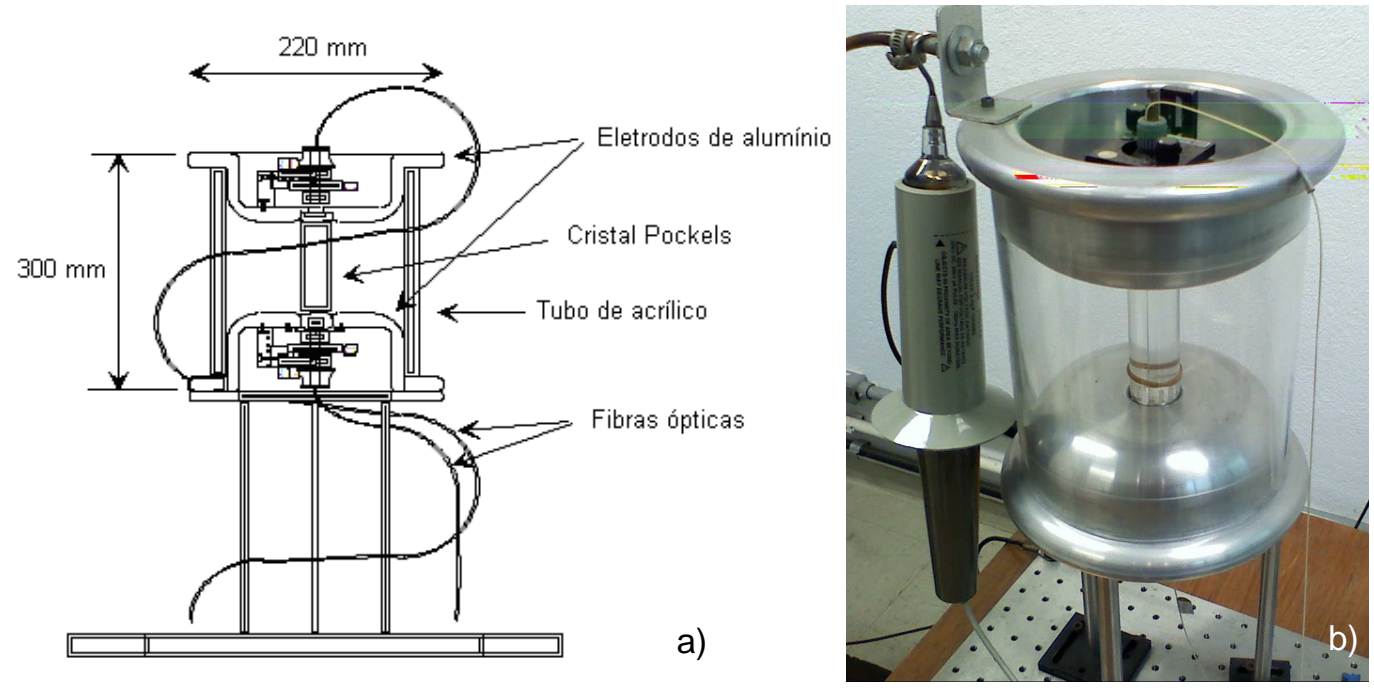

Figura 37 - a) Vista em corte da célula eletro-óptica de alta tensão [44] e b) Célula eletro-óptica sensora montada.

Na montagem apresentada na Figura 37, os eletrodos, superior e inferior, são feitos de alumínio maciço usinado e são separados por um tubo de acrílico de $200 \mathrm{~mm}$ de diâmetro interno. No centro do eletrodo inferior há um furo de $32 \mathrm{~mm}$ de diâmetro que permite a passagem do modulador de alta tensão e no eletrodo superior há uma reentrância para acomodar a "medalha" superior do modulador [7, 44].

$\mathrm{Na}$ parte interna de cada um dos eletrodos de alumínio são acomodados os componentes ópticos necessários para montagem do modulador Pockels: "medalhas", posicionadores, pigtails colimadores e suportes de fibras ópticas. A célula de alta tensão é a mesma que foi utilizada no trabalho de mestrado do autor e o valor da tensão de meia onda foi calculado a partir da equação abaixo [7, 44]:

$$
V_{\pi s}=\frac{\lambda}{2\left(n_{0}^{3}\right) r_{41}}
$$

onde:

$$
\begin{aligned}
& V_{\pi s}=69,4 k V_{r m s}, \text { para } \lambda=1321 \mathrm{~nm} \mathrm{e} \\
& V_{\pi s}=81,5 k V_{r m s}, \text { para } \lambda=1550 \mathrm{~nm} .
\end{aligned}
$$


Uma placa retardadora formada por uma lâmina de $1 \mathrm{~mm}$ de espessura de Niobato de Lítio em corte-X, com direção de propagação ao longo do eixo Z da Figura 26, foi utilizada para inserir no interferômetro sensor uma OPD fixa de aproximadamente 35 comprimentos de onda entre as componentes de polarizações ortogonais da onda óptica. Na situação em que este OPD é maior que o comprimento de coerência da fonte óptica empregada, a informação da tensão aplicada à célula de alta tensão está contida no espectro da luz e não em sua intensidade.

Na Figura 38(a), a seguir, mostra o aspecto final da célula sensora de alta tensão com o modulador eletro-óptico montado em seu interior. Pode-se notar, à esquerda da célula sensora, a ponta de prova de $20 \mathrm{kV}_{\mathrm{pp}}$ utilizada para o monitoramento da tensão aplicada à célula por meio de um osciloscópio. A Figura 38(b) mostra a mesma célula de alta tensão e o transformador de potencial indutivo utilizado para aplicar as altas tensões (CA) a serem medidas.

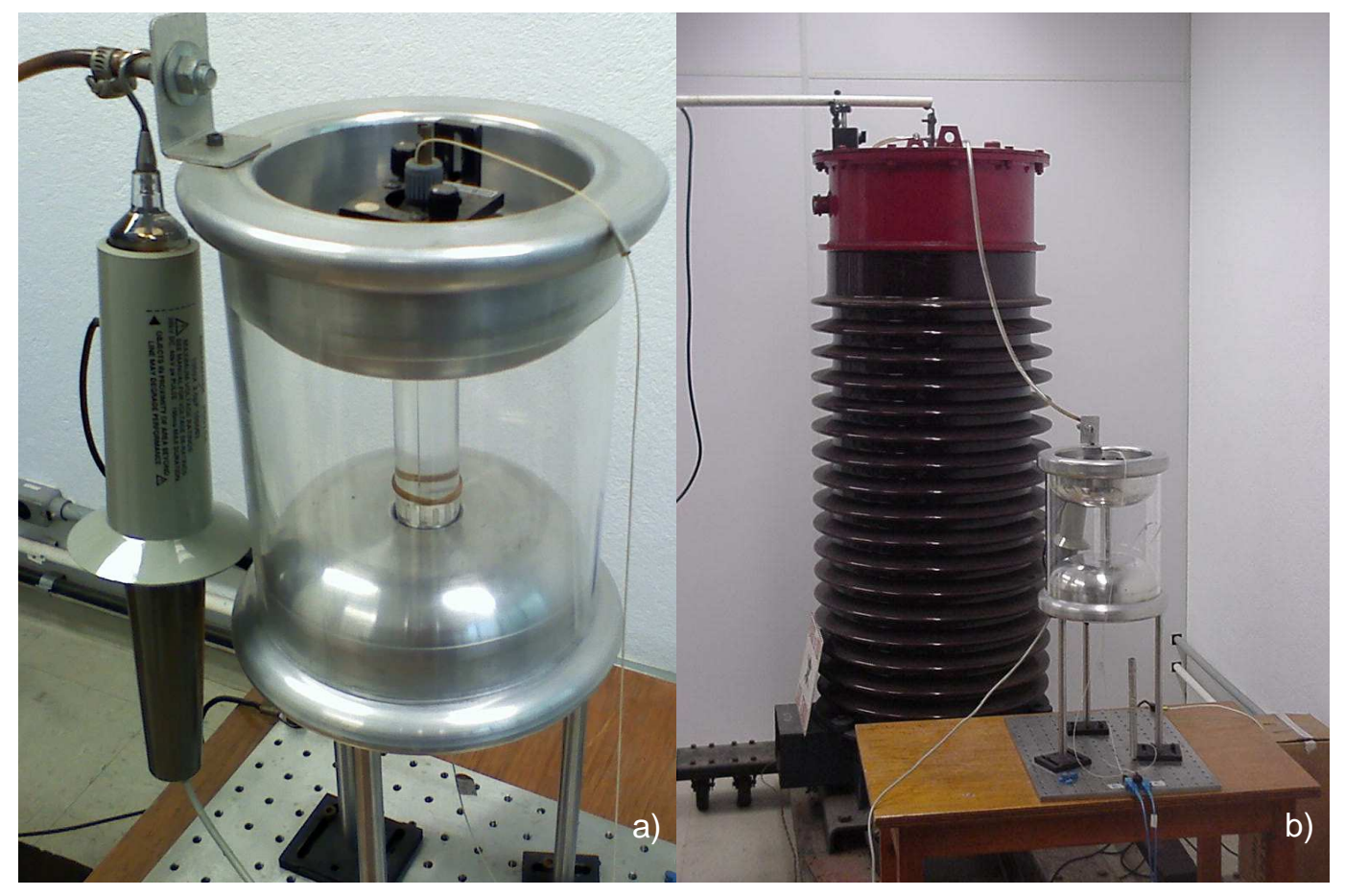

Figura 38 - a) Célula eletro-óptica de alta tensão e b) Célula de alta tensão e transformador de potencial. 


\subsubsection{ENLACE ÓPTICO}

O enlace óptico utilizado no TPO é composto basicamente por:

- Fibras ópticas monomodo;

- $\quad$ Pigtails colimadores;

- $\quad$ Conectores SC;

- Emendas;

- Fonte de luz;

- Fotodetector.

Com a finalidade de melhorar o desempenho do sistema sensor, escolheu-se empregar no enlace, ao invés de lentes discretas, trechos de fibras ópticas (pigtails) terminados por lentes colimadoras tipo índice gradual (Gradual Index -GRIN). Estes pigtails colimadores oferecem uma série de vantagens, tais como: apresentam baixa perda por inserção (por possuírem camadas anti-refletoras em suas faces e por estas estarem perfeitamente acoplados às fibras), produzem um feixe de diâmetro de cintura reduzido $(\cong 0,45 \mathrm{~mm})$, apresentam baixa divergência $\left( \pm 0,15^{\circ}\right)$ e produzem montagens mecânicas mais compactas e, portanto, mais robustas e estáveis (pois são encapsuladas em invólucro de aço de dimensões reduzidas. No entanto, o emprego das lentes GRIN no enlace óptico, apresentou a desvantagem de exigir alinhamento angular crítico, requerendo um esforço adicional e um cuidado especial no trabalho de alinhamento das lentes.

No intuito de minimizar as perdas por acoplamento e facilitar o alinhamento e manuseio dos componentes ópticos, procurou-se trabalhar com fibras ópticas monomodo conectorizadas no protótipo.

Por outro lado, por ser a luz emitida pelo SLD parcialmente polarizada, em uma razão de polarização de aproximadamente $5 \mathrm{~dB}$, o ideal seria empregar fibra mantenedora de polarização (Polarization-Maintaining Optical Fiber - PM) na conexão entre o SLD e o interferômetro sensor. 
Adicionalmente, pelo fato da luz na saída do interferômetro sensor ser polarizada e o interferômetro recuperador também ser um polarizador é importante manter constante a orientação da direção de polarização da luz entre os dois interferômetros, caso contrário pode ocorrer um efeito chamado desvanecimento (fading) do sinal interferométrico.

Como a fibra monomodo utilizada não mantém a direção de polarização o ideal seria utilizar fibras mantenedoras de polarização PM entre os interferômetros para evitar tal efeito.

A utilização de fibras ópticas do tipo monomodo não inviabilizou a realização do trabalho uma vez que, se estas fibras não forem perturbadas termicamente ou mecanicamente, ou, se as variações introduzidas por elas forem pequenas, é possível compensar o sistema (óptico e eletrônico) de modo que o sinal de saída do TPO não se degrade significantemente. Tais compensações são feitas no protótipo de TPO implementado.

Outros aspectos que impossibilitaram temporariamente a utilização de fibras ópticas do tipo PM neste trabalho foram seu elevado custo e a indisponibilidade de equipamentos para fazer emendas de fusão em fibras deste tipo. Desta forma, justifica-se, com estas considerações, a utilização de fibras monomodo, deixando para o futuro, a substituição das fibras monomodo pelas fibras PM.

Utilizou-se, sempre que possível, conectores do tipo SC, os quais, além da praticidade de encaixe rápido por pressão, vem demonstrando crescente melhora nos quesitos de perda por inserção e repetibilidade. Em alguns momentos do desenvolvimento deste trabalho, algumas fibras foram rompidas, por acidente, necessitando de emenda ou conectorização. Este tarefa foi realizada no laboratório de fibras ópticas do Centro de Computação Eletrônica (CCE-USP), que dispõe de máquinas apropriadas para este tipo de trabalho.

Para a escolha da fonte de luz empregada no TPO, o requisito básico é que ela deve produzir luz de baixa coerência temporal, ou banda espectral larga [7, 44]. Escolheu-se então empregar como fonte de luz um diodo superluminescente (SLD), 
pois este tipo de componente produz luz de coerência espectral moderadamente baixa, porém de alta coerência espacial, conseguindo assim acoplar uma quantidade significativa de luz nas fibras ópticas utilizadas.

O SLD empregado no TPO foi o modelo SLD - 76 - HP, fabricado pela empresa Superlum Diodes, LTD., que emite luz no comprimento de onda de $1560 \mathrm{~nm}$ e possui potência óptica da ordem de até $5 \mathrm{~mW}$, que apresenta as especificações técnicas contidas no Anexo 1.

$\mathrm{Na}$ conversão dos sinais ópticos em sinais elétricos, foi utilizado um fotodetector na entrada do circuito de processamento eletrônico de sinais. Este fotodiodo é um diodo PIN de (InGaAs), fabricado pela Appointech, Inc., cujas informações técnicas estão detalhadas no Anexo 4.

\subsubsection{INTERFERÔMETRO RECUPERADOR}

Para efeito de comparação com o interferômetro recuperador utilizando o modulador Y em óptica integrada desenvolvido neste trabalho, é feita, a seguir, a descrição do interferômetro recuperador em montagem volumétrica utilizado no mestrado do autor.

A célula sensora secundária, utilizada nos trabalhos anteriores, é formada por um modulador eletro-óptico secundário, ou interferômetro recuperador, instalado em um gabinete metálico termicamente isolado, adequada para operar em tensões de no máximo $2500 \mathrm{~V}_{\mathrm{rms}}$.

O modulador secundário foi projetado para exibir sensibilidade mais elevada possível, a fim de que, com uma tensão aplicada relativamente pequena pudesse igualar a OPD introduzida pelo sensor primário. Utilizou-se nele uma configuração transversal bi-segmentada cruzada, formada por dois cristais de Niobato de Lítio de mesmo comprimento, dispostos em série, mas com seus eixos de orientação transversais girados de $90^{\circ}$ entre si, a fim de praticamente eliminar a birrefringência natural do conjunto de cristais. 
Uma placa retardadora formada por uma lâmina de $1 \mathrm{~mm}$ de espessura de Niobato de Lítio, com direção de propagação ao longo do eixo $X$, foi utilizada para inserir no interferômetro recuperador uma OPD fixa próxima àquela inserida pelo interferômetro sensor.

Uma segunda placa retardadora, também formada por uma lâmina de $1 \mathrm{~mm}$ de espessura de Niobato de Lítio, mas com direção de propagação ao longo do eixo Z, foi montada sobre uma base giratória e posta em série com os demais elementos no caminho óptico, de forma a inserir uma pequena OPD ajustável segundo o ângulo entre a normal à superfície da lâmina e a direção de propagação da luz. Através deste ajuste é possível compensar exatamente a OPD inserida pelo sensor. Nestas condições, na saída do interferômetro recuperador, a informação da tensão aplicada à célula de alta tensão deixa de estar contida no espectro da luz para estar codificada em sua intensidade.

Nas Figuras 39 e 40, a seguir, apresentam-se, respectivamente, de forma mais detalhada, o esquema do sistema sensor e a foto do protótipo de interferômetro recuperador montado.

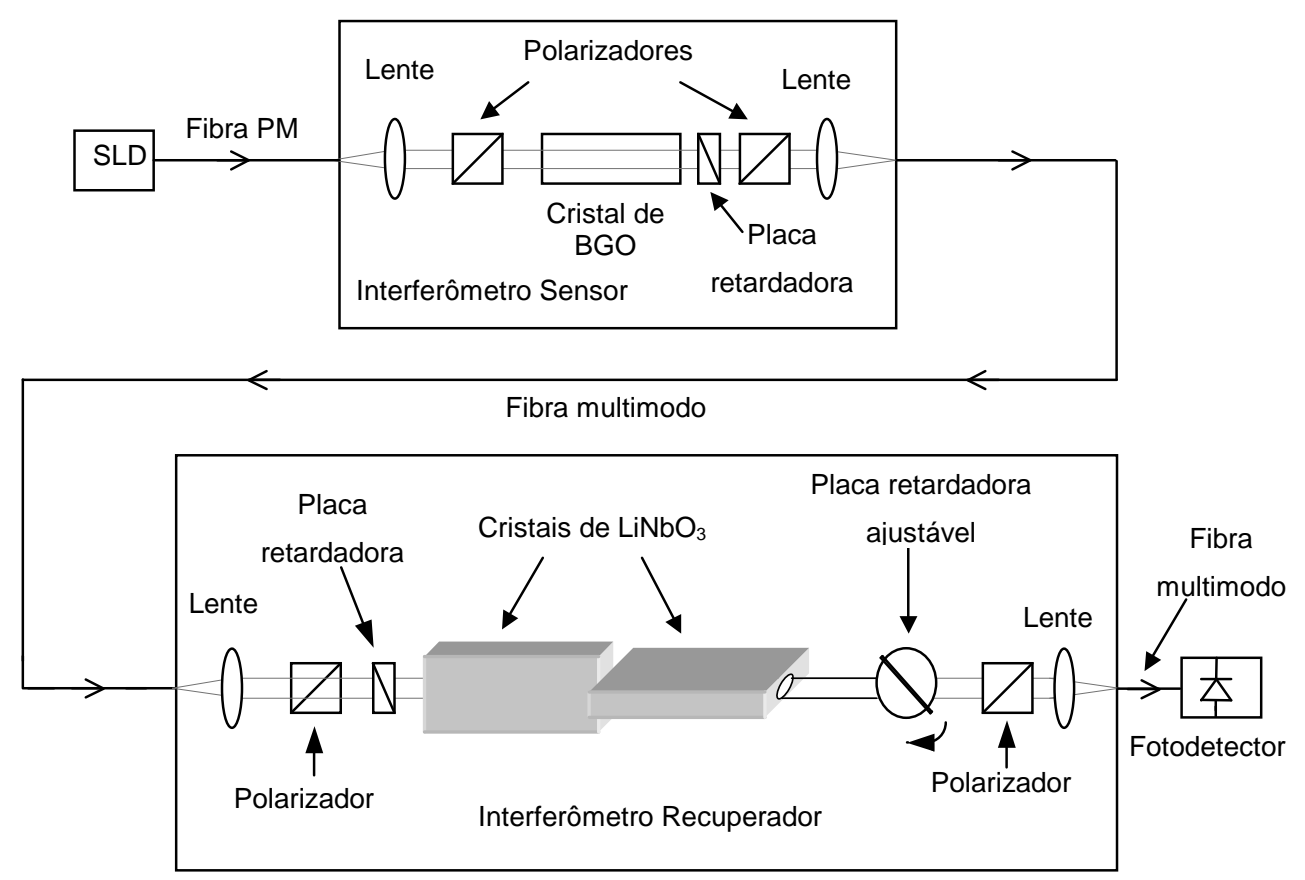

Figura 39 - Esquema do sistema sensor eletro-óptico por técnica de WLI montado [44]. 


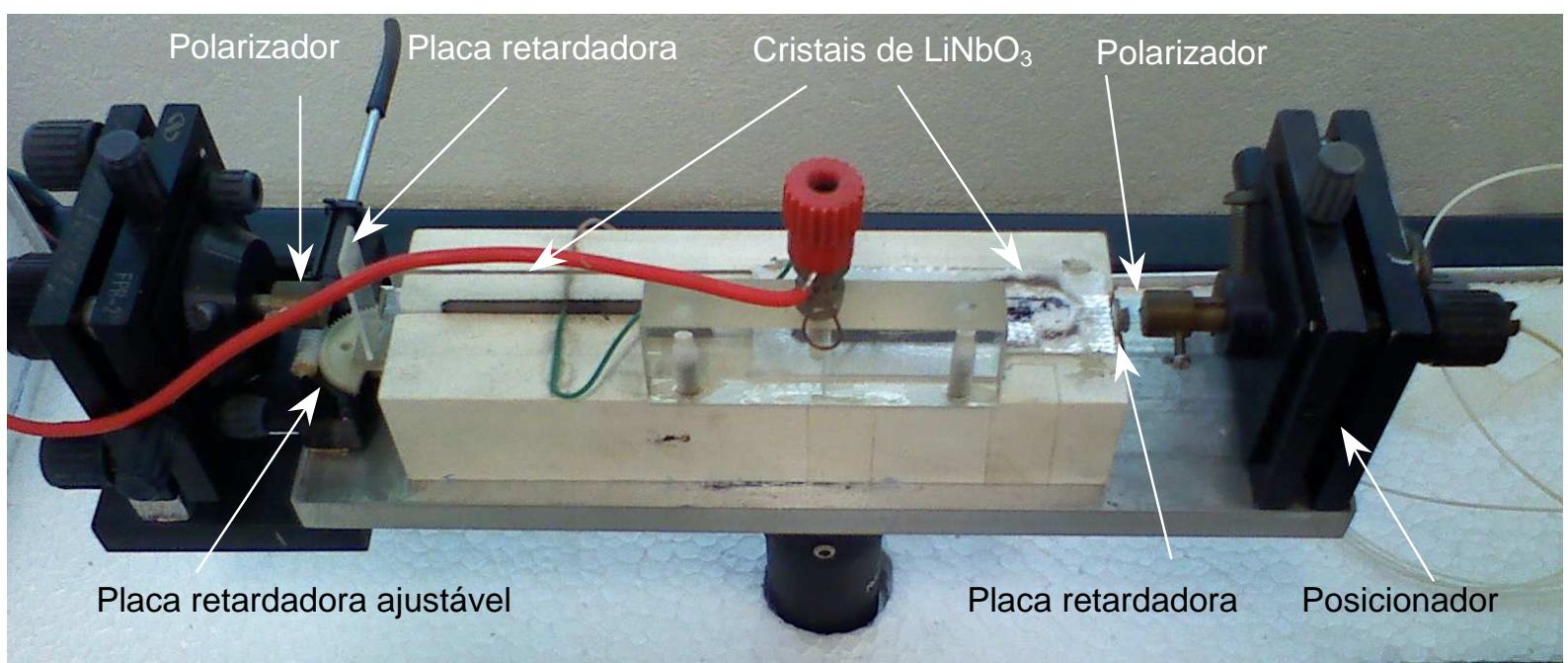

Figura 40 - Interferômetro recuperador desenvolvido para compor o protótipo de TPO.

O valor da tensão de meia onda do interferômetro recuperador, $V_{\pi r}$, mostrado na Figura 40, foi calculado a partir da equação a seguir [26]:

$$
V_{\pi r}=\left(\frac{\lambda}{n_{e}^{3} \cdot r_{33}-n_{o}^{3} \cdot r_{13}}\right) \cdot\left(\frac{d}{L}\right)=57,7 \mathrm{~V}
$$

onde:

$\lambda=1321 \mathrm{~nm}$ é o comprimento central da onda de luz, $n_{0}=2,2273 \mathrm{e}$ $n_{e}=2,1515$ são os índices de refração ordinário e extraordinário do cristal de Niobato de Lítio, respectivamente, $\quad r_{13}=8,6 \times 10^{-12} \mathrm{~m} / \mathrm{Ve}$ $r_{33}=30,8 \times 10^{-12} \mathrm{~m} / \mathrm{V}$ são os coeficientes eletro-ópticos, $d=1 \mathrm{~mm}$ é a espessura do cristal e $L=108 \mathrm{~mm}$ o comprimento dos eletrodos de baixa tensão aplicados sobre os cristais.

A relação entre as tensões $V_{\pi s}$ e $V_{\pi r}$ necessárias para gerar um mesmo atraso de fase nas células de alta e de baixa tensão é a própria relação de transformação $(K)$ do TPO, que no caso é de aproximadamente 1200 vezes, ou seja: 


$$
K=\frac{V_{\pi s}}{V_{\pi r}}=\left[\frac{69,4 \mathrm{kV}}{57,7 \mathrm{~V}}\right]_{1321 \mathrm{~nm}}=\left[\frac{81,5 \mathrm{kV}}{67,7 \mathrm{~V}}\right]_{1550 \mathrm{~nm}} \cong 1203
$$

O interferômetro recuperador eletro-óptico em montagem volumétrica, mostrado na Figura 39, foi projetado para varrer uma faixa de OPD capaz de reconstruir uma parcela considerável do padrão de franjas gerado pela resposta interferométrica do sistema sensor por WLI.

Com o valor de $\mathrm{V}_{\pi \mathrm{r}}$ dado e, como na prática, a tensão máxima segura aplicável à célula recuperadora, como foi dito anteriormente, ficou limitada em cerca de 2500 $\mathrm{V}_{\mathrm{rms}}$, o modulador secundário mostrou-se capaz de recuperar cerca de 18 franjas de interferência.

\subsubsection{PROCESSAMENTO ELETRÔNICO DO SINAL DE SAÍDA DO SISTEMA SENSOR ELETRO-ÓPTICO POR WLI}

As explanações contidas nesse item seguem de perto aquelas contidas no trabalho de Almeida [33], criador da técnica de demodulação síncrona de sinais interferométricos utilizada no protótipo de TPO desenvolvido, com sua colaboração, no LSO.

O processamento de sinais empregado neste trabalho pode ser descrito a partir da análise da fotocorrente, $I_{d}(t)$, detectada no fotodiodo conectado à fibra óptica de saída do interferômetro recuperador, pois a mesma contém a informação de alta tensão a ser demodulada.

Os fotodetectores são dispositivos optoeletrônicos capazes de detectar a potência luminosa que incide sobre eles, convertendo-a em corrente elétrica. Como a potência óptica é proporcional à intensidade luminosa, esta grandeza assume importante papel na implementação de sistemas ópticos. O valor da fotocorrente, $I_{d}$, produzida pelo fotodiodo quando um feixe de luz de potência $P$ incide sobre $o$ mesmo é dada por [9, 33]: 


$$
I_{d}=\eta_{d}\left(\frac{q \lambda}{h c}\right) P=\eta_{f d} P
$$

onde:

$q=-1,602177 \times 10^{-19} C$ é a carga do elétron, $h=6,629075 \times 10^{-34}$ J.S é a constante de Planck, $\lambda$ é o comprimento da onda associada ao fóton, $c$ é a velocidade de propagação da luz no meio, $\eta_{d}$ é a eficiência quântica do fotodiodo, $\eta_{f d}$ é a responsividade do fotodiodo e $P$ é potência óptica.

No entanto, o módulo do vetor de Poynting pode ser visto como sendo a densidade de potência transportada pela onda óptica na sua direção de propagação [26, 27].

$\mathrm{Na}$ equação (5.18) se informa que a foto-corrente é proporcional à potência óptica, $P$, que por sua vez é dada pela integral sobre a área do fotodiodo da intensidade, $I_{r}$, do feixe de luz trazido pela fibra óptica de saída do interferômetro recuperador.

Considerando que tanto a área do fotodiodo quanto a do feixe de luz que emerge da fibra óptica são finitas e fixas, pode-se afirmar que a potência óptica, $P$, é diretamente proporcional à intensidade óptica do feixe, $I_{r}$, ou seja:

$$
P=A_{e} I_{r}
$$

onde:

$A_{e}$ é a constante de proporcionalidade que relaciona a potência óptica recebida com a intensidade óptica do feixe de luz incidente sobre um determinado fotodiodo. $A_{e}$ possui dimensão de área e pode ser chamada de área efetiva do fotodiodo. 
Dessa forma, para um dado fotodiodo, de responsividade $\eta_{f d}$ e área efetiva $A_{e}$, iluminado por uma onda óptica de comprimento de onda $\lambda$, a corrente $I_{d}$ relacionase com a intensidade $I_{r}$ pela seguinte relação [8, 9]:

$$
I_{d}=\eta_{f d} \cdot A_{e} \cdot I_{r}
$$

Considerando-se que as OPD's dos interferômetros sensor e recuperador estão casadas, a intensidade óptica na saída do interferômetro recuperador, dada pela eq. (4.84) pode ser reescrita da seguinte forma [7-9, 33]:

$$
I_{r}=I_{r 0}\left\{1+\frac{1}{2} e^{-\left[\frac{\left(\phi_{1}-\phi_{2}\right) \lambda}{2 L_{c}^{2}}\right]} \cos \left(\phi_{1}-\phi_{2}\right)\right\}
$$

onde:

$\phi_{1}$ e $\phi_{2}$ são os atrasos de fase ópticos induzidos eletricamente pelos interferômetros sensor e recuperador, respectivamente.

A eq. (5.21) pode ser ainda mais simplificada adotando: $\phi=\phi_{1}-\phi_{2}$, assumindo a seguinte forma $[8,9,33]$ :

$$
I_{r}=I_{r 0}\left\{1+\frac{1}{2} e^{-\left[\frac{\phi \lambda}{2 L_{c}^{2}}\right]} \cos (\phi)\right\}
$$

Os atrasos de fase $\phi_{1}$ e $\phi_{2}$ na eq. (5.21) são equivalentes àqueles representados por $\Gamma$ na eq. (4.139). Neste item decidiu-se substituir a variável $\Gamma$ por $\phi$, pois deseja-se desvincular a idéia do atraso de fase de um tipo específico de modulador, 
deixando-o com um caráter genérico, a ser calculado em função do $V_{\pi}$ do modulador escolhido através da relação [33]:

$$
\phi_{i}=\pi \frac{V_{i}}{V_{\pi i}}
$$

onde:

O índice $i=1,2$; refere-se a um dos interferômetros do sistema. Sendo o valor 1 associado ao interferômetro sensor e o valor 2 ao interferômetro recuperador, respectivamente.

Aplicando-se ao modulador do interferômetro recuperador uma tensão de modulação senoidal da forma: $V_{2}(t)=V_{2} \operatorname{sen}\left(\omega_{2} t\right)$, o atraso de fase resultante do sistema será [33]:

$$
\phi_{2}(t)=\phi_{2} \operatorname{sen}\left(\omega_{2} t\right)
$$

onde:

$\phi_{2}=\pi \frac{V_{2}}{V_{\pi 2}}$ é o valor máximo do atraso de fase introduzido pelo interferômetro recuperador, quando a tensão de modulação secundária atinge o seu valor máximo, $v_{2}$.

Aplicando-se a eq. (5.24) na eq. (5.21) e esta na eq. (5.20) obtém-se a corrente $I_{d}(t)$ no fotodetector, expressa por [33]:

$$
I_{d}(t)=I_{d 0}\left\{1+\frac{1}{2} e^{-\left[\frac{\left(\phi_{1}(t)-\phi_{2}(t)\right) \lambda}{2 L_{c}^{2}}\right]} \cos \left[\phi_{1}(t)+\phi_{2} \operatorname{sen}\left(\omega_{2} t\right)\right]\right\}
$$


onde:

$I_{d o}=\eta f_{d} A_{e} I_{\text {ro }}$ é o valor médio de $I_{d}(t)$ e $\phi_{1}(t)=\pi \frac{V_{1}(t)}{V_{\pi 1}}$, sendo $V_{1}(t)$ a tensão, variável no tempo, aplicada ao sensor primário que se deseja medir, que também pode, ou não, ser puramente senoidal, como $V_{2}(t)$.

Caso ambas as modulações sejam pequenas, especialmente se não ultrapassarem os limites: $\phi_{1}<-\pi / 2$ e $\phi_{2}<\pi / 2$, pode-se considerar o termo que define a visibilidade praticamente constante e igual a 1, ou seja, $e^{-\left[\frac{\left(\phi_{1}(t)-\phi_{2}(t)\right) \lambda}{2 L_{c}^{2}}\right]} \cong 1$, o que conduz a eq. (5.25) à forma [33]:

$$
I_{d}(t)=I_{d 0}\left\{1+\frac{1}{2} \cos \left[\phi_{1}(t)+\phi_{2} \operatorname{sen}\left(\omega_{2} t\right)\right]\right\}
$$

A Figura 41, a seguir, ilustra a forma de onda de $I_{d}(t)$, para as modulações $\phi_{1}(t)=0,5 \operatorname{sen}\left(\omega_{1} t\right)$ e $\phi_{2}(t)=\pi / 2 \operatorname{sen}\left(\omega_{2} t\right)$, aplicadas aos atrasos de fase ópticos dos interferômetros sensor e recuperador, respectivamente.

Para melhor ilustrar o fenômeno físico, utilizou-se $\omega_{2}=16 \omega_{1}, \phi_{1}=0,5, \phi_{2}=\pi / 2$, onde $\omega_{1}=2 \pi / T_{1}$ e $T_{1}=1 / f_{1}$ é o período da frequência fundamental $f_{1}$ da alta tensão aplicada ao sensor. Analogamente, $\omega_{2}=2 \pi / T_{2}$. 


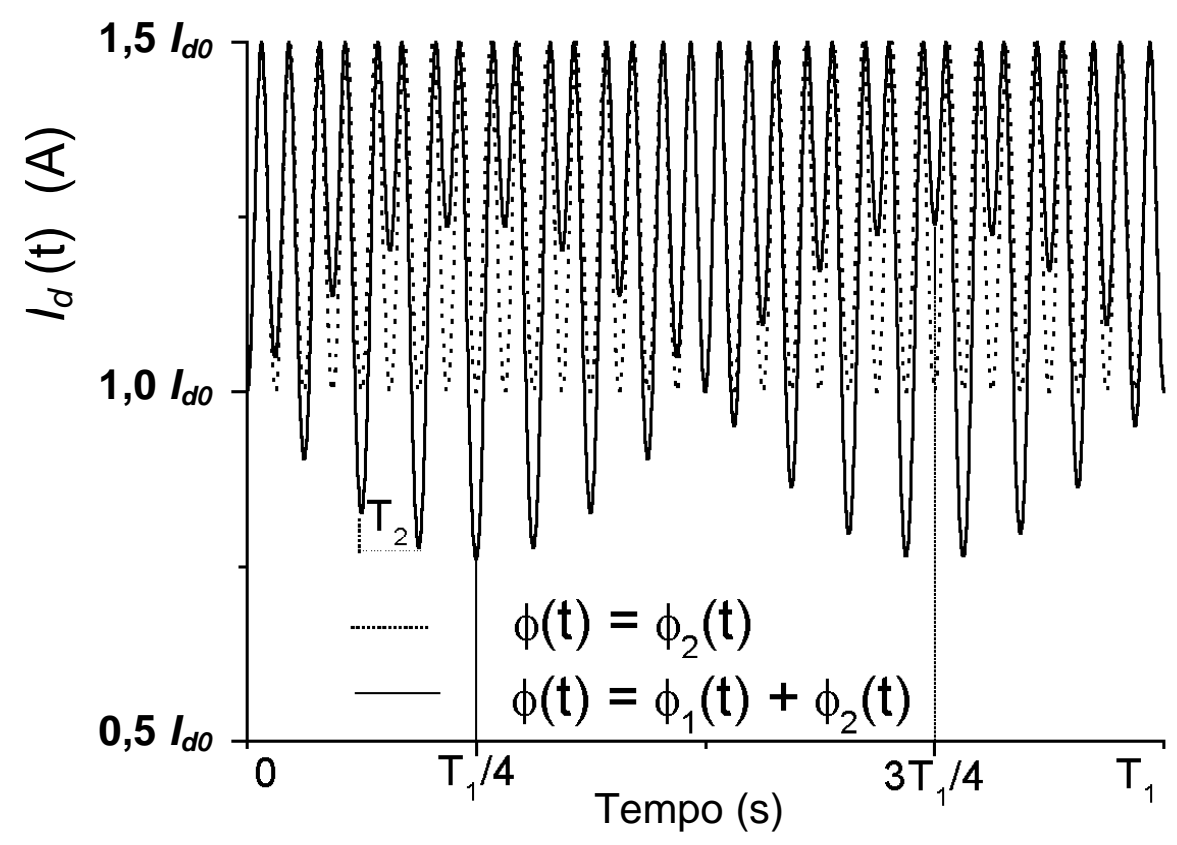

Figura $41-I_{d}(t)$, para as modulações $\phi_{1}(t)=0,5 \operatorname{sen}\left(\omega_{1} t\right)$ e $\phi_{2}(t)=\pi / 2 \operatorname{sen}\left(\omega_{2} t\right)$, sendo $\omega_{2}=16 \omega_{1}$ [33].

Observa-se para cada ciclo da frequência $\omega_{1}$ da alta tensão, que:

- Os valores dos vales variam com $\phi_{1}(t)$, e ocorrem próximos aos instantes $T_{2} / 4$ e $3 T_{2} / 4$ de cada ciclo da modulação de fase óptica $\phi_{2}(t)$. Os mesmos se alternam acima e abaixo do valor de referência obtido para $\phi_{1}(t)=0$;

- Os valores dos picos não variam com a modulação de fase óptica $\phi_{1}(t)$ e ocorrem em instantes simétricos à $T_{2} / 2$ em cada ciclo da modulação de fase óptica $\phi_{2}(t)$.

$\mathrm{Na}$ Figura 42, a seguir, proporciona-se uma melhor compreensão do que foi exposto anteriormente, pois ilustra, para $\omega_{2}=256 \omega_{1}$, a ampliação no domínio do tempo de um ciclo da curva da fotocorrente $I_{d}(t)$ [33]. 


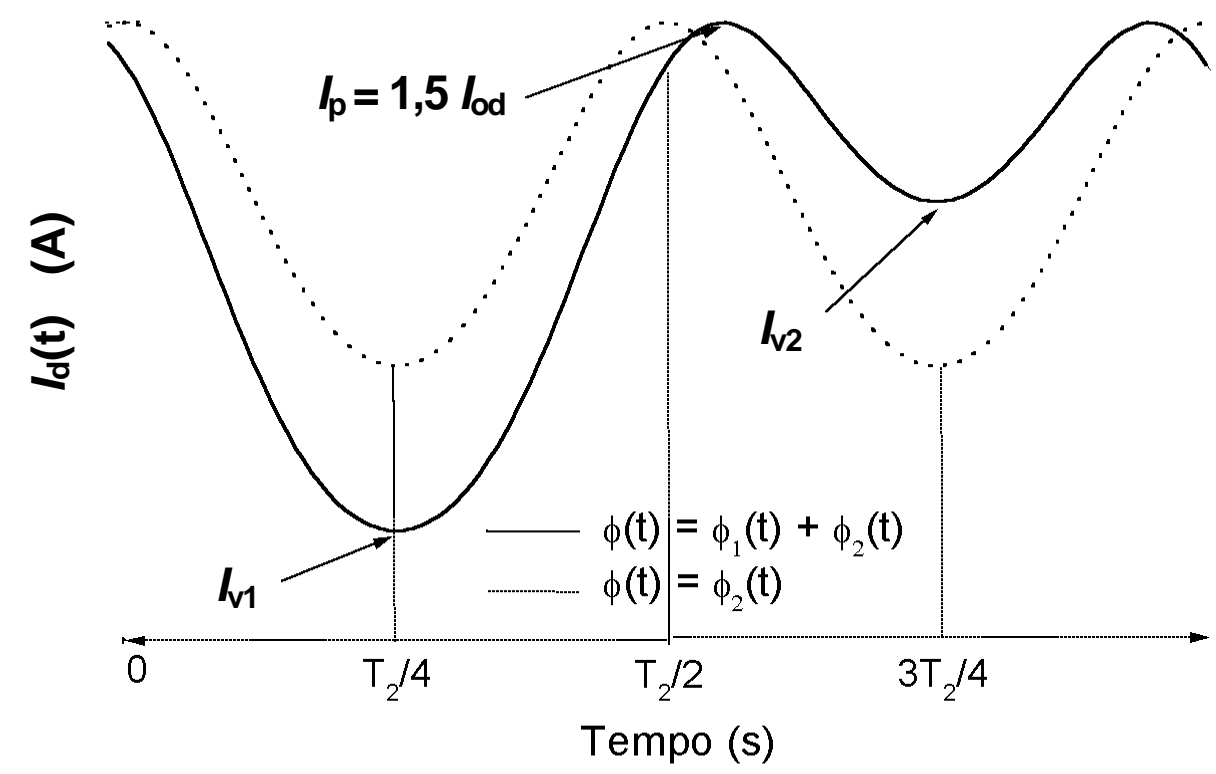

Figura 42 - Ampliação no domínio do tempo de um ciclo de $I_{d}(t)$, para as modulações $\phi_{1}(\mathrm{t})=0,5$ $\operatorname{sen}\left(\omega_{1} t\right)$ e $\phi_{2}(t)=2 \pi \operatorname{sen}\left(\omega_{2} t\right)$, sendo $\omega_{2}=256 \omega_{1}$ [33].

Observa-se na Figura 42, a ocorrência de:

- Um valor de vale $I_{v 1}$ e um valor de vale $I_{v 2}$, acima e abaixo, respectivamente, do valor de referência obtido para $\phi_{1}(t)=0$;

- Um valor de pico $I_{p}$, próximo à $T_{2} / 2$.

Expandindo $I_{d}(t)$ dada pela eq. (5.26) em funções de Bessel, obtém-se a expressão [33]:

$$
\begin{aligned}
I_{d}(t)= & I_{d 0}\left\{1+\frac{1}{2}\left[J_{0}\left(\phi_{2}\right)+2 \sum_{n} J_{2 n}\left(\phi_{2}\right) \cos \left(2 n \omega_{2} t\right)\right] \cos \left[\phi_{1}(t)\right]\right\}+ \\
& -I_{d 0}\left\{\sum_{n} J_{2 n-1}\left(\phi_{2}\right) \operatorname{sen}\left[(2 n-1) \omega_{2} t\right] \operatorname{sen}\left[\phi_{1}(t)\right]\right\}
\end{aligned}
$$


Na eq. (5.27), $n \in N^{*}, J_{n}$ é a função de Bessel de ordem $n$ e primeira espécie. Da eq. (5.26) e eq. (5.27) as componentes de baixa frequência, $\left(\omega<<\left(\omega_{2}-\omega_{1}\right)\right)$, da corrente $I_{d}(t)$ podem ser expressas por, $I_{b f}(t)$, como [33]:

$$
I_{b f}(t)=I_{d o}\left\{1+\frac{1}{2} J_{0}\left(\phi_{2}\right) \cos \left[\phi_{1}(t)\right]\right\}
$$

Em instrumentação óptica é comum o uso de amplificadores de transimpedância, para converter em tensão, a fotocorrente gerada por fotodiodos. Neste tipo de amplificador, cuja topologia básica é mostrada na Figura 43, abaixo, a tensão de saída, $V_{d}(t)$, relaciona-se com a corrente do fotodiodo utilizado, $I_{d}(t)$ da seguinte forma [33]:

$$
V_{d}(t)=R_{f} l_{d}(t)
$$

onde:

$R_{f}$ é a resistência de realimentação do amplificador de transimpedância.

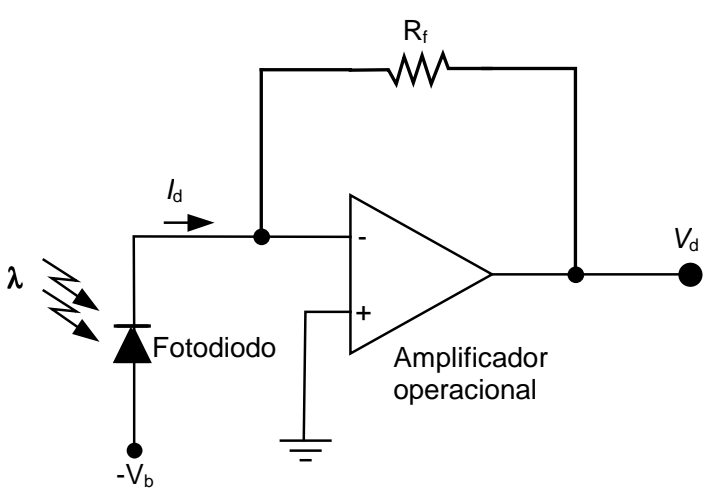

Figura 43 - Configuração básica e um amplificador de transimpedância. 
Portanto, utilizando um amplificador de transimpedância e substituindo a eq. (5.28) na eq. (5.29), as componentes de baixa frequência, $V_{b f}(t)$, da tensão de saída podem ser escritas como [33]:

$$
V_{b f}(t)=V_{0 d}\left\{1+\frac{1}{2} J_{0}\left(\phi_{2}\right) \cos \left[\phi_{1}(t)\right]\right\}
$$

onde:

$$
V_{0 d}=R_{f} I_{0 d}
$$

Da eq. (5.30) deduz-se que o valor de pico da tensão de saída do sistema é [33]:

$$
V_{p}=1,5 V_{0 d}
$$

Como foi feito anteriormente, infere-se da eq. (5.26) e (5.27) que as componentes de alta frequência, $V_{a f}(t)$ da tensão de saída do amplificador de transimpedância, caracterizadas por $\omega_{1}>\omega$, podem ser expressas como [33]:

$$
V_{a f}(t)=V_{0 d}\left\{\frac{1}{2}\left[\cos \left(\phi_{1}(t)+\phi_{2} \operatorname{sen}\left(\omega_{2} t\right)\right)-J_{0}\left(\phi_{2}\right) \cos \left(\phi_{1}(t)\right)\right]\right\}
$$

Portanto, da eq. (5.32) resultam as seguintes expressões para os valores dos vales, $V_{v 1}$ e $V_{v 2}[33]:$

$$
\begin{aligned}
& V_{v 1}=\frac{V_{0 d}}{2}\left[\cos \left(\phi_{2}+\phi_{1}(t)\right)-J_{0}\left(\phi_{2}\right) \cos \left(\phi_{1}(t)\right)\right] \\
& V_{v 2}=\frac{V_{0 d}}{2}\left[\cos \left(\phi_{2}-\phi_{1}(t)\right)-J_{0}\left(\phi_{2}\right) \cos \left(\phi_{1}(t)\right)\right]
\end{aligned}
$$


Das eqs. (5.33) e (5.34), pode-se expressar os valores das tensões de vale $V_{v 1}$ e $V_{v 2}$ como [33]:

$$
\begin{aligned}
& V_{v 1}=\frac{V_{0 d}}{2}\left\{\cos \left(\phi_{2}\right) \cos \left[\phi_{1}(t)\right]-\operatorname{sen}\left(\phi_{2}\right) \operatorname{sen}\left[\phi_{1}(t)\right]\right\}-\frac{V_{0 d}}{2}\left\{J_{0}\left(\phi_{2}\right) \cos \left(\phi_{1}(t)\right)\right\} \\
& V_{v 1}=\frac{V_{0 d}}{2}\left\{\cos \left(\phi_{2}\right) \cos \left[\phi_{1}(t)\right]+\operatorname{sen}\left(\phi_{2}\right) \operatorname{sen}\left[\phi_{1}(t)\right]\right\}-\frac{V_{0 d}}{2}\left\{J_{0}\left(\phi_{2}\right) \cos \left(\phi_{1}(t)\right)\right\}
\end{aligned}
$$

Conclui-se das eq. (5.35) e (5.36) que o valor absoluto do desvio máximo entre os valores consecutivos, $\left|\Delta V_{v}\right|$, é expresso como [33]:

$$
\left|\Delta V_{v}\right|=\left|V_{v 1}-V_{v 2}\right|=\left|-V_{0 d} \operatorname{sen}\left(\phi_{2}\right) \operatorname{sen}\left[\phi_{1}(t)\right]\right|
$$

No intervalo $0 \leq \phi_{2} \leq \pi$, o valor de $\left|\Delta V_{v}\right|$ é maximizado em relação à amplitude $\phi_{2}$ da modulação de fase óptica $\phi_{2}(t)$, quando $\phi_{2}(t)=\pi / 2$, e pode ser escrito por [33]:

$$
\left|\Delta V_{v}\right|_{\phi_{2}=\pi / 2}=V_{0 d}\left|\operatorname{sen}\left[\phi_{1}(t)\right]\right|
$$

Isolando $\phi_{1}(t)$ na eq. (5.38) acima, obtém-se [33]:

$$
\phi_{1}(t)_{\phi_{2}=\pi / 2}=\operatorname{arcsen}\left(\frac{V_{v 2}-V_{v 1}}{V_{0 d}}\right)=\operatorname{arcsen}\left(\frac{V_{v 2}-V_{v 1}}{\frac{V_{p}}{1,5}}\right)
$$

Infere-se da eq. (5.39) que, por se estar operando num ponto de máximo da função $\operatorname{sen}\left(\phi_{2}\right), \partial \Delta V_{v} / \partial \phi_{2}=0$ e que, portanto, uma variação de 500 ppm no parâmetro $\phi_{2}$ 
implicará numa variação inferior a $1 \mathrm{ppm}$ em $\Delta V_{v}$. Portanto, no intervalo $\left|\phi_{2}\right| \leq \pi$, $\phi_{2}=\pi / 2$ é o valor da amplitude de modulação de fase óptica que:

- Maximiza a sensibilidade diferencial dos valores dos vales com relação a $\phi_{1}(t)$;

- Minimiza a deriva do fator de escala eletrônico em relação à variação de $\phi_{2}$;

- Maximiza a faixa dinâmica de medida de $\phi_{1}(t)$, isto é, $\left|\phi_{1}(t)\right|_{\max }=\pi / 2$.

Uma vez apresentado e discutido o tratamento matemático do processamento utilizado, ilustra-se na Figura 43, a seguir, o diagrama de blocos do processador do sinal implementado para a demodulação do sinal de alta tensão em CA, aplicado ao interferômetro sensor do protótipo de TPO.

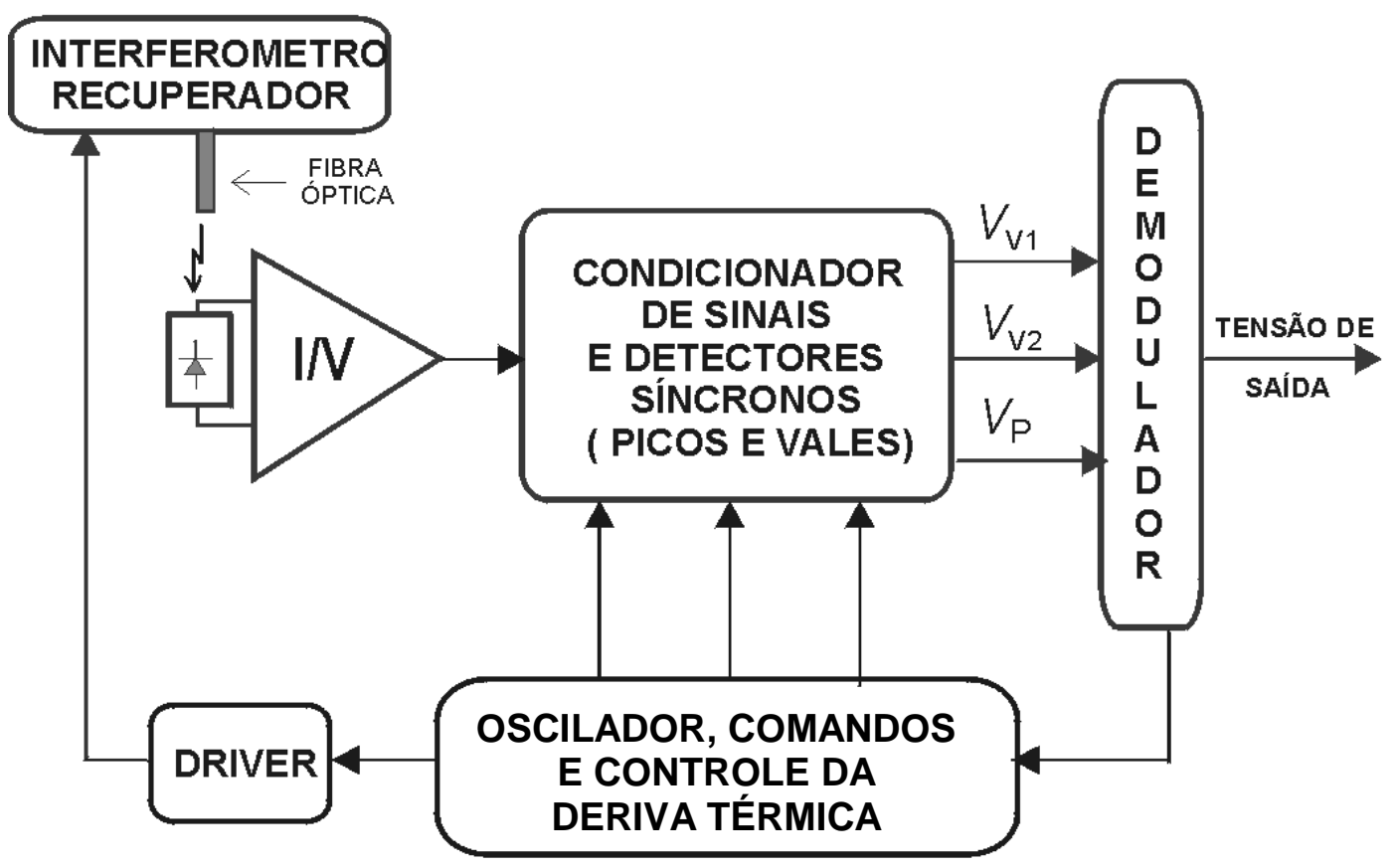

Figura 43 - Diagrama de blocos do processador do sinal de saída do interferômetro recuperador do protótipo de TPO [33]. 


\section{RESULTADOS EXPERIMENTAIS}

Conforme verificado pelo autor em seu trabalho de mestrado [7], o valor de $\mathrm{V}_{\pi 1}$ (célula de alta tensão) medido foi de aproximadamente 81,5 kV $\mathrm{rms}_{\mathrm{rms}}$ (1321 nm) enquanto que o valor previsto teoricamente pela eq. (5.15) é de $69,4 \mathrm{kV}_{\mathrm{rms}}$.

Constatou-se que essa diferença deve-se a um desalinhamento entre as direções dos eixos ópticos do cristal de BGO e as direções em que o mesmo foi cortado, o que pôde ser verificado através de uma medida feita por meio de um teste de difratometria (Lauegrama). Ainda segundo a eq. (5.15), mas agora com a fonte óptica de $1550 \mathrm{~nm}$, a partir do resultado experimental, o valor de $\mathrm{V}_{\pi 1}$ é de aproximadamente $93,9 \mathrm{kV}_{\mathrm{rms}}$, contra um valor teórico de $81,5 \mathrm{kV}_{\mathrm{rms}}$.

$\mathrm{O}$ valor de $\mathrm{V}_{\pi 2}$ (célula recuperadora) medido foi de aproximadamente 2,35 volts, que é aproximadamente a metade do valor da tensão de meia onda fornecido pelo fabricante do modulador eletro-óptico utilizado ( $\leq 4,5 \mathrm{~V} @ 1550 \mathrm{~nm})$. Esta diferença no valor de $\mathrm{V}_{\pi 2}$ justifica-se pelo fato da luz passar duas vezes pelo modulador, ou seja, uma no caminho de ida e outra no caminho de volta, devido à configuração reflexiva do modulador.

Desta forma a luz sofre a interação eletro-óptica duas vezes, ocasionando a redução do valor de $\mathrm{V}_{\pi 2}$ à metade. Por outro lado, como este valor não é exatamente a metade do valor da tensão de meia onda fornecido pelo fabricante, esta diferença pode ter ocorrido devido ao fato do comprimento de onda central do SLD utilizado ser de $1560 \mathrm{~nm}$, enquanto que o modulador é especificado para operar em $1310 \mathrm{~nm}$.

Os circuitos ópticos utilizados neste trabalho foram integrados à eletrônica de processamento de sinal e o conjunto submetido a ensaios de caracterização do protótipo de TPO. Na implementação do processador destacamos que:

- O interferômetro recuperador foi alimentado com sinal senoidal proveniente da Unidade de Processamento Eletrônico de Sinais (cuja frequência é de 16 $\mathrm{kHz}$, tensão de metade de $V_{\pi}$, ou seja, $V_{\pi} / 2=2,35 / 2 \cong 1,17 V$, etc; 
- Para atender ao requisito de se utilizar uma fonte de espectro largo (e baixa coerência temporal) devido à técnica utilizada, a fonte de luz empregada foi um diodo superluminescente (SLD), cujo comprimento de onda central típico é $1560 \mathrm{~nm}$ e potência de saída típica de $5 \mathrm{~mW}$;

- A detecção óptica foi feita através de um fotodiodo PIN (InGaAs), com faixa espectral de 1250-1600 nm e responsividade 0,9 (A/W).

- A fotocorrente detectada foi convertida em tensão por meio de um amplificador de transimpedância com ganho da ordem de $2,7 \times 10^{6}(\mathrm{~V} / \mathrm{A})$.

O protótipo de TPO ao qual foi integrado o processador de sinais desenvolvido foi submetido a ensaios funcionais para verificar o seu desempenho quando submetido a tensões CA na faixa de $690 \mathrm{~V}_{\text {rms }}$ a aproximadamente $8000 \mathrm{~V}_{\text {rms }}$.

Nestes ensaios foram feitas as análises, nos domínios do tempo e da frequência, da tensão elétrica em C.A. aplicada ao interferômetro sensor e da tensão demodulada na saída do processador de sinais. Estes ensaios foram realizados no LSO/PEAUSP e, posteriormente, outros ensaios poderão ser realizados no Laboratório de Altas Tensões do IEE-USP.

No que se refere ao percentual medido de luz refletida na extremidade metalizada das fibras ópticas de saída do modulador em $Y$ utilizado, o valor apresentado, ( $77 \%$ ), é menor do que o obtido em espelhos de Prata típicos, que podem alcançar a casa dos $99 \%$ [46].

Como possível causa dessa diferença, há que se considerar que a densidade de potência óptica proveniente da fonte óptica, concentrada na região extremamente pequena do núcleo da fibra óptica, ser muito elevada e que, dependendo da espessura da camada de Prata depositada, pode haver penetração de parte da luz no filme e sua consequente transmissão para o meio externo, ocasionando uma perda da potência óptica refletida para a fibra. 


\subsection{ENSAIOS FUNCIONAIS DO CONJUNTO TPO E PROCESSADOR DE SINAIS NO LSO}

$\mathrm{Na}$ Figura 44, abaixo, ilustra-se uma parte do LSO onde nota-se o transformador elevador capaz de aplicar tensões de até aproximadamente $80 \mathrm{kV}_{\mathrm{rms}}$, e cujo secundário está ligado ao interferômetro sensor do protótipo de TPO. Muito embora o transformador elevador possa fornecer tensões mais elevadas, nos ensaios realizados no LSO, usualmente, não são aplicadas tensões superiores a 13,8 kV rms $_{\text {s }}$ aos protótipos por motivos de segurança ligados às distâncias de isolação mínimas requeridas.

Os acessos do interferômetro sensor estão ligados por fibras ópticas monomodo à fonte de luz e ao circulador óptico que compõe, juntamente com o interferômetro recuperador e o fotodetector, o sistema de processamento de sinais ópticos do TPO. O interferômetro recuperador está ligado através de cabo coaxial à Unidade de Processamento de Sinais Eletrônicos do TPO.

Para obter os sinais de referência, que são comparados aos sinais de saída do processador eletrônico do conversor secundário, a medição direta das tensões aplicadas ao sensor primário foi realizada no secundário do transformador elevador por meio de uma ponta de prova de alta tensão fabricada pela empresa Tektronix, modelo PC60115A, capaz de medir com precisão tensões de até 20 kV $\mathrm{PP}$. Conforme foi dito anteriormente, o protótipo de TPO ao qual foi integrado o processador de sinais utilizado foi submetido a ensaios funcionais para verificar o seu desempenho quando submetido à tensões C.A. , em $60 \mathrm{~Hz}$, na faixa de $0,69 \mathrm{kV}_{\mathrm{rms}}$ a $8 \mathrm{kV}_{\mathrm{rms}}$, aproximadamente.

Nos ensaios procedeu-se as análises nos domínios do tempo e da frequência da tensão elétrica em C.A. aplicada ao interferômetro sensor e da tensão demodulada na saída do processador de sinais.

$\mathrm{Na}$ Figura 45, a seguir, são indicados os componentes utilizados no conjunto recuperador do protótipo de TPO, são eles: a unidade de processamento eletrônico de sinais, fonte óptica (SLD), circulador óptico, célula recuperadora volumétrica, 
modulador em Y, amplificador de transimpedância, acoplador direcional, fotodetector e o osciloscópio utilizado na aquisição das formas de onda.

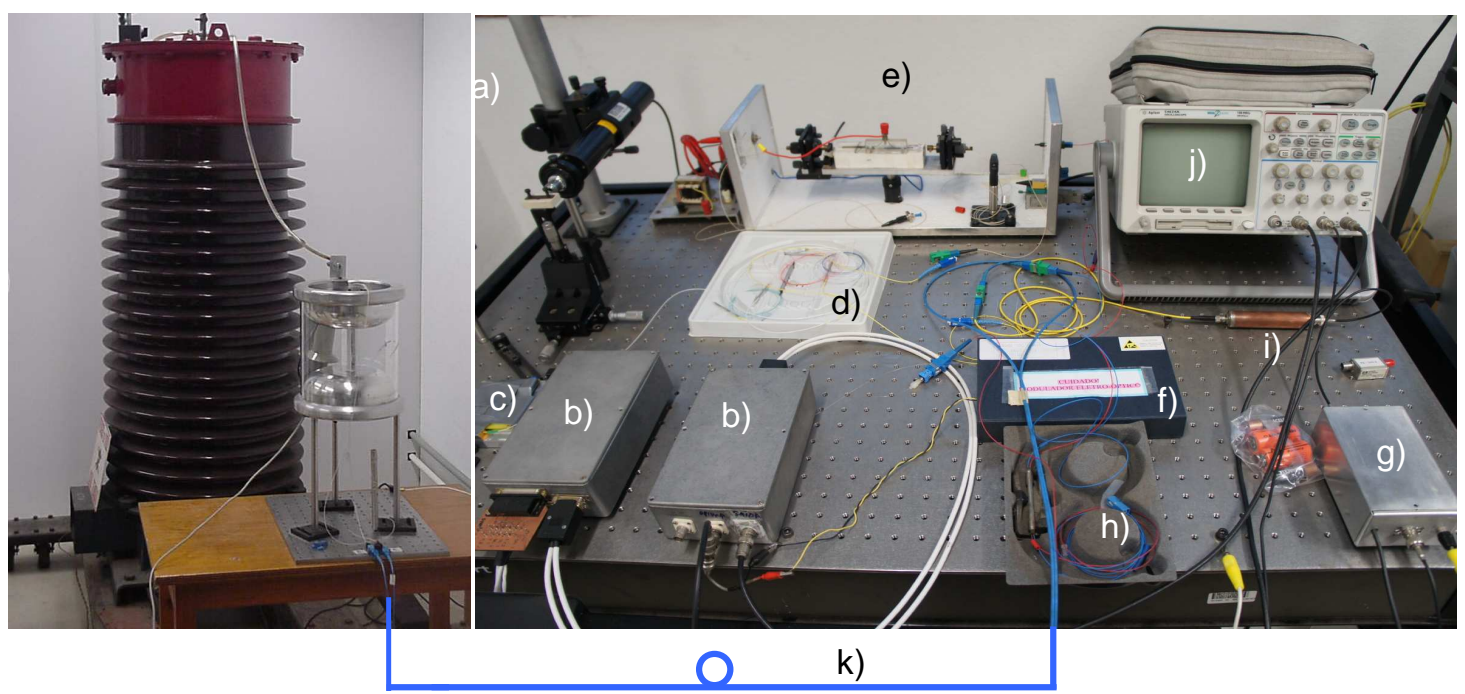

Figura 45 - llustrações do protótipo de TPO construído. a) Transformador elevador de tensão, b) unidade de processamento eletrônico de sinais, c) Fonte óptica (SLD), d) circulador óptico, e) célula recuperadora volumétrica, f) modulador em $\mathrm{Y}$ em óptica integrada, g) amplificador de transimpedância, h) Acoplador direcional, i) fotodetector, j) osciloscópio e k) par de fibras ópticas.

$\mathrm{Na}$ Figura 46, abaixo, ilustra-se a forma de onda da tensão, da ordem de $0,69 \mathrm{kV}_{\mathrm{rms}}$, aplicada ao interferômetro sensor, e a forma de onda da tensão correspondente na saída do processador de sinais do TPO. 


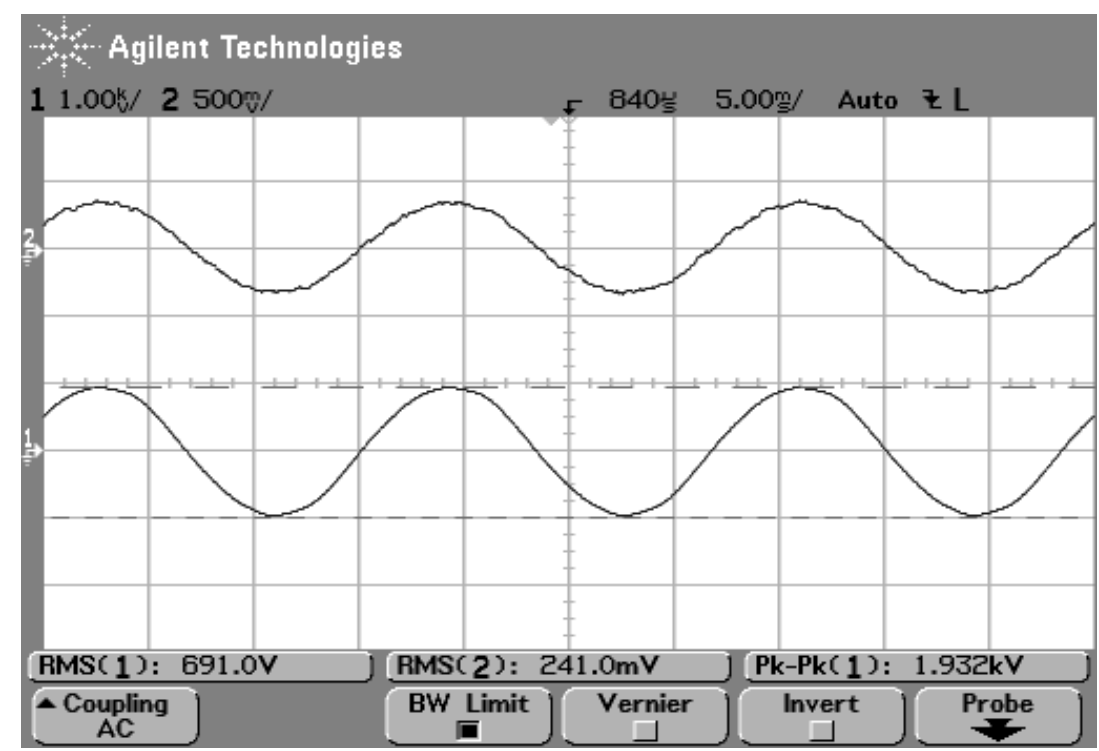

Figura 46 - Formas de onda da tensão da ordem de 0,69 kV $\mathrm{rms}_{\mathrm{rms}}$, aplicadas ao interferômetro sensor (canal 1, traço inferior) e da tensão correspondente na saída do processador de sinais (canal 2, traço superior) do TPO.

$\mathrm{Na}$ Figura 47, abaixo, ilustra-se o espectro de frequências na saída da ponta de prova de alta tensão monitorando o sinal de $0,69 \mathrm{kV}_{\text {rms }}$, aplicado ao sensor primário do TPO.

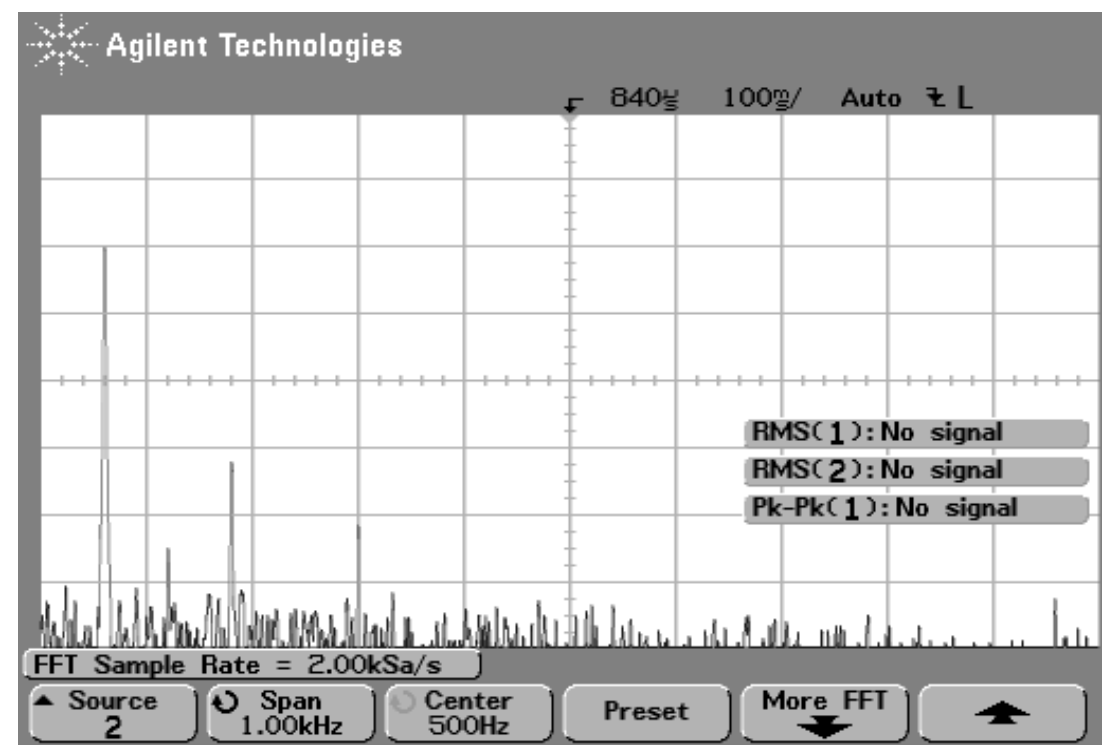

Figura 47 - Espectro de frequências do sinal alternado de $0,69 \mathrm{kV}_{\mathrm{rms}}$ aplicado ao interferômetro sensor do TPO. 
$\mathrm{Na}$ Figura 48, abaixo, ilustra-se o espectro de frequência na saída do processador de sinais para uma tensão alternada de $0,69 \mathrm{kV}_{\text {rms }}$, aplicada ao interferômetro sensor do TPO.

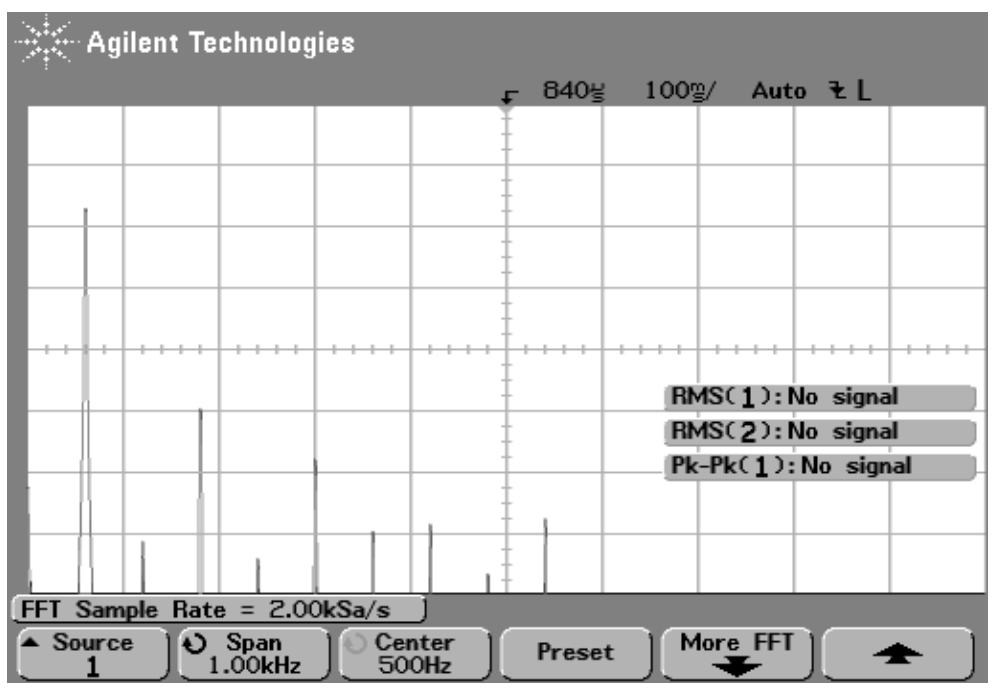

Figura 48 - Espectro de frequências do sinal na saída do processador de sinais para uma tensão alternada de $0,69 \mathrm{kV}_{\mathrm{rms}}$ aplicada ao interferômetro sensor do TPO.

$\mathrm{Na}$ Figura 49, abaixo, ilustra-se as formas de onda da tensão, da ordem de $1 \mathrm{kV}_{\mathrm{rms}}$, aplicada ao interferômetro sensor do TPO, e a forma de onda da tensão correspondente na saída do processador de sinais do TPO.

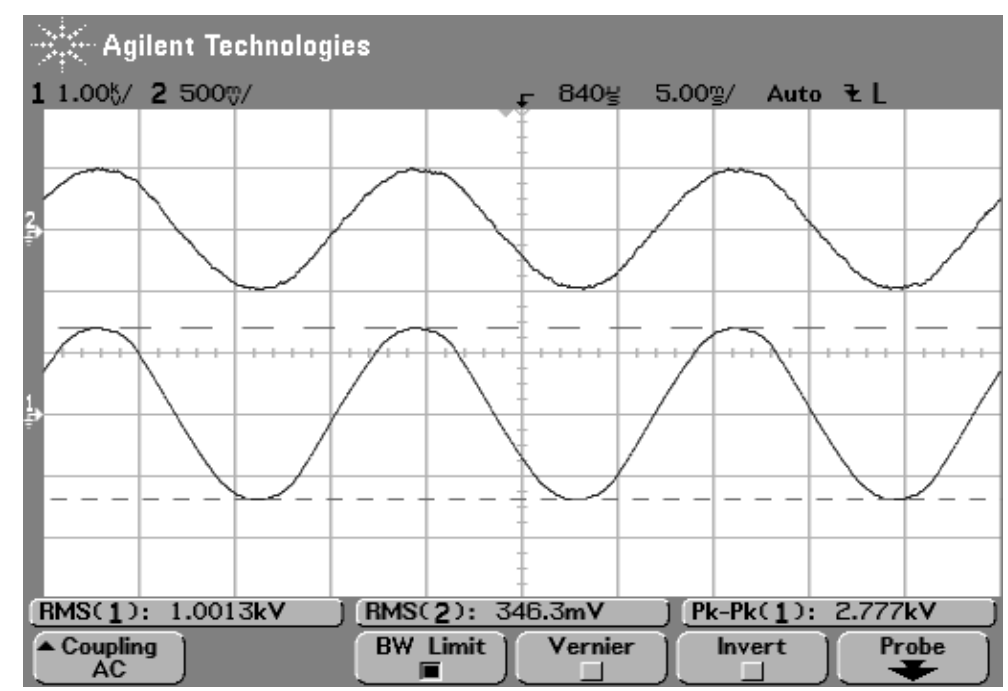

Figura 49 - Formas de onda da tensão da ordem de $1 \mathrm{kV}_{\text {rms }}$, aplicada ao interferômetro sensor (canal 1, traço inferior) e da tensão correspondente na saída do processador de sinais (canal 2, traço superior) do TPO. 
$\mathrm{Na}$ Figura 50, abaixo, ilustra-se o espectro de frequências na saída da ponta de prova de alta tensão monitorando o sinal de $1 \mathrm{kV}_{\text {rms }}$ aplicado ao interferômetro sensor do TPO.

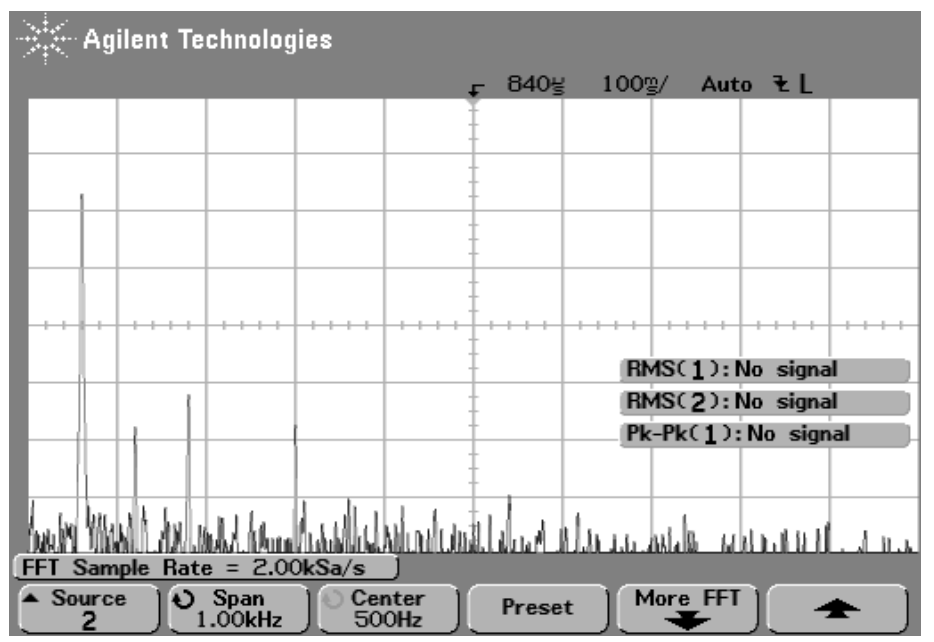

Figura 50 - Espectro de frequências do sinal alternado de $1 \mathrm{kV}_{\mathrm{rms}}$, aplicado ao interferômetro sensor do TPO.

Na Figura 51, abaixo, ilustra-se o espectro de frequência na saída do processador de sinais para uma tensão alternada de $1 \mathrm{kV}_{\mathrm{rms}}$, aplicada ao interferômetro sensor do TPO.

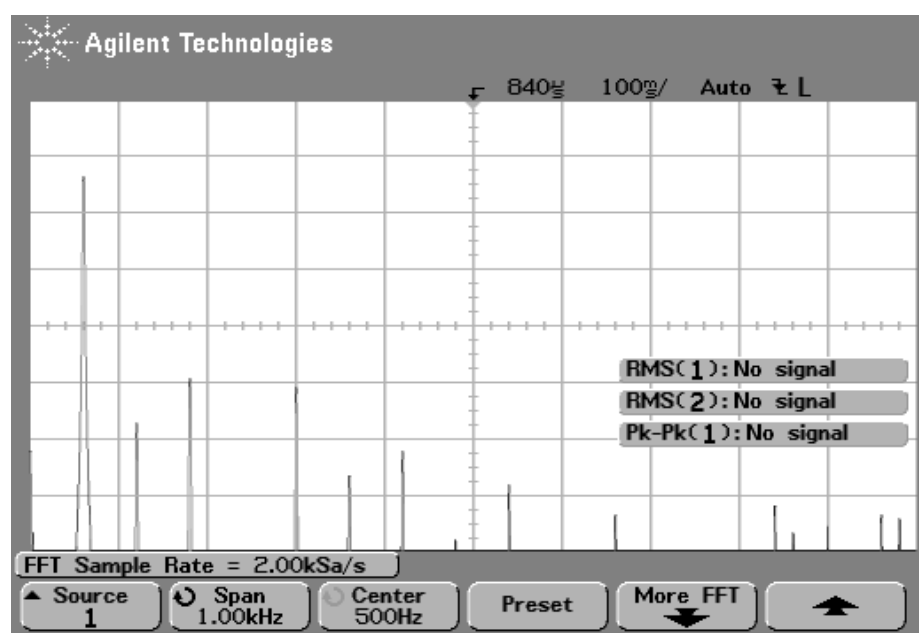

Figura 51 - Formas de onda da tensão da ordem de $2 \mathrm{kV}_{\mathrm{rms}}$, aplicadas ao interferômetro sensor (canal 1, traço inferior) e da tensão correspondente na saída do processador de sinais (canal 2, traço superior) do TPO. 
$\mathrm{Na}$ Figura 52, abaixo, ilustra-se a forma de onda da tensão, da ordem de $2 \mathrm{kV}_{\mathrm{rms}}$, aplicada ao interferômetro sensor, e a forma de onda da tensão correspondente na saída do processador de sinais do TPO.

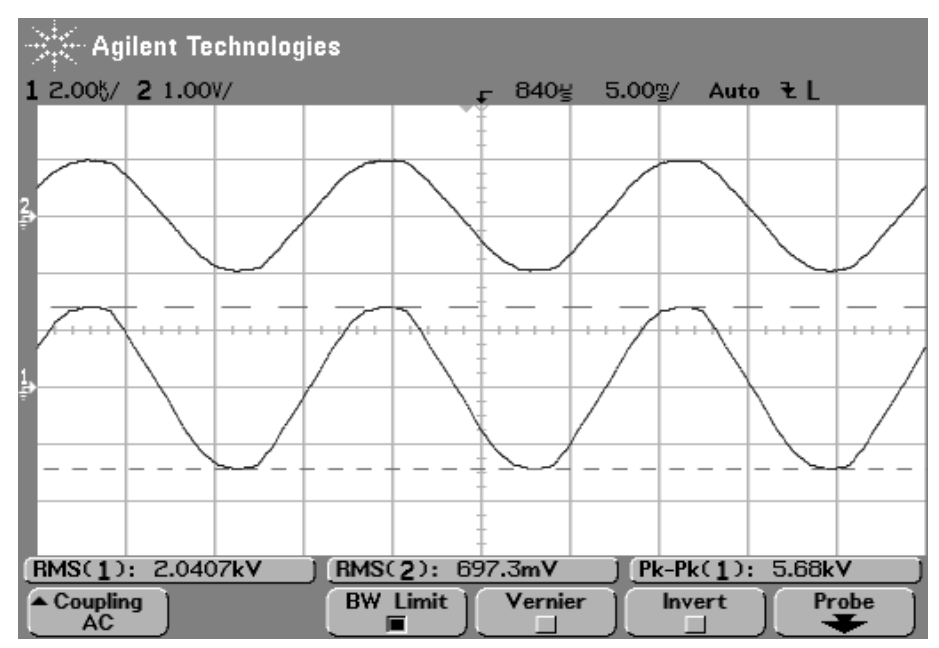

Figura 52 - Formas de onda da tensão da ordem de $2 \mathrm{kV}_{\mathrm{rms}}$, aplicadas ao interferômetro sensor (canal 1, traço inferior) e da tensão correspondente na saída do processador de sinais (canal 2) do TPO.

$\mathrm{Na}$ Figura 53, abaixo, ilustra-se o espectro de frequências na saída da ponta de prova de alta tensão monitorando o sinal de $2 \mathrm{kV}_{\mathrm{rms}}$, aplicado ao sensor primário do TPO.

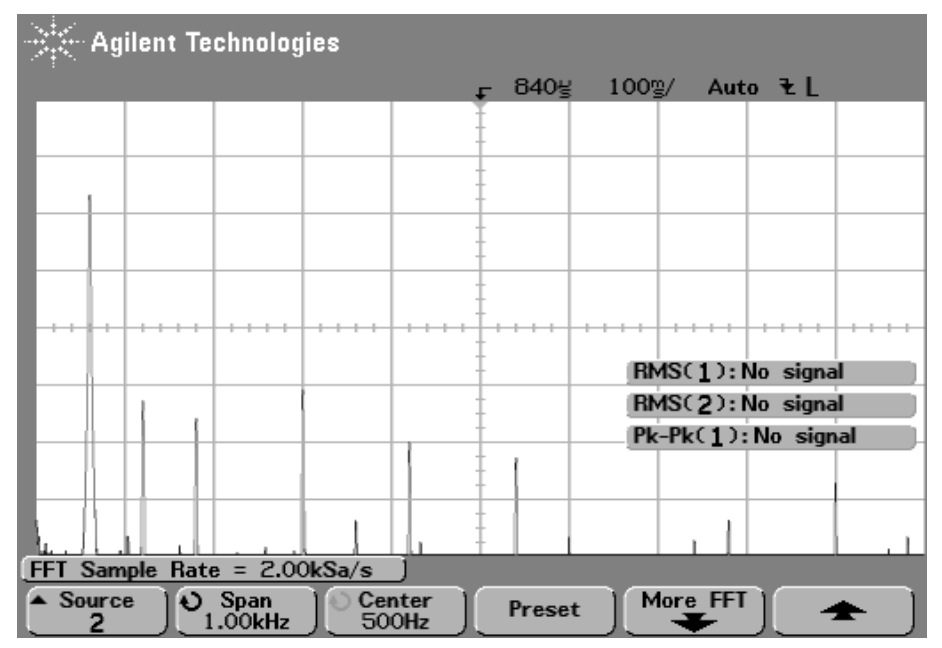

Figura 53 - Espectro de frequências do sinal alternado de $2 \mathrm{kV}_{\mathrm{rms}}$, aplicado ao interferômetro sensor do TPO. 
$\mathrm{Na}$ Figura 54, abaixo, ilustra-se o espectro de frequência na saída do processador de sinais para uma tensão alternada de $2 \mathrm{kV}_{\text {rms }}$, aplicada ao interferômetro sensor do TPO.

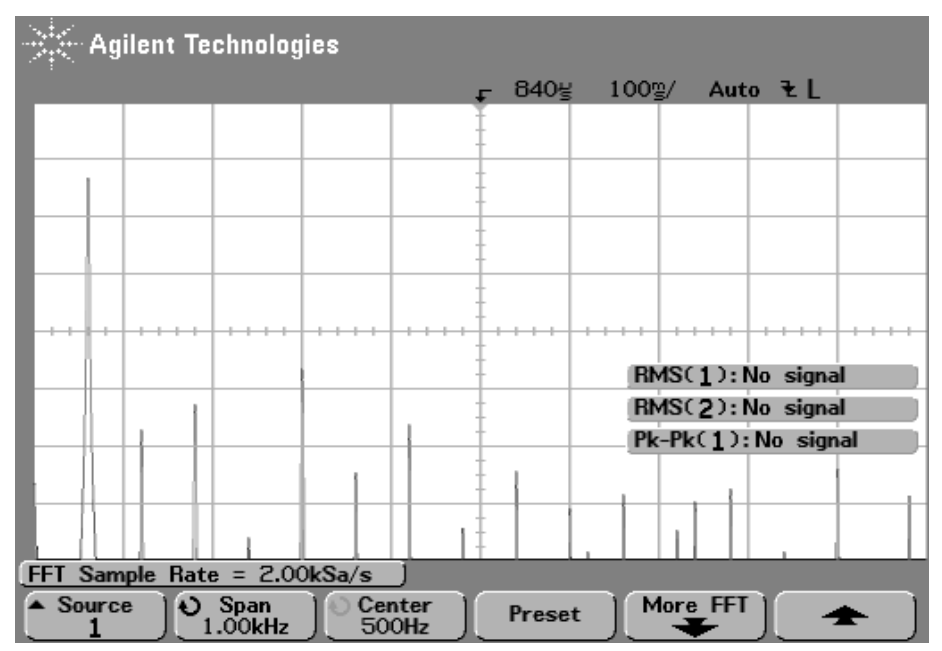

Figura 54 - Espectro de frequências do sinal na saída do processador de sinais para uma tensão alternada de $2 \mathrm{kV}$ rms aplicada ao interferômetro sensor do TPO.

$\mathrm{Na}$ Figura 55, abaixo, ilustra-se a forma de onda da tensão, da ordem de $4 \mathrm{kV}_{\mathrm{rms}}$, aplicada ao interferômetro sensor, e a forma de onda da tensão correspondente na saída do processador de sinais do TPO.

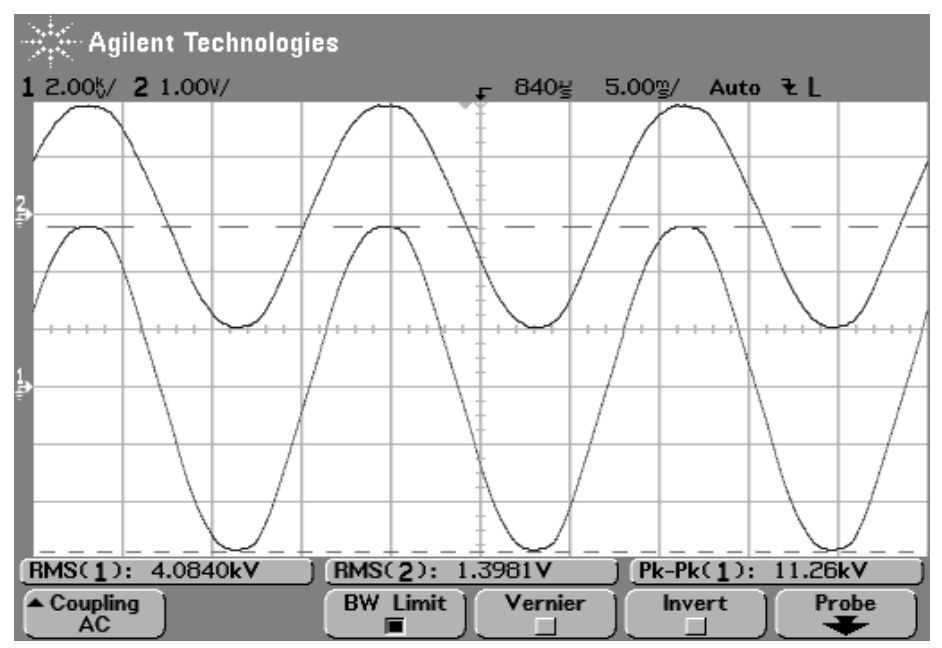

Figura 55 - Formas de onda da tensão da ordem de $4 \mathrm{kV}_{\mathrm{rms}}$, aplicada ao interferômetro sensor (canal 1, traço inferior) e da tensão correspondente na saída do processador d sinais (canal 2, traço superior) do TPO. 
$\mathrm{Na}$ Figura 56, abaixo, ilustra-se o espectro de frequências na saída da ponta de prova de alta tensão monitorando o sinal de $4 \mathrm{kV}_{\mathrm{rms}}$, aplicado ao sensor primário do TPO.

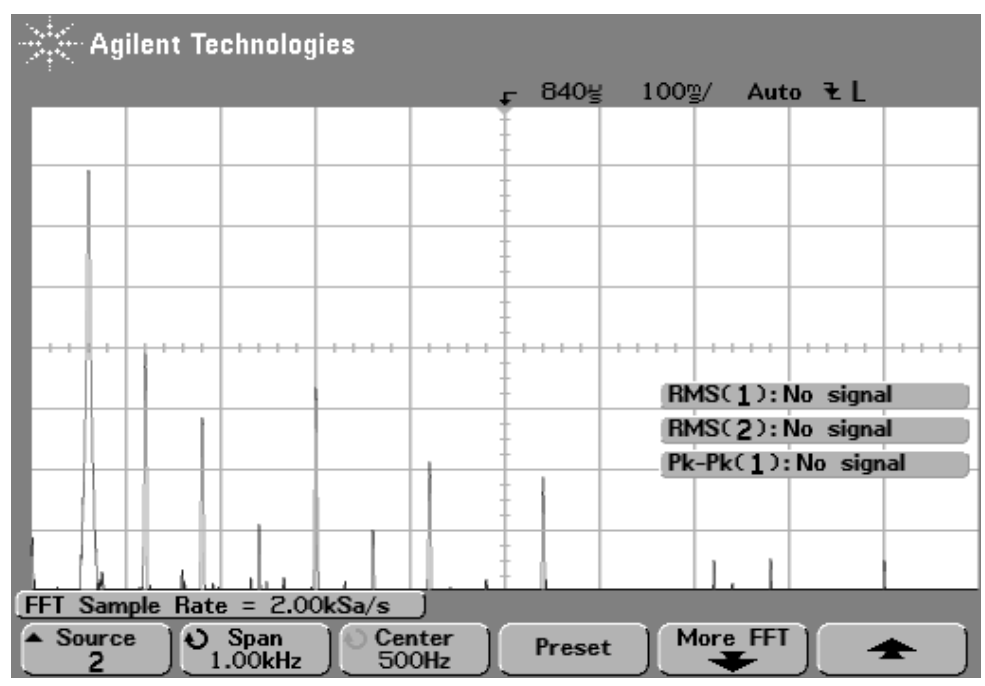

Figura 56 - Espectro de frequências do sinal alternado de $4 \mathrm{kV}_{\mathrm{rms}}$, aplicado ao interferômetro sensor do TPO.

Na Figura 57, abaixo, ilustra-se o espectro de frequência na saída do processador de sinais para uma tensão alternada de $4 \mathrm{kV}_{\text {rms }}$, aplicada ao interferômetro sensor do TPO.

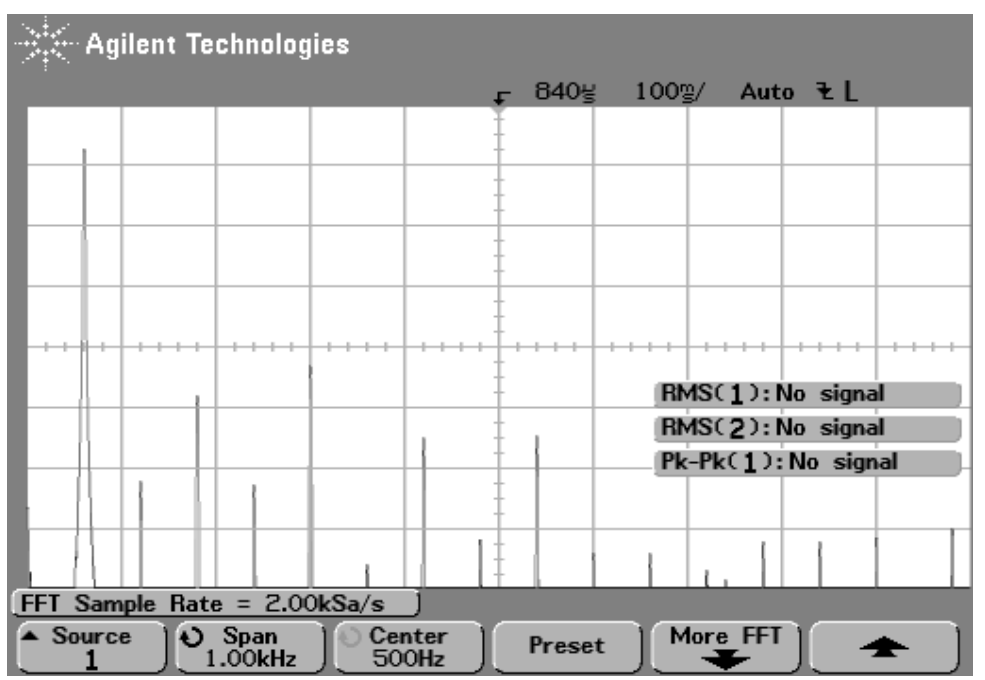

Figura 57 - Espectro de frequências do sinal na saída do processador de sinais para uma tensão alternada de $4 \mathrm{kV}_{\text {rms }}$ aplicada ao interferômetro sensor do TPO. 
Na Figura 58, abaixo, ilustra-se a forma de onda da tensão, da ordem de 8 kV $\mathrm{rms}_{\text {, }}$ aplicada ao interferômetro sensor, e a forma de onda da tensão correspondente na saída do processador de sinais do TPO.

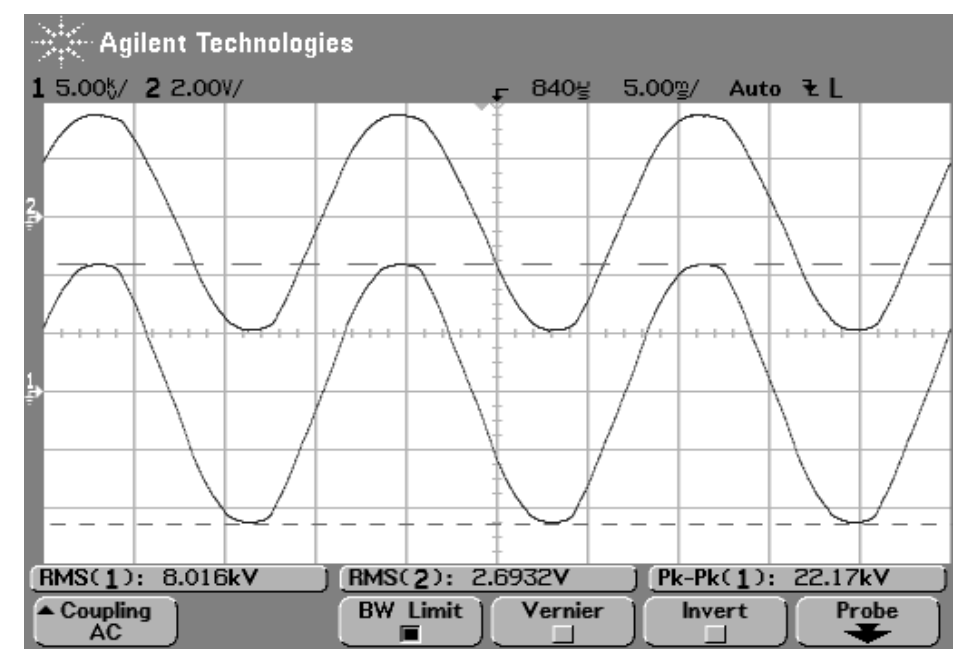

Figura 58 - Formas de onda da tensão da ordem de $8 \mathrm{kV}_{\mathrm{rms}}$, aplicada ao interferômetro sensor (canal 1, traço inferior) e da tensão correspondente na saída do processador de sinais (canal 2, traço superior) do TPO.

$\mathrm{Na}$ Figura 59, abaixo, ilustra-se o espectro de frequências na saída da ponta de prova de alta tensão monitorando o sinal de $8 \mathrm{kV}_{\mathrm{rms}}$, aplicado ao sensor primário do TPO.

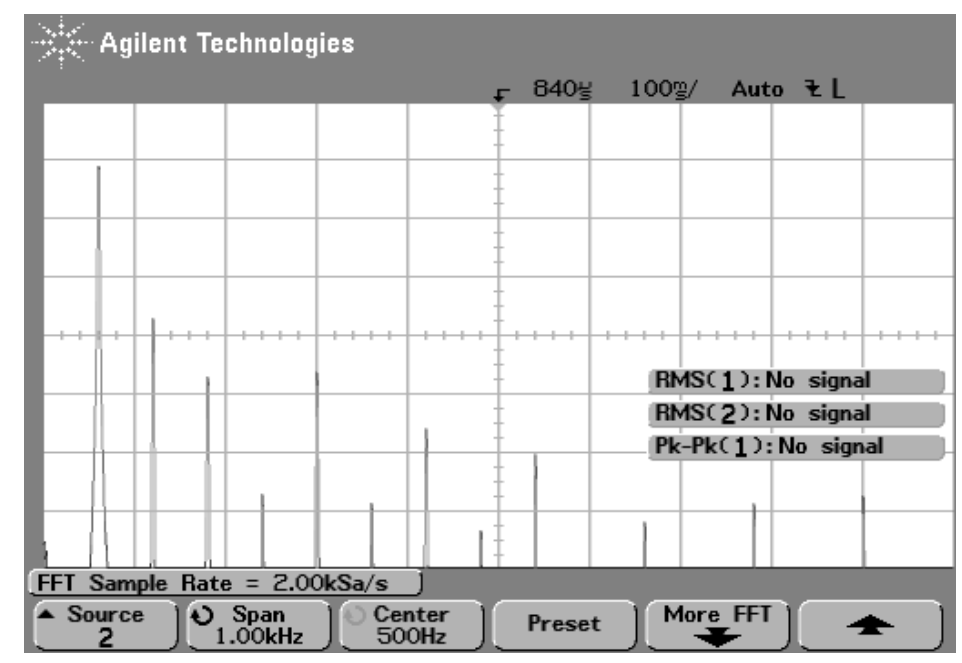

Figura 59 - Espectro de frequências do sinal alternado de $8 \mathrm{kV}_{\mathrm{rms}}$, aplicado ao interferômetro sensor do TPO. 
Na Figura 60, abaixo, ilustra-se o espectro de frequência na saída do processador de sinais para uma tensão alternada de $8 \mathrm{kV}_{\mathrm{rms}}$, aplicada ao interferômetro sensor do TPO.

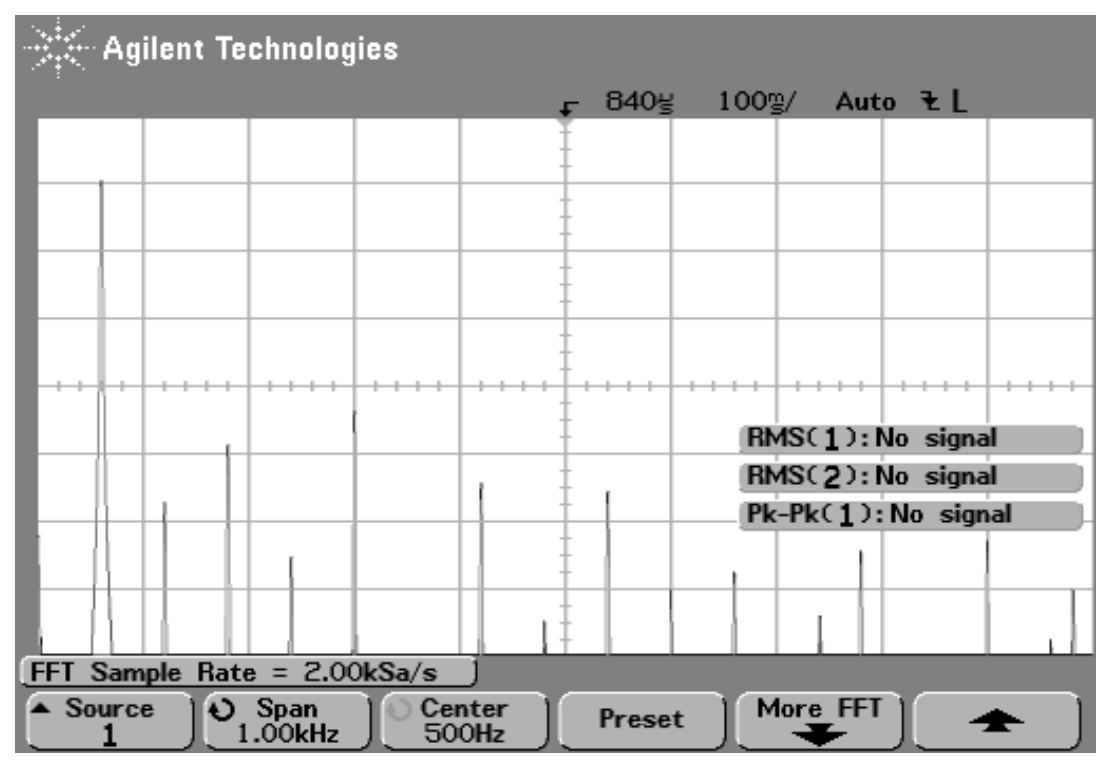

Figura 60 - Espectro de frequências do sinal na saída do processador de sinais para uma tensão alternada de 8 kV $\mathrm{rms}_{\text {sm }}$ aplicada ao interferômetro sensor do TPO. 


\section{DISCUSSÃO DOS RESULTADOS}

Os resultados obtidos neste trabalho, utilizando a célula recuperadora em montagem integrada, foram comparados com aqueles obtidos por Almeida [33] em que se utilizou a mesma célula recuperadora em montagem volumétrica montada pelo autor em seu trabalho de mestrado. Desta forma, justifica-se a comparação. Os ensaios do protótipo de TPO construído foram feitos no LSO/PEA e, pelos motivos de segurança expostos na seção 6.1, foram empregados os seguintes valores de tensão: $0,69 \mathrm{kV}_{\text {rms }}, 1 \mathrm{kV}_{\text {rms }}, 2 \mathrm{kV}_{\text {rms }}, 4 \mathrm{kV}_{\text {rms }}$ e $8 \mathrm{kV}_{\text {rms }}$.

Por outro lado, as tensões empregadas por Almeida [33] em seu trabalho no LSO/PEA foram de $0,55 \mathrm{kV}_{\text {rms }}$ e $8 \mathrm{kV}_{\text {rms }}$, e, os ensaios envolvendo tensões mais elevadas foram realizadas no Laboratório de Altas tensões do IEE-USP. Desta forma, apenas com estes valores, é possível fazer uma comparação entre as duas topologias empregadas.

Nas Figuras 61 a 63, a seguir, são apresentadas as formas de ondas destas duas topologias, onde a) representam as formas de onda obtidas por Almeida [33] $(0,55$ $\left.\mathrm{kV}_{\text {rms }}\right)$ e b) as formas de onda obtidas pelo autor $\left(0,69 \mathrm{kV}_{\mathrm{rms}}\right)$.

$\mathrm{Na}$ Figura 61, a seguir, ilustra-se a forma de onda da tensão, aplicada ao interferômetro sensor, e a forma de onda da tensão correspondente na saída do processador de sinais do TPO. 


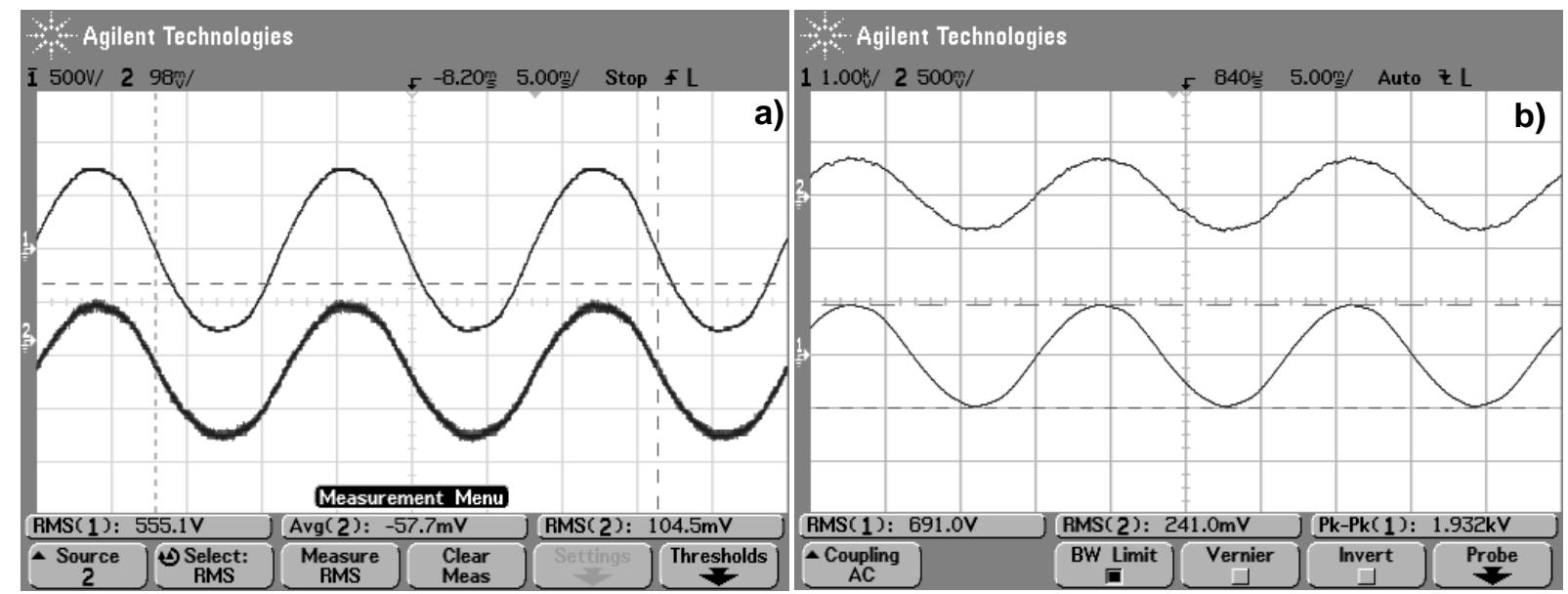

Figura 61 - a) Formas de onda da tensão da ordem de $0,55 \mathrm{kV}_{\mathrm{rms}}$, aplicada ao interferômetro sensor (canal 1, traço superior) e da tensão correspondente na saída do processador de sinais (canal 2) do TP Óptico [33]. b) Formas de onda da tensão da ordem de $0,69 \mathrm{kV}_{\mathrm{rms}}$, aplicadas ao interferômetro sensor (canal 1, traço inferior) e da tensão correspondente na saída do processador de sinais (canal 2, traço superior) do TPO.

A melhoria na relação sinal ruído dos sinais mostrados na Figura 61 (b) justifica-se pelos seguintes motivos:

1. A potência do SLD utilizado por Almeida [33] foi de $600 \mu \mathrm{W}$ enquanto que a potência do SLD utilizado pelo autor foi de $3 \mathrm{~mW}$;

2. No enlace entre a célula sensora e a célula recuperadora do trabalho de Almeida [33] foi utilizado um acoplador direcional enquanto que no trabalho do autor foi utilizado um circulador óptico.

3. Na célula recuperadora volumétrica utilizada por Almeida [33], o comprimento de onda central do SLD utilizado foi $1321 \mathrm{~nm}$ e o acoplador direcional de 1300 $\mathrm{nm}$. Neste trabalho, foi utilizada uma fonte cujo comprimento de onda central é de $1560 \mathrm{~nm}$, um circulador óptico de $1550 \mathrm{~nm}$ e um modulador em óptica integrada de $1310 \mathrm{~nm}$. Apesar do comprimento de onda do SLD não ser o mesmo do modulador em óptica integrada, a célula recuperadora em óptica integrada apresentou uma atenuação significativamente menor do que aquela introduzida pela célula volumétrica. 
4. Nas duas montagens, a tensão aplicada na célula sensora foi obtida a partir de Variacs diferentes e ligados em configurações também diferentes.

Desta forma, as perdas globais de intensidade óptica apresentadas pelo TPO construído, utilizando o modulador $Y$ em óptica integrada, foram significativamente menores do que a de seu correspondente com célula recuperadora volumétrica. Esta melhora se deu principalmente no aumento da relação sinal/ruído que, como observado nas Figuras 61 a 66, são melhores do que aquelas apresentadas pela célula recuperadora volumétrica referida. Consequentemente, com o aumento da relação sinal/ruído, houve uma melhora significativa na visibilidade dos sinais ópticos na saída do TPO, justificando assim, escolha do componente em óptica integrada selecionado.

Na Figura 62, abaixo, são apresentados os espectros de frequências na saída da ponta de prova de alta tensão monitorando o sinal aplicado ao sensor primário do TPO.
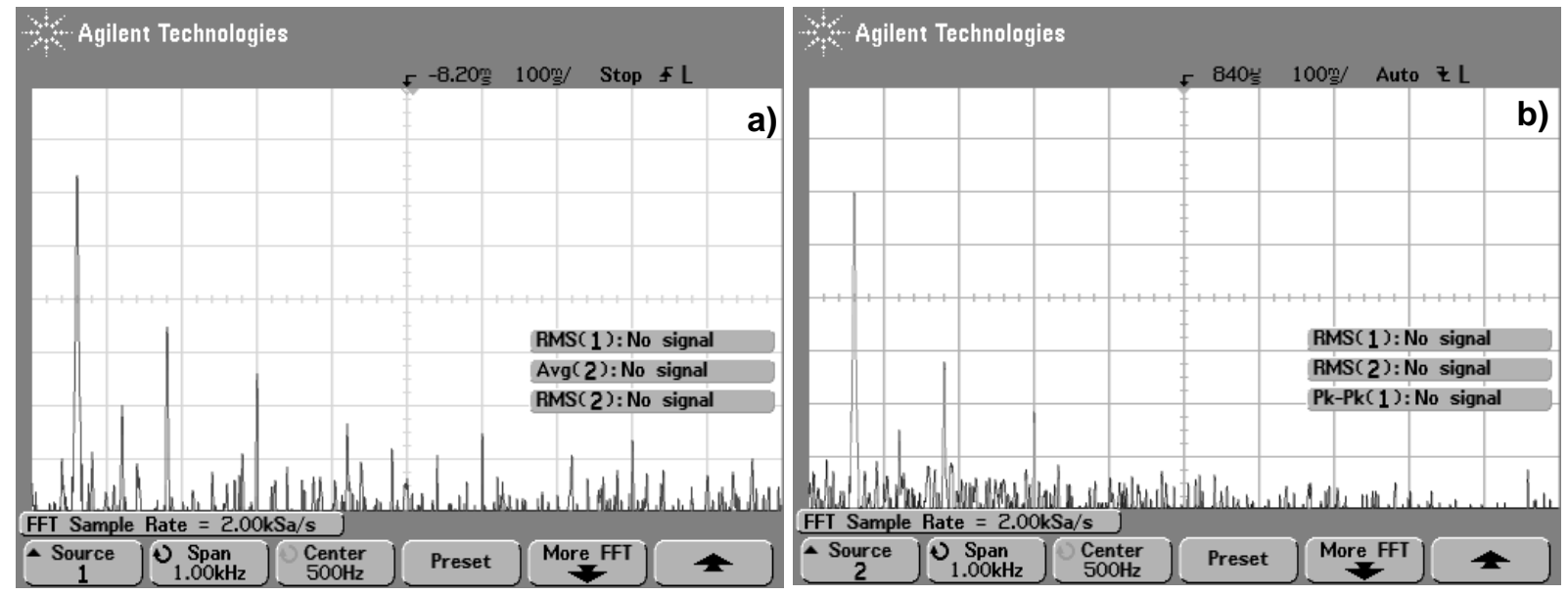

Figura 62 - Espectro de frequências do sinal alternado de $0,55 \mathrm{kV}_{\mathrm{rms}}$ aplicado ao interferômetro sensor do protótipo de TPO [33] b) Espectro de frequências do sinal alternado de 0,69 kV rms aplicado ao interferômetro sensor do protótipo de TPO. (SPAN $=1 \mathrm{kHz}$, ganho vertical $=10 \mathrm{~dB} / \mathrm{div}$, ganho horizontal $=100 \mathrm{~Hz} / \mathrm{div})$. 
É possível verificar nos gráficos da Figura 62 e 65, que os espectros de frequência dos sinais (a) e (b) apresentam-se de formas diferentes. Estas diferenças podem ser justificadas, como dito anteriormente, pelo uso de Variacs diferentes, montados em configurações também diferentes em cada um dos testes.

Como os Variacs possuem características de impedância e saturação diferentes, ao interagirem com a impedância primária do transformador elevador são geradas diferentes formas de ondas e consequentemente, espectros diferentes de tensão secundária em cada caso.

Na Figura 63, a seguir, são apresentadas os espectros de frequência na saída do processador de sinais para uma tensão alternada aplicada ao interferômetro sensor do TPO.

Da mesma forma que os Variacs introduziram formas de onda diferentes na tensão aplicada ao interferômetro sensor do protótipo de TPO, como no caso da Figura 62, o mesmo ocorreu com os sinais de saída do processador de sinais. Gerando assim, espectros diferentes, como pode ser observado nas Figuras 63 e 66.
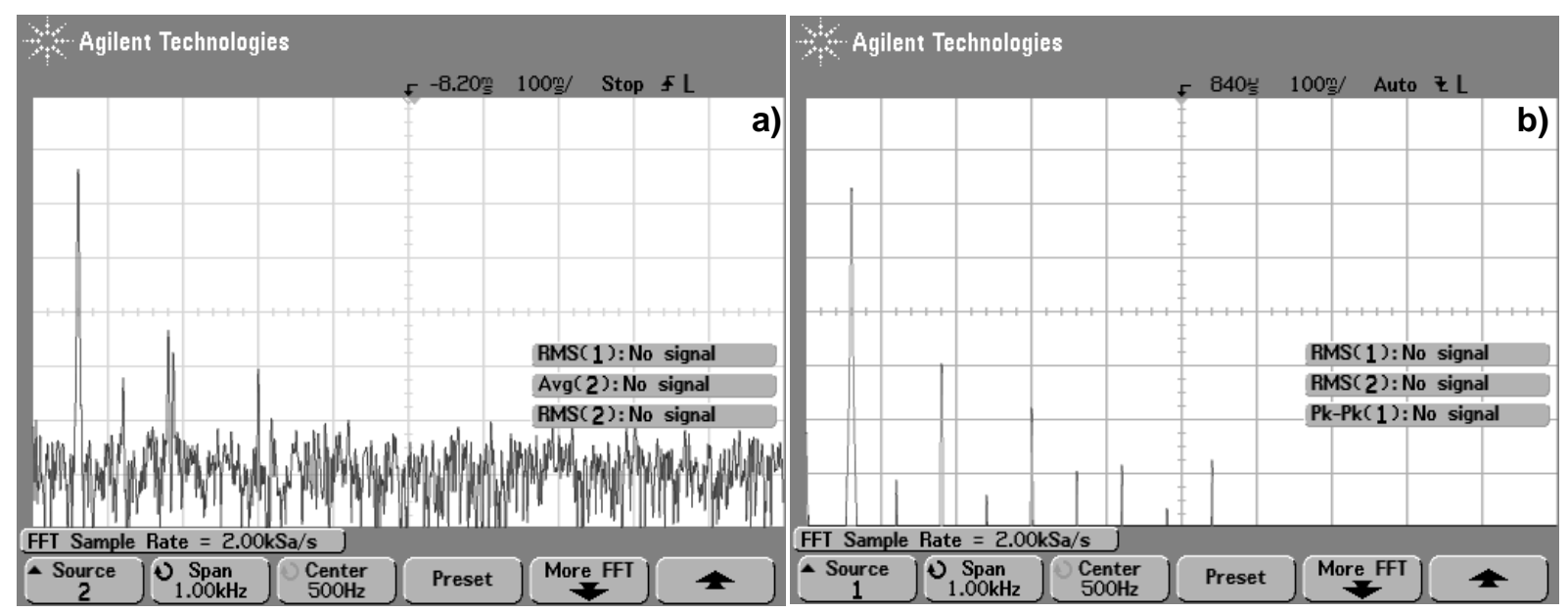

Figura 63 - a) Espectro de frequências do sinal na saída do processador de sinais para uma tensão alternada de 0,55 kV rms aplicada ao interferômetro sensor do TPO [33]. b) Espectro de frequências do sinal na saída do processador de sinais para uma tensão alternada de $0,69 \mathrm{kV}_{\mathrm{rms}}$ aplicada ao interferômetro sensor do TPO. (SPAN $=1 \mathrm{kHz}$, ganho vertical $=10 \mathrm{~dB} /$ div, ganho horizontal $=100$ $\mathrm{Hz} / \mathrm{div})$. 
Nas Figuras 64 a 66, a seguir, são apresentadas as formas de ondas dessas duas topologias, onde a) representam as formas de onda obtidas por Almeida ( $\left.8 \mathrm{kV}_{\mathrm{rms}}\right)$ e b) as formas de onda obtidas pelo autor $\left(8 \mathrm{kV}_{\mathrm{rms}}\right)$.

Na Figura 64, abaixo, são apresentadas as formas de onda da tensão, da ordem de $8 \mathrm{kV}_{\mathrm{rms}}$, aplicada ao interferômetro sensor do TP Óptico, e a forma de onda da tensão correspondente na saída do processador de sinais do TPO.
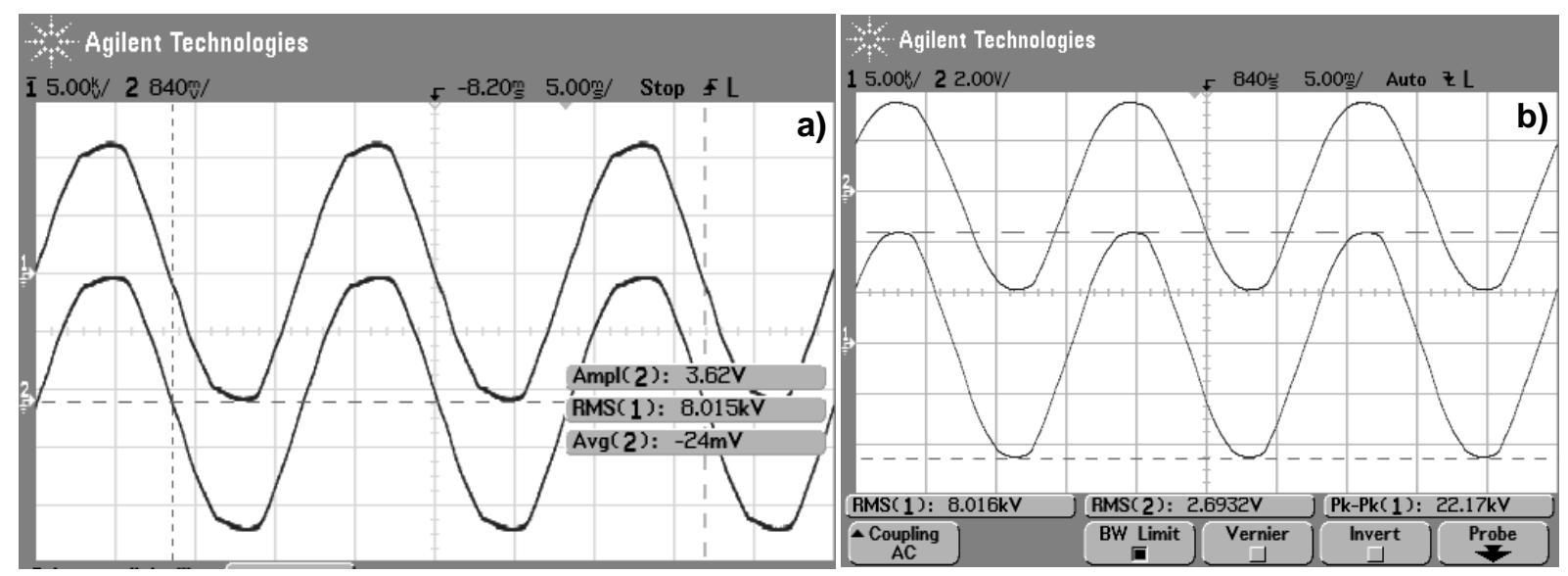

Figura 64 - a) Formas de onda da tensão da ordem de 8 kV rms, aplicada ao interferômetro sensor (canal 1) e da tensão correspondente na saída do processador de sinais (canal 2) do TPO [33]. b) Formas de onda da tensão da ordem de $8 \mathrm{kV}_{\mathrm{rms}}$, aplicada ao interferômetro sensor (canal 1, traço inferior) e da tensão correspondente na saída do processador de sinais (canal 2, traço superior) do TPO.

É possível observar uma melhoria da relação sinal/ruído na Figura 64(b) em relação à Figura 60(a) devido à aplicação de tensão mais elevada.

Na Figura 65, a seguir, são apresentados os espectros de frequência na saída da ponta de prova de alta tensão monitorando o sinal de $8 \mathrm{kV}_{\mathrm{rms}}$ aplicado ao interferômetro sensor do TPO. 


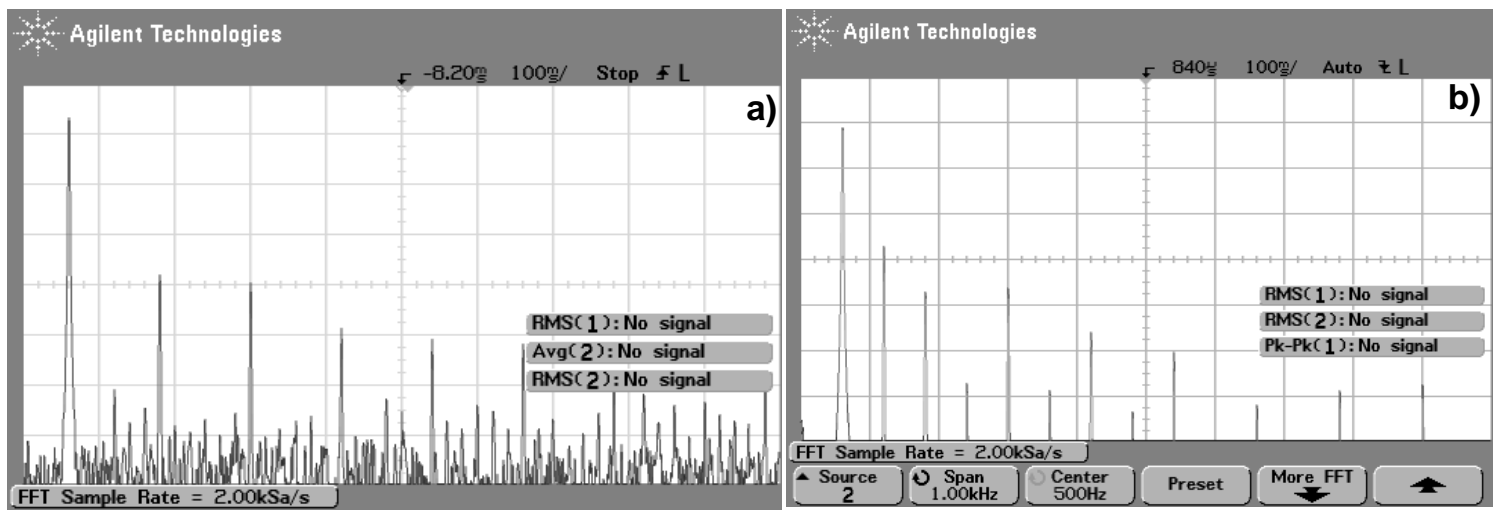

Figura 65 - Espectro de frequências do sinal alternado de 8 kV $\mathrm{rms}_{\mathrm{rms}}$ aplicado ao interferômetro sensor do protótipo de TPO [33]. b) Espectro de frequências do sinal alternado de $8 \mathrm{kV}_{\mathrm{rms}}$, aplicado ao interferômetro sensor do protótipo de TPO. (SPAN $=1 \mathrm{kHz}$, ganho vertical $=10 \mathrm{~dB} / \mathrm{div}$, ganho horizontal $=100 \mathrm{~Hz} / \mathrm{div}$ ).

Na Figura 66, a seguir, são apresentados os espectros de frequência na saída da processador de sinais para uma tensão alternada de $8 \mathrm{kV}_{\text {rms }}$ aplicada ao interferômetro sensor do TPO. Em a) a partir de $300 \mathrm{~Hz}$, existe a ação de um filtro passa-baixas de $1^{\mathrm{a}}$ ordem.
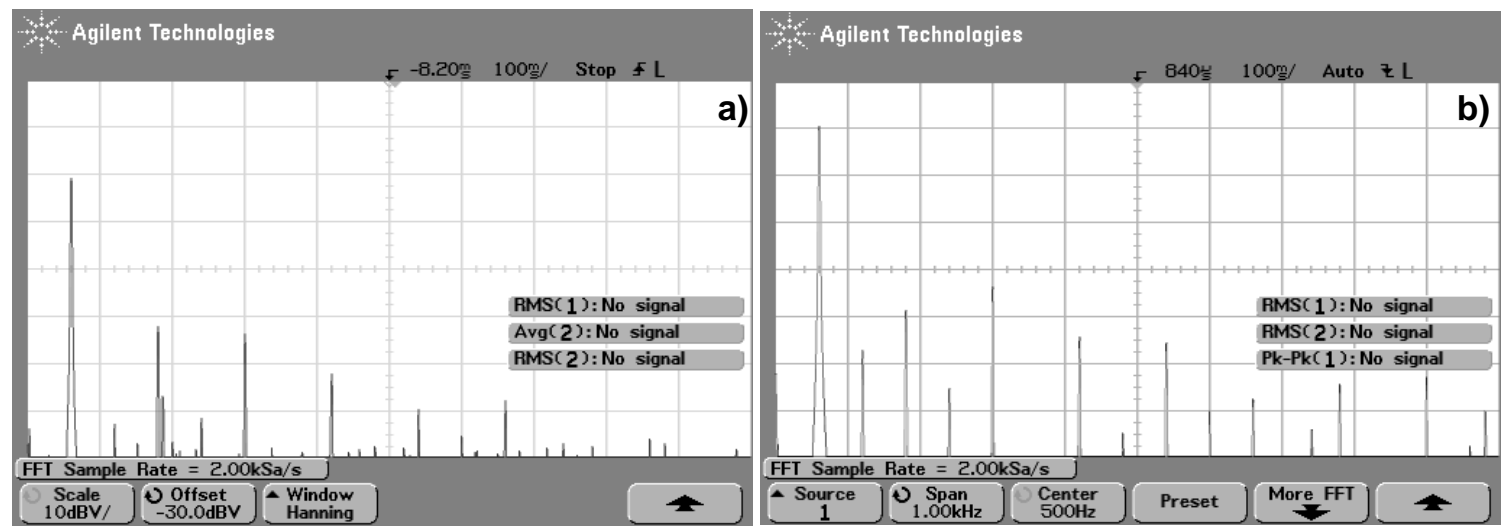

Figura 66 - a) Espectro de frequências do sinal na saída do processador de sinais para uma tensão alternada de $8 \mathrm{kV}_{\mathrm{rms}}$ aplicada ao interferômetro sensor do TPO [33]. b) Espectro de frequências do sinal na saída do processador de sinais para uma tensão alternada de $8 \mathrm{kV}_{\mathrm{rms}}$ aplicada ao interferômetro sensor do TPO. (SPAN $=1 \mathrm{kHz}$, ganho vertical $=10 \mathrm{~dB} / \mathrm{div}$, ganho horizontal $=100$ $\mathrm{Hz} / \mathrm{div})$. 


\section{CONCLUSÕES}

No que concerne ao estudo do estado da arte dos moduladores eletro-ópticos, buscando alternativas que apresentem características desejáveis, tais como: baixo valor de tensão de meia onda, insensibilidade a vibrações mecânicas, elevada imunidade eletromagnética, facilidade de conectorização, baixa sensibilidade à variação da temperatura, montagem compacta e robusta e a não necessidade de alinhamento axial e angular precisos, todos os objetivos foram alcançados.

A procura por um modulador eletro-óptico focada nas características desejáveis à aplicação no protótipo de TPO, para medição de altas tensões em desenvolvimento no LSO, levou a uma análise das alternativas em termos de dispositivos disponíveis no mercado nacional e internacional para aquisição e utilização imediatas.

Essa busca convergiu para a escolha de um interferômetro de Michelson, construído a partir de uma junção $Y$ em óptica integrada sobre substrato de $\mathrm{LiNbO}_{3}$, para ser empregado como interferômetro recuperador no sistema sensor WLI do protótipo de TPO, em substituição à versão volumétrica de célula recuperadora, utilizada no trabalho de mestrado do autor.

Foi selecionado, dentre as alternativas identificadas, um componente em óptica integrada capaz de compor a célula recuperadora de baixa tensão atendendo com sucesso aos requisitos pré-estabelecidos. Tal dispositivo demonstrou excelente desempenho comprovando, assim, a sua aplicabilidade na substituição com sucesso da célula volumétrica do trabalho anterior [7].

Foi realizada a implementação de um protótipo de interferômetro recuperador baseado neste modulador selecionado para compor o protótipo de TPO.

Testes em laboratório foram realizados para ensaiar o protótipo construído a fim de demonstrar a funcionalidade do dispositivo selecionado, e, verificou-se que com o interferômetro recuperador implementado foi possível recuperar os atrasos de fase introduzidos pelo interferômetro de birrefringência constituinte da célula eletro-óptica 
sensora de alta tensão com tensão muito menor do que aquela utilizada no trabalho anterior do autor.

Desta forma, está justificada a escolha do dispositivo em óptica integrada e os objetivos propostos no capítulo 2 foram cumpridos. 


\section{TRABALHOS FUTUROS}

Em um futuro próximo, algumas importantes melhorias poderão ser implementadas no protótipo de TPO apresentado neste trabalho. Ainda assim, a solução apresentada teve a sua eficácia comprovada e pode ser imediatamente utilizada em aplicações nas quais se busque as características desejadas propostas neste trabalho.

A seguir, apresentam-se alguns dos aperfeiçoamentos possíveis de serem implementados no protótipo de TPO que poderão ser feitos futuramente:

1. Mudança da Topologia da Célula Sensora;

A célula sensora apresentada neste trabalho possui topologia transmissiva, onde alinhamentos ópticos severos são requeridos. Para eliminar este problema, outra montagem poderá ser implementada em uma configuração reflexiva. Espera-se que com esta mudança de topologia (transmissiva para reflexiva), se elimine as dependências dos alinhamentos ópticos citados na seção 5.41 , que são sempre muito críticos. Diminui-se também, com esta mudança, a necessidade do rabicho de fibra óptica de retorno da célula de alta tensão para a célula recuperadora. Esta célula está sendo desenvolvida pela equipe do LSO/PEA-USP.

\section{Uso de Fibras PM;}

Conforme foi dito anteriormente, o uso de fibras PM em toda a montagem do TPO apresentado se faz necessário, uma vez que os feixes que trafegam pelas fibras ópticas são polarizados, necessitando assim, a conservação destes estados de polarização a fim de se minimizar efeitos nocivos à performance do sistema, como por exemplo, o fading de polarização. Esta mudança também contribuirá para a diminuição da ação de outros efeitos sobre o estado de 
polarização do feixe de luz na fibra óptica, tais como os mecânicos e térmicos, sofridos pela fibra monomodo utilizada neste trabalho.

3. Melhoria do Processo de Metalização com solução de Prata;

O processo de metalização com solução de Prata utilizado neste trabalho mostrou-se repetitivo e confiável. Embora, com os $77 \%$ de reflectividade alcançados na extremidade das fibras ópticas de saída do modulador em $\mathrm{Y}$, valores ainda maiores são esperados do processo. Sabe-se, por exemplo, que o controle da temperatura (na casa dos $38{ }^{\circ} \mathrm{C}$ ) melhora muito o processo de metalização $[45,46]$.

Desta forma justifica-se uma nova etapa, onde se possa variar a temperatura da solução em uma pequena faixa de valores em torno dos $38{ }^{\circ} \mathrm{C}$ e verificar a dependência da qualidade da metalização com a temperatura.

Outro fator importante, que também merece atenção especial, envolve a alta densidade de energia contida pelo feixe óptico na interface do espelho com a fibra óptica. Como foi dito anteriormente, parte da luz pode estar se perdendo nesta interface. Uma nova medida da refletividade poderá ser feita, mas desta vez, com potência óptica menor para averiguar sua dependência com a densidade óptica incidente na camada refletora.

4. Processamento Digital de Sinais;

O tratamento dos sinais presentes neste trabalho, realizado pela Unidade de Processamento Eletrônico de Sinais, são totalmente analógicos. Sendo assim, é natural que a evolução deste tratamento se dê de forma digital. 
5. Modulador Canal Birrefringente;

Um modulador de birrefringência eletro-óptico em óptica integrada tipo canal está sendo desenvolvido pela equipe do LSO/PEA-USP e poderá, futuramente, ser utilizado na substituição do modulador em $\mathrm{Y}$.

\section{Ensaios no Laboratório de Altas Tensões do IEE-USP;}

Outros ensaios com o protótipo de TPO desenvolvido poderão ser realizados futuramente no Laboratório do IEE-USP. Estes ensaios terão como objetivo a caracterização da célula sensora em níveis de tensão mais elevados do que aqueles utilizados neste trabalho.

7. Caracterização da Estabilidade de Longo Termo das Medidas com o Sistema Proposto;

Resta realizar medição de caracterização da estabilidade de longo termo das medidas obtidas com o protótipo de TPO construído. Tais medições deverão ser realizadas e seus resultados apresentados em um trabalho futuro.

8. Uso de Modulador sem Pigtails.

Como o modulador em $\mathrm{Y}$ é o foco deste trabalho, pode-se melhorar ainda mais o seu desempenho no que se refere às perturbações mecânicas e às variações de temperatura às quais as suas fibras ópticas de saída estão expostas. Uma solução alternativa para diminuir ainda mais os efeitos citados é o uso de um modulador sem os pigtails de saída, ou seja, o dispositivo teria apenas o acesso pela junção do Y, como mostrado na Figura 14. Embora tal dispositivo ainda não esteja disponível comercialmente, é possível desenvolvê-lo. 
Para funcionar nesta aplicação, o dispositivo deverá apresentar uma diferença de comprimento entre os braços, a fim de introduzir uma determinada diferença de caminho óptico desejada e ter as faces finais de cada braço espelhadas, fazendo com que esta tarefa não seja mais artesanal.

Desta forma, acredita-se que possam ser muito diminuídas tanto a sensibilidade à temperatura quanto às vibrações, além de compactar ainda mais sua montagem. 


\section{REFERÊNCIAS}

[1] Keiser, G. Optical Fiber Communications. McGraw-Hill, inc., New York, $2^{\text {nd }}$ ed., (1991).

[2] Jackson, D.A. and Jones J.D.C. Fibre Optic Sensors. Optica Acta 33, 1469, (1986).

[3] Udd, E. An Review of Fiber-Optic Sensors. Rev. Sci. Instrum. 66, 4015, (1995).

[4] Udd, E. Fiber Optic Sensors: An Introduction for Engineers and Scientists, John Wiley \& Sons, New York, ${ }^{\text {st }}$ ed., (1991).

[5] Dakin, J. and Culshaw, B. Optical Fiber Sensors: Principles and Components. Artech House, London, vol.1, (1989).

[6] Dakin, J. and Culshaw, B. Optical Fiber Sensors: Systems and Applications. Artech House, London, vol.2, (1989).

[7] Pinheiro, L.C.S. Transformador Óptico por Interferometria de Luz Branca para Medição de Altas Tensões. Dissertação de Mestrado apresentada à EPUSP para obtenção do título de Mestre em Engenharia, (2006).

[8] Santos, J.C., Pinheiro, L.C.S., Rubini, J.J. et al. FEM Simulation Method as a Designing Tool for Electrooptical Sensors Development. WSEAS Transactions On Power Systems. Issue 10, Vol. 1, Oct. 2006. ISSN 1790-5060.

[9] Santos, J.C., Almeida J.C.J., Pinheiro, L.C.S. WLI High Voltage Optical Fiber Sensor Systems with Compensation for Optical Power Fluctuations. European Workshop on Optical Fibre Sensors - EWOFS, Italy, 2007.

[10] Vali, V. and Shorthill R. W. Fiber Ring Interferometers. Appl. Optics 15, 1009, (1976). 
[11] Rogers, A.J. Optical Methods for Measurement of Voltage and Current at High Voltage. Opt. Laser Technology 9, 273, (1977).

[12] Santos, J.L. Sensores de Fibra Óptica: Aplicação à Medição de Deslocamentos. Dept. Física, FCUP, Porto, (1989).

[13] Santos, J.L. Multiplexagem e Processamento de Sinais de Sensores de Fibra Óptica. Tese de Doutorado, FCUP, Universidade do Porto, Portugal, (1993).

[14] Santos, J.C. Estudo e Desenvolvimento de Moduladores Eletro e Magnetoópticos e suas Aplicações como Transformadores de Medição (TP e TC Ópticos) em Sistemas Elétricos de Potência. Dissertação de Mestrado apresentada à EPUSP para obtenção do título de Mestre em Engenharia. (1993).

[15] Ben-Hur, V.B., Murilo, A.R., Amilcar, C.C. Sensores Ópticos Integrados e em Fibra. Sensores - Tecnologias e Aplicações, Vol.1. ISBN: 85-86686-30-1.

[16] Baptista, J.M.R.T. Concepção, Análise e Desenvolvimento de Sensores de Fibra Óptica de Intensidade auto-Referenciados. Tese de Doutorado, Faculdade de Engenharia da Universidade do Porto, Portugal, (2002).

[17] Grattan, K.T.V. and Meggitt, B.T. Optical Fiber Sensor Technology - Devices and Technology. Vol. 2, Chapman \& Hall, London, $1^{\text {st }}$ ed., (1995).

[18] Medlock, R.S. Review of Modulating Techniques for Fibre Optic Sensors. J. Opt. Sensors 1, 43, (1986).

[19] Jackson, D.A. Recent Progress in Monomode Fibre-Optic Sensors. Meas. Sci. Technol. 5, 621, (1994).

[20] Jackson, D.A. Monomode Optical Fibre Interferometers for Precision Measurement. J. Phys. E: Sci., Instrum. 18, 981, (1985).

[21] Goodman, J.W. Introduction to Fourier Optics. McGraw-Hill International Editions Electrical Engineering Series. Second Edition, 1996. 
[22] Grattan, K.T.V. and Meggitt, B.T. Optical Fiber Sensor Technology: Optical and Quantun Electronics. Vol. 2. Chapman \& Hall, London, $1^{\text {st }}$ ed., (1995).

[23] Hecht, E. and Zajac, A. Optics. Addison Wesley, London, 2nd ed., (1987).

[24] Kitano, C. Aplicação da Abordagem de Domínio Espectral para Análise de Moduladores Eletro-ópticos Integrados. Tese apresentada ao Instituto Tecnológico de Aeronáutica para obtenção do título de Doutor em Ciências. (2001).

[25] Kitano, C. Análise do Interferômetro Mach-Zehnder com Controle acústico. Tese de Mestrado. ITA, São José dos Campos, SP. 1993.

[26] Yariv, A. and Yeh, P. Optical Waves in Crystals - Propagation and Control of Laser Radiation. Wiley Interscience. USA. 2003.

[27] Faria, J.A.B. Óptica: Fundamentos e Aplicações. Editora Presença. 1994.

[28] Okamoto, K. Fundamentals and Applications of Optical Waveguide: Optics and Photonics. Academic Press.

[29] Ghatak, A. K. and Thyagarajan K. Optical Electronics. Cambridge University Press, Cambridge. 1989.

[30] Grattan, K.T.V. and Sun, T. Fiber Optic Sensor Technology: an Overview. Sensors and Actuators 82, 40-61. 2000.

[31] Cavaleiro, P. M., Ribeiro A.B. L. and J. L. Santos. Referencing Technique for Intensity-Based Sensors Using Fibre Optic Bragg Gratings. Electron. Lett. 31, 392. 1995.

[32] Newton I. Princípios Matemáticos de Filosofia Natural: Principia. Livro I e II. Edusp. 2008.

[33] Almeida, J.C.J., Santos, J.C. Demodulação Coerente do Sinal de Saída de Transformador de Potencial Óptico. Revista IEEE América Latina. 2005. 
[34] Rao, Y.J. and Jackson, D.A. Recent Progress in Fibre Optic Low-Coherence Interferometry. Meas. Sci. Technology, v. 7, p. 981-999. 1996.

[35] Tolansky, S. An Introduction to Interferometry. Longman, London. 1973.

[36] Al-Chalabi, S.A. et al. Partially Coherent Sources in Interferometric Sensors. In: $1^{\text {st }}$ International Conference on Optical Fibre Sensors. London, p. 132-135. 1983

[37] Hickman, D. An Optical Sensor Based on Temporal Coherence Properties. J. Phys. E. Sci. Instrum., n. 21, p. 187-192. 1988

[38] Bosselmann, T. and Ulrich, R. High-Accuracy Position-Sensing with FibreCoupled White-Light Interferometers. In: $2^{\text {nd }}$ International Conference on Optical Fibre Sensors. Berlin, p. 361-364. 1984

[39] Choi, H.S. et al. High-Performance Fiber-Optic Temperature Sensor Using Low-Coherence Interferometry. Optics Letters, v. 22, n. 23, Dec.1997.

[40] Yuan, L.B. et al. Fiber Optic Temperature Sensor with Duplex Michleson Interferometric Technique. Sensors and Actuators, n. 86, p. 2-7. 2000.

[41] Zhou, Y. and Qiang, X. Dual Fizeau Heterodyne Interferometry for HighPrecision Fibre-Optic Displacement Sensor. Sensors and Actuators, v. A, n. 65, p 1-4. 1998.

[42] Wang, T. et al. A High Precision Displacement Sensor Using a Low-Finesse Fiber-Optic Fabry-Perot Interferometer. Sensors and Actuators. v. A, n. 69, p. 144-138. 1998.

[43] Fischer, K. et al. Elastooptical Properties of SiON Layers in a Integrated Optical Interferometer used as a Pressure Sensor. J. Lightwave Technology, v. 12, n. 1, p. 163-169, Jan. 1994.

[44] Santos, J.C. New Optical Pockels Techniques for Direct Measurement of High Voltage. Tese de Doutorado - Universidade de Tóquio, Japão. 1996. 
[45] Morais, R.P.S. Poling em Fibra Ópticas. Tese submetida à Faculdade de Ciências da Universidade do Porto para obtenção do grau de mestre em optoeletrônica e lasers. Departamento de Física. 2003.

[46] www.chem.wisc.edu University of Wisconsin-Madison: Chemistry Department - Demonstration Laboratory. 2010.

[47] Texereau J., How to Make a Telescope. $2^{\text {nd }}$ English Edition. Willmann-Bell, inc. 1984. 


\section{APÊNDICE A - Técnicas de Fabricação de Dispositivos em Óptica Integrada}

Nesta seção é feita uma breve descrição sobre técnicas usuais de fabricação de dispositivos ópticos integrados. São descritas as técnicas de implementação de guias canal através da difusão de dopantes, como por exemplo, os métodos de difusão de titânio e de troca de prótons. O principal interesse concentra-se em uma descrição elementar dos processos de confecção de dispositivos funcionais sobre substrato cristalino de Niobato de Lítio.

\section{A TÉCNICA DE DIFUSÃo TÉRMICA DE METAIS}

O uso da alteração das propriedades ópticas da superfície de substratos para a produção de guias de ondas superficiais, através da retirada de alguns de seus componentes químicos, ou da substituição por outros componentes, constitui um procedimento clássico. Entretanto, os detalhes específicos de cada um desses procedimentos variam muito de material para material [24].

O grau de integridade estrutural, índice de refração e uniformidade estequiométrica necessários para fabricar dispositivos em óptica integrada devem satisfazer padrões rigorosos. Para cristais de $\mathrm{LiNbO}_{3}$ com pureza adequada para óptica integrada, as perdas no substrato são extremamente baixas como, por exemplo, 0,030 dB/cm no comprimento de onda de $1,3 \mu \mathrm{m}$ e 0,050 dB/cm em 1,55 $\mu \mathrm{m}$. Segundo Kitano [24], um renomado fabricante de cristais de $\mathrm{LiNbO}_{3}$ com padrão de grau óptico para óptica integrada é a empresa Crystal Technology Inc., que afirma que seus substratos apresentam variação de composição menor que $\pm 0,02 \mathrm{~mol} \%$, com menos de $5 \mathrm{ppm}$ de ferro e menos de $1 \mathrm{ppm}$ de outros metais de transição. $O$ material é extremamente transparente ao longo da faixa de comprimento de onda de $0,4 \mu \mathrm{m}$ a $4,5 \mu \mathrm{m}$ e apresenta reduzidos espalhamento óptico e esforço residual (strain) interno. Ainda segundo ele, o padrão de qualidade é tal que garante uma 
orientação dos eixos cristalográficos dentro de aproximadamente 30 minutos de arco.

Os substratos de $\mathrm{LiNbO}_{3}$ podem ser encontrados comercialmente na forma de lâminas onde os eixos cristalinos são rigorosamente demarcados, conforme ilustrados na Figura 67. Uma lâmina cujo eixo óptico (eixo Z) seja perpendicular a sua face maior (e sobre a qual são estabelecidos os dispositivos integrados) é referida como lâmina em corte-Z. Caso o eixo cristalino normal à face seja $X$ ou $Y, 0$ cristal é dito estar em corte-X ou corte-Y, respectivamente.

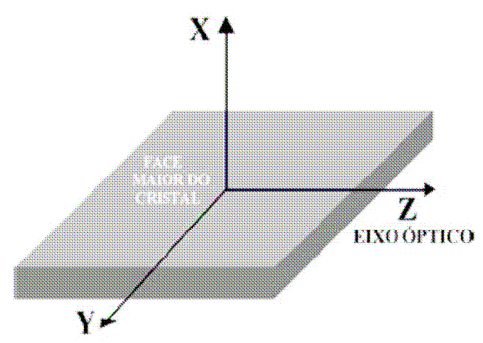

(a)

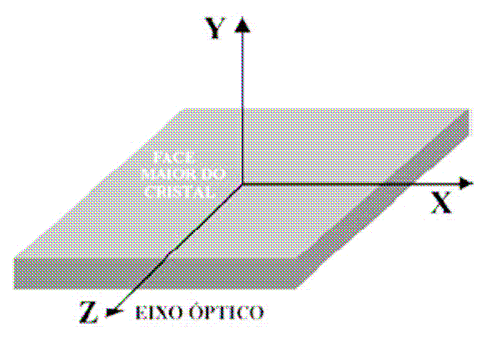

(b)

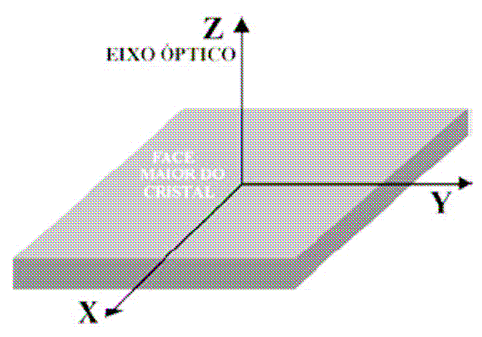

(c)

Figura 67 - Lâminas de Niobato de Lítio: a) Corte-X. b) Corte-Y. c) Corte-Z [24].

De forma genérica, a difusão de massa pode ser definida como um processo no qual algumas partículas migram ao longo de um sistema, como resultado de seus movimentos moleculares aleatórios. Um fluxo resultante de partículas será estabelecido se existir uma variação nos potenciais químicos. No entanto, na prática, isto é causado por um gradiente de concentração constituindo, portanto, o parâmetro responsável pela ocorrência da difusão [24].

Geralmente, no processo de difusão, um substrato é colocado em contato com o material dopante e ambos são aquecidos a uma temperatura situada na faixa de 800 ${ }^{\circ} \mathrm{C}$ a $1100^{\circ} \mathrm{C}$. Nestas temperaturas, as energias térmicas dos átomos do dopante e do substrato encontram-se muito elevadas, o que aumenta consideravelmente suas mobilidades em relação aos valores em temperatura ambiente. Quando os átomos vibram, alguns sítios podem torna-se vagos, e assim, átomos migratórios de dopante podem se mover para os seus interiores. 
$\mathrm{Na}$ difusão térmica de metais, uma fina camada metálica de espessura $\tau$ é depositada por evaporação sobre a superfície de um substrato. Em seguida, o sistema é aquecido até uma temperatura $T$, numa atmosfera não reativa, durante um determinado tempo $t$. Os parâmetros do guia óptico, como números de modos, máxima variação de índice de refração e espessura efetiva do guia podem ser controlados independentemente através dos parâmetros de difusão $\tau, T$ e $t$. Os metais utilizados neste processo são elementos de transição, como Titânio, Vanádio, Nióbio e Níquel. Deste modo, tanto o índice de refração ordinário $\left(n_{0}\right)$ quanto o índice de refração extraordinário $\left(n_{e}\right)$ do $\mathrm{LiNbO}_{3}$ sofrem alterações significativas no processo.

Um processo de difusão de metal muito utilizado é o da difusão de Titânio (Ti) para o interior de um substrato de $\mathrm{LiNbO}_{3}$. Esse problema encontra-se esquematizado na Figura 68, a seguir, onde a fita de Titânio possui largura uniforme igual a $2 \mathrm{w}$ e espessura igual a $\tau$.

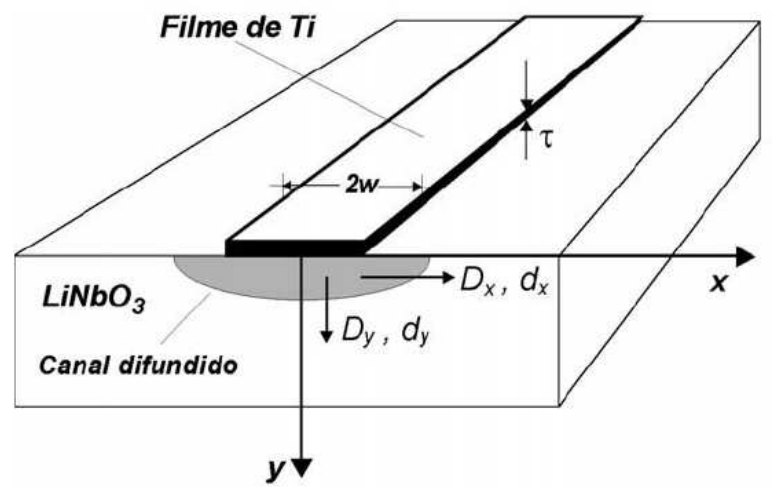

Figura 68 - Fita de titânio com largura $2 \mathrm{w}$ e espessura $\tau$ depositada sobre 0 substrato de $\mathrm{LiNbO}_{3} \mathrm{a}$ ser difundida termicamente para o seu interior. $D_{x}$ e $D_{y}$ referem-se às constantes de difusão na direção x e y, respectivamente. O canal óptico será estabelecido após a difusão [24].

Para o desenvolvimento de guias ópticos integrados são necessárias algumas etapas de definições do guia, primeiro em fotoresiste e depois em Titânio, sobre um substrato de $\mathrm{LiNbO}_{3}$. Os guias ópticos são formados por difusão dessas fitas de 
Titânio para o interior dos substratos, mediante a aplicação de temperaturas elevadas. Os eletrodos são então definidos adjacentes aos guias, de forma tal que campos elétricos possam ser usados para alterar suas características ópticas. Neste processo dois tipos de dispositivos podem ser obtidos: os dispositivos passivos e os dispositivos funcionais. Os dispositivos funcionais, que são mais importantes, exigem processos adicionais para fabricação de eletrodos para controle eletrônico das propriedades ópticas de guiagem.

\section{A TÉCNICA DE TROCA DE PRÓTONS}

Conforme relata Kitano [24], neste processo utiliza-se o ácido benzóico para a fabricação do guia óptico. Este ácido é fundido e mantido à temperatura constante. Em seguida o cristal deve ser imerso na efusão por um tempo que pode variar desde 5 minutos até 1 hora e depois deve ser removido e resfriado. Neste processo, como na difusão de Titânio, outras etapas estão previstas, como por exemplo, o recozimento (annealing), a litografia para troca de prótons, o acabamento e 0 encapsulamento do dispositivo óptico, por exemplo.

Uma das características deste processo de fabricação é que resulta em um guia aproximadamente do tipo degrau, com elevada variação de índice de refração. Contudo, esta variação não é isotrópica, uma vez que apenas o índice extraordinário $\left(n_{e}\right)$ é modificado significativamente. Consequentemente, apenas o modo com polarização ao longo do eixo óptico do cristal pode ser guiado. Esta é uma das principais vantagens do método da troca de prótons, sobre o método de difusão em Titânio, proporcionando um guia óptico com ação polarizadora [24, 25]. 


\section{ANEXO 1 - Datasheet do Diodo Superluminescente (SLD) utilizado no trabalho.}

\section{Superlum Diodes, 1 to. SLD-76-HP: High-Power SLDs at 1440; 1480; $1560 \mathrm{~nm}$}

Features:

- High Output power, $10 \mathrm{~mW}$ ex SM fiber

flat spectrum with small Fabry-Perot modulation depth

Packages: DBUT; others on request

Additional \& customized:

- $\quad$ PM fiber pigtails, polarized / depolarized output

FC/APC terminated pigtails

Specifications

(Nominal Emitter Stabilization Temperature $+20^{\circ} \mathrm{C}$ )

\begin{tabular}{|c|c|c|c|c|}
\hline Parameter & Category & Min & Typ & $\operatorname{Max}$ \\
\hline $\begin{array}{l}\text { Output power ex SM fiber, emitter @ } \\
+20^{\circ} \mathrm{C} \text { SLD-76-HP fiber pigtailed }\end{array}$ & $\begin{array}{l}\text { HP1 } \\
\text { HP2 }\end{array}$ & $\begin{array}{l}4.0 \\
7.5 \\
\end{array}$ & $\begin{array}{c}5.0 \\
10.0\end{array}$ & 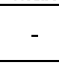 \\
\hline SLD direct current, $\mathrm{mA}$ & $\begin{array}{l}\mathrm{HP1} \\
\mathrm{HP2}\end{array}$ & - & - & $\begin{array}{l}400 \\
600\end{array}$ \\
\hline Forward voltage, $\mathrm{V}$ & All & - & 1.9 & 2.5 \\
\hline Peak wavelength*, $\mathrm{nm}$ & All & \multicolumn{3}{|c|}{$1440,1480,1560 \pm 10$} \\
\hline Spectrum width, $\mathrm{nm}^{\star \star}$ & All & $30-35$ & 45 & - \\
\hline $\begin{array}{l}\text { Residual spectral modulation } \\
\text { depth, dB }\end{array}$ & All & - & 0.25 & 0.5 \\
\hline $\begin{array}{l}\text { Secondary coherence subpeaks } \\
(10 \mathrm{log}), \mathrm{dB}\end{array}$ & All & - & - & -20 \\
\hline $\begin{array}{l}\text { Slow / fast polarization ratio } \\
\text { (PM "polarized" modules), dB*** }\end{array}$ & All & 5 & 10 & - \\
\hline $\begin{array}{l}\text { Operation temperature range } \\
\text { (case) at full power, }{ }^{\circ} \mathrm{C}\end{array}$ & $\begin{array}{l}\mathrm{HP1} \\
\mathrm{HP2}\end{array}$ & -55 & - & $\begin{array}{l}+70 \\
+60 \\
\end{array}$ \\
\hline Cooler current, $\mathrm{A}^{* \star \star *}$ & All & - & - & 1.2 \\
\hline Cooler voltage, $V^{\star \star \star \star \star}$ & All & - & - & 3.5 \\
\hline
\end{tabular}

* each specific wavelength is subject for availability

** depending on center wavelength, please ask for details

*** Lyot-depolarized version available upon request

**** $2.5 \mathrm{~A} / 4 \mathrm{~V}$ TE cooler may be used to extend operation temperature range

Following marking should be used for ORDERING

$$
\begin{gathered}
\text { SLD-761-HP(N)-(c)-(d)-wavelength } \\
\text { Where: } \\
\mathrm{N}=1 \text { or } 2 \text { (for HP1 or HP2 respectively) } \\
\text { C=package type }
\end{gathered}
$$

$\mathrm{d}=\mathrm{SM}$ (isotropic) or PM (polarization maintain)

wavelength: required wavelength

Example: SLD-761-HP2-DBUT-SM-1560

$10^{-3}$ maximum feedback is allowed to run HP series SLDs safely at full power.

All specifications are subject to change without notice.
Applications:

- optical sensing

- optical coherence tomography

optical measurements

testing WDM/DWDM components

\section{PERFORMANCE EXAMPLES}

SLD-761-HP2-SM. Light-current curve

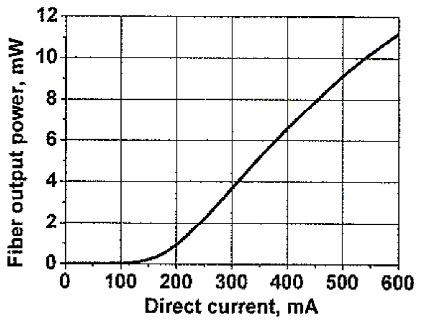

Spectrum, Iog plot. 761-HP2 @ 1560 nm
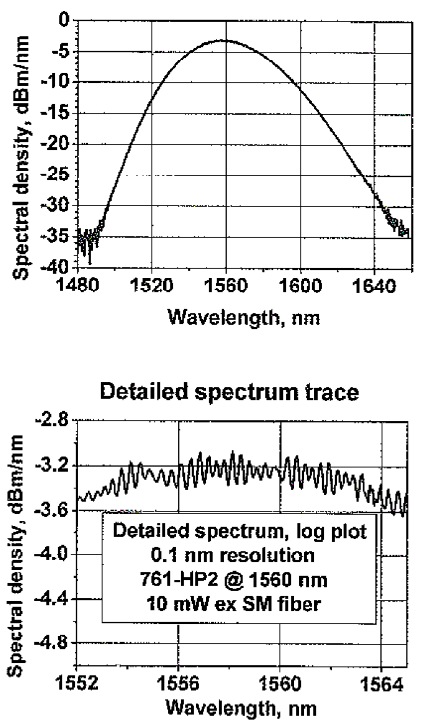

Extended displacement

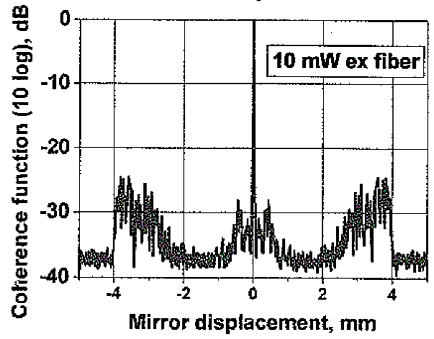

Mirror displacement $=$ Optical path difference $/ 2$ 
ANEXO 2 - Datasheet do Circulador Óptico utilizado no trabalho

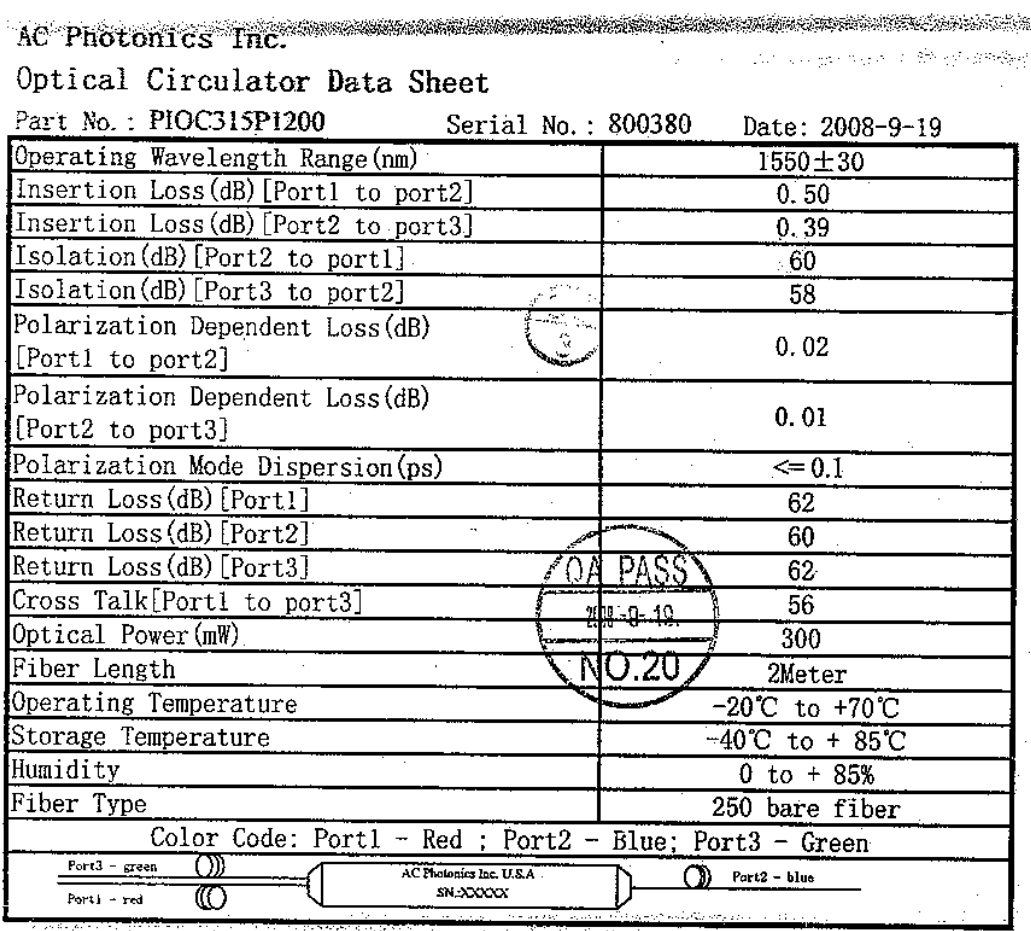




\section{ANEXO 3 - Datasheet do Modulador em Y utilizado no trabalho}

\section{LiNbO3 Muli-function Integrated Optical Chip}

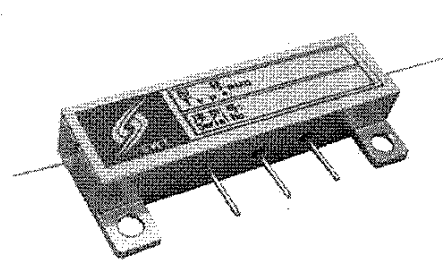

\section{Key Capability}

$\diamond \quad X$-cut, y-propagating $\mathrm{LiNbO}_{3}$

$\diamond$ Very low insertion loss

$\diamond$ APE process for waveguide

$\diamond$ Push-pull electrode design

$\diamond$ Small packaging and light weigh

$\diamond$ Excellent long-term stability

LiNbO3 multi-function integrated optical chip (IOC) is manufactured by micro-electronics technology, which can get different waveguide and electrode graph on the surface of LiNbO3 chip. There are several cells integrated on the same chip, include polarizer, splitter /combiner, phase modulator, etc. The characteristic of this device is fast responding, small packaging, lightweight and anti-disturbance of electromagnet, etc.

\section{Applications}

$\diamond$ Fiber optic gyroscopes (FOG).

$\diamond$ Hydrophone and other optic sensitive fields 


\section{Device Schematic}

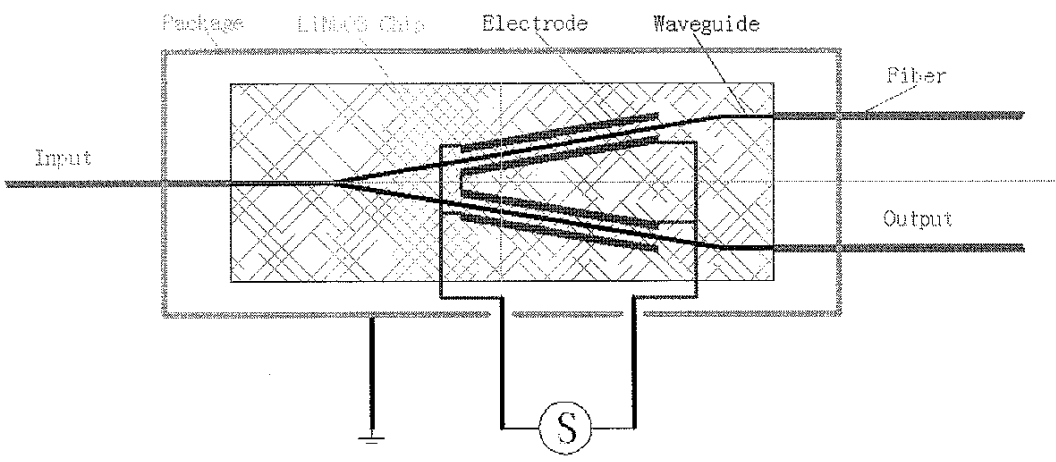

Package Outline:(PMD08xx-S, PMD13xx-S, PMD15xx-S)
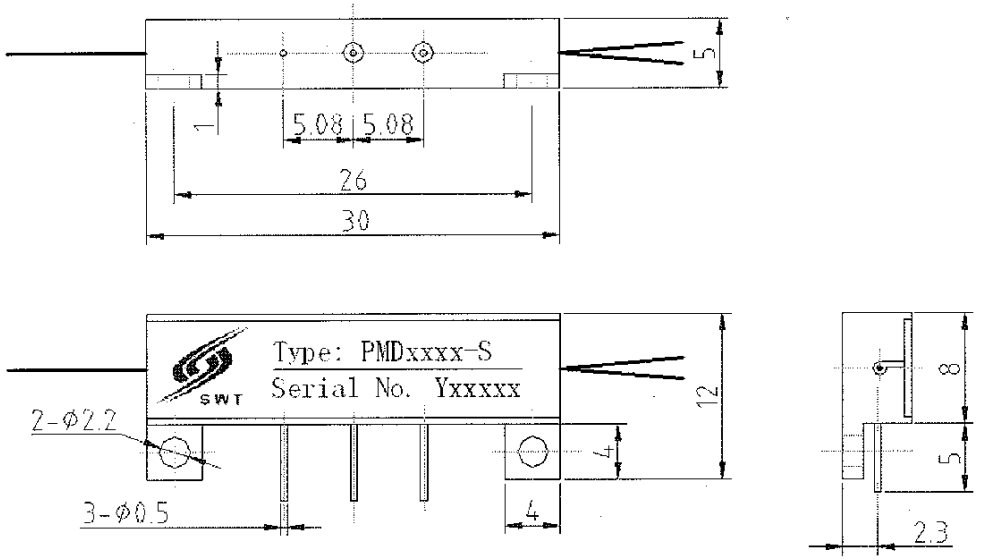


\section{Specifications $\left(23^{\circ} \mathrm{C}\right)$}

\begin{tabular}{|c|c|c|c|c|c|}
\hline & Parameter & Unit & & lues & \\
\hline & Operating Wavelength & $\mathrm{nm}$ & $820 \sim 850$ & 1310 & 1550 \\
\hline & Insertion Loss & $\mathrm{dB}$ & & $=4.0$ & \\
\hline & Splitting Beam Ratio & - & $47 / 5$ & $\sim 53 / 47$ & \\
\hline Optical & Optical Return & $\mathrm{dB}$ & & $\geq 50$ & \\
\hline & Polarization extinction, chip & $\mathrm{dB}$ & & $\geq 55$ & \\
\hline & Additional Intensity Modulating & - & & $0.2 \%$ & \\
\hline & PM Pigtail Crosstalk & $\mathrm{dB}$ & $\leq-27$ & $\leq-30$ & $\leq-30$ \\
\hline & Half wave Voltage & V & $\leq 3.0$ & $\leq 4.0$ & $\leq 4.5$ \\
\hline Electrical & Applied DC Voltage & V & & $15 \mathrm{~V}$ & \\
\hline & Electrode type & - & Push-pu & modula & ing \\
\hline & Bandwidth & $\mathrm{MHz}$ & & 2300 & \\
\hline & Electrical connector & - & & PIN & \\
\hline Mechanical & Pigtail type & - & & or SM & \\
\hline & Packaging dimensions & $\mathrm{mm}$ & & $\times 8 \times 5$ & \\
\hline Environmental & Work temperature & ${ }^{\circ} \mathrm{C}$ & & $\sim+85$ & \\
\hline
\end{tabular}

We can provide different pigtail and package by customer requirement. Welcome to contact us.

Address: 10th, Floor, Tower C2, Oriental P1aza, No.1 East Chang An Avenue, Dong Cheng District, Beijing, China. Post Code: 100738 Beijing SWT Optical Communication Technology Co., Ltd.

Tel: +86-10-61597788 Fax: +86-10-61598065

E-mail: huayong@swt-oc. com 


\section{ANEXO 4 - Datasheet do Fotodiodo utilizado no trabalho}

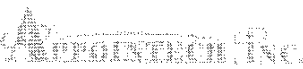

$1.5 \mathrm{GHz}$ InGaAs PIN Photodiode Module

\section{Features}

- High Responsivity

- High speed, typical $1.5 \mathrm{GHz}$

- Low dark current, < InA

- Low capacitance, typical $0.7 \mathrm{pF}$

- Operating temperature range $-40^{\circ} \mathrm{C}$ to $85^{\circ} \mathrm{C}$

- Hermetically sealed TO-18 package in pigtailed or receptacle housing with $\mathrm{FC}, \mathrm{ST}, \mathrm{SC}, \mathrm{LC}, \mathrm{MU}$ or SMA connector

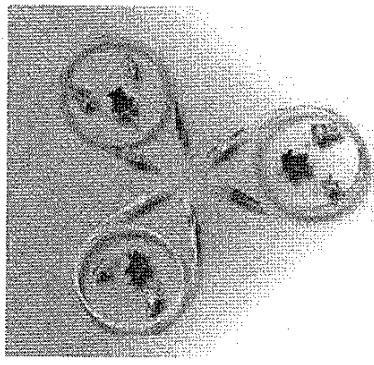

Specifications $\left(\mathrm{T}=25^{\circ} \mathrm{C},-5 \mathrm{~V}\right)$

\begin{tabular}{|c|c|c|c|c|c|c|c|}
\hline \multicolumn{2}{|l|}{ Parameter } & Symbol & Test Condition & Min. & Typ. & Max. & Unit \\
\hline \multicolumn{2}{|l|}{ Responsivity } & $\mathrm{R}$ & & & & & \\
\hline 9/125 um fiber & $\begin{array}{l}-1 \\
-2\end{array}$ & & $\begin{array}{c}\text { Laser source of } \\
10 \text { uw }(\lambda=1310 \mathrm{~nm})\end{array}$ & $\begin{array}{l}0.7 \\
0.8\end{array}$ & $\begin{array}{l}0.8 \\
0.9\end{array}$ & - & $A N$ \\
\hline $50 / 125$ um fiber & $\begin{array}{l}-1 \\
-2 \\
\end{array}$ & & $\begin{array}{c}\text { LED source of } \\
10 \text { uw }(\lambda=1310 \mathrm{~nm})\end{array}$ & $\begin{array}{l}0.65 \\
0.75 \\
\end{array}$ & $\begin{array}{l}0.75 \\
0.85\end{array}$ & - & AIW \\
\hline $62.5 / 125$ um fiber & $\begin{array}{l}-1 \\
-2\end{array}$ & & $\begin{array}{c}\text { LED source of } \\
10 \text { uw }(\lambda=1310 \mathrm{~nm})\end{array}$ & $\begin{array}{l}0.6 \\
0.7 \\
\end{array}$ & $\begin{array}{l}0.7 \\
0.8\end{array}$ & $\begin{array}{l}- \\
- \\
\end{array}$ & AlW \\
\hline \multicolumn{2}{|l|}{ Spectral Range } & & - & 1250 & - & 1600 & $\mathrm{~nm}$ \\
\hline \multicolumn{2}{|l|}{ Dark Current } & Id & $\mathrm{V}_{\mathrm{R}}=2 \mathrm{~V}, 0$ to $1 \mathrm{MHz}$ & - & - & 1 & $n A$ \\
\hline \multicolumn{2}{|l|}{ Capacitance } & $\mathrm{Ct}$ & $\mathrm{V}_{\mathrm{R}}=2 \mathrm{~V}, 1 \mathrm{MHz}$ & - & 0.7 & 0.8 & $\mathrm{pF}$ \\
\hline \multicolumn{2}{|l|}{ Rise/fall Time } & tr/tf & $V_{R}=2 V_{1} 20 \%$ to $80 \%$ & - & $<1$ & - & ns \\
\hline Bandwidth & & $\mathrm{B}$ & & - & 1.5 & - & $\mathrm{GHz}$ \\
\hline \multicolumn{8}{|l|}{ Return Loss } \\
\hline \multicolumn{2}{|l|}{-1 (Receptacie) } & & & 14 & - & - & $\mathrm{dB}$ \\
\hline \multirow{2}{*}{\multicolumn{2}{|c|}{$\begin{array}{l}-4 \text { (Pigtail) } \\
-5 \text { (Pigtail) }\end{array}$}} & & & 40 & - & + & $\mathrm{dB}$ \\
\hline & & & & 50 & - & - & $\mathrm{dB}$ \\
\hline
\end{tabular}

\section{Absolute Maximum Rating}

\begin{tabular}{|l|c|c|c|c|}
\hline & Symbol & Min. & Max. & Unit \\
\hline Operating Temperature & $T_{0}$ & -40 & +85 & ${ }^{\circ} \mathrm{C}$ \\
\hline Storage Temperature & $T_{\text {stg }}$ & -40 & +125 & ${ }^{\circ} \mathrm{C}$ \\
\hline Forward Current & $I_{F}$ & - & 5 & $\mathrm{~mA}$ \\
\hline Reverse Voltage & $\mathrm{V}_{R}$ & - & 30 & $\mathrm{~V}$ \\
\hline Reverse Current & $\mathrm{I}_{\mathrm{R}}$ & - & 500 & $\mathrm{UA}$ \\
\hline Lead Soldering Temperature $(10 \mathrm{seC})$ & $\mathrm{T}_{\mathrm{L}}$ & - & 260 & ${ }^{\circ} \mathrm{C}$ \\
\hline
\end{tabular}

\section{Ordering Information}

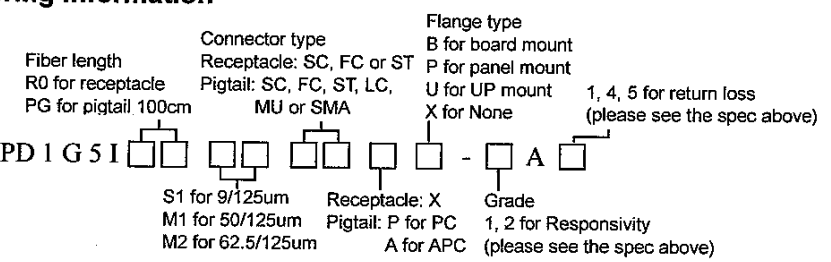


4.

$1.5 \mathrm{GHz}$ InGaAs PIN Photodiode Module
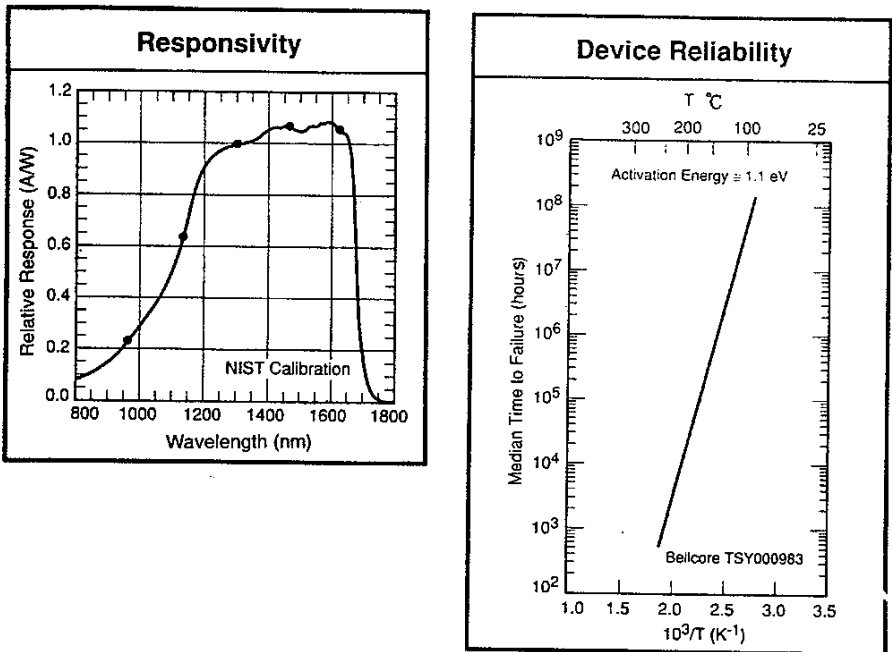

2005-11 


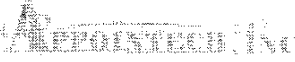

$1.5 \mathrm{GHz}$ InGaAs PIN Photodiode Module

BOTTOM VIEW

PIN CONNECTIONS

$2 \cdot 93$

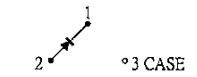

UNIT : MM

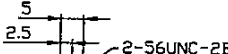

FC-BM

ST-BM

FC-PM

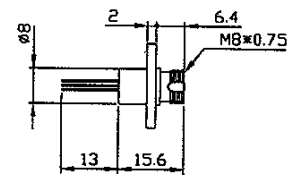

FC-BM
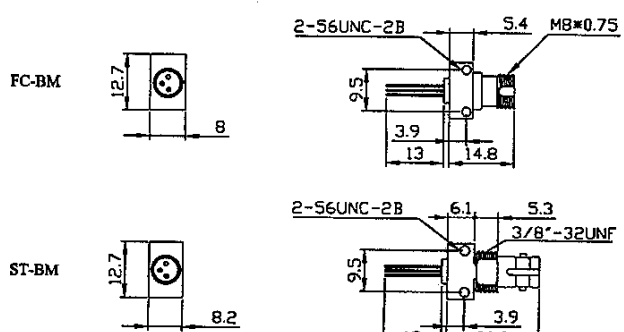

2-56UNC-2B $6.10 \frac{5.3}{3 / B^{\circ}-32 \text { UNF }}$

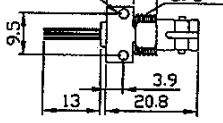

ST-PII
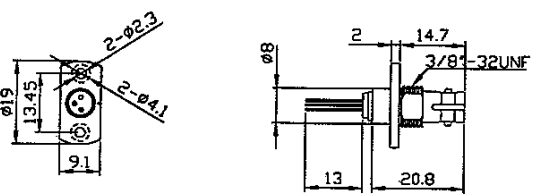

sc
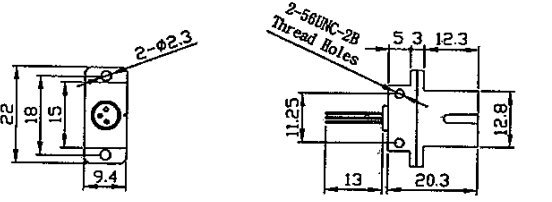


\section{Technical Data}

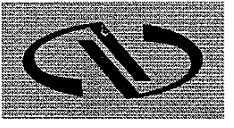

\section{Newport}

Newport Corporation
1791 Deere Avenue

Irvine, CA 92606

Part No. F-CPL-F22/35.

Serial No. N 10152

Fiber Type: $\quad S M-O 2 R$

Port Identification:

Pigtails marked as follows:

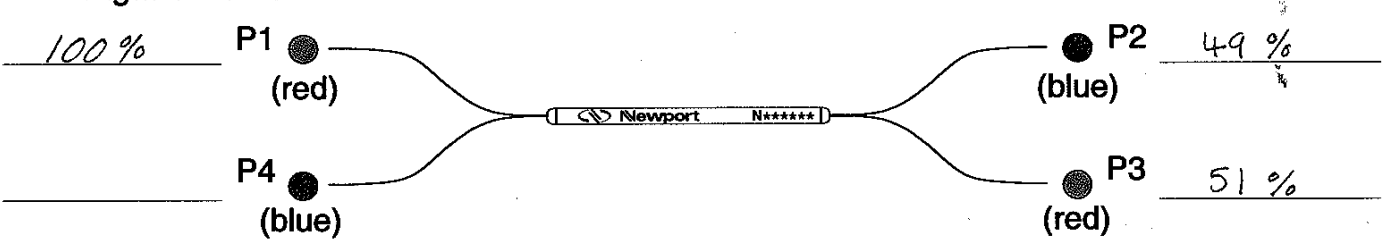

Test Data:

\begin{tabular}{|c|c|}
\hline Wavelength $(\mathrm{nm})$ & 1310 \\
\hline Insertion Loss $(\mathrm{dB})$ & \\
P1 to P2 & 3.28 \\
P1 to P3 & 3.02 \\
\hline
\end{tabular}

Inspection: 